Portland State University

PDXScholar

$1-1-2011$

\title{
Navigating the Edges: An Examination of the Relationship between Boundary Spanning, Social Learning, and Partnership Capacity in Water Resource Management
}

Stephan Edward Brown

Portland State University

Follow this and additional works at: https://pdxscholar.library.pdx.edu/open_access_etds Let us know how access to this document benefits you.

\section{Recommended Citation}

Brown, Stephan Edward, "Navigating the Edges: An Examination of the Relationship between Boundary Spanning, Social Learning, and Partnership Capacity in Water Resource Management" (2011). Dissertations and Theses. Paper 285.

https://doi.org/10.15760/etd.285

This Dissertation is brought to you for free and open access. It has been accepted for inclusion in Dissertations and Theses by an authorized administrator of PDXScholar. Please contact us if we can make this document more accessible: pdxscholar@pdx.edu. 
Navigating the Edges: An Examination of the Relationship between Boundary Spanning, Social Learning, and Partnership Capacity in Water Resource Management

by

Stephan Edward Brown

A dissertation submitted in partial fulfillment of the requirements for the degree of

\author{
Doctor of Philosophy \\ in \\ Urban Studies \\ Committee: \\ Vivek Shandas, Chair \\ Charles Heying \\ Connie Ozawa \\ Craig Shinn \\ Wayne Wakeland
}

Portland State University

(C)2011 


\begin{abstract}
This study proposes a framework for measuring and explaining partnership formation and resilience. The motivation for this study is that we currently do not understand the precise mechanism by which partnerships form or how they stay together in the face of change. The framework draws on a design view of systems to argue that partnerships manage change through boundary spanning practices that operate on multiple levels of social reality. The literature suggests that there are many different types of boundary spanning practices. Some types foster socialtechnical innovations called "boundary objects" while others facilitate the progressive standardization of those practices through the comparison and selection of boundary objects by social actors who are themselves transformed by their adoption of these objects. The framework proposes a way to measure partnership capacity and social learning that corresponds to the orders of boundary spanning practices. It furthermore proposes three hypotheses, one concerned with partnership formation and two concerned with resilience. The first hypothesis states that partnerships form through a convergence of boundary spanning practices and a community of practice. Convergence depends on a host of factors, including the capacity of innovators and early adopters to leverage their early successes to build additional capital to further promote and eventually institutionalize their boundary spanning practices. The second hypothesis predicts that partnerships that demonstrate a pattern of alignment practices integrating operational and strategic concerns will tend to oscillate within a defined range of
\end{abstract}


partnership functions or "states" (restricted resilience). The third hypothesis predicts that partnerships that inculcate a learning culture of institutional design practices will tend to persist under a theoretically limitless range of environmental demands (general resilience). To assess the framework, four case studies of water resource management partnerships in the Columbia River Basin were carried out. Data collection centered on interviews with boundary spanners, field trips, and secondary data. The results partially confirmed the first hypothesis, while evaluations of the resilience hypotheses were inconclusive. However, boundary spanning practices were catalogued according to the various types of partnership processes to demonstrate how the methodology can be used for cross-case comparisons and theory-building. 


\section{Dedication}

For my father Edward Lee Brown, who instilled in me the sense of adventure that comes with learning, and for my mother Asbjørg Solvik Brown, who never gave up on me 


\section{Acknowledgments}

This dissertation marks the culmination of a personal and intellectual journey. As with most journeys, I was helped along the way, sometimes at critical moments, by steadying hands, helpful perspectives, and encouraging words. I wish to thank the following individuals and organizations for their support with this project.

First, I am grateful to Portland State University's Nohad A. Toulan School of Urban Studies and Planning for its support during my graduate education. My gratitude extends to the Miller Foundation for funding the data collection phase of this project.

To my advisor, Vivek Shandas, I say "thank you," knowing that words can never really express my gratitude for your unflinching support of my intellectual, professional, and personal development. Your passion for collaborative teaching and learning created an ideal environment where I began to find my voice and my community. Every student should be so lucky to have a mentor like you. To my first advisor Connie Ozawa: I will always be grateful for your steadfast support and faith in me. You patiently guided me as I searched for that voice within the field of urban studies, alternately challenging me and getting out of the way. My gratitude to Charles Heying, especially for the intellectual joy of our many discussions. Although I was not usually aware of it at the time, some of my deepest learning occurred when our conversations strayed the most from their topics. Thank you, Wayne Wakeland, for the passion you brought to your classrooms and to our discussions, 
and for your appreciation, combined with healthy skepticism, for the "softer" side of systems thinking. Thank you, Craig Shinn, for your steadfast support of my project and for the many thought-provoking discussions of institutional analysis and development.

Of course, this project would not have occurred without the support of key individuals - Bobby Cochran, Kevin Scribner, Ryan Houston, and Lorna Stickel who believed enough in its merits to put me in touch with the partnerships that served as my case studies. Each of them has given me invaluable time and attention, and this project would not have been the same without their support. My deepest gratitude goes out to the boundary spanners who agreed to be interviewed by me. They are in my mind unsung heroes for the often thankless partnership work they do. I only hope that this project has helped them in some small way to tell more of their story. In the same spirit, I am deeply grateful to the Counting on the Environment Working Group, the Upper Deschutes River Partnership, the Regional Water Providers Consortium, and the Walla Walla Watershed Alliance for graciously granting me the opportunity to hear those stories.

There are simply too many individuals to thank for the space allowed. I have, over the course of the past few years benefitted from many wonderful discussions with colleagues and friends, all of whom have shaped me in some way, including, in no particular order: Renee Bogin, Alan DeLaTorre, Nicholas Lovrich, Daniel Lerch, Samantha Soma, Janet Hammer, and Luke Friendshuh. Thank you, Ranjit Bhaskar, for giving me shelter when I was practically homeless. I will always be especially 
grateful for the regular Skype sessions with Kirsten Herrick as we labored to finish our respective dissertation marathons: those sessions and your words of encouragement helped me when I most needed them. Special thanks go to my sister Ahne Kristin Bjelica and brother Morten Solvik for always being there, and to both my parents for your love and support in all its forms. And finally, to my wife Tara: thank you for all that you have done for me over the years to help me reach this milestone. Whether it was feeding, editing, or encouraging me, you have given me a joy that has been one of the sources of my inspiration.

While many people and organizations leave their mark on this project, in the end any errors, omissions, or faults are wholly my own. 


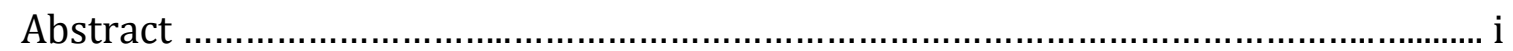

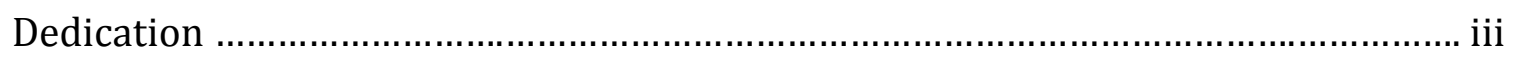

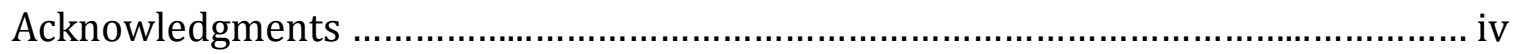

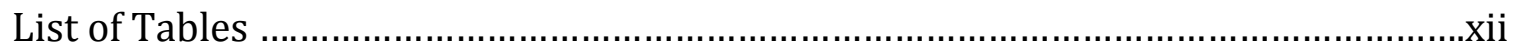

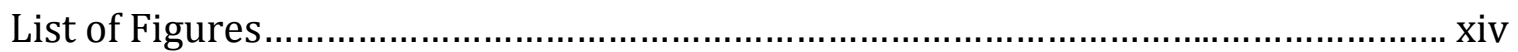

\section{Chapter 1}

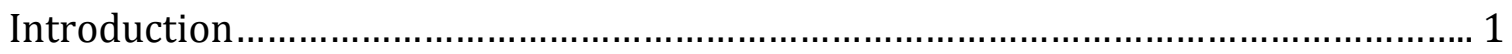

Toward a Unified Theory of Partnership Processes .............................................. 7

A Methodology of Institutional Change ............................................... 11

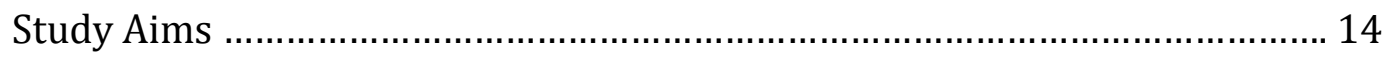

Research Questions and Hypotheses ................................................... 16

\section{Chapter 2}

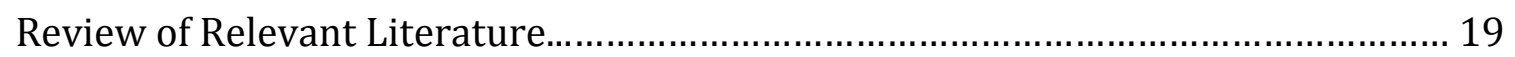

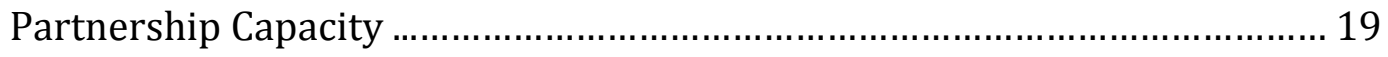

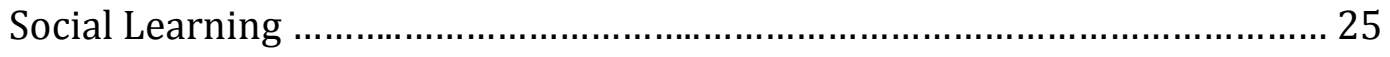

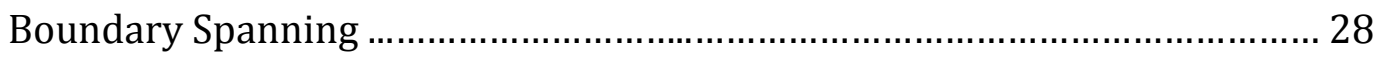

Summarizing the Gaps in Literature .................................................. 32 
Toward a Unified Theory of Partnership Processes

Chapter 3

Methodological and Theoretical Framework ……….......................................... 45

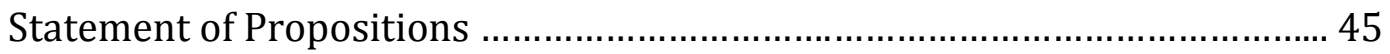

Understanding Boundary Spanning as a Communicative Practice ................ 45

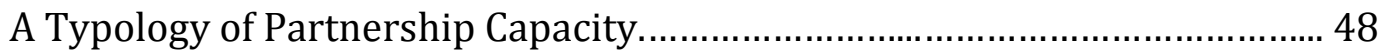

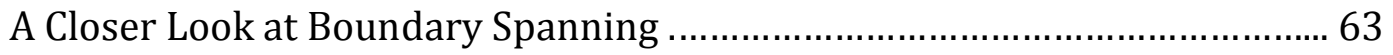

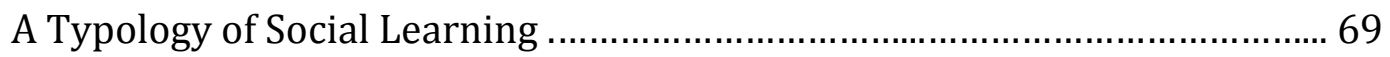

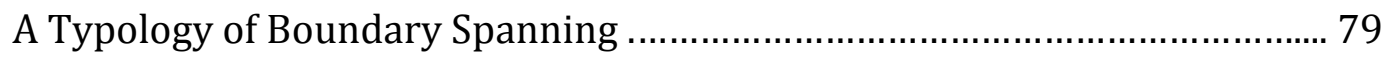

Operationalization of Framework Concepts ................................................ 84

Research Questions and Hypotheses ......................................................... 92

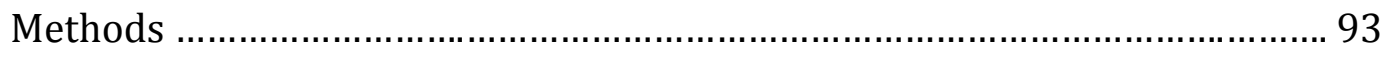

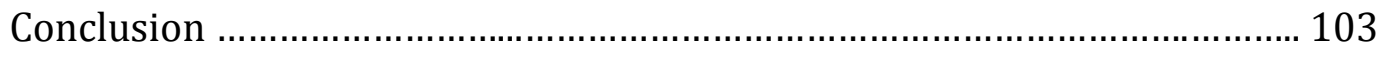

Chapter 4

Counting on the Environment Working Group (COTE WG) …….............................. 105

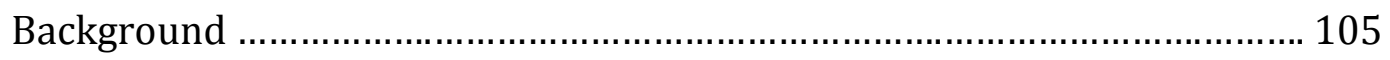

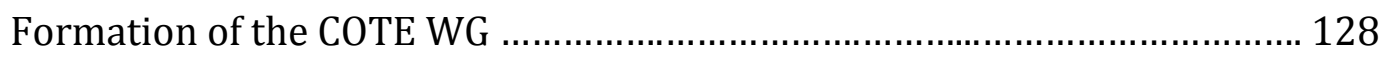


Boundary Spanning and Social Learning in the COTE WG

Chapter 5

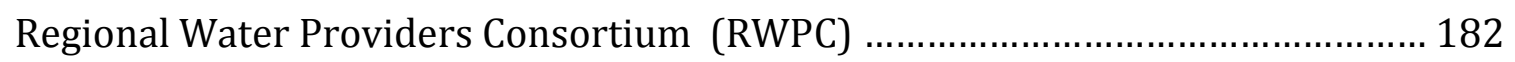

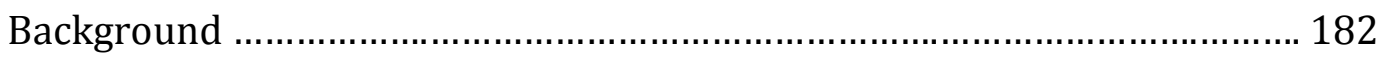

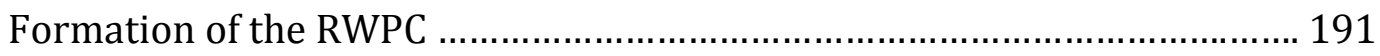

Boundary Spanning and Social Learning in the RWPC ............................... 202

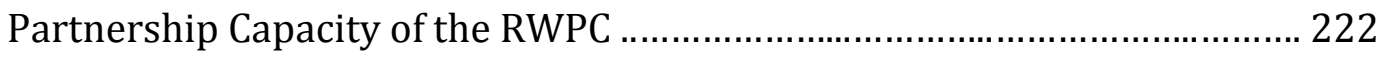

Conclusion and Recommendations ........................................................ 228

\section{Chapter 6}

Upper Deschutes River Partnership (UDRP) ………………………………..... 235

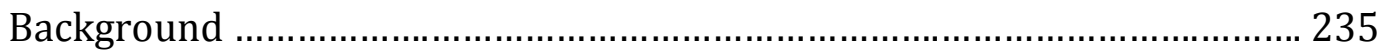

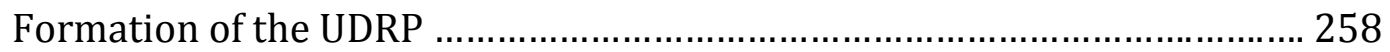

Boundary Spanning and Social Learning in the UDRP ................................ 289

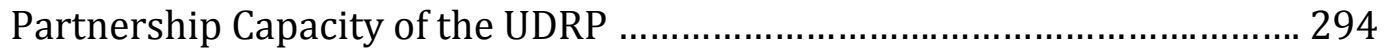

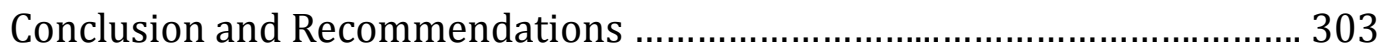




\section{Chapter 7}

Walla Walla Watershed Alliance …………………........................................... 311

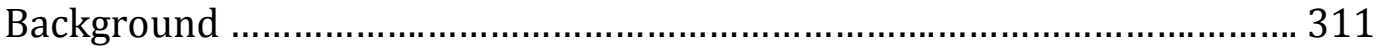

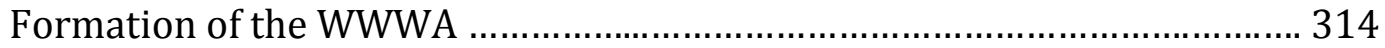

Boundary Spanning and Social Learning in the WWWA ….......................... 349

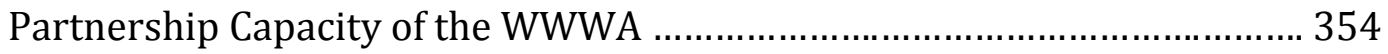

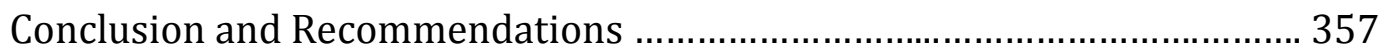

Chapter 8

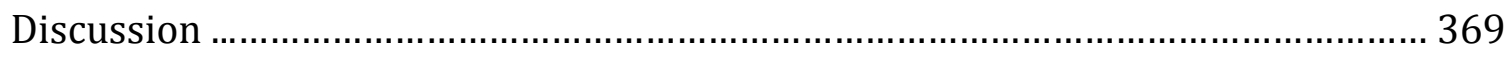

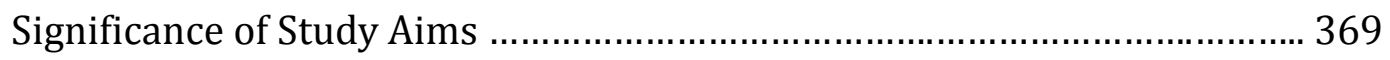

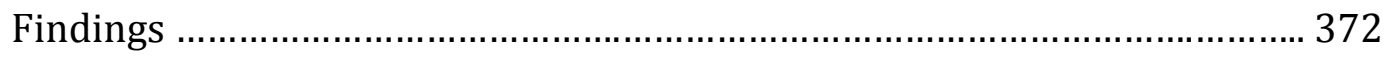

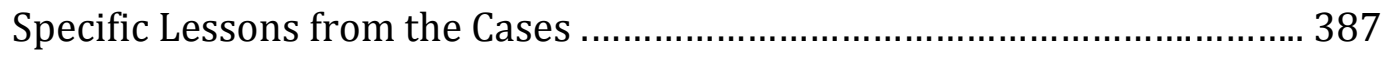

Chapter 9

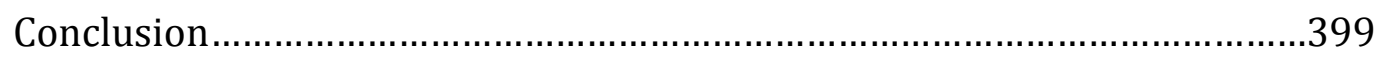

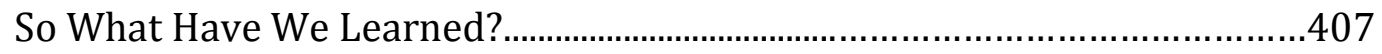

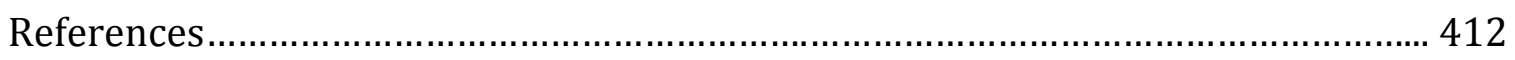

Appendices

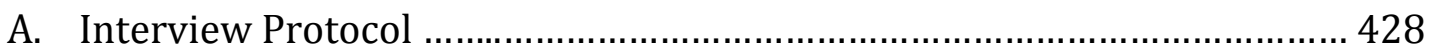




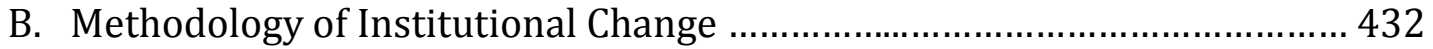

C. Workshop Rich Pictures of Institutional Change Scenarios ........................ 434 


\section{List of Tables}

\section{Table 1}

Typology of Boundary Spanning Practices

Table 2

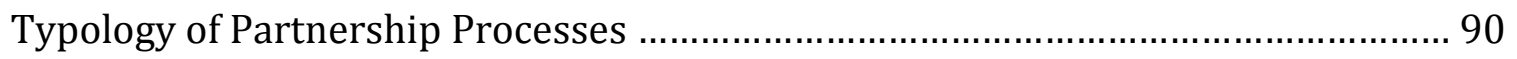

\section{Table 3}

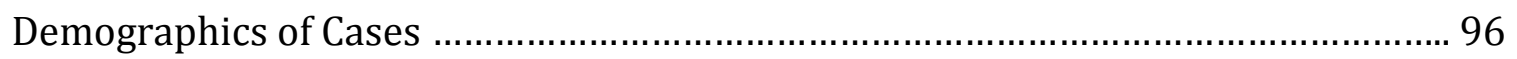

\section{Table 4}

Boundary Spanning Practices in COTE WG

Table 5

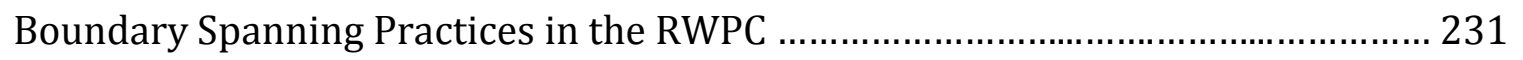

Table 6

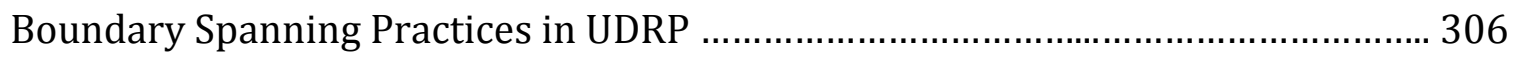

Table 7

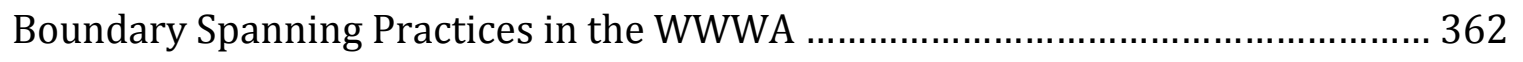

Table 8

Observations of Boundary Spanning Across Cases and Orders

Table 9

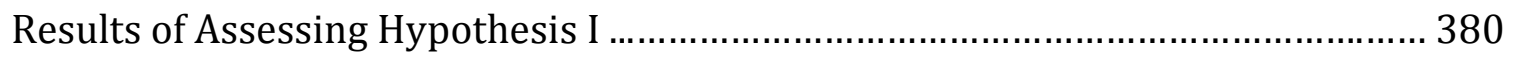


Table 10

Logic to Assess Hypothesis IIa ........................................................................... 383

Table 11

Results of Assessing Hypothesis IIa ................................................................ 384

Table 12

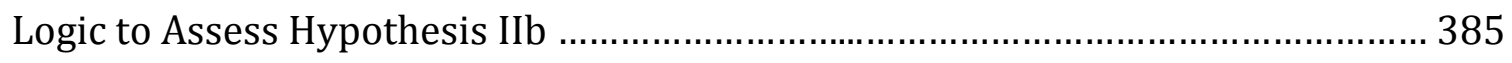




\section{List of Figures}

Figure 1

Design View of Systems 35

Figure 2

Partnership system comparing the structure of relations of the partnership field and its relevant institutional ecology. 47

Figure 3

Partnership on a Continuum of "Coupling Tightness" 52

Figure 4

Alignment practices confer PC II by closing a loop about input and output .54

Figure 5

CLD of Partnership Capacity I

Figure 6

CLD of Partnership Capacity II

Figure 7

CLD of Partnership Capacity III 62

Figure 8

Process View of Partnerships 71 
Figure 9

Convergence Leading to the Formation of a Partnership

Figure 10

Partnership Work as an Ongoing Process of Mutual Adjustment

Figure 11

Mapping SSM onto framework showing possible intervention points 102

Figure 12

COTE WG Process Structure 135

Figure 13

Actual and Potential Drinking Water Sources of the Portland Metropolitan Area in 2004 183

Figure 14

Water Providers in the Portland Metropolitan Area in 2010 184

Figure 15

Upper Deschutes River Basin 257

Figure 16

Map of the Walla Walla River Basin 313 
"We must not cease from exploration, and the end of all our exploring will be to arrive where we began and to know the place for the first time." - T.S. Elliot

\section{Chapter 1}

\section{Introduction}

The present study proposes a framework for understanding and examining boundary spanning practices and processes as they relate to the formation and continuing success of partnerships. This framework will then be assessed in 4 case studies of water resource management partnerships in the Columbia River Basin located in Oregon and Southwest Washington. The study grows out of the recognition that, to date, we still do not understand very well the processes involved in forming partnerships. All too often, partnerships are explained away by simplistic references to "cost-efficiencies" or "collaborative synergies" that assume social actors are for the most part rational. Yet there are many instances where such potential advantages exist and still partnerships fail to form. Similarly, case studies of partnerships already on the ground often take their continuing success for granted, an assumption perhaps reinforced by the tendency to study only "successful" partnerships. The problem, however, is not only empirical but also theoretical. When confronted with the real-world limits of collaborative efforts, normative theories of partnerships tend to lay the blame on one side or other of the agency-structure debate. Thus, depending on whom you ask, either irrational power is to blame or naïve rationalism is the problem. Yet regardless of which side of the debate one is on, ad hoc references to factors extraneous to one's model to 
explain some anomaly amount to an implicit admission that our current theories of partnerships, and collaboration more generally, are either inconsistent, incomplete, or both.

Working in the crevices between the "great divide" have been practitioners and theorists of a pragmatic bent who prefer a more balanced approach to understanding and building partnerships. The central problem that has been the focus of this work is the problem of collective action: how to organize the actions of otherwise disparate institutional actors toward a common purpose? Practitioners and policymakers confronting increasingly wicked environmental and social justice problems have not had the luxury to wait for an answer. Over the past thirty years environmental governance has witnessed a remarkable shift toward more decentralized and distributed forms of policy-making that are characterized by creative adaption of policy principles to local conditions (Hajer \& Wagenaar, 2003). Policies are now regularly deliberated and made through local experiments as much as through administrative or judicial ruling. The adaptive, networked form of governance, with its creative integration of local practices and grander theories, reflects profound changes in the relations between the state, market, and civil society (M. P. Mandell, Spring 1999).

Social theorists have struggled to adequately account for the implications of this shift in governance, in large part because their theories and frameworks are based on dualisms, including the separation of agency and structure, that no longer apply, if they ever did. More successful accounts, in contrast, eschew such easy 
oppositions and instead attempt to treat collective action as a problem requiring explanation. Some rather sophisticated frameworks, mostly coming out of the New Institutionalist vein, have been proposed in an attempt to explain these newer governance structures. The Institutional Analysis and Development framework developed by Elinor Ostrom (1999) is a notable example. But these approaches usually fall short of their promise by reducing institutional effects to either aggregates of individual decisions or to the constraints of monolithic institutional fields, or both. Consequently, they often cannot sufficiently capture the dynamics of "meso-level" actors, including multi-sector partnerships, that operate between the level of individual and organizational actors and the larger society. Another promising line of work draws on practice theory to posit that social actors engage in multiple and overlapping fields or "communities of practice" (E. C. Wenger \& Snyder, 2000). A key insight to emerge from this work is that communities of practice must strike a balance between differentiation from and communication with "others."

A primary claim of the present framework is that boundary spanning is centrally concerned with striking this balance. There are in fact many different types of boundary spanning, but they all have the common element of bringing different ideas, practices, objects, and agents from different fields of practice into interaction with one another. Boundary spanning is closely associated with the work of collaborative leadership and will typically involve a combination of: building sustainable relationships, visioning, influencing and negotiating, honest 
brokerage, managing the complexities associated with institutional and strategic interdependencies, and managing roles, accountabilities, and motivations to ensure collaborative processes continue to move forward. The literature on boundary spanning suggests that it is more of an art than a science that depends in large part on the ability of boundary spanning practitioners to make good and timely judgments about which actions are appropriate to take under a given circumstance (Williams, 2002). Boundary spanning calls on a wide range of skill sets, which may explain why collaborative leadership, and therefore boundary spanning, is typically distributed to include: thought leaders and "imagineers," networkers, codifiers and documenters, and pioneers, among others (Austin, 2002; Koppenjan \& Klijn, 2006; E. C. Wenger \& Snyder, 2000). Boundary spanning must somehow integrate collaboration ideals and pragmatism, "rational" and "irrational power" (Vangen \& Huxham, 2003).

The framework proposed here starts with the idea that communities of practice are shot through with boundaries of all kinds - be they technical, social, economic, political, ideological, linguistic, or cultural - that serve to socially differentiate ideas, practices, objects, and communities. Partnerships, then, are basically composed of boundary spanning practices and processes. This is, in a sense, simply a reformulation of the problem of collective action. But this reformulation suggests yet another question concerned with the emergence of new joint fields of action, namely: how does the social learning underlying coordinated action take place? Two points are worth noting here. The first concerns the change 
in the language of our question as we go from inquiring about joint fields to inquiring about the emergence of joint fields. This change introduces the phenomenon of orders of language, or logical typing, which, in and of itself, suggests that social learning is ordered. The second point harkens back to our reformulation of the problem of collective action. If communities of practice are, in fact, organized by boundaries, then this suggests that social learning is primarily concerned with spanning those boundaries in new, boundaried, ways. This conceptualization shifts the emphasis in environmental governance away from achieving consensus to the management of differences and to the creative management of uncertainty associated with changes in those management regimes. Viewed in this light, the problem of collective action becomes a variant of the age-old problem of change.

A central challenge we face at this point in the discussion is that while practice-theoretic formulations like the concept of "communities of practice" at least acknowledge the importance of boundaries, they typically lack a language of orders to account for social learning. The same limitation plagues social network and actor-network theories. To address this shortcoming, the present framework proposes a framework based on the design view of systems that treats fields of practice as social communication systems capable of learning. The design view of systems conceives of fields as consisting of nested levels of feedback processes. The conceptualization lends boundaries a more recursive rather than lineal quality, and provides a more natural basis by which to map the interaction of multiple boundaries that characterize complex social situations. Furthermore, the 
framework treats partnerships as instances of fields of practice. This moves us away from overly-narrow, juridical-legal definitions of partnership entities to consider how partnerships participate in communities of practice. It is an attempt to locate partnerships within an institutional ecology of communicative practices.

The framework also seeks to clarify the role that perception plays in the interaction of structure and agency, particularly in the formation and evolution of joint fields of practice. Cognitive models of institutions tend to conceptualize social perception largely in rational terms (e.g., "bounded rationality"), which leads to confusion not only in locating agency but also in explaining social change and learning (Berger \& Luckmann, 1966; DiMaggio \& Powell, 1983; D. Katz \& Kahn, 1978; R. N. Osborn \& Hagedoorn, 1997). The current framework, in contrast, allows for "social mind" to operate on and between many orders of social reality. It can therefore begin to account for the peculiar convergence of ideas and practices from adjoining fields which more conventional theories of social and policy learning that rely on a largely lineal (even spatial) conception of innovation and diffusion cannot. More fundamentally, a socio-cybernetic framework locates causality in the differences or gaps between processes. These gaps constitute ruptures in the fabric of expectations that have the potential to carry new meanings and produce novel, i.e., "boundary spanning," social practices and objects. The framework draws on Punctuated Equilibrium Theory to show that these ruptures can occur dramatically and without warning. From a methodological standpoint, the framework allows us to more systematically study how the misunderstandings that emerge from 
boundary encounters themselves interact through the selective sorting of the consequences of those misunderstandings on the parties and fields involved. The process of "sorting out" can be long and fraught with uncertainty. When we consider that this sorting occurs along multiple dimensions, we begin to understand why partnership work is so difficult. As the study title suggests, partnership work entails "navigating the edges" of substantive, institutional, and strategic uncertainties. And of all the edges to navigate perhaps the most important is the one where those uncertainties meet.

\section{Toward a Unified Theory of Partnership Processes}

By conceptualizing partnerships in terms of boundary spanning, the framework treats partnerships as problematic, rather than taking them for granted. But this approach also moves us away from any normative theorizing about boundary spanning. Boundary spanning isn't necessarily “good." Indeed, a boundary spanning practice may in fact be quite disruptive to partnership work - it all depends on one's perspective, or more precisely, on one's system level-ofreference. A design view of systems suggests general typological criteria by which to classify boundary spanning processes that refer to changes in their orders. This point is worth reiterating - it is the change in orders, not the orders themselves, that is our concern. After all, if we are to accept that a system and its functions are always defined by an observer - in other words, if systems are perspective-driven then the idea of "absolute orders" becomes meaningless. And if, as our theory contends, partnerships are primarily concerned with the management of change 
and uncertainty, then our typology of boundary spanning will be based on criteria for detecting changes in their orders. Such a typology requires, in turn, that our system level-of-reference does not change. For any given level of analysis, then, the framework posits the following types of boundary spanning processes: "core practices" are associated with the routine practices or operations of a partnership; paradigmatic "boundary spanning practices" are innovative practices which have the potential to transform a given field of practice; while "alignment practices," are concerned with the mutual adjustment of operational and strategic concerns. A fourth kind of boundary spanning, institutional design, can be added to our typology to capture a learning culture that encourages the creative generation, modeling, and documentation of issues associated with institutional processes.

It should be noted that this formulation brings concepts from neoinstitutionalism and practice theory into closer alignment and, in some cases, reinterprets those concepts. The principal concepts that comprise the framework fall under the familiar labels "boundary spanning," "partnership capacity," and "social learning." But these labels acquire new and arguably richer and more rigorous meaning in the context of the present framework. As already stated, the design view of systems taken here emphasizes that partnerships are recursive processes and furthermore that those processes are organized into a (nested) hierarchy that effectively classifies processes into discrete communicative events, or messages. Socio-technical practices that break the mold, as it were, are transformative. It follows from this that partnership work is fundamentally about 
organizing innovative but otherwise "noisy" boundary spanning practices into a community of practice which lends them some coherence. Partnerships reduce environmental uncertainty by folding a part of it into its management domain or, viewed by the alternative vantage-point, by expanding its sphere of ownership. Once we view partnerships as ordered processes, it becomes natural to inquire into the relations between partnerships. In principle, we can imagine partnerships achieving some integration in "meta-partnerships." But sooner or later all systems must confront the fact that they are bounded and therefore subject to error. A problem of a new order arises: how to learn to learn? And having surmounted that problem, how can we replicate learning communities elsewhere?

We can discern in this discussion at least 3 , if not 4, general types of collective action problems of increasing orders of complexity. At this point we are in a position to classify partnership or community capacities in terms of the orders of the general problems they address: Partnership Capacity I (PC I), Partnership Capacity II (PC II), and Partnership Capacity III (PC III). ${ }^{1}$ PC I refers to the capacity of a joint field to regularly sponsor the interaction of agents, practices, and their objects among the different partnering fields to solve "routine" problems. By "routine problem" is meant a problem that does not require a structural change in the organization of the partnership to solve or address it. PC II, in contrast, refers to the capacity of the partnership to reinvent itself in the face of a recurring set of

\footnotetext{
${ }^{1}$ Partnership Capacity IV - the institutional capacity to establish learning partnerships on a regular basis - will not be explicitly examined in the present study, although the framework predicts that fields of practice demonstrating PC IV will of necessity be found in fairly complex fields or communities of practice and are probably rare.
} 
challenges. An important aspect of PC II is that the reinvention tends to be of a cyclical nature, so that a partnership with PC II will tend to anticipate, rather than simply react to, problems. This notion of PC II is closely related to a more restricted notion of resilience. In the context of the case studies, this means looking at the extent to which a partnership drives, rather than simply follows, the water resource management agenda of its community. A key ingredient of PC II is what Etienne Wenger (2000) calls "alignment practices," which are essentially social actions and processes that allow for the mutual adjustment of everyday and more strategic practices. One example might be the communication between staff and board, a challenge, we may note in passing, with which many watershed councils have struggled. Similarly, partnerships that incorporate implementation planning into their strategic planning are often more effective than those that carry out implementation planning as an afterthought. Finally, PC III refers to a more general capacity of a community of stakeholders to learn and adapt. In the case of PC III, alignment practices are themselves subject to periodic review and modification. Such a capacity is necessarily of a fairly high order and requires a culture of learning that promotes rather than discourages inquiry and even dissent. The concept behind "PC III" closely follows Churchman's (1971) "Singerian System" and the notions of the "learning organization" and "learning network" which it inspired. Having established such a typology of partnership capacities, we have a natural basis by which to classify social learning. Social learning is about "bringing forth," to paraphrase Maturana and Varela (1992), a worldview that organizes 
boundary spanning practices into a coherent pattern of interaction. Since social learning can be properly understood as the acquisition of a given capacity to communicate across socio-technical boundaries, our typology of partnership capacities suggests a typology for social learning: Social Learning (SL) I, referring to the emergence of a new joint field of action, or partnership; SL II, referring to a partnership field learning how to anticipate its own problems; and SL III, referring to a partnership community learning how to adapt to socio-technical and policy surprises. The typology of social learning proposed here corresponds closely to Bateson's (1972) “levels of learning." Indeed, Bateson's typology comprises the backbone of the current process framework, which enables us to take previously disparate concepts of institutional capacity and place them in a system of classification that measures them in a consistent and coherent manner. For, as Bateson recognized, to measure something is to act on it, and vice-versa.

\section{A Methodology of Institutional Change}

Such a general system of classification is intended to inform, rather than replace, any understanding of the particular historical form a given partnership will assume. It predicts that a partnership will demonstrate some pattern in its boundary spanning practices, but it cannot predict the precise form of that pattern. Further classification of partnerships and the boundary spanning practices that comprise them requires empirical study grounded in a particular context. But the framework provides a place to a start such an empirical study by anchoring our inquiry in a particular level of analysis that corresponds to the order of the 
partnership process we happen to be examining. That is, we can start by grouping boundary spanning practices that fall under the same descriptor of change - e.g., “deviation in Partnership X's way of doing business with the timber industry community" - and proceed to look for patterns among those practices. A pattern or set of patterns would be evidence of a still-more complex partnership process, which may, in turn, provide a descriptor of change - e.g., "change in core (partnership) business practices between Partnership X and the timber industry community" - for further inquiry, and so on. Our final mapping would contain 2 important pieces of information: first, it would communicate something about the general capacity of the partnership under investigation to manage changes of varying orders; and second, it would convey a "thick description" of the specific boundary spanning practices occurring at the various levels of governance and, if our study is longitudinal, occurring at the various stages of the partnership's evolution.

Some of the advantages of this framework over existing approaches have already been suggested, but let us state them more clearly now. First, the framework represents not only a more complete synthesis of neoinstitutionalist and practice-theoretical approaches, but it also suggests a methodology for measuring these rather abstract concepts. For example, the framework links Wenger's (2000) notion of alignment with the framework's concept of "meta-boundary spanning" to suggest that PC II can be demonstrated by the existence of an enduring pattern of alignment practices. And this point is not just academic: it turns out that the 
operationalization of the concept "partnership capacity" can inform strategic interventions designed to enhance partnership effectiveness. In addition, the proposed methodology requires us to state the level of analysis we're applying, which enables the reader to critically evaluate whether that analysis is internally consistent and complete. This is an improvement over practice-oriented accounts that tend to obscure and even falsify the level of causation, and therefore agency, in structuration.

And finally, we have a set of typological criteria to measure these concepts which, if it is validated, will enable us to investigate the distribution of their variants across cases. We can then start to determine whether certain kinds of partnership practices - for example, education and outreach - tend to be associated with a certain class of boundary spanning, for example, alignment practices. In other words, we can start to determine whether these practices tend to carry a specific function with respect to the management of institutional change. This, in turn, will enable us to formulate testable hypotheses about the correlation, if any, between specific forms of boundary spanning-, partnership-, and social learning processes. For instance, Rugkåsa et al. (2007) discuss the difference between "boundary spanning across," which refers to communication and learning across peer networks, and "boundary spanning downward," which refers to communication and learning with a community of users who are to adopt a given innovation. We can now inquire whether one kind is more prevalent in partnerships with PC I as opposed to those with PC II or PC III. In some cases we may discover that 
distinctions in the literature become meaningless in the current framework, or, contrawise, we may discover important distinctions between previously conflated concepts or terms. Either way, we will have learned something.

\section{Study Aims}

The study, then, has 3 principal and related aims. First, it proposes and assesses a new methodology for studying boundary spanning, social learning, and partnership capacity. Especially, it posits general criteria for measuring these concepts that are rooted in a process view centrally concerned with the problem of change. Assessment of the framework will be driven by several criteria. For one, the framework can be judged by its theoretical and methodological coherence, which concerns both its logic as well as its alignment with our current state of knowledge about partnership processes. The framework can also be judged by how well it "covers" the range of observations we make about those processes. And finally, the framework can be assessed indirectly by the predictions of its model. These last two criteria anticipate the next 2 study aims.

The second aim of the study is exploratory, namely: to begin to catalogue the many varieties of boundary spanning practices in different partnership contexts and to sort those varieties by their orders to determine the relationships, if any, between these varieties and the types of social learning, partnerships, and partnership capacities we encounter. To this end, each of the 4 partnership cases in this study will be summarized with tables enumerating the various instances of boundary spanning that fall under each major type: core-, alignment-, and institutional design 
practices. This enumeration will then be transposed from each case study into a table listing the boundary spanning observations for all 4 cases. The structures of the tables - as well as the transposition - reflect the assumptions of the model showing the link between types of boundary spanning, social learning, and partnership capacity. In the exploratory mode, these assumptions are not tested; rather, the objective of the tables is to compare the distribution of observations across cases for each boundary spanning type to determine whether there are any patterns. For example, we may start to determine whether education and outreach appears to play an alignment function in partnership work.

The third aim is to evaluate the theory embedded in the framework by assessing its predictions with respect to 2 questions that motivated this study: first, how precisely do boundary spanning practices on the edges of fields coalesce into new joint fields of practice in the form of partnerships?; and, second, how do partnerships adapt to changing social, technical, and policy conditions? It is now possible to begin to formulate hypotheses to these questions. First, if boundary spanning practices and processes persist for long enough, eventually they may spawn new joint fields of practice, complete with their own identities, knowledgebases, practices, and objects (e.g., standard operating procedures, models, and other social-technologies). As already stated, partnerships are treated here as instances of these joint fields of practice. Furthermore, the theory contends that an extra ingredient for the emergence of new joint fields is some kind of opening in the larger social, technical, or policy environment that creates a demand for its "boundary 
objects." And, according to the theory, the process of this emergence is often even more nuanced, since these partnership fields can catalyze, as it were, their own crystallization by helping to create demand for their products.

\section{Research Questions and Hypotheses}

Having sketched the relationships between the theory's core propositions, we can restate the research questions and propose some preliminary answers:

1. Research Question I: How do partnerships form exactly?

Hypothesis I: A socio-technical or policy need creates a structural opportunity for boundary spanning practices to begin to influence the larger institutional ecology. Boundary spanning practices will begin to converge with the ecology of participating fields through an iterative process of social judgments embedded in communicative practice and capital exchange. If the boundary objects (innovations) are deemed both technically desirable and culturally feasible, then the practices and ideas that produced them diffuse along with the innovations, further reinforcing the convergence. Boundary spanners play an important role in managing the convergence (however imperfectly) through visioning, strategic judgments, and steering capital flows, even as they are thereby changed in the process. The entire process is summarized as "Social Learning (SL) I" and results in a partnership with a basic capacity (Partnership Capacity I) to address a fairly welldefined policy problem.

2. Research Question II: How do partnerships sustain themselves over time? 
To survive in the face of changing policy conditions, a partnership must learn (SL II) to engage in alignment practices that periodically allow for the mutual adjustment of core operations and more strategic and even constitutional concerns. This ensures that partnership goals and strategies are informed by local practices and conditions and facilitates the partnership's role in shaping the community agenda on a policy issue. Therefore:

Hypothesis IIa: Partnerships demonstrating a pattern of alignment practices will tend to oscillate about a defined range of "partnership states," as measured by programs, initiatives, or other strategic emphases.

Partnerships that develop the capacity (SL III) to reconfigure or "design" alignment practices to address socio-technical and policy surprises acquire a general capacity to learn and adapt that is enhanced with each iteration of the social learning cycle. Partnerships demonstrating PC III are characterized by a learning culture that promotes innovation and critical reflection of alignment practices in experimental settings. Therefore:

Hypothesis IIb: Partnerships demonstrating a pattern of institutional design practices will tend to persist in varying forms and under a wide range of environmental conditions.

This framework and its hypotheses will be assessed through 4 case studies of water resource management partnerships in the Columbia River Basin. Cases were to a large extent selected to enhance the study's replication logic as called for in explanatory case study designs. Thus, every attempt was made to select 
partnerships that shared as many extraneous traits as possible while focusing on the model's major relevant variables. For Hypothesis 1 (explaining partnership formation), these include: presence of pre-existing "need," presence of innovative (boundary spanning) practices, technical desirability, cultural feasibility, degree of interest and support for innovations, the exchange of capital forms to promote innovations, extent of adoption, "structural distance" between innovations and wider community of practice (measure of convergence), and pattern of boundary spanning practices (measure of PC I). For Hypothesis IIa (explaining partnership PC II), the relevant variables are: coherence of alignment practices and presence of defined range of partnership states (measure of PC II). And for Hypothesis IIb, the relevant variables are: coherence of institutional design practices and the absence of outstanding partnership issues (measure of PC III). Otherwise, cases were selected which were similar with respect to several potentially significant, complicating factors, including: policy domain (water resource management), cultural-geographic region (the Columbia River Basin), scale (regional partnerships), and historical incidence (contemporary).

Nevertheless, 4 case studies can only provide a very selective sample of partnership experiences, especially when one considers the number of variables contained in the model. Subsequent empirical studies will need to be carried out to more fully test and develop the ideas proposed here. An ongoing research challenge will be to identify those conditions where the framework applies and those where it does not. 


\section{Chapter 2}

\section{Review of Relevant Literature}

\section{Partnership Capacity}

Contemporary commentators of policy processes observe that the world has experienced over the past 40 years a remarkable reshuffling of the relations between state, civil society, and the market (Kettl, 2002; Salamon, 2002). Technocratic and managerialist approaches to governance that were largely premised on the ideological if not practical separation of the major sectors are giving way to new, networked forms of governance characterized by "deliberative policymaking" in which the institutional context of collective action is improvised along with policy (Hajer \& Wagenaar, 2003; Toffler, 1970). Adaptive networked governance is not only upending policies but also deeply held assumptions about policymaking, especially the separation of planning and implementation and even of theory and practice (Fischer, 2000, 2003; Keast, Mandell, Brown, \& Woolcock, 2004; Koppenjan \& Klijn, 2006; M. P. Mandell, Spring 1999; Ozawa, 1991; Selsky \& Parker, 2005). In its wake, classical models of decision- and policymaking that often assumed actors were rational, even if boundedly rational, are being replaced with new theories highlighting the ways actors both shape, and are shaped by, the institutional context in which they engage (Giddens, 1984). In the context of pluralism and socially wicked problems, the long-standing problem of collective action - how do differently (and differentially) constituted actors nevertheless manage to organize their actions toward a common purpose? - acquired a new level 
of urgency. This question has had special relevance for the planning and management of common pool resources like water, where "defection" is always a real possibility (Axelrod, 1984; Dietz, Ostrom, \& Stern, 2003; Hardin, 1968; Karkkainen, 2002; Ostrom, 1999).

A number of schools of thought drawing on social constructionism have emerged in the past 30 years to better account for collective action, including Institutional Analysis and Development (IAD), which contends that policy actors make strategic decisions to form alliances and mobilize discourses or resources according to "structures of opportunity" which may themselves change as a result of these decisions (Ostrom, 1999; Rydin, 2003). Sabatier and Jenkins-Smith’s (1999) Advocacy Coalition Framework (ACF) propose a similar marriage of structure and agency in their model of policy systems and subsystems. More generally, the “communicative turn" in policy analysis and planning theory during the 1980's began to shed light on how social actions, including policies, could be made to communicate something about, and therefore impact, the social relations engaged in the action (Fischer \& Forester, 1993; Hajer \& Wagenaar, 2003; P. Healey, 1996; Hoch, 2007).

The (Deweyian) pragmatist impulse, particularly in the United States and Great Britain, has brought greater attention to the subtler operation of "power" both within and outside of planning processes (Flyvbjerg, 1998; Forester, 1989, 1999; P. Healey, 1996, 1999; Hillier, 2003; Innes \& Booher, 1999). However, this more pragmatic approach is also marked by an optimism, especially embodied in 
negotiation theory, that implies that sufficiently undistorted disclosure of interests, or "communicative rationality," can counteract "irrational power" and lead to innovative solutions that expand the pie of payoffs (Carpenter \& Kennedy, 1988; Fisher, Ury, \& Patton, 1991; Lax \& Sebenius, 1986; Poirier Elliott, 1999; Scharpf, 1993; Susskind \& Cruikshank, 1987). But missing from this formulation is an appreciation of the importance of relational dynamics with the result that it overestimates the capacity of human reason to solve social problems. Especially, if interests are context-dependent, this suggests that a stable solution may not be found by merely articulating those interests. Furthermore, we need to consider how interests are culturally construed and negotiated in the identity politics of social interactions. There have been some notable exceptions of attempts to theorize "the shadow negotiation" of relationships, but they have focused on dyadic or at least face-to-face interactions (Kolb \& Williams 2003; although cf. d'Estree 2003). We need a better understanding of the institutional processes governing policymaking, particularly on the "meso-level" of inter-organizational action.

To address this lacuna, new institutionalists focus on the institutional "fields" or "communities of practice" in which social actors engage (Berger \& Luckmann, 1966; DiMaggio \& Powell, 1983; D. Katz \& Kahn, 1978; Meyer \& Rowan, 1977; Meyer \& Scott, 1983; R. N. Osborn \& Hagedoorn, 1997; W. R. Scott, 1992; Silverman, 1971; Smircich \& Stubbart, 1985; Thompson, 2005; Weick, 1995; Zucker, 1991). This line of thinking has informed important theoretical work not only in policy analysis but also organizational learning and development. Unfortunately, however, 
application of these theories has been mostly limited to strategic planning in the private sector (Banner \& Gagné, 1995; Collins \& Porras, 1996; Haines, 2000). And even within the private sector, most theoretical and empirical work has predominantly been concerned with firms, although strategic alliances have deservedly gotten more attention in recent years (R. N. Osborn \& Hagedoorn, 1997; Pentland \& Feldman, 2007; Zollo, Jeffrey, \& Harbir, 2002).

Not surprisingly, there has been a lot of interest in understanding collaborative or partnership capacity and ways to bring it about (Agranoff \& McGuire, 2003; Gronn, 2002; Huxham \& Vangen, 2004; Lasker, Weiss, \& Miller, 2001; Vangen \& Huxham, 2003). Notions of "collaborative advantage" and "partnership synergy" have been developed to describe the accomplishment of a task or function which individual partners could not accomplish on their own (Weiss, Anderson, \& Lasker, 2002). Research on partnership capacity suggests that partnerships that afford their members opportunities to collectively reflect on their experiences are often more effective (Armistead \& Pettigrew, 2004; Sullivan, Barnes, \& Matka, 2002). Much of this work has been carried out in the context of water resource management, where the complex intersection of technical, policy, and social problems typically call for a collaborative approach (Bidwell \& Ryan, 2006; Connick \& Innes, 2003; Shandas, Graybill, \& Ryan, 2008; although cf. Imperial, 2005). Some attempts, popularized of late by the concept of "social sustainability," have been made to measure the relationship between stakeholder views about one another and collaborative capacity (see, for example, Weber et al., 2007). These 
studies are to be commended for conceptualizing "collaborative capacity" as an outcome measure rather than as a given. Still, there is a tendency to confuse collaboration with consensus. More generally, there is currently a dearth of understanding of inter- (or "trans-") organizational dynamics and the institutional conditions that promote collaborative capacity (Agranoff, 2007; Rodrl̀guez, Langley, Béland, \& Denis, 2007). At the same time, while network actor and learning network theories have shed important light on the contemporary conditions of governance, empirical studies show that there are forms of inter-organizational innovation that do not conform neatly to a network structure (David, 2004; M. Mandell \& Steelman, 2003). More seriously, the network analytic lens tends to flatten our view of social processes and thus fails to account for both the differential capacities to manage change and the changes in those capacities.

Some important work has been done to situate collaboration in larger fields of practice (Hardy \& Phillips, 1998; Miner, Amburgey, \& Stearns, 1990). Zollo et al. (2002) introduce the concept of "interorganizational routines" referring to "stable patterns of interaction among two firms developed and refined in the course of repeated collaborations," and argue that these routines are useful predictors of the performance of strategic alliances. Pentland and Feldman (2007) similarly introduce a concept of "narrative network" to describe "patterns of 'technology in use"' (2007: 781). In addition, some promising lines of analysis that build on the Open Systems tradition have started to shed light on the influence that broader institutional fields have on organizations and inter-organizational dynamics (Baum 
\& Rowley, 2005; DiMaggio \& Powell, 1983; Smircich \& Stubbart, 1985). Many of these studies show that partnerships whose members vary in their collaborative commitment and resources must strike a balance between setting and meeting standards and being flexible to allow for diverse forms of participation that are sensitive to the real constraints of the organizational and interorganizational environment (Ivery, 2007; Takahashi \& Smutny, 2001).

Ivery (2007), for example, uses an organizational ecology approach in a case study of the Tri-cities Partnership (TCP) to address homelessness. "Linking pin," or bridging organizations, like the TCP that overlap in their ties to different components can: serve as communication channels between organizations; provide general services by transferring people, information, and resources across the network; and serve as models or otherwise influence partners toward collective action. Ivery concludes her case study by arguing that the organizational ecology view allows one to focus on both the relations within a partnership and on the nested structure of those relations. She points out that more often than not partnerships are composed of subsystems having both strong (core members) and weak (periphery members) coupling. Finally, Ivery calls for research that studies collaborative partnerships in all its diverse organizational forms.

However, the majority of the work has tended to focus on the impacts that inter-organizational collaboration have on the single organization, reflecting its status as the dominant unit of analysis (Hardy, Phillips, \& Lawrence, 2003). But even firm-level studies can be mined for insights into partnership capacity. For example, 
Von Krogh and Vicari (1993) employ an autopoiesis approach to conceptualize an organization's knowledge-base as part of the organization's environment, with implications for managing strategic issues. They define "strategic issues" as those environmental disturbances relevant to the system which, if unaddressed, will change the system ("S"). For Von Krogh and Vicari, then, Strategic Issue Management (SIM) is about managing surprises through continuous scanning, diagnosis, and response. This entails the "management of strategic experiments:" triggering and discovering experiments; retaining knowledge about the experiments; and applying knowledge from the strategic experiments. More generally, there is a rich and still growing literature on learning organizations, including strategies for measuring the learning capability of organizations (see, for example, Goh \& Richards, 1997). Summarizing, there is growing appreciation that partnership capacity centers in some way on the inculcated capacity and inclination to manage change in a consistent manner.

\section{Social Learning}

Because partnerships require the integration of diverse perspectives, identities, interests, and resources, the capacity to build and maintain partnerships implies social learning. Baumgartner's (2006) Punctuated Equilibrium Theory ("PET") attempts to explain changes in policy images - what he calls "heuristic short-hands" - and institutional venue, noting that they tend also to interact. The central mechanism hypothesized in PET is the interaction of negative and positive feedback loops which, Baumgartner observes, make them unpredictable on a case- 
by-case basis. Among the processes comprising these loops are the interactions of policy streams which policy entrepreneurs both bring about and capitalize on (F. R. Baumgartner \& Jones, 2002; Bogason, 2009; Patsy Healey, 2005; Kingdon, 1995; Marcussen \& Torfing, 2003). Furthermore, while the processes may vary in their content, the overall structure should be the same across different levels of analysis. Baumgartner calls for case studies that can elucidate just how these positive feedback processes come to interact to create sudden change. He adds that case studies of successful cases need to be carried out over long periods of time to see whether it was a change in response to changing contextual variables or if indeed a positive feedback process occurred that would explain the punctuated change (Baumgartner, 2006).

PET provides a useful framework to understand the emergence of partnerships. Indeed, in the context of water resource management, partnership capacity is often discussed in conjunction with "social learning" (Armistead \& Pettigrew, 2004; Berkes, 2009; Davidson-Hunt, 2006; Fernandez-Gimenez, Ballard, \& Sturtevant, 2008; Ison, Roling, \& Watson, 2007; Maarleveld \& Dabgbegnon, 1999; Manring \& Pearsall, 2005; Maurel et al., 2007; Pahl-Wostl et al., 2007; Tabara \& Pahl-Wostl, 2007). Unfortunately, however, these discussions often fail to make meaningful distinctions between social learning occurring at different levels of governance. There are, however, some notable exceptions. Gonzalez and Healey (2005) propose a three-level conception of governance dynamics - specific episodes, governance processes, and governance cultures - to address 3 questions, 
basically: 1) how to identify and assess urban governance changes; 2) how to evaluate whether any changes promote social innovation (in their case, social justice); and 3) what are the "power dynamics" that come into play (both for and against) during the attempted diffusion and institutionalization of such innovations? They argue that real innovations change governance relations in some way, but perhaps most relevant here, they argue that a focus should be on the interaction of actors from different communities of practice and on sustaining or institutionalizing such interactions in new forms of governance. Echoing PET, the authors speculate such changes occur in the interaction of "endogenous processes and exogenous forces" that create "cracks" or openings in the opportunity structure from which novel practices may emerge and take hold. As they write:

Innovations which manage to insert themselves in such a 'crack' may, in favourable conditions, come to have considerable power to transform governance relations. Endogenous and exogenous forces are therefore not separate, encountering each other in septic institutional sites. They are mutually interacting and, over time and space, co-constituting 2005 , pg. 2065).

The critical ingredient then becomes planting "seeds" or "sediments" that can have a cumulative or reinforcing effect in the direction of social innovation. Describing their own case study of a citizen network that formed to challenge the local and regional government's planning vision for Ouseburn Valley in Newcastle, U.K., they note that the very act of deliberating with different actors in novel contexts was disruptive:

In the case used above, a non-traditional mobilisation initiative opened a crack and softened a boundary. This fissure in the traditional and tight governance mechanism has been mostly made by active linking by key 
individuals across arenas, cultures and frames often by-passing formal structures. The ability to link across structural holes (Burt, 2002) creates an exchange around non-redundant information $(2005,2065)$.

Perkins et al. (2007) similarly take a level-of-analysis approach to social learning to propose 3-dimensional cube that links 3 levels of learning - the individual, organizational, and community - with 2 distinct orders of change, one ameliorative and the other "transformative" or systemic. Their 3 case studies show, among other things, the importance of overlapping institutional roles in fostering broader learning. Methodologically, they show how a level-of-analysis approach can help clarify the different orders of social learning that occur and the dependencies and linkages between them. An important insight is that complex adaptive systems survive not by eliminating but rather "enveloping" and managing change (Harter \& Krone, 2001; Innes \& Booher, 1999). But, as with many of these accounts (Alutto, 2002; Jansen, 1996; Whelan-Berry, Gordon, \& Hinings, 2003), the authors reify their levels of analysis by relying on overly concrete objects ("individual," "organization," and "community") to serve as reference, leading to a simplistic and even reductionist treatment of social learning. More systemic approaches to strategic change and learning are less susceptible to this problem (see, for example Jelinek, 2003).

\section{Boundary Spanning}

The most promising lines of inquiry into social learning focus on, to use Burt's (2002) evocative phrase, the "structural holes" and the bridgework over them. The term "boundary spanning" emerged largely in the context of classical 
studies of firms, where it was evaluated for its role in enhancing (or dampening) the information-processing capacity of a firm (Dollinger, 1984; R. Katz \& Tushman, 1979; Tushman \& Scanlan, 1981). These earlier studies suggested that evaluations of boundary spanning depended on one's level of analysis. On the one hand, there is clear evidence that activities and exchanges across socio-technical or policy boundaries could induce system-wide changes. On the other, in fluid and complex environments, boundary spanning appears to be an important survival strategy. In fact, the literature on boundary spanning has grown considerably as the decentralization and fragmentation of governance has placed greater emphasis on the ability of "boundary spanners" to "manage out," or across, social and professional ties to influence policies and practices (Austin, 2002; cf. also Bradshaw, 1997 ; Cash, 2006; Klein, 1996). Austin (2002) shows how much of boundary spanning work is focused on community practices, that is, on external relations between an organization and its community and on balancing those with internal demands. For middle-managers, "managing out" means devoting more time to building interdisciplinary relationships, especially with counterparts. For uppermanagement, it means paying more attention to external issues, building community partnerships, and cultivating a learning organization culture. Similarly, in her study of public and independent human service organizations (HSOs), ManoNegrin (2003) observes that the different sources of funding between public and independent HSOs was such that the latter's reliance on less stable funding meant that their managers and units had to function more as boundary spanners searching 
out and interpreting signals from the environment about how the organization was doing and correct course as needed.

However, Rugkåsa et al. (2007) argue that too much attention has been paid to boundary spanning upward and across and not enough on boundary spanning "downward" that is, boundary spanning with the clients or community that the partnership supposedly serves. Downward boundary spanning, they contend, serves both the community and the partnership by providing the clients with support and information needed to benefit from and utilize the services, thereby improving implementation. All indications are that boundary spanning is important for both generating and managing uncertainty. Studies on knowledge and technology brokers emphasize how organizational intermediaries facilitate learning by making analogies between problems in different sectors and combining technologies in creative ways and adapting them to "local" problems, creating value to their clients (for review, see Winch \& Courtney, 2007 ; see also Conway, 1995 ). Furthermore, studies of cooperative technical organizations show how boundary spanning reduces the uncertainty of innovation by providing standards and interfaces for firms working from different industries to address a problem or need, thereby facilitating implementation. Here, innovation brokerage functions to provide standards, role clarification and accountability (Winch \& Courtney, 2007). More generally, it appears that organizations and partnerships rely on boundary spanning practices to manage, as Harter and Krone (2001) succinctly put it: "the 
ongoing dialectic of controlling and being controlled by their environments" (pg. 257)

Other observers highlight the varied management skill set required of boundary spanners and boundary spanning organizations. Boundary spanning entails managing, through influencing and negotiating: complexities and interdependencies, as well as roles, accountabilities, and motivations (Koppenjan \& Klijn, 2006; Williams, 2002). Boundary spanners are especially effective when they have both the familiarity, legitimacy, and position to know how to navigate and enhance inter-organizational structures. Ideally, therefore, boundary spanners possess that rare combination of technical, policy, and socio-cultural competencies.

Much of the theoretical and applied work on boundary spanning emphasizes its close relationship to "collaborative leadership." A boundary spanning form of leadership operates through building and influencing relationships and corresponding frames to bring about collective change (Austin, 2002; Crislip, Larson, \& King, 1997; Feyerherm, 1994; Uhl-Bien, 2006). That is, boundary spanning is critical to "social learning systems" by creating and enacting novel structures of social interaction (Kerson, 2002; E. Wenger, 2000). Viewed this way, boundary spanning practices function as "framing practices" (Gray, 1989). Furthermore, to the extent that partnerships must manage change, they require continuous and "embedded" boundary-spanning in all stages (Feyerherm, 1994; Orlikowski, 2002). The literature is convergent on this point: successful partnership 
managers are collaborative leaders and therefore successful boundary-spanners (Ferreyra \& Beard, 2007; Miller, 2008; Vangen \& Huxham, 2003).

Researchers furthermore describe the "distributed" quality of collaborative leadership, noting that many of the leadership functions are usually not restricted to a single individual or authority (Armistead \& Pettigrew, 2004; Gronn, 2002; Hahn, Olsson, Folke, \& Johansson, 2006; Yukl, 1999). Collaborative leadership's many dimensions include: thought leaders, networkers, people who document the practice-in-question, and pioneers (E. Wenger, 2000). The distributed nature of collaborative leadership also means that partnership success cannot be adequately explained by "strong leaders" alone; instead, it requires "interorganizational leadership infrastructures" (Miller 2008 ; cf. also Bardach, 2001). It follows that boundary-spanning is also typically distributed among individuals or other functional units (Orlikowski, 2002) that must integrate collaboration ideals and pragmatism (Vangen \& Huxham, 2003) or "rational" and "irrational power" (Flyvbjerg, 1998).

\section{Summarizing the Gaps in Literature}

Still, despite the inroads that both research and experience have made in understanding the vital role that boundary spanning and boundary spanners play in partnership work, our view of partnerships is still rather static when one considers the many orders of change that are involved in their formation and management. As Williams (2002) writes:

"The skill demands of each of these phases [of partnership development], and the relationship between strategic and operational boundary spanners, 
represents an interesting avenue for further exploration. A deeper understanding of the dynamics of boundary spanners' interventions would also be an invaluable contribution." (122).

Specifically, a review of these literatures suggest 2 important gaps in our current state of knowledge about partnership processes. First, there is relatively little understanding of the processes by which partnership capacity actually gets established through boundary spanning activities and interventions. And second, there is relatively little understanding of how partnership capacity, once established, is sustained over time (Ferreyra \& Beard, 2007; Gronn, 2002; Miller, 2008).

\section{Toward a Unified Theory of Partnership Processes}

This study proposes a framework for conceptualizing "fields" or communities of practice as socio-cybernetic systems that manage change through a recursive hierarchy of feedback processes and thereby organize "differences" into classes of social facts. Social practices entail the interaction and comparison of actions and traits that thereby either reinforce or challenge this system of distinction (Bourdieu, 1977, 1984; Giddens, 1984; Luhmann, 1995). Since a field is internally differentiated, there must already be some competence for boundary spanning among its constituent members, objects, and practices (cf. also Wenger, 2000). Viewed more dynamically, the central practices of any field are "remnants" of what were once marginal practices on the periphery of other fields, just as today's marginal practices could constitute part of tomorrow's central practices of an asyet-unimagined community of practice. 
Fundamentally, the framework adopts a design view of systems by positing that a field's boundary condition is embedded in, and gives structure to, the relations among its parts (Larsson 2001 ; cf. also: Brocklesby 2007 ; Romme 2003 ; Vickers 1965, 1968, 1973; West 2005). The design view builds on Action Theory (AT) to assert that systems are "doubly problem-driven:" first, a system recognizes problems it can anticipate and therefore address; in this sense communication and cybernetic control are related (Ashby, 1956). Secondly, this problem recognition is itself governed by a deeper purpose that, to the extent the system-as-search-rule "survives," addresses a correspondingly deeper problem (D. T. Campbell, 1974; Simon, 1996). A design view stresses the importance of the observer who defines or "brings forth" a system as the focus of some kind of intervention (Lendaris, 1986; Maturana \& Varela, 1992).

AT asserts that the "purpose" of a given action is only revealed in the effect that the relation between the action and the evoked response has in addressing a given problem. Thus, "behavior" is properly understood as a pattern of interaction. AT also emphasizes the importance of implementation since, in this view, a system of interacting parts is only as good as its performance in its relevant, or task, environment. The task environment is a "world of differences" between a desired behavior pattern (DBP) and the system's actual behavior, where these differences comprise the "stuff" of communication and control. The task environment, in other words, centers on system implementation. 
Figure 1 illustrates the design view of systems. The 2 nested circles together represent the system's structure or "metasystem," which is some observer or designer/intervener. The metasystem reflects a given purpose by acting as a fundamental boundary condition or filter that deteörmines which part of the real world is a relevant problem ("input"). The filtering has the tautological effect of suggesting its own response ("output"). Thus, the system's behavior pattern is "downwardly caused" (in terms of orders of abstraction) by its design:

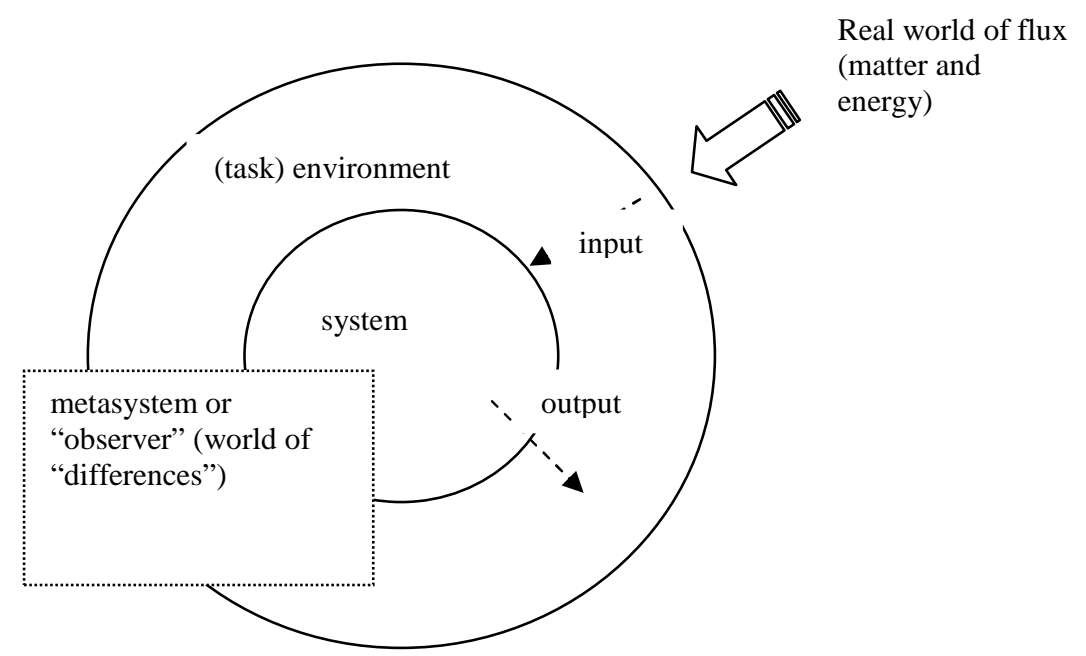

Figure 1: A Design View of Systems holds that "systemness" is a function of an observer or intervener in the form of a boundary condition. The boundary condition acts as a filter and a rule for transforming input to output. Systems thereby reduce the uncertainty in their environment by selecting a part of it and "folding" that part into itself (Baum \& Rowley, 2005; Smircich \& Stubbart, 1985).

A design view of systems is consistent with the recursive paradigm in communication theory (Pearce \& Cronen, 1980; B. Scott, 2002). In this paradigm, 
social action is meaningful to the extent that it fits within a context of interaction that is itself selected for (Luhmann, 1995).

The boundary condition, then, can be thought of as an institutional field's most fundamental parameter. This means that a field's internal boundary spanning competence coincides with increased differentiation with other fields of practice. ${ }^{2}$ In terms of orders of abstraction, the direction of cybernetic control is "downward" (cf. D.T. Campbell, 1974). An important implication is what Bateson (1979) calls an "economy of flexibility": a communication system can only obtain greater flexibility and thus resilience vis-à-vis environmental disturbances by losing some of its autonomy to a more encompassing communication system. All fields or communities of practice must therefore strike a balance between differentiation from and communication with "others." This view is consistent with the use of the concept of "BATNA" to explain collaboration: partnerships form when the calculus for each stakeholder shifts such that the benefits of collaboration outweigh the best alternative to a negotiated agreement, or "BATNA" (Fisher, et al., 1991). But the tradeoff between integration and flexibility is not linear, for a field's core competencies can also enhance its ability to exchange and learn from other fields, and vice-versa, but only up to a certain point. There is a sweet spot where core competency and new experiences may serve one another (S. Campbell, 1996; Star, Bowker, \& Neumann, 2003; E. Wenger, 2000).

\footnotetext{
${ }^{2}$ In socio-cybernetic systems, change is regulated and managed through communication of encoded difference. The tautological character of these systems centers on the social production and reproduction of "problems" for which there is already a response (Bateson, 1972; Luhmann, 1995). 
This theoretical framework also carries methodological implications for studying boundary spanning. First, the measurement of boundary spanning depends on the level of description and analysis. If boundaries are a function of systems, then so is boundary spanning. And since systems are by their very nature internally differentiated - that is, they are composed of a nested hierarchy of boundaries - it is important to first identify the focal level-of-reference against which boundary spanning will be measured. The internal boundaries of a field are not the same as the field's boundary condition that organizes them. By extension, boundary spanning at the center of a field - communication across internal boundaries - is not the same as boundary spanning at its edges, which entails communication across the field's boundary. Boundary spanning within an already specified system implies communication across difference and can be thought of as that system's basic unit of information. In contrast, boundary spanning across specified systems is by definition unclassifiable with respect to those systems. The

first entails routine operations that reinforce the field; boundary spanning at the edges is more problematic since it holds the potential to transform the entire field. "Boundary spanning," then, is a function of system perspective: what may appear on one level to be truly transformative boundary spanning will appear at the next "higher" (or "deeper") level to be routine social practice.

\section{Toward a Methodology of Institutional Change}

We therefore need a methodology to distinguish orders of boundary spanning that correspond to the orders of events and processes that are implicated 
in boundary spanning. Gregory Bateson's (1958) ground-breaking application of Bertrand Russell's Theory of Logical Types to problems in cybernetics provides an important starting point for developing such a framework. In short, Bateson's methodology calls for us to be explicit about the explanatory status of our statements about communicative processes. His line of reasoning starts by observing that causation in communicative systems is not material but rather informational: behavior, be it biological or social, is organized by classification of changes. Since our systems of explanation of behavioral phenomena are themselves communicative systems, they are subject to the same principle of causation. A sound explanation should therefore be an isomorphic mapping of the structure of relations underlying the observed patterns of behavior. An explanation is an aggregate of linked propositional statements about change. A "naturalistic methodology" like the one proposed by Bateson requires that the logical status of each descriptive proposition in our explanation be properly "typed" to reflect this structure. The result is an internally consistent and complete explanation with a logical typology that corresponds to the complexity of the problem and composed of statements whose logical typings correspond to the orders of change they describe (Bateson, 1958: 296).

To emphasize the problematic nature of boundary spanning from a design view of systems, this study will use the term "boundary spanning" in the transformative sense, that is: social and cultural practices at the margins which bring together agents, objects, and practices from different fields in novel ways and 
which have the potential to thereby form new fields of practice. Boundary spanning may entail many things, but it essentially involves making connections across technical, policy, and social differences. It is in these boundary encounters with others that a community of practice is able to reflect on itself through a mode of belonging which Wenger calls "imagination" (E. Wenger, 2000). In contrast, routine, or institutionalized, boundary spanning occurs at the system level. This study will refer to institutionalized boundary spanning practices, which take the form of various established policies, processes, and procedures, as "core practices." ${ }^{3}$ These core practices comprise a "way of doing things" that often has a taken-for-granted quality to it. Wenger contends that the predominant mode of belonging in core, or everyday, practices is "engagement," where socially differentiated actors, objects, and practices interact in ways that tend to reinforce prevailing norms and identities (E. Wenger, 2000).

Third, we should expect that a well-established field of practice will manifest a relatively stable and comprehensive pattern of core practices from which a "local" typology of practices may be derived. Core practices will be more or less loosely coupled in a system of differentiation. They routinely communicate information about the relationship between whatever agents, objects, or other practices are involved in the interaction or comparison being made. We know too that systems of

\footnotetext{
${ }^{3}$ The use of the term "core practices" here, which diverges somewhat from Wenger's $(1998,2000)$ use of the term, to refer to routine boundary spanning is meant to emphasize the idea that, contrary to popular thinking, fields or communities of practice are organized around difference, not sameness. A community's "way of doing things" consists, upon closer scrutiny, of a complex repertoire of social practices that is based on, and elaborates, social distinctions along multiple dimensions and levels (cf. Bourdieu, 1984).
} 
differentiation link multiple dimensions and levels of distinction that cover the social, economic, political, cultural, and symbolic domains (Bourdieu, 1977, 1984). Thus, a mature field of practice will tend to carry a unique and distinct culture of discourses, policies, procedures, and other artifacts embodying an equally unique set of rules, norms, competencies, identities, and ultimately, worldviews. This "grammar of practices" gives a field its distinct pattern of core practices. All fields of practice, ranging from businesses and organizations to sectors, academic disciplines, professions, and policy systems, are organized by some sort of grammar that can become an object of study.

At the same time, a field of practice is always subject to change, in part because the communicative aspect of social practice also affords agents the opportunity, albeit constrained, to reflect on and negotiate the meaning of these relationships. The literature on boundary spanning suggests that it is at the edges of a field, where its boundary spanning practices facilitate the interaction and novel recombination of agents, objects, and practices originating in different fields, that the identity and function of a field is reflected on and negotiated (Levina \& Vaast, 2005; E. Wenger, 2000). ${ }^{4}$ As defined here, boundary spanning brings together diverse practices and associated objects and agents in novel ways. If those novel recombinations find sufficient technical and social support, they are likely to change

\footnotetext{
${ }^{4}$ The degree of freedom that boundary spanners working on the edges enjoy will depend on the strength of the coupling of each field's elements and processes. As stated before, dominant core cultures will tend to lead to anemic boundary spanning. Compounding matters for aspiring boundary spanners, the principal of unintended consequences will operate to frustrate the best-laid plans.
} 
the relations between those practices to form a new field of engagement (Levina \& Vaast, 2005). The emergence of a new joint field of practice also changes the fields that participate in it. As more agents adopt the innovations of the joint field, these innovations become what Levina and Vaast (2005) refer to as "boundary objects-inuse." Some of the agents may themselves participate in the production of boundary objects-in-use to become "boundary spanners-in-practice"(Levina \& Vaast, 2005). More fundamentally, the relations between the fields will change, resulting in changes in the core practices and functions of those fields.

Wenger's (2000) framework for understanding “boundary spanning processes" is useful in highlighting the fact that boundary spanning involves brokering among people, boundary objects, and boundary interactions. His typologies for each of these elements provide a starting point to study boundary spanning processes. Most germane to this discussion is Wenger's classification of boundary interactions according to their duration and intensity. "Peripheries" refer to those visits by outsiders or the larger public who are curious about the field or community of practice in question and may even be contemplating joining. "Boundary encounters" afford opportunities for agents to participate directly in another field for just enough time to get a taste for its culture and way of doing things, as in the case of sabbaticals or most ethnographic fieldwork. Finally, Wenger's "boundary practices" are more protracted interactions that become institutionalized to a certain extent as a field or community of practice in its own right. It is a central hypothesis of this study that Wenger's "boundary practices" 
contribute significantly to the emergence of new joint fields of practice such as partnerships. ${ }^{5}$

While Wenger's framework helps to clarify the major dimensions of boundary spanning, its emphasis on "processes" tends to gloss over the important interaction of structure and agency in these processes (cf. also Levina \& Vaast, 2005). In contrast, this framework attempts to integrate a design view of systems with practice theory to highlight the way that the entire boundary spanning process is driven by exchanges of what Bourdieu (1977) identified as varying forms of economic, social, political, cultural, and symbolic capital that reflect and reinforce changing relations among existing and emergent fields of practice. Here it is important to stress that Bourdieu's concept of "capital" is intended to operate within a practice-theoretical framework that integrates the communicative aspects of social practice and the reflexive modes with which social actors engage during social interaction. A key insight of Bourdieu's theory of practice is that capital formation entails an exteriorization and distortion of otherwise embodied competencies. Thus, for example, economic wealth is ideologically separated from social connectedness, cultural upbringing, and political influence, effectively obscuring their interdependence and representing these various measures of value as natural

\footnotetext{
${ }^{5}$ The stricture that we be consistent in the logical typing of our account of boundary spanning processes means that Wenger's "boundary encounters" and "peripheries" would not be treated as boundary spanning practices within the present framework, since they do not by themselves entail changes in communities (systems) of practice. Indeed, this slippage in logical typing is a serious shortcoming in Wenger's framework. However, the present study also acknowledges the important roles that these other kinds of boundary spanning practices play in sustaining communities of practice, such as those involving partnerships, once they are established.
} 
or intrinsic. Bourdieu's concept of "capital" and capital exchange is useful for studying boundary spanning and the emergence of joint fields by providing a way to link the strategic, if always somewhat misguided, actions of individual boundary spanners to larger systemic processes of social communication and control. By extension, this approach can shed light on the gaps between agentic and institutional understandings or expectations that translate into ruptures in institutional fields and which may trigger larger order changes. In short, the conceptual integration of structure and agency affords us the opportunity to examine the ways in which technical, institutional, and strategic uncertainties interact in the complex and dynamic context of networked governance (Koppenjan \& Klijn, 2006; Ostrom, 1999).

For example, boundary spanning carries inherent risks for its practitioners vis-à-vis their field-of-origin, but if a new joint field is able to establish itself, boundary spanners-in-practice may eventually accumulate sufficient capital in various forms to further support their boundary spanning activities (Levina \& Vaast, 2005). This all suggests that there is a threshold of institutional legitimacy which marks a tipping point in the establishment of new joint fields (Lawrence, Hardy, \& Phillips, 2002). Particularly skilled boundary spanners are able to mobilize diverse forms of capital from their respective fields in such a way that participation in the emergent field translates to benefits back in the home field, and the cycle of capital accumulation repeats itself. We may surmise that the strategies used to link the inchoate system of capital exchange with those of the surrounding fields to produce 
this positive feedback loop entail an especially sophisticated form of boundary spanning. They reduce the "entry costs," transaction costs, and associated risks for would-be participants who might not otherwise adopt practices of the new field and enhance the legitimacy of the boundary spanning practices in the new field. Boundary spanners-in-practice, boundary objects-in-use, and the new joint field emerge together and thereafter co-evolve with linked agents, objects, and fields of practice.

Boundary spanning changes relations in partnering fields through the creative recombination of practices and functions that transforms the system of value exchange itself. If a perceived need for the creative boundary spanning practices of the new field - say, for example, a perceived need for an interstate compact - can take hold, then eventually those practices will accrue value of their own. At root is the accumulation of a certain "institutional cache" associated with these creative practices, and this cache depends on the parallel process of generating demand for the practices and their products. Leaving aside, for the moment, the question of demand creation, the theoretical framework being proposed here suggests that once the partnership field is established as an institutionalized field of boundary spanning practices, an "indigenous" system of capital exchange will operate as a sort of evolving model of the relations between the partnering fields. It is through the creation and exchange of boundary objects that the relative standings, roles, and responsibilities of the partnering fields are reflected on, negotiated, and elaborated. 


\section{Chapter 3}

\section{Methodological and Theoretical Framework}

\section{Statement of Propositions}

This study draws on practice theory, social constructionist theory, and systems theory to propose a framework for understanding the relationship between boundary spanning, social learning and partnership capacity. The following propositions comprise the skeleton of the framework:

1. Proposition: social practice is communicative, that is, it achieves its effects to the extent that it is meaningful

2. Proposition: routine social practices also reflect and reinforce a cultural boundary that defines a field of practice

3. Proposition: these fields can be conceived as systems of relations governing the interaction of elements and processes nested within them

4. Proposition: a system manages change by "coordinating" the changes in its parts and the changes in the relations between the parts, thereby reducing the "total uncertainty" in its relevant environment

5. Proposition: from propositions 1-4, it follows that the unit of social practice is the message embedded between events or actions (viewed diachronically) and between traits (viewed synchronically)

\section{Understanding Boundary Spanning as a Communicative Practice}


Applying this understanding to partnerships, it is clear that we should treat a partnership as a field of relations and various demands on those relations. For convenience, we may conceptualize the partnership field as the "system" and the various socio-technical and policy demands as the partnership's institutional ecology or "environment." The "partnership system," then, is the partnership field plus its institutional ecology (system + environment). A central argument being put forward here is that communities of practice can be conceptualized as "partnership systems," in the sense of the term used here. This conceptualization suggests that partnerships derive capacity from reflecting and anticipating the values and mores of the communities they serve. In a completely determined system, the partnership and its community reflect and anticipate one another perfectly. In actuality, however, the degree of correspondence between the two will always be incomplete to the extent that the coupling is incomplete. Thus, for example, partnership costsharing arrangements that value, either explicitly or implicitly, the contributions or skill sets of one partner-organization over another may become a source of disagreement if they conflict with the way the organizations normally do business with one another outside of the context of the partnership. Perhaps more fundamentally, the partnership and its community may differ in the degree to which they are organized. A partnership that prefers, for example, a more rigid structure of roles, responsibilities, and standards will have a hard time recruiting from a community that prefers a more informal approach. 
Figure 2 illustrates the partnership system as a system-environment relation having some degree of uncertainty. The "variables" in the schematic are meant to represent the various socio-technical and policy practices, agents, and objects that are organized into a field of practice.

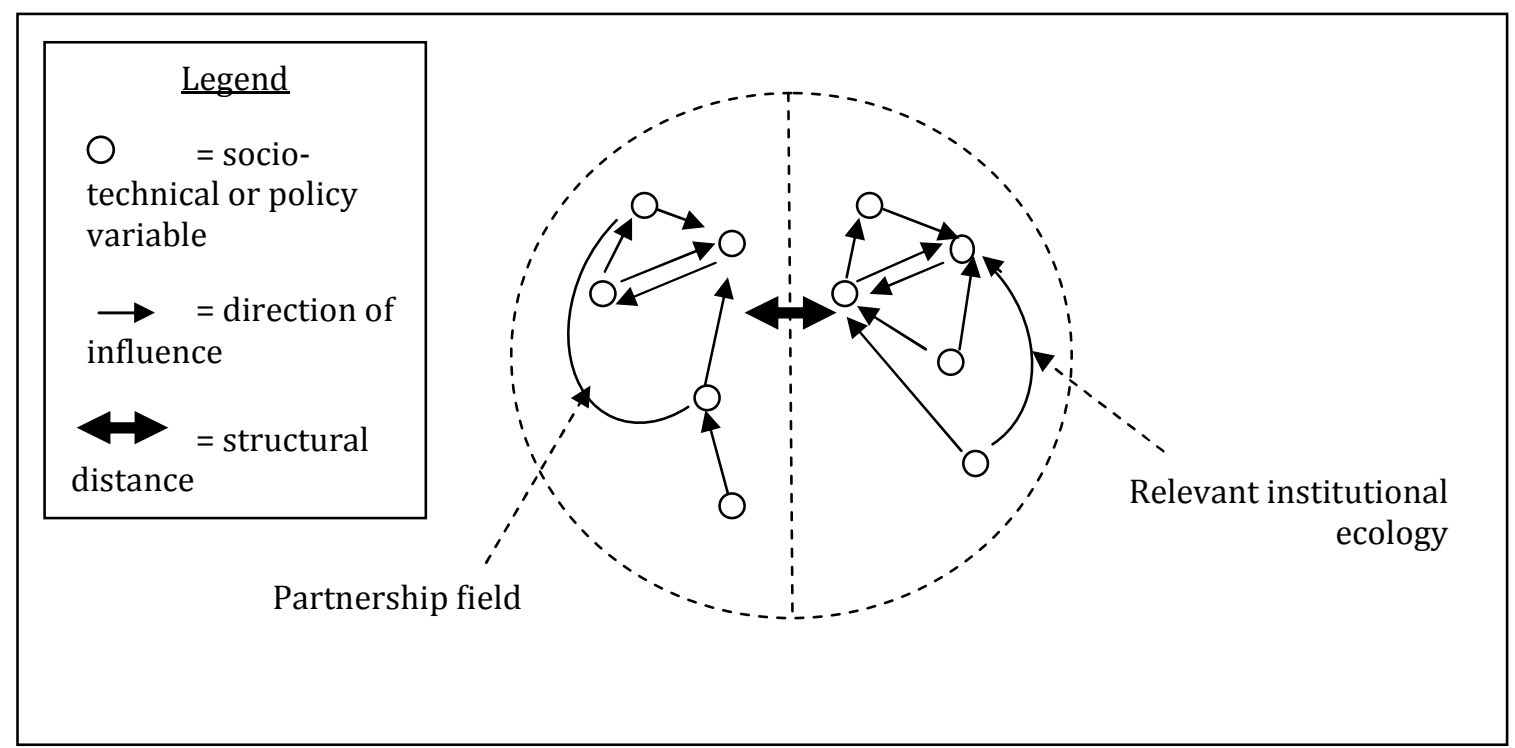

Figure 2: Partnership system comparing the structure of relations of the partnership field and its relevant institutional ecology. The total uncertainty of the partnership system is equal to the uncertainty within partners, between partners, and the discrepancy ("structural distance") between the partnership and its community.

Partnership work is difficult because it requires managing many different and often conflicting demands on the partnership, on each member organization and participating field, and on the larger community. At times the interests and allegiances align but often they don't. Caught in the middle of the dance between a partnership and its community are the participating fields which must negotiate these competing demands, their internal demands, and finally the always 
unpredictable demands of the still larger socio-technical and policy environment. This condition introduces a significant amount of institutional uncertainty about the trajectories of the fields, including the trajectory of the partnership itself, which manifests itself in the disparity between the partnership and its community. From the point of view of the partnership, its environment often appears to be complex and unpredictable (cf. Emery \& Trist, 1965). This disparity is a source of continual tension, particularly to the extent that partnerships are decentralized, but this discrepancy, or more precisely the management of it, is also the basis of partnership work and partnership resilience.

\section{A Typology of Partnership Capacity}

Given the above discussion, we may now propose a relationship between the concepts of "boundary spanning" and "partnership capacity." First, if we conceive of a partnership in systems terms as an embodied social model of relations between fields of practice having different worldviews, inclinations, customs, and so forth, then on a general level, partnership capacity is simply the institutional competence to organize and communicate these differences through boundary spanning practices. Partnership capacity always assumes a particular form of institutional competence adapted to a specific context. But because contexts may change, we must distinguish partnership changes that constitute adaptation and those that constitute demise. We need a language that is suitable for talking about orders of change. 
Thus, the study proposes the term "Partnership Capacity I" to refer to an institutional capacity of a partnership to organize boundary spanning practices of participating fields under a specific environmental condition. Usually, this implies a specialized partnership addressing a specific coordination problem. In contrast, "Partnership Capacity II" is the institutional capacity of a partnership to renew itself over a defined range of changing environmental conditions. Such a partnership can address a range of coordination problems either simultaneously, by strategically deploying multiple programs and initiatives, or dynamically, by shifting its focus through a defined range of problem filters, as needed. "Partnership Capacity III" shall refer to the general capacity of a partnership to reinvent itself as changing environmental conditions demand. It is inspired by the concept of "Singerian" or Inquiring System first described by Churchman (1971) and later developed in literature on "learning organizations" and "learning networks" (see, for example, Senge, 1990; McDermott, 1999). Partnership Capacity III is closely related to the concept of resilience, and as such can only be assessed over time. Moreover, general resilience implies a degree of creative freedom that is only possible if the partnership is not unduly constrained by partnership obligations of its own. In other words, we can expect that PC III will be an attribute of fields of a fairly high degree of order and scale. These would be communities of practice that periodically produce novel partnerships of varying capacities. For example, the prevalence of watershed management partnerships suggests that the watershed management field, taken as a whole, has an institutional capacity that could be classified as PC III. 
This typology of partnership capacity relies on a design view of systems and is intended to move away from normative theorizing that tends to assume that partnerships are self-sufficient and toward a more empirically-driven framework that attempts to explain their survival and demise. It also compels us to specify the system-level-of-focus we are using when assigning partnership capacity types, since the classification of capacities will depend on our frame of reference. A watershed basin may contain a diverse array of partnerships. Treated as separate cases, the partnerships do not provide any basis to infer anything about the institutional capacity of the basin community itself. But if a comparison across those cases reveals an underlying pattern of organization in boundary spanning practices, we may infer an underlying capacity of the basin community - what the framework refers to as "PC II" - to coordinate partnerships toward a common purpose. Beyond that, if it can be shown that the basin community spontaneously reorganizes the coordination of those partnerships to meet changing extra-community demands, then we may classify the basin community as having PC III, as being generally resilient. Note that we have come full circle, and yet are transformed: if we regard each instance of coordination as a partnership case, the situation appears indistinguishable from the first scenario describing separate partnerships classified as "PC I." The transformation can only be discerned by specifying the change in our focal level. Finally, it should be clarified that the typology does not have a spatial dimension, but rather refers to the organization (and communication) of relations 
and does not have a spatial dimension. Under this framework, partnerships and their capacities are not necessarily place-bound.

Second, the framework posits that the primary concern of a partnership is to foster and organize boundary spanning among its members and their respective communities. A partnership's environment is not monolithic but instead composed of manifold layers of relations cutting across the various partnering fields of practice. Ideally, a partnership enhances the density but also strategic coherence of connections for the community it serves. The core practices of the effective partnership will therefore be concerned with facilitating inter-organizational and inter-community communication and coordination. At the same time, the boundary spanning practices of the partnership field itself will be concerned with value questions about how the partnership should be organized. From this point of view, partnership work centers on parallel and occasionally mutually informative boundary spanning processes - one set of processes at the level of operations and the other set at the more strategic and constitutional levels. The mutual adjustment between these levels entails a kind of meta-boundary spanning which will be discussed more below.

This conceptualization implies that a partnership consists of boundary spanning practices that have become institutionalized to some degree as core practices operating in a particular field of conjoint practice. It is reasonable to expect that the strength of the coupling between a partnership and its institutional ecology will fall along a continuum. The discussion so far identified a complex 
relationship between a field's internal coherence and its communicability with other fields - this relationship is inverse except in "local regions" of what we may call the "partnership state-space," where the two factors may reinforce one another. The literature supports this view by suggesting that effective partnerships manage the considerable uncertainties associated with networked governance by striking an appropriate balance between formal and informal rules as well as between weak and strong ties (Koppenjan \& Klijn, 2006). Thus, we should expect effective partnerships will fall somewhere on the continuum between a loose collection of independent organizations where partnerships exist in name only, and dominant or "strong" partnerships where member organizations are essentially co-opted entities subject to the rules and reproductive requirements of a partnership bureaucracy.

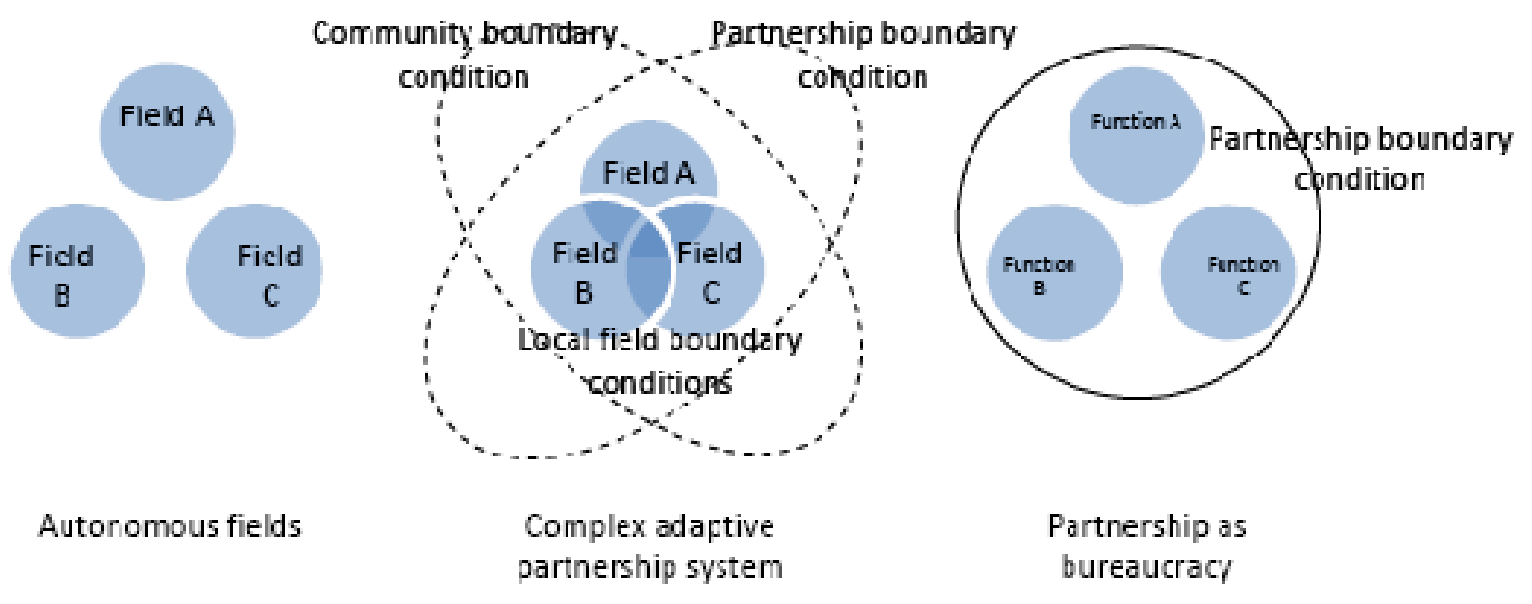

Figure 3: Partnership on a Continuum of "Coupling Tightness" 
Partnerships that endure can be thought of as complex adaptive systems in which partnerships and their community co-evolve (Innes \& Booher, 1999). The framework posits, then, that such partnerships will tend towards a hybrid condition characterized by a fluid exchange of agents, ideas, objects, and practices both among the partnering fields and between these fields and the partnership as a whole. Indeed, the boundaries themselves will tend to shift back and forth in their salience between home field boundaries and the partnership boundary. The present framework posits that resilient partnerships neither completely govern their institutional ecologies nor are they completely governed by them; rather, they are interdependent.

Because boundary spanning at the partnership level changes the partnership field as a whole, this mutual adjustment will be reflected in a parallel process of mutual adjustment between the partnership core and boundary spanning practices in what observers have described as a kind of dialectic between creative idea generation and problem structuring (Knight \& Pye, 2005; Koppenjan \& Klijn, 2006; Senge, 1990; Thompson, 2005). A simple adjustment of core operations to fit an existing goal(s) and action plan - what we may call "simple alignment" - involves feeding the discrepancy between the goal(s) and the actual state of affairs back to change partnership functioning. This process is a relatively straightforward matter of monitoring and control. However, if these changes are allowed to somehow inform partnership goals or, similarly, management of the discrepancy, then the loop of adjustment is closed and the result is a dynamic partnership with the 
capacity to precipitate and thereby control changes in its relevant socio-technical and policy environment. Figure 4 depicts a local partnership learning to cooperate with a federal agency through the complex alignment of operational and strategic concerns. The figure builds on Figure 1 to illustrate how complex alignment confers PC II by closing a loop about the environmental input and system output. Both the system and the environment become variables on a still-larger-ordered cybernetic circuit or system:

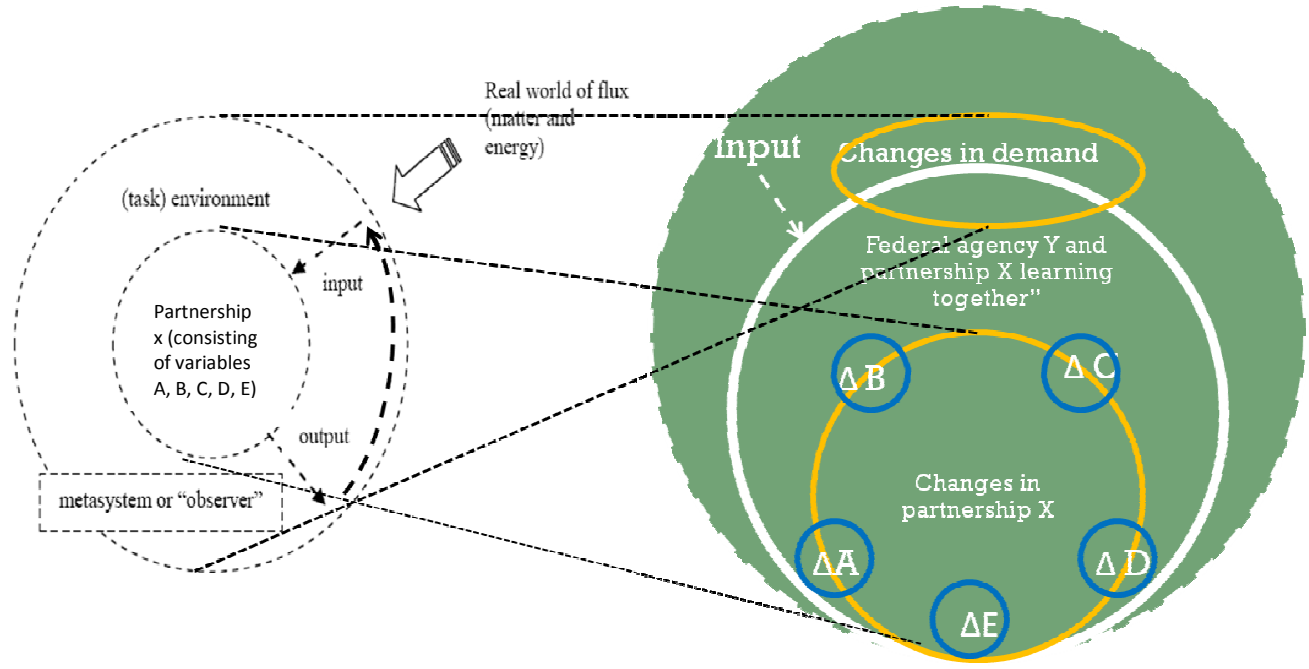

Figure 4: Alignment practices confer PC II by closing a loop about input and output

Vital partnerships set community agendas as much as follow them, while the mutual adjustment of boundary spanning and core practices helps to ensure that partnership goals remain grounded in local contexts of practice. Partnerships that 
endure tend to strike a balance between being visionary and relevant. ${ }^{6}$ The general picture of resilience described here is not unlike the ideal community of practice described by Wenger (2000) and characterized by the balancing of engagement and imagination through periodic alignment. But the framework goes one step further by distinguishing restricted, or "bounded" resilience (i.e., PC II) and the general capacity to learn and adapt (i.e., PC III).

We may now summarize this discussion in a set of causal loop diagrams. PC I can be explained in terms of a simple negative feedback loop that guides a partnership towards its stated vision. This is the "simple alignment" of monitoring and control, described above. PC II subjects this implementation regimen to periodic review and amendment.7 In other words, PC II implies that the alignment practices are somehow coordinated over time to achieve a more general purpose. We may furthermore posit that the criteria of meta-boundary spanning will center on both the technical or "systemic" desirability and social or "cultural" feasibility of the implementation regimen itself. For instance, a partnership may decide that its response to certain policy stressors is too weak or too slow and evaluate alternative response strategies. The governance structure of a partnership with PC II - the aggregate of links that bind disparate ideas and practices, and the quality and strength of those links - will tend to reflect the community's worldview of the partnership's proper role in it.

\footnotetext{
${ }^{6}$ I owe this insight to a conversation I had with John Moriarty, former Executive Director of the Network of Oregon Watershed Councils (personal correspondence, December 17, 2009).

${ }^{7}$ It is important to stress that PC II implies that this governance process recurs with some regularity of pattern - otherwise, a one-off change in the regimen constitutes a single case of partnership boundary spanning.
} 
Figure 6 and 6 show causal loop diagrams (CLDs) depicting Partnership Capacity I and II, respectively. Wenger's modes of belonging and Checkland's twin concepts "systemic desirability" and "cultural "feasibility" have been superimposed on the concepts "core practices," "boundary spanning," and "meta-boundary spanning" in order to clarify the relationships of the concepts in the present framework. The figures emphasize that alignment practices are distributed: they are embedded in the entire cybernetic circuit. ${ }^{8}$ Furthermore, the CLD's represent "Larger socio-technical and policy processes," “Ideal correction," and "Ideal discrepancy" as exogenous variables to underscore their status as environmental variables (i.e., "givens") with respect to partnerships: they are rooted in community- and larger processes. The model status of "Vision" varies between the two scenarios. Under PC I, it is for all intents and purposes exogenous to the partnership process, reflecting the partnership's role as an implementing agent of the community's vision. Under PC II, the partnership plays an active role in shaping the vision and associated policy agenda. Its resilience - in the restricted sense of PC II - stems from this capacity to influence its immediate socio-technical and policy environment. A couple final notes on the CLD: while valances are not indicated for the arrows, the letter "B" denotes a negative or "balancing" feedback loop among the

\footnotetext{
${ }^{8}$ Alignment practices are distributed in the sense that they cannot be assigned in any straightforward way to one social position, act, or domain of action. For example, staff sometimes act as a voice for the community and sometimes that role is enacted by the board. Even if we were to only consider staff-speaking-for-community functions, those functions may either be operational or more strategic. In fact, we can represent the distributed nature of alignment practices using a $2 \times 2 \times 2$ matrix intersecting the binary variables staff/board, core/boundary, and partnership/community. From this system-theoretic perspective, alignment practices are distributed over a state space of $2^{3}=$ 8.
} 
enclosed elements in question. In addition, the CLDs do not show time delays in problem perception, decision-making, and response which are implied in the diagrams and indeed may be objects of strategic intervention: 


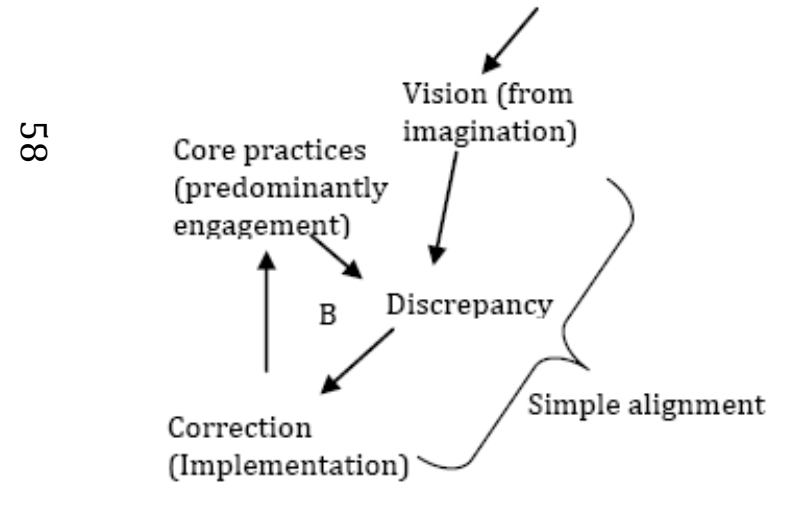

Figure 5: CLD of Partnership Capacity I

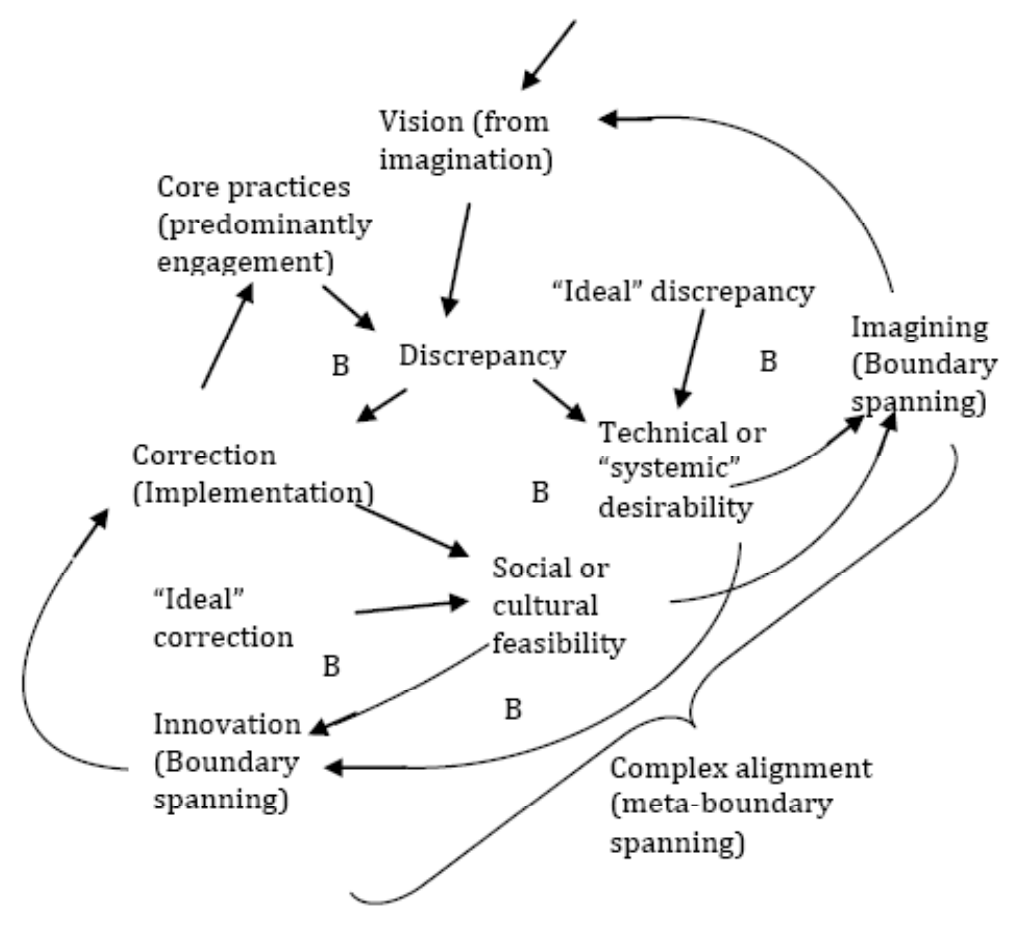

Figure 6: CLD of Partnership Capacity II (all loops are balancing) 
Viewing PC II in system dynamics terms, we can expect to observe partnership core, boundary spanning, and alignment practices oscillating around a set of values or configurations and furthermore that these oscillations will be linked.

Finally, PC III can be represented by a CLD of continuous learning and adapting. In this schema, partnerships are designed as experiments whose function is not to "solve," but rather to generate, new problems from which the learning cycle repeats. In this scenario, boundary spanning practices routinely combine elements in new ways - much as many learning organizations will encourage socio-technical experimentation - and then look for issues that arise which defy classification. Bateson (1958: 280), paraphrasing Whitehead, points out that the goal of science is to leave the "darkness unobscured." Similarly, learning partnerships routinely map their own darkness.

We can imagine a kind of "laboratory of social learning" that grows rather than diminishes surprises through a positive feedback loop that increases rather than decreases the discrepancy between expectations and observations. These problems are then catalogued or "typed" according to the order of boundary spanning processes that are associated with them. That is, the problems will be explained in a language appropriate for describing changes in the partnerships they represent. The successful modeling of these problems reduces the discrepancy and triggers subsequent experimentation. In the spirit of Senge’s (1990) "system archetypes," partnerships with PC III can build a library of problems and a corresponding repertoire of responses. They will feature an experimental test bed 
for developing what amount to socio-technical models for collective action appropriate to specific contexts. ${ }^{9}$ As the combinatorial possibilities of these models explode with the number of stakeholders and technologies, PC III partnerships are in a position to address a potentially vast range of problems. We may assume that such laboratories of social learning will only be found in partnerships with the resources required to invest in them. We can furthermore safely assume a learning curve function operates which increases the efficiency of learning with each iteration of the learning cycle so that the partnership becomes progressively adept at responding to surprises. Of course, the notion of continuous learning and adapting implies some monitoring and control that reflects a culture that values learning for its own sake. This includes promoting "useful ignorance" in which not knowing is encouraged, rather than shunned (McWilliam et al., 2007; see also: Cohen et al., 2007; Gonzalez \& Healey , 2005).

Figure 6 is a CLD depicting the learning cycle associated with PC III. Related concepts have been similarly superimposed, and the CLD is, in fact, consistent with Checkland's (2000) depiction of the learning cycle in Soft Systems Methodology. "Innovation" refers of course to a creative activity of combining disparate elements and processes in new ways - it is quintessential boundary spanning. Since innovation - which is basically model-building - is always driven by a particular perspective, and since there are almost invariably multiple perspectives, it follows that innovation activities will produce multiple socio-technical models. Scanning for

\footnotetext{
${ }^{9}$ Because these models are rooted in specific historical contexts, they differ from Senge's archetypes, which he terms "generic structures."
} 
issues involves critical thinking in a more reflexive mode than is usually the case with boundary spanning or even alignment practices, for it involves stepping outside of each partnership innovation and questioning its most basic assumptions, usually through comparison to other innovations. ${ }^{10}$ It involves, as Checkland (2000) terms it, "a structured debate about desirable and feasible change." "Institutional design" involves configuring the compared innovations so that the various issues actually support one another's resolution. Outstanding issues become inputs that drive a larger partnership process. ${ }^{11}$ Note that we similarly see social learning distributed among scanning and designing for institutional issues. In fact, the notion of mutual accommodation of innovations anticipates our discussion, in the next section, of convergence leading to the formation of partnerships. Finally, the same general comments concerning the conventions and limitations of representation in the previous 2 figures apply here, except the letter "R" denotes "reinforcing" to indicate a positive feedback loop among the enclosed elements in question:

\footnotetext{
${ }^{10}$ Scanning for issues is akin to model-testing in which models are put through a rigorous and iterative process of de-bugging, verification, and validation.

${ }^{11}$ Note that this is consistent with our understanding of abduction as the primary mechanism of learning which involves searching for rules which, if they were true, would transform surprising cases into expectable ones (Khisty, 2000).
} 


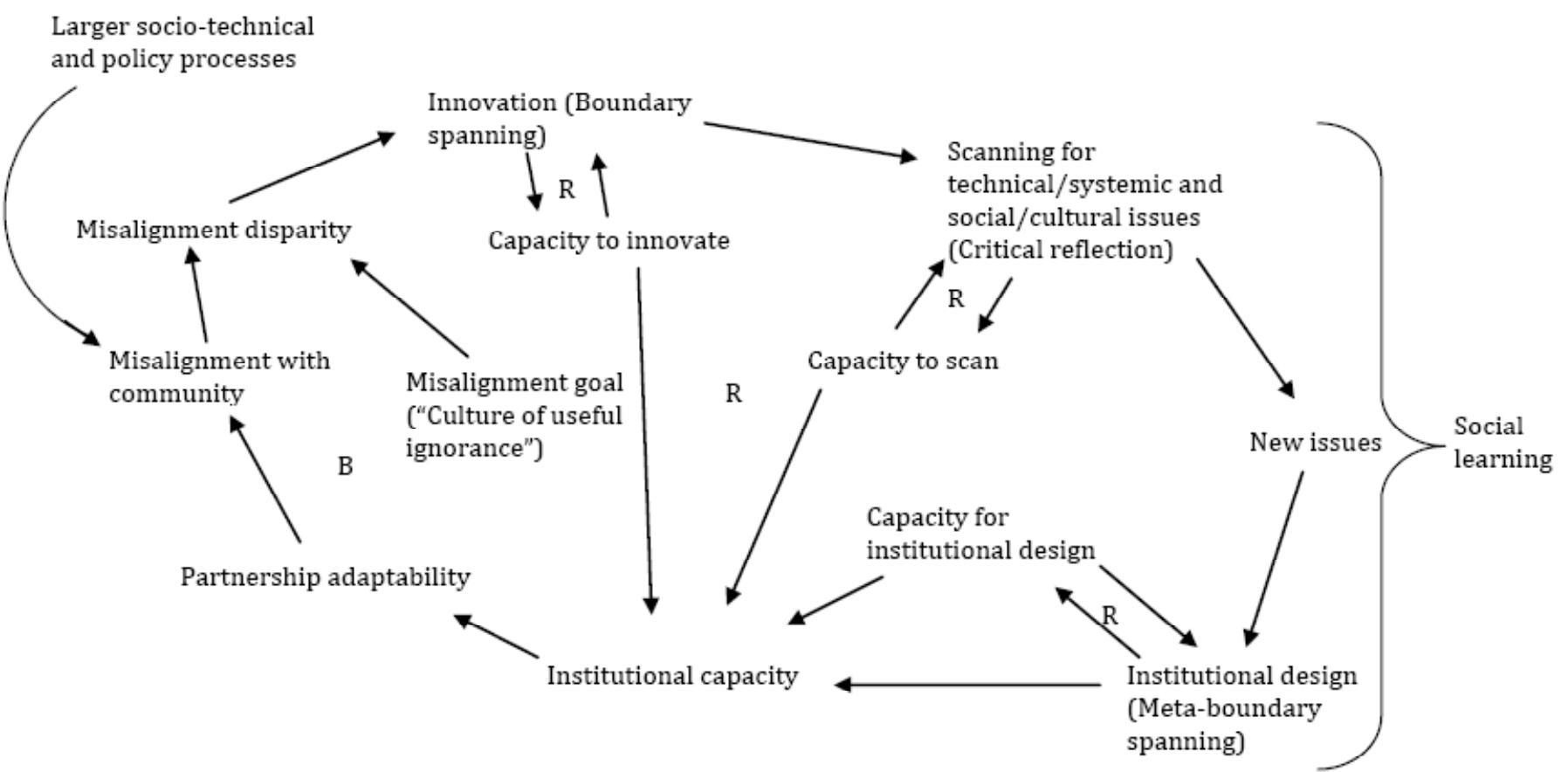

Figure 7: CLD of Partnership Capacity III 


\section{A Closer Look at Boundary Spanning}

It is now necessary to describe what these core, boundary spanning, and mutual adjustment processes look like in more concrete terms, starting with the core practices. First, if core partnership practices can be thought of as mostly routine boundary spanning, then we should look for them in partnerships that have already been established. Furthermore, these practices will consist of mostly routine exchanges between: partnering organizations and their respective communities of people, discourses, perspectives, knowledges, information, policies, heuristic procedures, and resources, including tools, technical documents, and models. Core practices cannot become too formalized or rigid since this only defeats the purpose of the partnership. Many partnerships will be governed by rules of engagement ranging in formality from a memorandum of understanding (MOU) or an intergovernmental agreement (IGA) to bylaws and charters, as in the case of, for example, a 501(c) 3. In many cases of looser networks or affiliations, however, standardization of practices will most likely be restricted to social technologies that facilitate communication, interaction, and coordination (e.g., communication and information systems such as listserves, databases, various decision support tools, and social networking). But even in less formal partnerships, core practices also serve to reflect and reinforce the relations among the partner organizations and their respective fields. Thus, there will be a division of labor in roles and responsibilities that tend to reflect the social differentiation of the larger community of practice which the partnership serves. The various forms 
of capital will also be distributed among partnership members to reflect this social differentiation. From an organizational point of view, core partnership practices will include shared staff positions and other cost-sharing arrangements, as well as mixed teams or committees that bring together diverse disciplines, professions, policies, and socio-political philosophies.

Given the dynamic quality of partnerships, some of the core practices of partnerships may appear, from the perspective of member organizations anyway, as boundary spanning practices. In fact, the boundary spanning among members and the core practices of the partnership entity will be essentially indistinguishable to the extent that boundary spanning practices do not deviate from partnership rules and norms. Furthermore, we can expect that partnership functioning will often depend on a certain amount of deviance within participating fields. For example, boundary spanners will often pull their constituents out of their comfort zone advocating for an unpopular or otherwise risky position, say - in an attempt to quell reactionary or extremists elements that threaten a coalition. In this way, boundary spanners act as political buffers for the partnership: they, in effect, dampen schismogenic processes between partnering fields by amplifying differentiation within them. Of course, if political buffering continues unabated, it may, under the right conditions, actually induce schisms within the partnering fields that ultimately undermine the partnership itself.

How do we explain the fact that differentiation sometimes facilitates communication and sometimes inhibits it? The apparent paradox is resolved once 
we assume a level-of-analysis approach. When we do, we see that differentiation "within" has an entirely different effect compared to differentiation "between." Similarly, how are we to distinguish boundary spanning and core practices? The distinction is clarified once we maintain a consistent frame of reference. Boundary spanning practices that transgress a field's rules and norms, such as clandestine communications, subversive coalitions, subterfuge, treason, or heresy can then be distinguished from boundary spanning practices that support the social reproduction of that field. With respect to any given field of (conjoint) practice, the former are properly understood as "boundary spanning practices" and the latter as "core practices."12

The distinction is important because it means that it is difficult, if not impossible, to attribute partnership formation to specific boundary spanning practices until the partnership has congealed enough to enable the investigator to match its criteria to those practices. The inherent difficulties of studying such an emergent phenomenon as partnership formation will be discussed more below. Suffice to say, however, that once a partnership and its membership rules are somewhat established, it should be possible to identify those core practices that serve the overall function of the partnership to coordinate the communications and actions of community partners toward a common purpose.

\footnotetext{
${ }^{12}$ Note that this framework makes no normative assumptions about "boundary spanning" being either "good" or "bad." Our principal criterion is simply that the practice or process cannot be accommodated by - and is therefore transformative for - a system that has already been specified. Boundary spanning is by this definition unsustainable.
} 
Alongside these core practices, we can expect to see boundary spanning practices at the edges of the partnership community that support but also occasionally inform the partnership's routine operations. At the partnership level, the principal function of boundary spanning between the partnership and its members is to ensure that the partnership does not become too set in its ways and thereby become alienated from the community it is supposed to serve. As stated before, partnership boundary spanning is largely a strategic affair concerned with protecting the partnership against obsolescence. Thus, we can expect partnership boundary spanning to include the ongoing collection and integration of viewpoints and pertinent information regarding what the partnership should look like. This sweeping-in of different perspectives invariably centers on a range of questions germane to the organization of the partnership field, especially: what is the proper problem domain?, what is the overall vision and mission of the partnership?, what are the membership criteria and the roles and responsibilities attached to membership?

In this way, boundary spanning articulates community norms that guide the day-to-day operations of the partnership. By collecting and assembling different perspectives on these fundamental matters, and by providing a forum for comparing and integrating these viewpoints, a partnership's boundary spanning practices provide the partnership community opportunities for collectively reflecting on what the partnership should look like. On a concrete level, then, partnership boundary spanning will include all those activities and practices that emphasize - to use 
Wenger's terms - imagination, including: newsletters, executive or board meetings, discussions regarding values, vision or mission statement, criteria for partnership, membership, success, or other "constitutional" matters, white papers, listserve discussions or other community fora, and special events such as future search conferences. ${ }^{13}$

But these collective imaginings are not, by themselves, sufficient to ensure that the partnership remains relevant. There must be a sustained interaction between core and boundary spanning practices. As suggested earlier, this interaction or mutual adjustment between the two types of practices is what Wenger (2000) refers to as "alignment."14 Thus, we should expect to find, to use a somewhat clumsy term, "meta-boundary spanning" that supports the strategic alignment of partnership operations with its values and vision. As already suggested, this alignment includes critically re-evaluating partnership and, ultimately community, goals and changing them, if necessary, to adapt to changing circumstances. The emphasis is in articulating goals and plans that are grounded in, rather than divorced from, the technical, policy, and social realities of everyday practice. In doing so, meta-boundary spanning confers what we have called Partnership Capacity II. We should furthermore expect to find these alignment practices in contexts similar to those enumerated in the discussion of imagining

\footnotetext{
${ }^{13}$ It should be clarified that the collection of information and viewpoints regarding the partnership and its overall organization may include those from outside of the partnership, but the subsequent deliberations are likely to involve only its members and "honorary affiliates."

14 The concept of "alignment" is similar to Schön and Rein's (1994) "reflection-in-action," whereby opposing frames are compared to generate new metaphors that enable users to move between frames (cf. also Barrett \& Cooperrider, 1990; Gold, 2001; Torlak ,2001).
} 
practices but with more explicit emphasis on strategies for bringing about organizational and institutional change.

The theoretical framework used here suggests that these "imagining-" and "alignment practices" are facilitated by the mobilization and exchange of various forms of capital that carry communicative consequences for the partnership and its partnering fields. Collective imagining raises existential questions about the partnership that places it in a suspended state of scrutiny and uncertainty with regard to its future. Similarly, alignment tackles tough questions about how to translate abstract values and visions into concrete identities and practices. Given the stakes, it is reasonable to expect the "expenditure" of various forms of capital within the partnership community to continually re-establish the partnership's legitimacy as the primary broker for the community. This may range from mundane fund-raising, calling on favors, or lobbying, to more elaborate symbolic efforts that seek to tie the partnership to a larger social cause or community identity. The important point to make here about alignment practices is that they help to establish and maintain a system of capital exchange between the partnership's exchange system and those of its partnering fields. It is in the alignment of the diverse systems of capital exchange that meta-boundary spanning operates.

In many if not most cases, interest blocs will compete and negotiate to define what the partnership is or at least ought to be. Boundary spanning practices may then become proxy struggles among blocs that, if left unchecked, threaten to dissolve the entire partnership. In such circumstances one may observe boundary 
spanning practices that attempt to reconcile competing or otherwise destructive boundary spanning practices. These may take the form of de-escalating measures such as throwing one's weight to a probable "victor," succoring, negotiation, mediation, or some combination of these. In all these instances of boundaryspanning, the mobilization and exchange of various forms of capital, and the social communication that accompanies such exchanges, may range from ritualized to highly strategic. Clearly, there is a need for empirical research to uncover the distinct varieties of boundary spanning practices that fall under the general headings "imagination" and "alignment."

Finally, it should be stressed that the framework described here is not meant to imply a strict correspondence between Wenger's three modes of belonging engagement, imagination, and alignment - and the core, boundary spanning, and mutual adjustment practices, respectively. Given the distributed and dynamic nature of communities of practice, and as Wenger's own framework implies, all three modes of belonging are likely to operate to varying degrees and at various times on all three levels. However, the implication is that engagement is likely to predominate in core practices, imagination is likely to be predominate in boundary spanning, and alignment is the dominant mode in the mutual adjustment between the two.

\section{A Typology of Social Learning}

The motivating research question driving this study is: how do boundary spanning practices foster and sustain partnership capacity? In the present 
theoretical framework the question can be reworded as: how do boundary spanning practices that bring together agents, objects, ideas, and practices from diverse fields in novel ways become institutionalized in the form of partnerships with boundary spanning practices of their own? The term "social learning" shall be used here to refer to the institutionalization of boundary spanning practices in the form of partnerships of varying capacities. If social learning is the emergence of partnership capacity, then there are at least 3 types of social learning that correspond to the 3 types of partnership capacity. "Social Learning I" shall refer to the emergence of Partnership Capacity I, that is to say, the emergence of a particular institutional competence for routine boundary spanning appropriate for a specific policy task. "Social Learning II" shall refer to the development of Partnership Capacity II, namely: the development of an institutional capacity to routinely align core and boundary spanning practices into a specific range of configurations that addresses a specific range of issues. "Social Learning III" is akin to Argyris and Schön's (1978) concept of "double-loop learning” and refers to a partnership developing a culture of learning to innovate new partnerships of varying capacities as needed.15 Figure 8 illustrates the relationships between the types of social learning and partnership capacities. The relationships that comprise the "partnership system" are embodied in nested processes of communication and

\footnotetext{
${ }^{15}$ Although outside the purview of this study, at least a fourth type of social learning - and, by extension, partnership capacity - suggests itself: the development of the capacity to form partnerships with the general capacity to learn (PC III). As with the simpler forms of social learning, SL IV is usually inferred after the fact. Fields must demonstrate a capacity to routinely generate PC III partnerships. Obviously, PC IV fields are necessarily of a high order of complexity and will usually involve management on large scales. Within the private sector, for instance, there are certain industries that could be classified as having PC IV.
} 
control. Partnerships are not really "things," but rather boundary spanning processes:

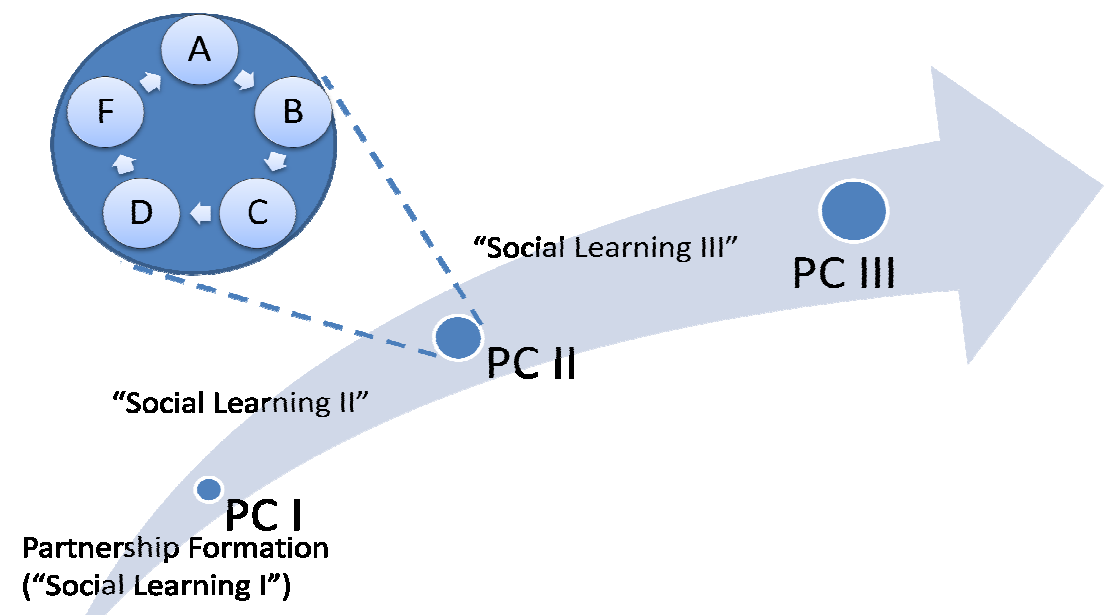

Figure 8: Process View of Partnerships

The inherent difficulties of studying emergent phenomena such as partnership formation have already been suggested. If boundary spanners-inpractice and boundary objects-in-use co-emerge with the joint field that organizes them, then the chain of causation connecting boundary spanning practices between fields and the formation of a partnership is not a lineal one. There are no a priori criteria we can use to predict either which boundary spanning practices will produce partnerships or, for that matter, what those partnerships will look like. The two will always coalesce in a particular and historically unique form. Boundary spanning practices cannot, strictly speaking, bring a partnership into existence. 
Instead, the recursive framework proposed here suggests that it is a change in the relations between fields that precipitates the formation of a partnership. As already discussed, partnerships are distinct forms of social organization characterized by their distributed or networked structure connecting semiautonomous organizations and institutional fields through webs of communication and mutual influence. Partnership formation entails participating fields losing some autonomy and their relationships with one another being reshuffled.

Whenever boundary spanning practices become institutionalized, it is always in a particular form precisely because they rely for their legitimacy and social reproduction on the degree to which they conform to the institutional ecology of fields in which they participate. At the same time, the boundary spanning practices between fields are not completely determined by this ecology - indeed, once a partnership field is established, both its core and boundary spanning practices will partially govern it. Thus, boundary spanning practices between fields appear to be a necessary but not sufficient condition of partnership formation - some extra ingredient is needed.

This framework follows the punctuated equilibrium theory (PET) of policy dynamics (F. Baumgartner, 2006; Repetto, 2006; cf. also: Kingdon, 1995; Sabatier \& Jenkins-Smith, 1999) to propose that, in most cases, the extra element is a perceived policy or other socially construed need - a threshold of demand that is usually relatively unarticulated - which creates a structural opportunity from which boundary spanning practices may begin to reconfigure relations in the larger 
institutional ecology to respond to that need. There will be a certain degree of "readiness" for innovation. The need will often arise from exogenous changes originating in the larger socio-technical or policy environment, such as changes in environmental standards, which introduce opportunities for local policy innovations. In some cases, however, the extra element comes from the surprising creativity of individual and organizational boundary spanners to meet an existing demand. Regardless of the source of change, however, under such cuspcatastrophic conditions, the direction of influence abruptly flips, and the boundary spanning practices between certain fields go from being trivial and sporadic to transformative. A new circular chain of causation comes into effect: the boundary spanning practices among the fields and the larger institutional ecology begin to influence one another in a self-correcting process that will tend to reduce the discrepancy between them. A key result is that the boundary spanning practices of the previously disparate fields becomes more organized. A phase space depiction of this process would show boundary spanning practices beginning to coalesce into a bounded region.

Viewed from a social or networked learning perspective, there is a process of self-organization in which the network of organizations and their institutional fields reconfigures itself "from within," that is to say: innovative boundary spanning practices and boundary objects "pull" the ecology of fields toward a partnership structure that is more suitable to addressing the problem, while at the same time the institutional ecology imposes certain constraints on the direction that those 
innovations can take. The present framework holds that this description applies not only to partnership formation but to all innovation and diffusion processes associated with policy and social learning where nascent learning among a small group of visionary stakeholders must translate to larger-order institutional change.

A central hypothesis of this study, then, is that partnerships form through a "sideways convergence" of boundary spanning practices among established fields and their institutional ecology. The convergence is sideways in the sense that it is neither completely top-down nor completely bottom-up, but rather a mixture of the two - a mixture of structure, agency, and chance. As the boundary spanning practices begin to take a definite shape, a kind of conversation ensues between a new joint field of practice, a partnership of sorts, and a community of fields composed of organizations and fields participating in that partnership. The framework's concept of convergence is similar to one proposed by Susan Star and her colleagues who describe a "convergence of communities of practice and information artifacts" in digital libraries and other large-scale information systems (Star, et al., 2003).

The framework proposes that the central mechanism of this convergence is the development and testing of boundary spanning practices and objects. Boundary spanning practices produce novel patterns of interaction and boundary objects-inuse. The convergence begins once these novel forms of social interaction and boundary objects-in-use accrue sufficient significance and value so that their enactment draws the attention of partnering fields beyond their boundary spanning 
practitioners. This leads to the comparison of relations among practices (and associated agents, ideas, and objects) in the partnership field and participating fields. ${ }^{16}$ We know from the communicative aspects of social practice that these comparisons are enacted in various ways through social interactions, technical reflection and, more indirectly, through capital exchanges, especially in the boundary spanning regions between participating fields where much of the social experimentation takes place. The social learning underlying these comparisons centers on the development of social heuristics or "matching theorems" that search for patterns of homology between the relations of practice in participating fields and corresponding relations of practice in the emergent partnership field. The resulting heuristic represents something of a relational compromise between the fields, albeit usually tilted in favor of one or the other. ${ }^{17}$

It is important to emphasize that in most cases the comparisons are not cerebral exercises but rather enacted through social interactions and exchanges that confer differential outcomes to innovations, akin to evolution by natural selection. Acts of distinction effectively function as social computations that assign values to practices and objects according to assumptions about how those practices and objects should be organized. By acting through positive and negative reinforcements, these meta-boundary spanning practices function as enacted

\footnotetext{
${ }^{16}$ The criteria of relevance determining which practices are compared will themselves be in flux until the new field achieves sufficient coherence.

17 The model of innovation and diffusion that is proposed here is more closely aligned with theories of social and policy learning, especially those addressing the processes of mutual adjustment (see, for example, Lindblom, 1959), than with contagion models (for example, the Bass Diffusion Model and its variants).
} 
judgments that nudge disparate practices and fields closer to one another. But the process is also iterative: initial heuristics will themselves be implicitly tested by how well their products - i.e., patterns of distribution of outcomes - "do" (see Figure 9). For example, is the distribution of risks and benefits of a management plan fair? More often than not, the results of competing boundary spanning practices and boundary objects-in-use are then compared to one another according to a set of meta-criteria, out of which a heuristic is selected, and the cycle repeats itself. The meta-criteria driving the convergence operate at a "deep" system level and are usually not directly accessible for reflection by social agents. However, we can surmise, reiterating Checkland (2000), that the meta-criteria are generally speaking concerned with balancing the "systemically desirable and culturally feasible."

Up until now the discussion has focused on the evolution of the new joint, partnership field. But this evolution would not even occur except for the fact that each iteration of "heuristic judgment" induces corresponding changes in participating fields which will tend to reinforce the innovation and diffusion of boundary spanning practices and objects-in-use even as they are refined. The changes in the fields may include: formal endorsements from managers or community leaders, financial support, changes in laws, policies, procedures, and processes that align with or otherwise support changes in the new joint field, the development of other boundary spanning practices such as interdisciplinary committees or planning processes in related problem domains, and direct adoption of the boundary spanning practices and objects. Furthermore, the direction of 
influence is not one-directional. The "pull" from the nascent partnership field is weak at first until it is able to establish itself. More fundamentally, the institutional ecology will impose constraints on the organization of the partnership. But the process is even more complex than that, for the two influences are interdependent. The problem domain and policy response co-evolve:

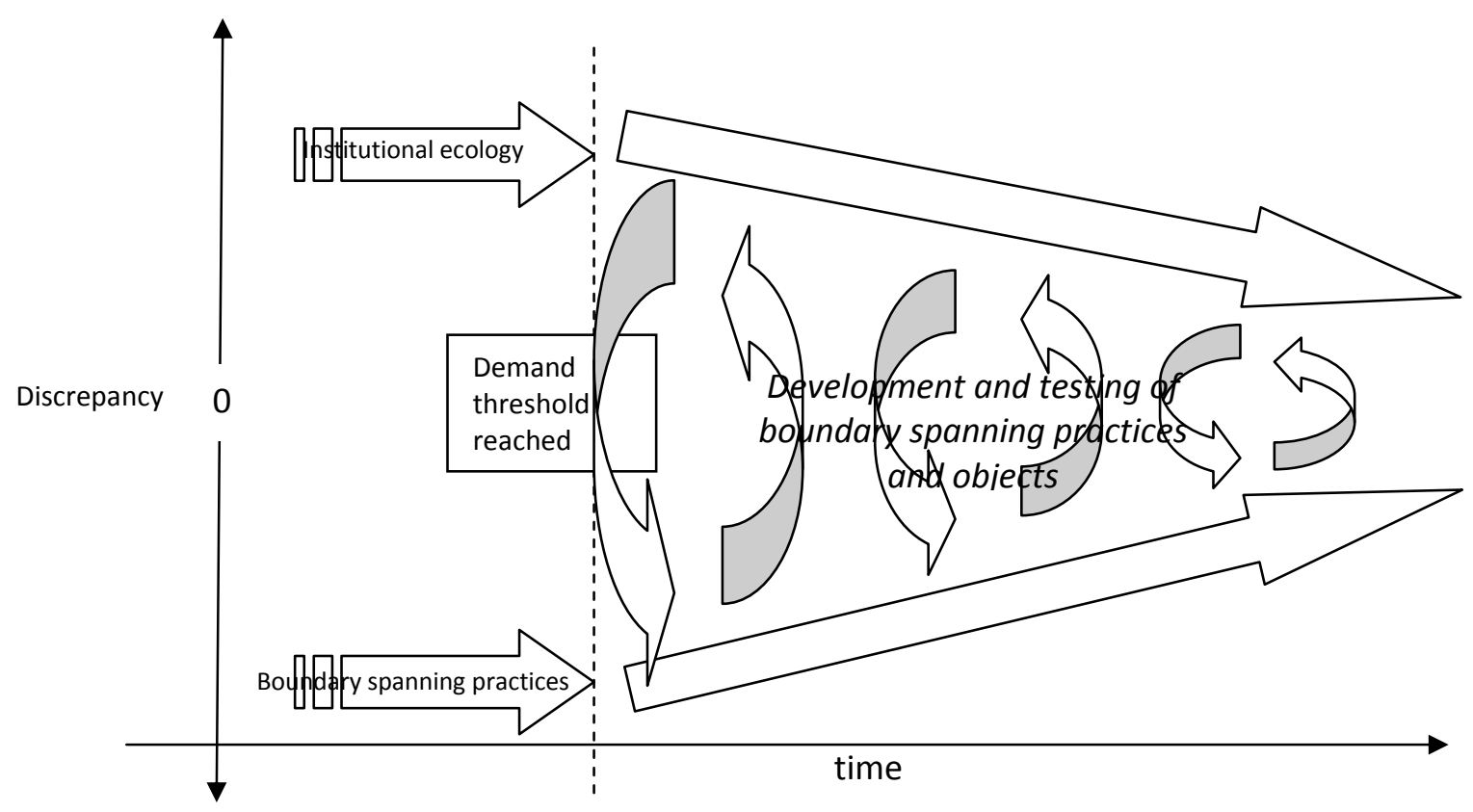

Figure 9: Convergence Leading to the Formation of a Partnership

During much of the process, the formation of a partnership is by no means assured - any of a number processes or events that interrupt boundary spanning critical to the convergence will tend to hamper partnership formation - but, at a certain critical point, the new partnership field will develop a distinctive set of practices and objects that no longer depend entirely on external validation and capital flows. The emergence of an indigenous system of interaction and exchange, complete with its own identity, social heuristics, and boundaries, will mark the 
maturation of the partnership as a relatively distinct and semi-autonomous field of practice. It should be noted, however, that even a "mature" partnership community will continue to experience some degree of disparity between the partnership and the larger institutional ecology. In fact, it is probably more accurate to think of convergence as a more-or-less ongoing process, occasionally interrupted by periods of divergence (Note that a "complete convergence," where the correspondence between fields is complete, implies their merger into a single, unified field). The work of partnerships is never done.

A dynamic systems view suggests that once a partnership is established, the periodic alignment of its core and boundary spanning practices is simply an elaboration of this convergence. A partnership's survival is not a foregone conclusion: partnerships must continually renew themselves by re-establishing their relevance vis-à-vis the community of partnering fields. In more concrete terms, it is incumbent on a partnership to project, both through its practices and ideologically, a vision for how the relevant fields will interact that feels salient, even necessary, to those fields. As the framework implies, this salience is anticipated by the partnership to the extent that the community already reflects partnership practices. Partnership systems that survive tend to have a tautological quality about them: a partnership remains relevant in part by routinely generating coordination problems that call for its unique ability to address them. At the same time, the influence which the partnership enjoys in the community of practice it 
serves depends, in turn, on the extent to which the partnership can meet the

multiple and ever-changing policy demands that impinge on that community.

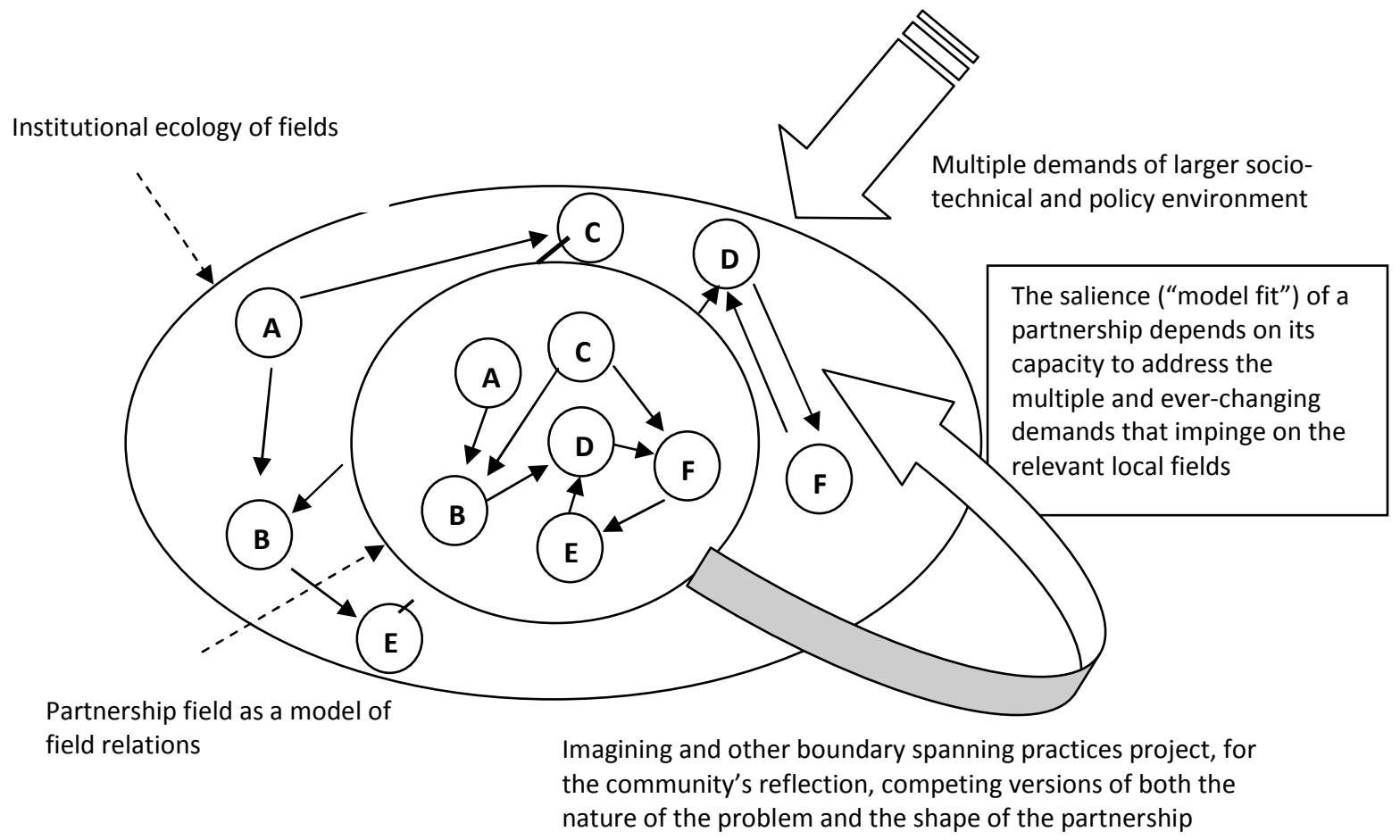

Figure 10: Partnership Work as an Ongoing Process of Mutual Adjustment

Whether in fact the expected divergence between a partnership field and the institutional ecology of fields is accidental or itself part of a still larger order policy system is an empirical question that can only be answered on a case-by-case basis. It is clear, however, that any accounts of the latter class of cases will generally speaking have a logical typology 1 degree more complex than those of the former class of cases.

\section{A Typology of Boundary Spanning}


From the discussion so far, several general implications for studying the relationships between boundary spanning, social learning, and partnership capacity can now be summarized. Starting with the most general level, if social systems are primarily about the management of change through communicative practices, then these practices and their changes are organized in levels or orders. It follows that their study should be about mapping practices and their changes the contrasts in orders. This study will treat fields of practice as communication systems composed of rules for organizing communicative practices. This approach treats boundary spanning practices as communicative practices to the extent that they refer to specific boundaries. It is therefore important to first specify the system level of description and analysis against which changes associated with boundary spanning will be measured. As defined in this study, "boundary spanning" refers to the bringing together of agents, objects, and practices from different fields in new ways. However, boundary spanning does not necessarily imply a change in the fields themselves. Field change first requires that the new practices and objects cannot be accommodated by the field, that is to say, that the practice in question cannot be fit into the existing field's grammar of practices. In addition, these "deviant" practices must also persist long enough to become a problem. But new practices on the boundaries may never take hold for whatever reason or will simply be added to the existing repertoire of more superficial boundary spanning practices. With respect to a given field, those boundary spanning practices that do not induce changes in the field itself are of a lower order than those boundary spanning practices that do. We 
are therefore driven to devise a classification of boundary spanning practices, objects, and identities that reflects these distinctions. ${ }^{18}$ The typology in Table 1 can be used for evaluating boundary spanning practices of partnership systems, so long as it is clear which field is serving as the reference point. Note that the typology is designed to capture those rarer cases of boundary spanning practices that become core practices without changing the field in question.

Table 1: Typology of Boundary Spanning Practices

\begin{tabular}{|c|c|c|c|c|c|}
\hline & \multicolumn{2}{|c|}{$\begin{array}{l}\text { Does the practice bring together } \\
\text { practices, objects, and agents from } \\
\text { different fields in new ways? }\end{array}$} \\
\hline & & & & Yes & $\begin{array}{l}\text { No ("core } \\
\text { practices") }\end{array}$ \\
\hline \multirow{4}{*}{$\begin{array}{l}\text { Can the resulting new } \\
\text { practice, object, or identity } \\
\text { be accommodated by the } \\
\text { existing participating fields? }\end{array}$} & \multirow[t]{2}{*}{ Yes } & \multirow{2}{*}{$\begin{array}{l}\text { If yes, is the } \\
\text { routine practice, } \\
\text { object, or identity } \\
\text { persistent? }\end{array}$} & Yes & "core practices" & $\mathrm{N} / \mathrm{A}$ \\
\hline & & & No & $\begin{array}{c}\text { "boundary encounters, } \\
\text { peripheries" }\end{array}$ & N/A \\
\hline & \multirow[t]{2}{*}{ No } & \multirow[t]{2}{*}{$\begin{array}{l}\text { If no, is the } \\
\text { deviant practice, } \\
\text { object, or identity } \\
\text { persistent? }\end{array}$} & Yes & $\begin{array}{l}\text { "boundary spanning } \\
\text { practices," "mutual } \\
\text { adjustment practices" } \\
\text { (meta-boundary } \\
\text { spanning practices) }\end{array}$ & N/A \\
\hline & & & No & $\begin{array}{c}\text { "boundary encounters, } \\
\text { peripheries" }\end{array}$ & N/A \\
\hline
\end{tabular}

The typology provides a starting point, but distinctions within cells still need to be made. Most importantly, boundary spanning practices are different from mutual adjustment (i.e., alignment) practices that integrate them and are therefore a typologically more complex form of ("meta to") boundary spanning. And, as already stated, much of the classification of boundary spanning practices can only be developed through empirical study.

\footnotetext{
${ }^{18}$ Henceforth, the term "typology of boundary spanning practices" shall be taken to mean typologies that cover boundary spanning practices as well as boundary objects and boundary spanners.
} 
Special methodological challenges arise in trying to use a typology of boundary spanning practices to explain the formation of partnerships. Partnership fields are like any other field to the extent that they have their own set of core and boundary spanning practices. Any account of partnership formation must therefore have some way of distinguishing core practices of the emergent partnership field and the boundary spanning practices of the fields from which they evolve. A similar problem holds for distinguishing changes in home field boundary spanning practices that lead to core partnership practices and those that don't. We are particularly interested in measuring and classifying changes in the discrepancy between the boundary spanning practices of the participating fields (and, eventually, core practices of the partnership field) and the larger institutional ecology. In other words, we must devise a similar typology classifying the sorts of changes we can expect to see during partnership formation.

This approach conceptualizes partnership formation in terms of processes, as opposed to agent-oriented practices, and relies on first specifying the system-ofreference. In other words, before we can use our typology of boundary spanning practices, we must be able to distinguish, for any given case, the partnership field and the fields that participate in it. We need some criteria for determining the emergence of partnerships, for answering the question: "how do we recognize a new partnership when we see it?" Obviously, the emergence of a legally named and chartered entity does not, by itself, fit our definition of a partnership. Rather, the emergence of a distinct partnership field coincides with the emergence of a novel 
and self-defined system of interaction and exchange, complete with its own grammar of practices. In other words, we should observe a definite pattern of interaction between the boundary spanning practices of the participating fields. The same holds for boundary objects and boundary spanners. A pattern of interaction is nothing more than a typology expressed in a particular form. Therefore, if such an indigenous pattern of boundary spanning practices, objects, and boundary spanners can be discerned, then we have clear evidence that the boundary spanning practices of the various partnering fields are somehow coordinated, that the boundary objects are actually being used, and boundary spanners have a function beyond name only. We will have evidence of a partnership.

\section{Operationalization of Framework Concepts}

Clearly, then, a general typology of partnership formation processes requires using our general typology of boundary spanning practices in conjunction with "local typologies" of boundary spanning practices, objects, and agents. These local typologies provide a context with which to classify boundary spanning practices in terms of the emergence of new joint fields of practice. Because partnerships are conceptualized as systems that manage change through the organization of otherwise disparate boundary spanning practices, then it follows that any boundary spanning practices which can be fit into a local typology of boundary spanning practices - since our local typology will presumably change over time, it may take some searching to find a match - can be classified as a "partnership core practice"; 
otherwise, it is essentially unclassifiable, that is, merely a "boundary spanning practice."

But a sticky issue remains: how do we measure the discrepancy between the institutional ecology and relevant boundary spanning practices leading up to the emergence of the partnership, that is, before they are organized into a definite pattern that can be measured? The short answer is: of course, we cannot. Because the emergence of a partnership field cannot be predicted from boundary spanning practices alone, we have no criteria to differentiate and therefore compare boundary spanning practices of the partnership-to-be and those operating outside of it. Nor do we have the benefit of historical hindsight, for such hindsight is illusory: we would be confined to evaluating the correspondence of boundary spanning practices to a typology we devise post factum, invariably reducing our explanations of partnership formation to either "just so" stories or teleological appeals. This problem represents an insurmountable "gap" in the methodology. A similar problem holds for classifying the convergence of boundary spanning practices and the larger community of practice. The framework posits that this convergence reflects social learning leading to the emergence of a partnership field, but testing this claim on a case-by-case basis is not straightforward. First, as already stated, convergence by itself does not assure partnership formation: any of a number of events or processes both internal and external to the inchoate joint field may interrupt the convergence process. Even if a new joint field appears, the analyst must be wary of ad hoc reasoning which 
selectively assigns changes in adjoining fields to the same local typology of practices used to define the new joint field. This runs the risk of attributing convergence among adjoining fields where there is none. Second, while the framework posits that the convergence process is continuous, in practice, it is difficult to measure the change in discrepancy using a continuous (i.e., "ratio") level of measurement. Instead, in most cases, the investigator must rely on comparing discrete typologies of practices that are observed at different points over the course of time. This also means that, for practical reasons, comparisons of structural or topological "distance" will rest on qualitative judgment.

A typology of boundary spanning practices must similarly inform the classification of the general types of partnership capacity and social learning that we have already identified. As defined in our framework, Partnership Capacity I is the particular institutional capacity of a field to organize boundary spanning practices among interacting fields in the form of routine core practices that will tend to reflect the mores of a community of practice. Thus, Partnership Capacity I can be measured as a typology of boundary spanning practices, whatever its form. If "Social Learning I" refers to the emergence of Partnership Capacity I, it follows that it can be measured as the emergence of a definite pattern of interaction among boundary spanning practices.

Social Learning II, the development of an institutional capacity of a partnership to renew itself within a defined range of environmental conditions (Partnership Capacity II), is more abstract and more difficult to measure. For one, 
its measurement will usually require longer time scales to demonstrate a partnership's resilience. Most simply, of course, the persistence of a partnership over a defined period of time suggests Partnership Capacity II. But the simplicity is deceptive, for it begs the question: if partnerships are by definition dynamic systems, then which changes in their behavior pattern or core practices are routine and which changes are not? How are we to distinguish normal social reproduction of a partnership field from its entire replacement with another? Our general methodological framework suggests at least three ways to answer this question. A dynamic approach holds that a partnership with Partnership Capacity II will display a "steady state" pattern over time in which the partnership being measured oscillates around a series of states. Each state embodies a structure of boundary spanning practices, a particular Partnership Capacity I, and is mapped as a particular typology of boundary spanning practices. As the terms are intended to convey, Partnership Capacity II is one degree more complex than Partnership Capacity I, so if the latter can be measured as a typology of boundary spanning practices, then the former can be mapped as a typology of the interactions of types of boundary spanning practices. Although technically correct, this rather abstract approach gives us no clear sense of how, practically speaking, to measure Partnership Capacity II.

Another measurement strategy is to consider that Partnership Capacity II resides at the level of the partnership system that mediates between the partnership field and its ever-changing institutional ecology. Thus, a partnership having 
Partnership Capacity II will also tend to exhibit a pattern of interaction with its partnering fields. It should be possible, in other words, to construct a typology of the interaction between a partnership's core practices and the core practices of the field of fields, that is, the patterned interactions among fields occurring outside of the partnership. This concept is somewhat more concrete and, in fact, builds on the methodological strategy, outlined above, for measuring changes in discrepancy during partnership formation. However, we still encounter the difficulty of tracking potentially numerous changes in typologies of interactions over time. In addition, our comparisons are complicated to the extent that the social practices and interactions within the partnership and those of the participating fields reflect one another.

A still more straightforward way to measure Partnership Capacity II starts with the assumption that partnerships with PC II will tend to enjoy widespread and consistent implementation of its multiple functions. One of the theoretical assertions of this framework is that the mediation between the partnership and its community of practice is indirectly accomplished through the mutual adjustment of the partnership's core and boundary spanning practices. One of this study's predictions is that a stable pattern of interaction between a partnership's core and boundary spanning practices will tend to produce a partnership that enjoys largescale and consistent implementation of multiple functions (PC II). That is, if we can construct a coherent typology of alignment practices, the theory holds, we have 
evidence of Partnership Capacity II. By extension, Social Learning II will tend to be associated with the emergence of such a local pattern of interaction.

The measurement of Partnership Capacity III is perhaps the trickiest, since we must be able to distinguish situations where the formation or replacement of partnerships is exogenous - driven by external processes - and situations where that formation or replacement is endogenously driven by a deeper institutional capacity for learning and adapting.

From our discussion on PC III, we know that a defining characteristic is the absence of persistent institutional issues that remain unaddressed. PC III is often achieved by replacing palliative remedies with more fundamental solutions to the underlying issue. The theory predicts that PC III will often be associated with a laboratory of learning where community members are encouraged to create social technologies and then critically inquire about outstanding issues, leading to a series of technically desirable and cultural feasible models for collective action under welldefined scenarios. If the prediction holds, we may begin to infer PC III if we observe a definite pattern in critical reflection centered on innovating, scanning for issues, and institutional design. Of course, we should also expect to find "native" models or institutional designs of partnerships that suggest some capacity of a community of stakeholders for reflexivity. Such models may assume many different forms ranging from narratives to computer simulations.

It follows from the discussion that any partnership exhibiting Partnership Capacity II is necessarily a general order more complex than a partnership 
exhibiting Partnership Capacity I, and by extension, one order simpler than one exhibiting Partnership Capacity III. The logical typing of our mappings should reflect this contrast.

We are now in a position to propose a general typology of partnership processes which, if the underlying theory is validated, can guide their measurement. The typology can be formulated as a series of linked decision rules for classifying changes associated with social learning as shown in Table 2. Note that typologies for boundary objects and boundary spanners - as well as for changes in boundary objects and boundary spanners - are implied and follow the same general procedure as for classifying changes in boundary spanning practices. Appendix B summarizes the methodology as a "methodology of institutional change." 
Table 2: Typology of Partnership Processes

\begin{tabular}{|c|c|c|c|c|c|c|}
\hline & \multicolumn{6}{|c|}{ Methodological criteria } \\
\hline Processes & $\begin{array}{l}\text { Can be fit in a } \\
\text { local typology of } \\
\text { boundary } \\
\text { spanning } \\
\text { practices? }\end{array}$ & $\begin{array}{c}\text { Does the change } \\
\text { coincide with a new } \\
\text { pattern of boundary } \\
\text { spanning practices } \\
\text { (Partnership Capacity } \\
\text { I)? }\end{array}$ & $\begin{array}{l}\text { Can be fit in a } \\
\text { local typology } \\
\text { of alignment } \\
\text { practices? }\end{array}$ & $\begin{array}{l}\text { Does the change } \\
\text { coincide with a new } \\
\text { pattern of alignment } \\
\text { practices (Partnership } \\
\text { Capacity II)? }\end{array}$ & $\begin{array}{l}\text { Can be fit into a } \\
\text { local typology of } \\
\text { institutional } \\
\text { design practices? }\end{array}$ & $\begin{array}{c}\text { Does the change } \\
\text { coincide with a new } \\
\text { pattern of institutional } \\
\text { design practices } \\
\text { (Partnership Capacity } \\
\text { III)? }\end{array}$ \\
\hline \multirow{4}{*}{$\begin{array}{l}\text { Local boundary } \\
\text { spanning practices }\end{array}$} & $\begin{array}{l}\text { Yes: Core } \\
\text { partnership } \\
\text { practice (STOP) }\end{array}$ & & & & & \\
\hline & No & & $\begin{array}{l}\text { Yes: } \\
\text { Partnership } \\
\text { alignment } \\
\text { practice (STOP) }\end{array}$ & & & \\
\hline & & SKIP & $\begin{array}{l}\text { No: Boundary } \\
\text { spanning } \\
\text { practice }\end{array}$ & & $\begin{array}{l}\text { Yes: Institutional } \\
\text { design practice } \\
\text { (STOP) }\end{array}$ & \\
\hline & & & & SKIP & $\begin{array}{l}\text { No: Boundary } \\
\text { spanning practice }\end{array}$ & \\
\hline $\begin{array}{l}\text { Changes in } \\
\text { disparity between } \\
\text { boundary spanning } \\
\text { practices and } \\
\text { institutional } \\
\text { ecology }\end{array}$ & & $\begin{array}{l}\text { Yes: Social Learning I } \\
\text { (STOP) }\end{array}$ & & & & \\
\hline
\end{tabular}




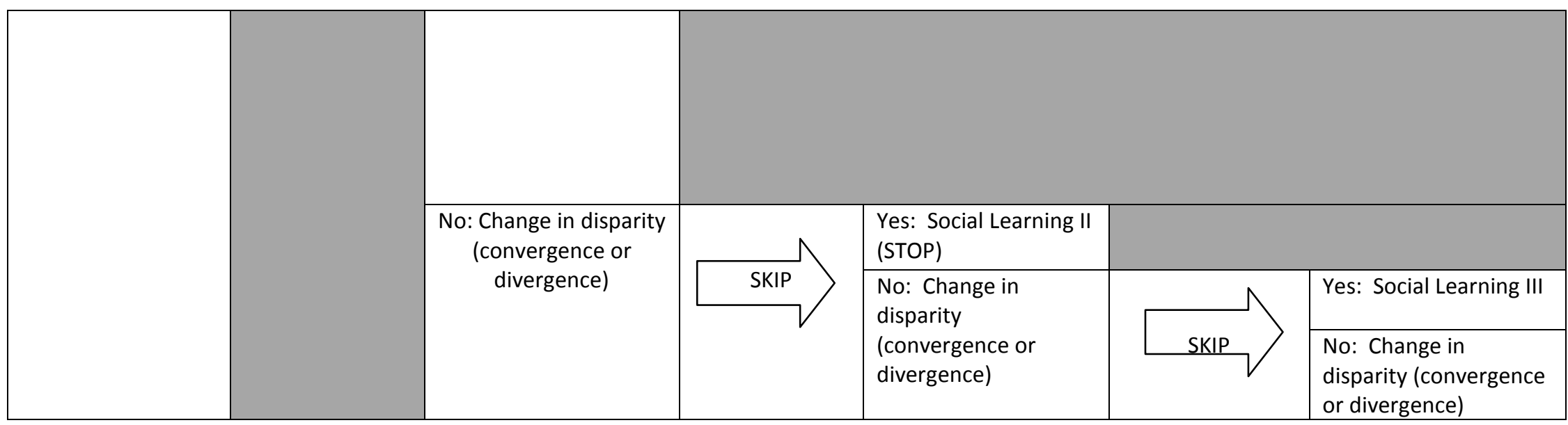




\section{Research Questions and Hypotheses}

The present study partially assesses the framework by proposing and evaluating hypotheses to two motivating research questions:

Research Question I: How do partnerships form exactly?

Hypothesis I: A socio-technical or policy need creates a structural opportunity for boundary spanning practices to begin to influence the larger institutional ecology. Boundary spanning practices will begin to converge with the ecology of participating fields through an iterative process of social judgments embedded in communicative practice and capital exchange. If the boundary objects (innovations) are deemed both technically desirable and culturally feasible, then the practices and ideas that produced them diffuse along with the innovations, further reinforcing the convergence. Boundary spanners play an important role in managing the convergence (however imperfectly) through visioning, strategic judgments, and steering capital flows, even as they are thereby changed in the process. The entire process is summarized as "Social Learning (SL) I" and results in a partnership with a basic capacity (Partnership Capacity I) to address a fairly welldefined policy problem.

Research Question II: How do partnerships sustain themselves over time?

Hypothesis IIa: To survive in the face of changing policy conditions, a partnership must learn (SL II) to engage in alignment practices that periodically allow for the mutual adjustment of core operations and more strategic and even constitutional concerns. This ensures that partnership goals and strategies are 
informed by local practices and conditions and facilitates the partnership's role in shaping the community agenda on a policy issue. Therefore: partnerships demonstrating a pattern of alignment practices will tend to oscillate about a defined range of "partnership states," as measured by programs, initiatives, or other strategic emphases.

Hypothesis IIb: Partnerships that develop the capacity (SL III) to reconfigure or "design" alignment practices to address socio-technical and policy surprises acquire a general capacity to learn and adapt that is enhanced with each iteration of the social learning cycle. Partnerships demonstrating PC III are characterized by a learning culture that promotes innovation and critical reflection of alignment practices in experimental settings. Therefore: partnerships demonstrating a pattern of institutional design practices will tend to persist in varying forms and under a wide range of environmental conditions.

\section{Methods}

To assess these hypotheses and the theory and methodology underlying them, this study carried out 4 case studies of water resource management partnerships in the Columbia River Basin: the Counting on the Environment Working Group (COTE WG) working in the Willamette River Basin in Oregon, the Regional Water Providers Consortium (RWPC) based in the Portland (OR) Metropolitan Area, the Walla Walla Watershed Alliance (WWWA) working in the Walla Walla River Basin in south-central Washington, and what this study is calling the Upper Deschutes River Partnership (UDRP). 


\section{Case Selection}

Cases were selected from a "sampling frame" of roughly 30 partnerships. The primary source of data for the cases were interviews. An important case selection criterion, then, was whether a sufficient number of interview subjects - between 5 and 10 per case - indicated they were willing to be interviewed. This criterion introduces an additional selection bias in an already non-random sample: it is quite conceivable that motivation to participate in the study was linked in some way with the model's variables, further distorting results.

Cases were to a large extent selected to enhance the study's replication logic as called for in explanatory case study designs (Yin, 2003). Thus, every attempt was made to select partnerships that shared as many potentially confounding factors as possible while focusing on the model's major relevant variables. For Hypothesis 1 (explaining partnership formation), these include: presence of pre-existing "need," presence of innovative (boundary spanning) practices, technical desirability, cultural feasibility, degree of interest and support for innovations, extent of adoption, the exchange of capital forms to promote innovations, "structural distance" between innovations and wider community of practice (measure of convergence), and pattern of boundary spanning practices (measure of PC I). For Hypothesis IIa (explaining partnership PC II), the relevant variables are: coherence of alignment practices and presence of defined range of partnership states (measure of PC II). And for Hypothesis IIb, the relevant variables are: coherence of 
institutional design practices and the absence of outstanding partnership issues (measure of PC III).

To increase the likelihood of observing a range of partnership capacities and social learning orders, partnerships were selected that ranged from relatively "young" (COTE WG) to relatively mature (RWPC). Selection also allowed some variance in specific policy area. Finally, the study drew on Mandell \& Steelman's (2003) typology type of inter-organizational innovation to classify the partnerships after they had already been selected. These variables are not considered part of the model and potentially capture effects which the model could not anticipate. While they complicate analysis, these variables also make it more likely that any patterns that are detected are in fact significant. Otherwise, cases were selected which were similar with respect to several potentially significant, complicating factors, including: policy domain (water resource management), cultural-geographic region (the Columbia River Basin), size and complexity (regional partnerships), and historical incidence (contemporary). Table 3 shows the relevant "demographics" of the 4 cases: 
Table 3: Demographics of Cases

\begin{tabular}{|c|c|c|c|c|c|c|c|}
\hline Case & Years & $\begin{array}{l}\text { Age (at } \\
\text { study) }\end{array}$ & $\begin{array}{l}\text { Number } \\
\text { of } \\
\text { Partners }\end{array}$ & $\begin{array}{c}\text { Interorganizational } \\
\text { Innovation (Mandell \& } \\
\text { Steelman, 2007) }\end{array}$ & Policy Area & Geographic Area & Scale \\
\hline $\begin{array}{l}\text { Counting on the } \\
\text { Environment WG }\end{array}$ & 2009- & 1 & 25 & temporary taskforce & $\begin{array}{l}\text { Ecosystem Service } \\
\text { Markets }\end{array}$ & $\begin{array}{l}\text { Willamette River } \\
\text { Basin }\end{array}$ & Regional \\
\hline $\begin{array}{l}\text { Regional Water } \\
\text { Providers Consortium }\end{array}$ & 1997- & 13 & 26 & $\begin{array}{c}\text { permanent and/or regular } \\
\text { coordination }\end{array}$ & Water Supply & $\begin{array}{l}\text { Portland } \\
\text { Metropolitan Area }\end{array}$ & Regional \\
\hline $\begin{array}{l}\text { Upper Deschutes } \\
\text { River Partnership }\end{array}$ & 2005- & 5 & 4 & $\begin{array}{c}\text { permanent and/or regular } \\
\text { coordination }\end{array}$ & $\begin{array}{l}\text { Reintroduction } \\
\text { Effort }\end{array}$ & $\begin{array}{l}\text { Upper Deschutes } \\
\text { River Subbasin }\end{array}$ & Regional \\
\hline $\begin{array}{l}\text { Walla Walla } \\
\text { Watershed Alliance }\end{array}$ & 2001- & 9 & 14 & $\begin{array}{l}\text { hybrid of permanent } \\
\text { and/or regular } \\
\text { coordination and coalition }\end{array}$ & $\begin{array}{l}\text { Watershed } \\
\text { Management }\end{array}$ & $\begin{array}{l}\text { Walla Walla River } \\
\text { Basin }\end{array}$ & Regional \\
\hline
\end{tabular}




\section{Interviewee Recruitment}

Once the partnerships were selected individual subjects who are identified others or by me as "boundary spanners" or closely involved with boundary spanning activities were recruited to be interviewed. For this study, and as already stated, boundary spanning is defined as bridge-building work that connects practices, agents, objects and ideas from different social, technical, and policy domains. For the purposes of subject recruitment, "boundary spanners" referred to those individuals who directly or indirectly engage in boundary spanning activities. I used snowball and convenience sampling strategies to identify recruitment subjects. Sampling consisted of mostly telephone and some face-to-face conversations with partnership contacts introducing myself and the research project and asking for referrals for boundary spanners or other promising interview subjects. These "sampling conversations" served not only as data reconnaissance for case selection but also to identify candidates for interviews in the event that the partnership was selected as a case. The core of data collection centers on interviews with individual subjects. In order to ensure an adequate representation of boundary spanning perspectives for each partnership case, subjects were recruited and individually interviewed until testimonies begin to overlap and settle onto a "saturation point." Altogether, 40 subjects were formally interviewed, averaging 10 per case. 


\section{Data Collection}

Data collection consisted mostly of one-on-one, in-depth interviews with boundary spanners from each of the cases; in a few cases, interviews were conducted over the telephone. The interviews averaged around 90 minutes and consisted of a series of open-ended questions about the formation of the partnership and boundary spanning activities that have occurred since then. Questions were designed beforehand to capture the central concepts embedded in the theory, including: boundary spanning practices, innovation, need or demand, convergence, core practices, and alignment practices. In addition, to help meet the study's aim to document the many varieties of boundary spanning, the open-ended structure of the interview helped capture incidental information about boundary spanning in partnership processes. The interview protocol and questions were pilot-tested on 2 individuals working in related policy areas to test for measurement validity. Feedback was then used to make adjustments in the protocol, questions, and probes. Appendix A shows the final interview instrument.

Secondary data, including archival and website materials, technical documents and memos, meeting minutes, media coverage, correspondence records, and existing reports, were also collected and analyzed for evidence of boundary spanning, partnership capacity, and social learning. I also carried out field trips observing partnership activities, including public meetings.

Analysis 
Interviews were recorded, transcribed, coded, and analyzed using Atlas.gi, as qualitative analysis software. The statements and points of view expressed by interviewees were interpreted on an individual basis and should not be taken to represent those of their agency, organization, or other affiliation.

Exploratory tables describing the various instances of boundary spanning practices were populated by first classifying the partnership processes for each case (e.g., SL I, PC I). The boundary spanning practice categories were arrived at through a process of induction from the cases. The present framework defined boundary spanning as any interaction between 2 or more practices, ideas, entities, and objects associated with different fields of practice, or any process or practice that supports such interaction. The codings were as descriptive as possible to aid in interpretation and validation of the observations. Practices were generalized just enough to capture similarities across cases without obscuring important distinctions. The categorization underwent several cross-case iterations until they began to settle.

The assignment of values for the model variables comprising the hypotheses was based on summary analyses of the case studies. Because the categories were derived beforehand, data collection was more targeted than in the cataloguing of boundary spanning varieties. Interview questions (see Appendix A) were designed to capture many of the factors, while primary and secondary data were also analyzed in accordance with the methodological framework. Still, assignment of values relied a great deal on qualitative judgment. The outcome measures especially, 
"structural distance" and "pattern of boundary spanning practices?", were measured by a rather general assessment only after the case studies were written.

Finally, I held and facilitated an optional half-day SSM workshop in September, 2010, where participants from the different partnerships collectively reflected on boundary spanning and ways to build partnership capacity. The workshop provided an opportunity to present preliminary findings to key informants for face validation. But the workshop was also designed as a collaborative research component for the study itself. Participants and I collectively used a collaborative learning process called "Soft Systems Methodology" (SSM) to explore and model institutional change scenarios selected by participants from 1 of the 4 case studies. SSM is a collaborative modeling process designed to assist stakeholders in thinking about issues associated with bringing about change in a situation that they view as problematic. This process is more "inquiry and design" than "strategic planning," because while strategic planning tends to be goaloriented, SSM focuses instead on the transformation that gets stakeholders from where they are today to where they want to be. ${ }^{19}$ SSM's process-focus helps stakeholders stay aware of the deep values and assumptions driving institutional change and enables them to collectively explore how their perspectives are themselves subject to negotiation and change. Ultimately, the objective is to arrive at stories of change, or "holons," which stakeholders can reflect on and compare in order to identify and address issues associated with the sustainability of the change

\footnotetext{
${ }^{19} \mathrm{SSM}$ is not, strictly speaking concerned with implementation planning either. Rather, it strives for more of an integration of strategic and implementation planning. 
effort. Issues might include: implementation being inconsistent with local customs; change introducing contradictions between partnership functions; lack of capacity and other inputs to carry out change.

The selection of SSM was driven by several considerations. First, SSM coincides closely with the study's framework. The perspective-driven methodology starts from a design view of "human activity systems" that explicitly uses a grammar of change ("root definition grammar") appropriate for planning for and managing institutional change. Indeed, the study's system-as-process framework suggests natural intervention points for SSM in the ladder of social learning and partnership capacity, as Figure 11 illustrates: 


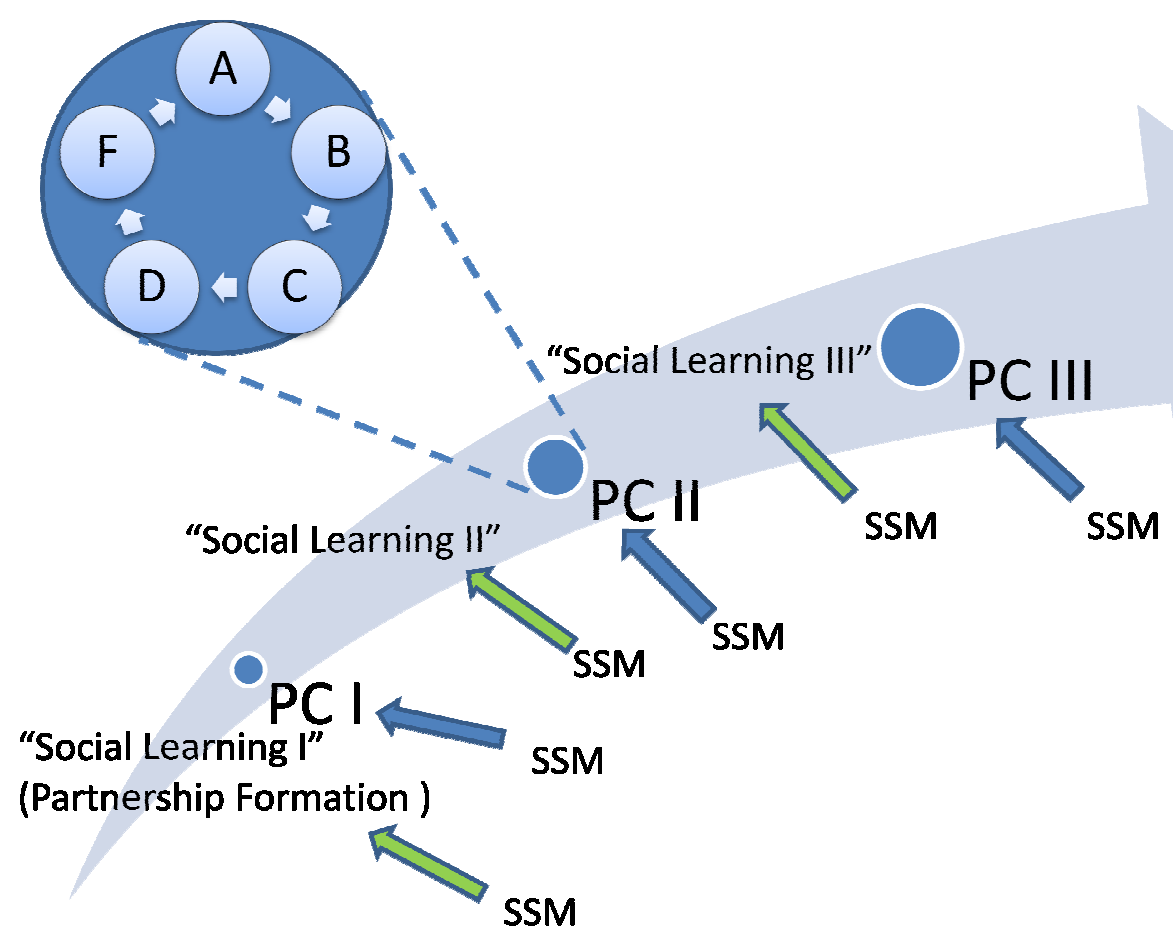

Figure 11: Mapping SSM onto framework showing possible intervention points

Prior to the workshop, representatives of each partnership were given an assignment to select from 1 of 3 general types of partnership processes and to develop from that starting point a description of the current "problematic partnership situation." They were then asked to develop a statement of the process which they desired to see in their partnership, identifying key elements of the process, as well as evaluation criteria by which that process would be judged. Although not made explicit to the participants at the time of the assignment, the 3 general types of processes corresponded in fact to SL I, PC II, and PC III. Each participant thereby engaged with SSM at the corresponding intervention point (see Figure 11). The assignment's questions roughly corresponded to SSM's first 3 formal stages (Mode 1): problem structuring (technical, social, and political analysis); 
identification of major elements of vision statement (What is the desired change?, How does the change come about?, and Why do the change?, along with criteria to evaluate success); and finally, a rudimentary statement of the envisioned partnership process using SSM's root definition grammar.

Based on the information collected from the assignment, I then constructed rich picture diagrams of the problematic situation along the root definition statements. Appendix C shows the SSM rich pictures for each of the 4 "change scenarios." The rich pictures generated rich group ("plenary") discussion that was organized around identifying outstanding issues associated with the envisioned process and ways to address those issues (see Appendix D). The intention was to document these issues and proposed strategies for each scenario and then "triangulate" these findings with the study's findings in order to look for associations between boundary spanning practices and partnership processes, including strategies to address specific types of issues associated with specific types of processes. Thus, the workshop was conceived as an instance of collaborative learning between an academic and a group of practitioners that would simultaneously enrich the study's findings while also providing an opportunity to evaluate SSM as a social learning tool.

\section{Conclusion}

Studies of boundary spanning, partnership formation and social learning more generally, and partnership capacity are difficult not only because our methodologies are not yet up to the task, but also because the subject matter is 
intrinsically complex. The dynamics of partnership formation, with its ever-shifting reference points, frustrate conventional methodologies which rely on a fixed ground against which to measure change. The same can be said for the fluid character of partnerships once they are established. At times they appear as autonomous fields of practice, at other times more as boundary regions between interacting fields. But partnerships, at least the ones that tend to survive, are neither one nor the other: rather, they are more properly understood as complex adaptive systems that navigate the liminal state between them. According to this view, the study of partnerships and partnership formation should focus on the management of disparity between the boundary spanning practices occurring within the joint field and those operating outside of it. Furthermore, we can expect that this management will center on negotiating definitions of the nature of the management problem and what the appropriate form of partnership is to address it. 


\section{Chapter 4}

\section{Counting on the Environment Working Group}

\section{Background}

The Counting on the Environment Working Group (COTE WG) formed in 2008 to develop a set of principles, procedures, and test-pilots for a multi-credit ecosystem services marketplace in the Willamette River Basin of Central Oregon. An "ecosystem service" refers to the benefits that natural ecological processes produce, such as clean water, carbon sequestration, and stormwater recharge. An ecosystem marketplace is any location, real or virtual, where conservation and restoration outcomes can be bought and sold. A buyer - often it is a land user seeking to offset or mitigate for environmental harm from economic activity - can purchase "credits" produced by another party carrying out environmental conservation or restoration activities elsewhere. The COTE WG consists of a group of stakeholders representing regulatory and non-regulatory agencies, environmental interests, the state's natural resources industries and related businesses, municipalities, farmers, and other landowners and users in the Willamette Valley. This group has come together to develop and test a standardized set of crediting methodologies, protocols, assurances, and tools that would be used to measure and account for multiple types of ecosystem service credits in a marketplace where they could be traded. It is the first marketplace of its kind to integrate credits spanning multiple ecological concerns - in this case, water quality, salmon habitat, wetland, and upland prairie. As of this writing, these policy innovations are already being field-tested in 4 pilot 
restoration projects. The COTE WG's accomplishments to-date are truly remarkable, considering the ambition of the policy agenda and the speed with which they have progressed in promoting it. To appreciate the work that the COTE WG partnership has carried out, as well as the challenges that remain to the larger ecosystem services marketplace agenda, we have to understand the historical and policy context in which the COTE WG formed.

The concept behind the term "ecosystem service" is a relatively modern one. Although observers have noted some of the vital functions of natural processes dating back to Antiquity, these functions have tended to remain a concern for natural philosophy and later biology and ecology, but not economics. In the West, the ideological separation of "man" and nature meant that these functions were not assigned economic values. Nature attained economic value only through humans transforming it. Ironically, the notion of ecosystem services has some of its earliest roots in the dismal science's observation that natural resources were not unlimited (see especially, Marsh, 1864). But it wasn't until the mid-20th century that writers began to raise awareness of the vital functions that nature provides humans, and the idea of "natural capital" was born (Leopold, 1949; F. Osborn, 1948; Vogt, 1948). In 1956, Sears highlighted the important role that ecosystems play in processing waste and recycling nutrients. In 1970, at the height of the environmental movement, a report issued by the Study of Critical Environmental Problems (SCEP), coined the term "environmental services" to refer to a range of services that were valuable to human societies, including: pollination, fisheries, climate control, and flood control. 
In the subsequent decades, the notions behind environmental services were gradually given more definite shape by scientists and environmental thinkers who grappled with numerous problems relating to valuing "ecosystem services," as these services came to be called (see for example Heal, 2000). These discussions culminated in a 4-year United Nations study carried out by 1,300 scientists worldwide entitled Millennium Ecosystem Assessment (MEA). The MEA formally identified 4 broad classes of ecosystem services: provisioning of benefits (e.g., food and water); regulating of processes (e.g., climate and disease control); supporting functions (e.g., nutrient cycles and pollination); and finally cultural, which refers to recreational and spiritual benefits. Since then, the MEA has provided a framework for developing ecosystem service policies around the world, including in Oregon. Still, various problems centering on demand, value capture, measurement, barriers-to-entry, assurances, and accounting practices will need to be addressed. In addition, currently the policy landscape remains fragmented with respect to developing ecosystem service marketplaces. The disparate laws, rules, and incentive programs spanning the sectors will need to be strategically aligned to promote the development and smooth functioning of marketplaces (INR report, 2008). Finally, accounting practices will need to be updated to better integrate mitigation crediting with the larger capital markets (INR report, 2008). Until these structural changes are made, it will be difficult for ecosystem marketplaces to establish themselves. As with most innovations in the early stages, ecosystem service marketplaces face a chicken-and-egg credibility dilemma - the larger society 
requires these marketplaces to address some of its challenges before it will fully embrace them, while at the same time these marketplaces require a minimal level of buy-in and participation by the larger society in order to address those challenges.

Emergence of Policy Readiness

These issues notwithstanding, ecosystem service markets have found some traction in Oregon. Since the 1990's Oregon has experimented in ecosystem service markets in the areas of carbon trading and water quality. In 1997, the Oregon Legislature passed its landmark House Bill 3283 establishing caps on greenhouse gas emissions and requiring power plants to make offsets on any discharges above their allotted amount. A third party, Climate Trust, was set up to handle trades of credits between polluters and mitigators. In 2004, Clean Water Services (CWS), a special district agency that services water and sewage for Washington County, procured a National Pollutant Discharge System (NPDS) permit from the EPA that combined permits for both waste water treatment and stormwater management. This bundling of permits has enabled CWS to take a more comprehensive and holistic approach to water quality. The NPDS permit allows the agency to trade "water quality credits" generated through creative and efficient solutions that capitalize on leverage points in the larger Tualatin River Valley watershed. In one program, CWS has worked with farmers and other landowners to sponsor the planting of shade trees along strategically selected riparian zones that help to cool the river and thereby offset heating pollution from the agency's waste water treatment facilities. 
Similar benefits have been recognized from increasing instream flow, and once again, legislative innovation was key. The Instream Water Right Act in 1987 authorized the sale, lease, and gifting of water specifically for the purpose of keeping more water in Oregon's creeks and streams. The law made it possible to lease or transfer conserved water on a temporary basis, providing agencies and communities the flexibility to protect stream flow during periods that were especially critical for salmon and other species. But the law also authorized the permanent conversion of consumptive water rights into instream water rights. The legislative act effectively created markets that could fund and underwrite these transfers. The Oregon Water Trust (OWT) has emerged as a significant "banker" of water rights in the state. Building on the successful model of land trusts, the OWT strategically acquires water and instream water rights and targets their transfers in smaller tributaries that provide a critical supporting function for salmon spawning and rearing. In return, farmers and other water right holders receive various forms of compensation ranging from cash and replacement feed for lost production to tax breaks. OWT's portfolio now includes over 160 cubic feet/second (cfs) of water rights in 86 different streams involving transactions with over 200 landowners. In the Deschutes River Basin, the Deschutes River Conservancy (DRC) has expanded on the water banking model to address new hydrological findings that show a critical link between groundwater and instream flow, particularly in the Lower Deschutes. Changes in state water laws that required new applicants of groundwater permits in the basin to acquire instream mitigation credits helped spur 
the creation of a market for these credits. The DRC has worked with landowners, irrigation districts, municipalities, and the Oregon Water Resources Department (OWRD) to generate, certify, and track these credits as offsets for groundwater permits, leading to significant progress in meeting ODWR's targets for instream flow in critical stretches of the Deschutes River (INR, 2008). The Columbia Basin Water Transactions Program (CBWTP), started in 2002, offers a similar system for incentivizing landowners to help restore stream flow. The CBWTP, like the other markets, is actually a partnership of a diverse set of stakeholders. Funding is provided by the Bonneville Power Administration (BPA) in cooperation with the Northwest Power and Conservation Council (NPCC), and administered by the National Fish and Wildlife Foundation (NFWF) which reviews and ultimately certifies proposed transactions. As in the other cases, transactions involve either permanent acquisitions, leases, or incentives for improving efficiency and conservation that are carried out through various programs and partnerships (INR, 2008).

Wetland mitigation banking is another policy tool used in the protection of the country's wetlands. Starting with the George H.W. Bush administration, both the EPA and the U.S. Army Corps of Engineers (USACE) have pursued a policy of "no net loss" of wetland. The principle means of federal enforcement was through the Clean Water Act, Section 404, which requires any unavoidable fill of wetlands receive onsite mitigation. Since then, these agencies have partnered with state and sometimes local governments to establish wetland mitigation banking programs to provide 
more flexible, efficient, and effective mitigation. As with other credit banking, the idea is that a landowner or sponsor that creates, restores, and protects wetlands can bank credits which are sold to private and public developers who in effect fund those wetland banks. The Oregon Department of Transportation (ODOT), for instance, has a wetland mitigation banking program to offset any unavoidable impacts from road and bridge projects. As the federal agency enforcing Section 404, the USACE wields considerable influence on wetland mitigation banking through its rules and guidelines that define what constitutes avoidable versus unavoidable impact and allowable offsets to mitigate those impacts. In Oregon, the Department of State Lands (DSL) administers the State's wetland mitigation program in cooperation with the USACE, assisting landowners with setting up and monitoring banks. However, under current laws, wetland mitigation credits can only be transferred or sold for purposes of permitting or offsetting violations. This effectively eliminates the possibility of a third party facilitating trades and makes an ecosystem services marketplace for wetland mitigation banking cumbersome (LaRocco \& Vickerman, 2007). Similarly, ODOT is statutorily restricted from using gas-tax revenues for purposes other than building or improving transportation roads and bridges (LaRocco \& Vickerman, 2007). Furthermore, off-site mitigation on which a robust marketplace depends is currently limited by state laws. DSL, for example, cannot approve offsite mitigation banking unless all on-site mitigation options have been deemed impractical. More generally, wetland mitigation banking has been agency-driven. The risk-averse culture of agencies, combined with 
statutory restrictions that constrain their actions, mean that wetland mitigation has tended to be relegated to on-site, and the market for wetland mitigation credits remain underdeveloped. Despite this, wetland mitigation banking programs certainly lend credence to the idea of banking offsets and have raised awareness of the possibilities for creating markets where these offsets could be traded.

Crystallization of an Ecosystem Services Policy Network

Emboldened by these successful experiments, a small group of community and policy leaders emerged to propose developing a comprehensive ecosystem service marketplace that would accommodate multiple kinds of credit to address the diverse array of environmental problems the state now faces. A central premise of the multi-credit ecosystem services marketplace is that such an approach enables markets to more strategically target synergies and leverage points across ecosystem functions. A multiple credit schema greatly simplifies the mitigation process both for developers and for those wishing to carry out and fund conservation or restoration. Instead of having to interact with multiple agencies, permitting requirements, and programs, market participants would only have to interface with a single set of rules and incentives. But perhaps even more importantly, a multicredit approach leads to a more comprehensive and integrated framework for valuing and restoring ecosystem services, at least at the site level. Land-users who are allowed to either "bundle" or "stack" credits of different types (e.g., water quality, habitat, wetland, carbon) are incentivized to concentrate mitigation in those 
areas where multiple ecosystem services support one another. ${ }^{20}$ Thus, for example, properly targeted wetland restoration can simultaneously improve flood control, water quality, and habitat that protect biodiversity, and, more fundamentally, the integrity and resilience of the underlying ecosystem itself.

Perhaps no organization has championed the idea of establishing a multicredit ecosystem marketplace in Oregon more than has the Willamette Partnership (WP). Officially formed in 2004, WP is a non-profit organization with a board comprised of local and state leaders spanning the public, private, and civil sectors all variously concerned with, as the mission statement says, "increasing the pace, expanding the scope, and improving the effectiveness of conservation," starting in the Willamette Basin. The organization's roots date back to 1996 when Governor John Kitzhaber convened the "Governor's Willamette Basin Task Force" to develop policy tools for better coordinating and managing conservation and restoration in the Willamette River Basin. This led to the formation of the Willamette Restoration Initiative in 1997 which was charged with developing a comprehensive strategy that would simultaneously address water quality, flood control, fish population health, and habitat. Four years later the "Willamette Restoration Strategy" identified high priority areas for protection and restoration, including riparian areas, detailed strategies for improving water quality, and created new communication channels to better coordinate regulation at the state and federal levels.

\footnotetext{
20 "Bundling" refers to counting different types of credits on the same site without distinguishing physical areas within the site. "Stacking" refers to dividing a site into distinct sub-areas where only one type of credit is counted for each sub-area.
} 
These efforts led to some early on-the-ground successes, and, more importantly, helped to build relationships among leaders from a diverse range of sectors and interests, including: environmental conservation, municipalities, natural resource industries, businesses, farming, and research. A coalition of community and policy leaders was forged from a combination of shared experiences with both policy failures as well as recent successes in credit markets. Although they came from different backgrounds, these leaders began to coalesce around a common emphasis on "ecosystem services" that helped shape both their perception and response to the environmental degradation of the Willamette River Basin.

Building on these earlier initiatives in the Willamette Basin, and drawing on the lessons of ongoing mitigation banking experiments, both in Oregon and elsewhere, this coalition of leaders formed WP in 2004 for the express purpose of researching, developing, and promoting ecosystem services markets. Presently, the partnership includes: Clean Water Services, the Oregon Business Council, Wildwood, Inc., Defenders of Wildlife, Willamette Riverkeeper, The Conifer Group, the Oregon Association of Nurseries, Weyerhaeuser, the Oregon Association of Conservation Districts, SOLV, the Network of Oregon Watershed Councils, Portland's Bureau of Environmental Services, local law firms, and the state's universities. In 2005, WP was 1 of 12 recipients nationally of the EPA's Targeted Watershed Grant to create a water quality trading program for the Basin that initially focused on 
water temperature in support of salmon recovery. ${ }^{21}$ The original proposal had the backing of a wide range of stakeholders, including: Governor Kulongoski, The Confederated Tribes of Grand Ronde, the Oregon Association of Conservation Districts, DEQ, and other government agencies, the major cities of the Willamette River Basin, special utility districts, industry associations like Associated Oregon Industries, environmental groups, the University of Oregon, and Oregon State University. WP convened a process to develop a water quality trading market, but with no clear sideboards to organize discussion, the group got bogged down in disagreements and ultimately "died under its own weight," as one of participants described it. The same year, Clean Water Services established their water quality trading program on the Tualatin River.

Birth of an Idea for a Multi-Credit Marketplace

Up until that point, ecosystem credit markets had largely been used to address separate regulatory concerns, such as water quality or wetland mitigation, but in 2006, ODOT's Mitigation and Conservation Coordinator, Bill Warncke, rolled out a program for his agency that would address multiple resources, including water quality, wetlands, fish and wildlife habitat, and endangered species (Ness, 2009). Essentially, the ODOT Banking Program proposed a currency called "Habitat Value" which would assess the habitat value of a site based on a comprehensive evaluation of functions supporting biodiversity. By building in "backstops" to account for

${ }^{21}$ The regulatory driver for the program was the Department of Environmental Quality's Total Maximum Daily Load (TMDL) requirements governing water quality in Oregon's streams and tributaries. One TMDL concerns temperature, which stipulates the maximum temperature that waters are allowed to reach on any given day of the year, and is designed to protect salmon requiring a specific stream temperature range to flourish. 
specific regulatory concerns, the Habitat Assessment Method (HAM) represented an innovation in multiple-credit accounting. It was, among other things, one of the first efforts of its kind in Oregon to quantify habitat value.22 The ODOT Banking Program, taken as a whole, was also a policy innovation. Its Comprehensive Mitigation and Conservation Strategy (CMCS) broke from traditional mitigation banking in shifting the focus from individual sites (and acreage measurement) to the landscape scale where more ecosystem service values could be captured. Following this strategic approach, the program's “Ecoprovince Priorities” identified restoration goals for each watershed in Oregon that targeted ecologically significant habitat and species where ODOT's mitigation program could make the most difference. It effectively challenged Oregon's regulatory community to think beyond narrow silos and minimal compliance to achieve superior environmental results. But perhaps the most significant innovation was at the process level. The ODOT Banking Program included an inter-agency Mitigation and Conservation Bank Review Team (MCBRT) that was no doubt inspired by the successful inter-agency collaboration model developed within ODOT several years before called the Collaborative Environmental and Transportation Agreement for Streamlining (CETAS). In a manner similar to CETAS, MCBRT folded different regulatory processes associated with permitting and mitigation for transportation projects into

\footnotetext{
${ }^{22}$ It is important to note the important role that research played in developing ODOT's Habitat Assessment Method. To calculate habitat value, HAM relies on information about the habitat-species associations that are documented in Wildlife-Habitat Relationships in Oregon and Washington (Johnson and O'Neil, 2001). The actual calculations involve running queries of the Interactive Biodiversity Information System database.
} 
a single program that served to streamline the development and certification of mitigation banks. By agreeing to a strategic, integrated framework upfront, the signatory agencies could review and approve specific mitigation banking projects with greater efficiency and effectiveness (Warncke, 2006). The collaborative model carried the additional advantage that the program's performance would improve as relationships of trust between the agencies were built.

Ultimately ODOT concluded that its project impacts were not sufficient to justify the cost of building and maintaining banks, and the program dropped the multi-credit, functional-based approach in favor of more traditional conservation banking (LaRocco \& Vickerman, 2007). However, Ness (2009) reports that the reasons Warncke's proposal was ultimately dropped had less to do with pragmatic constraints and more to with an agency culture wary of experimenting outside of traditional regulatory approaches (Ness, 2009). This resistance was perhaps surprising, given the agency's success with CETAS, which had become touted as model for inter-agency collaboration. It is therefore unlikely that the process design was the issue; instead, resistance seems to have centered more on cultural and substantive issues, starting with the idea of multiple-credit banking. In a sign of things to come, the agency management was reticent to take on such path-breaking approach without sufficient assurances that ODOT's regulatory obligations would be met (Ness, 2009). Mitigation banking was and continues to be viewed by many agency staff with skepticism as a policy tool that primarily serves development interests. Combining ecosystem service credits only compounds much of the 
uncertainty and confusion for bureaucrats consumed with managing and communicating about risk. Their tendency is to favor precision of measurement even at the expense of actual policy outcome. Thus, Warncke's call to agencies to think beyond narrow regulatory and compliance goals and to strive for improvements in environmental outcomes represented a criticism of agency culture more generally. As a call to change, it was probably viewed by some as a threat as well.

While Warncke's Habitat Banking Program proposal never materialized, others within the emerging ecosystem service policy network took notice. The failed proposal made its rounds through various channels, including Warncke's (2006) article "Oregon Innovates," which was published on the website of The Katoomba Group, a prominent organization promoting ecosystem marketplaces (http://www.ecosystemmarketplace.com/pages/dynamic/article.page.php?page id $\equiv 4298 \&$ section $=$ home\&eod=1 accessed November 5, 2010). Agencies and consultants like Parametrix who were affiliated with ODOT's Conservation and Mitigation Program were of course familiar with the proposal, and the ideas contained within it made their way into discussions involving other institutional stakeholders working on banking projects and programs, many of whom had forged relations while working on the Willamette Basin Initiative. Within a few years, several key policy actors in the Willamette River Basin began exploring various forms of the multiple-credit ecosystem marketplace. Parametrix built on the program's methodology for calculating salmon backstops and eventually completed 
a salmon crediting methodology. The Institute for Natural Resources (INR) began a 2-year research project to examine ways to better integrate wetland and endangered species concerns in transportation planning, while Defenders of Wildlife began experimenting with a voluntary "Marketplace for Nature" both in the Willamette River Basin and in Chesapeake Bay (Ness, 2009).

Soon after Warncke's proposal, and building on the EPA Targeted Watershed grant project, WP began to develop a concept of a "Willamette Ecosystem Marketplace" (WEM). The Partnership staff and board led the effort, with critical assistance from partners and stakeholders. It was an ambitious, large-scale effort. The Mid-Willamette Valley Council of Governments acted as fiscal agent of the project and technical assistance was provided by CH2MHill, David Evans \& Associates, Parametrix, and 4 task teams: A Synthesis Map Working Group tasked with carrying out a more accurate delineation of conservation and restoration priority areas; a Practitioner Working Group consisting of potential restoration providers (sellers of credit) to help identify and implement potential banking projects as well as develop temperature crediting protocols; a Transaction Working Group that developed credit trading documents such as credit exchange and registration agreements; and a Technical Team that explored ways to quantify ecosystem service improvements from floodplain restoration. Countless other stakeholders, including many of the same supporters of the original EPA Targeted Watersheds grant, provided technical and in-kind assistance (Primozich, 2008). The WEM project, by the time it was completed in 2008, could boast several 
important accomplishments, including a market appraisal identifying high priority areas as potential markets and a "centralized market infrastructure" consisting of a credit registry, trading platform, and supporting documents that could account for many different kinds of credits (Primozich, 2008).

During this time, members of the Board emerged as important champions of the concept as well, including: David Hulse of the University of Oregon, Bill Gaffi of Clean Water Services, and Sarah Vickerman of Defenders of Wildlife. At the same time that she was developing Defenders of Wildlife's "Marketplace for Nature," Vickerman led her organization in co-sponsoring with WP a series of stakeholder fora to formally discuss the challenges and opportunities for developing a comprehensive marketplace. These fora, which were facilitated by INR, produced several reports, including one Vickerman co-authored with her colleague Gina LaRocco (LaRocco \& Vickerman, 2007). Indeed, 2007 saw the circulation of several working papers authored by some of the key figures within the policy network. These papers amounted to a collective vetting of issues that helped to focus the different conversations occurring within the network during this time. Of course, as authors of these papers, these actors had a significant role in shaping the overall policy agenda of the ecosystem services marketplace. In 2007, the Oregon Business Summit hosted a special session on "Creating an Ecosystem Services Marketplace" featuring prominent figures of the nascent policy network. Among others, Bill Gaffi joined with Allen Alley, Governor Kulongoski's Deputy Chief of Staff, in calling for a state-level effort to build an ecosystem services marketplace (Ness, 2009). All of 
these policy discussions culminated in a special report published by the INR entitled Policy Cornerstones and Action Strategies for an Integrated Ecosystem Marketplace in Oregon which identified the institutional building blocks of a multi-credit marketplace and proposed several policy recommendations, including: removing statutory obstacles, authorizing agencies to carry out adaptive management, improving communication and coordination among agencies and programs, and building agency cultures that embrace adaptive management (INR, 2008).

Convergence of Innovative Ideas and Policies

For regional initiatives like WEM to take hold, it must be embraced by the state. This was especially the case here, since, as the reports made clear, the current statutory and regulatory framework in Oregon was going to make it difficult to establish a successful multi-credit ecosystem marketplace. History favored state support of the WEM initiative, since the Governor's Office had remained involved in the developments since Kitzhaber's “Governor's Willamette Basin Task Force” and continuing with the EPA's Targeted Watersheds grant project, as well as the fora that culminated in the INR report. In addition, the successful experiments with environmental credit markets both in Oregon and elsewhere convinced many lawmakers of the potential that a comprehensive multi-credit ecosystem marketplace held for revitalizing the state's natural resource, recreational, and economic base. These markets seemed to hold particular promise for rural areas that were still recovering from the collapse of the logging industry. And it was largely with the aim of rural revitalization in mind that the Oregon Legislature 
adopted, with some modifications, the Millennium Assessment's definition of ecosystem services when it updated its Forest Resource Trust HB 2293 in 2007.

The convergence of local and government experiments in ecosystem service markets accelerated in 2008 with the passage of the Food, Conservation, and Energy Act (or "Farm Bill"). Section 2709 of the Farm Bill called for the USDA to work with other agencies and land-using stakeholders to develop guidelines for measuring, valuing, and monitoring ecosystem services with the express purpose of facilitating the establishment of ecosystem service markets. It stipulated that the technical guidelines should be used to develop measurement and reporting protocols and registries to track credits, along with a system of verification (H.R. 2419: 2719, 2008). As a result of the Farm Bill, a new Office of Ecosystem Services and Markets (now called the Office of Environmental Markets) was created within the U.S. Department of Agriculture to implement Section 2719.

By 2008, therefore, there was a policy "readiness" in Oregon to begin to transform the multi-credit ecosystem services marketplace concept into a concrete policy. Building largely on Policy Cornerstones and Action Strategies for an Integrated Ecosystem Marketplace in Oregon, Defenders of Wildlife proposed to lawmakers a bill that would begin to address the issues raised in the report. The proposal was backed by a diverse array of stakeholders, including: the Willamette Partnership, the Oregon Forest Industries Council, the Oregon Business Council, Ecotrust, Sustainable Northwest, Wildlands Inc., Parametrix, Clean Water Services, and the City of Portland (Vickerman, 2009). In 2008, lawmakers began 
crafting a bill, and in July of 2009, Senate Bill 513 was signed into law by Governor Ted Kulongoski. The bill proposes a framework within which lawmakers and stakeholders can craft rules, regulations, policies, and practices that will lead to the development of a comprehensive ecosystem services marketplace in Oregon covering: water quality, habitat and biodiversity, wetlands, and carbon sequestration. Among other things, the bill: recognizes the importance of sustaining rural landscapes and communities, advocates combining regulatory and market mechanisms, calls for more flexible zoning practices that maximize ecosystem service benefits, and acknowledges the need to provide adequate oversight to prevent "double-dipping" of credits.

Finally, SB 513 directs the Office of Sustainability Board to create a task force, the SB 513 Working Group (SB 513 WG), to write a report and present policy recommendations to the 2011 Legislature. The bill furthermore stipulates that SB 513 WG representatives must "be active in improving the ecological effectiveness of ecosystem services markets." SB513 Working Group members include: representatives of federal, state, and local agencies, environmental interests, natural resource industries, farmers, developers and landowners (Vickerman, 2009). The major areas the SB 513 WG is required to address are: implementation (guidance, facilitation, and management of the marketplace); developing a methodology for consistently quantifying ecosystem services in a practical way; establishing consistent evaluation and accounting; clarifying government's role both as regulator and participants; clarifying mechanisms for bundling and stacking; and stimulating 
demand that includes voluntary or incentive-based approaches. The SB 513 WG started meeting in the fall of 2009 with staff support provided by the Oregon Watershed Enhancement Board (OWEB).

The legislative proposal that Defenders of Wildlife, WP, and their partners put together that led to SB 513 was actually part of a larger effort to develop a multicredit marketplace in Oregon. These policy actors and leaders recognized that, given the very market-driven nature of their proposal, legislation alone would not be sufficient. Policy experimentation and development would also have to occur in the private and civil sectors. It was in this spirit of policy innovation that the Willamette Partnership applied for and received a Conservation Innovation Grant from the National Resource Conservation Service (NRCS) in 2007 to develop tools and mechanisms for landowners and regulators that would facilitate credit markets in water quality, habitat conservation, wetland services, and carbon sequestration. The grant also targeted building capacity to integrate these credit markets into a comprehensive marketplace in the Willamette River Basin. With support from the Conservation Innovation Grant, WP convened a group of stakeholders to form the Counting on the Environment Working Group (COTE WG) in 2008 with the explicit task of developing crediting methodologies, protocols, assurances, and tools for quantifying multiple ecosystem services and implementing credit transactions. It was furthermore tasked with developing marketplace pilots which would provide valuable information on what was working or not and why. From the beginning, then, it is clear that WP and its partners conceived of the COTE WG as aiding the 
larger effort to build a case for a comprehensive ecosystem services marketplace. Although the COTE WG predates the SB 513 WG, the COTE WG's work anticipates several areas of concern which the SB 513 WG was later mandated to address, particularly in the areas of methodology, evaluation and accounting, and bundling and stacking credits.

This, then, is the general institutional and policy context in which the COTE WG formed. It can be seen as a policy response to a perceived need to address the accelerating degradation of environmental conditions in the Willamette River Basin. This need was already framed by the long-standing discourse linking natural resources, economic development, and quality of life, but this frame also took an historically particular shape during the late 1990's and early 2000's under the idea of "ecosystem services." Gradually, a coalition of policy actors formed that began to articulate a vision for a comprehensive marketplace that challenged Oregon's environmental governance structure. The comprehensive ecosystem service marketplace idea built on earlier innovations, both within the state and elsewhere, but what made it a policy innovation in its own right was its proposal to integrate different credit markets. The innovation started as a program innovation within ODOT, but was readily adopted by policy entrepreneurs like Vickerman, Gaffi, and ultimately WP.

The ecosystem services policy network took shape around the state-directed Willamette River Basin Initiative, but it was decentralized enough to encourage innovation in thinking about, and experimenting with, ecosystem service markets 
while enjoying critical state-level support. The rich collaborative research environment involving federal and state agencies and universities not only produced valuable data and tools for marketplace development, but fostered a community of practice characterized by a unique blend of political philosophies, technical skills, interests, and policy approaches. This community has secured statelevel support for its policy agenda to establish a comprehensive ecosystem services marketplace in Oregon, culminating in the signing of SB 513, which proposes to change the regulatory and policy landscape in Oregon to favor such a marketplace.

But despite these policy victories, the ecosystem services marketplace remains more an idea than a reality. Serious hurdles to implementation remain, including a bureaucratic and policy culture wedded to procedures and silo approaches, as well as larger socio-economic and political barriers to participation by the private sector. The policy network finds itself at a critical juncture in its history as it seeks to build the institutions that will support a multi-credit marketplace on a large enough scale to make it both effective and efficient. SB 513 and the SB 513 WG represent the spearhead of this effort. But while the network is held together by both strong and weak ties of professional and personal association, implementation of a marketplace will require a more coherent coordination of efforts than has been accomplished to date. One of those efforts is WP's COTE WG. In many ways, the COTE WG serves the policy agenda of SB 513, particularly as a "laboratory" to research, develop, and test crediting methodologies and tools in pilot markets which would eventually be adopted on a larger scale. This makes the COTE 
WG somewhat of a transitional entity within the ever-evolving ecosystem services marketplace policy network, both influencing and being influenced by it.

Because the ecosystem policy network is itself still taking shape, the story of the formation of the COTE WG is therefore a story of change on multiple levels: the ground on which the policy actors have built relations and carried out their work within the COTE WG continues to move. The formation of the COTE WG, then, is a special case of social learning within social learning. This layering of changes presents special challenges for investigating the formation of the COTE WG and requires above all that we clearly define our levels of analysis with respect to one another. By keeping these levels distinct, we will be in a better position to describe and evaluate the different kinds of boundary spanning practices that have shaped the COTE WG as well as the continuing co-evolution of the COTE WG and the larger ecosystem services marketplace policy network. As in the other cases, how we draw the boundaries of partnerships carries implications for our assessment of social learning - who or what is learning and what is being learned? - and partnership capacity.

But a similar condition holds also for the boundary spanners working both within and outside of the COTE WG. Because the network and its vision is still rather loosely defined, the COTE WG has had to learn to define its role within the larger network and manage expectations accordingly. For the boundary spanners this has meant wearing different hats at different times, and it has meant learning when an issue was a COTE WG issue and when it was best handled in another 
context of deliberation. For the COTE WG itself, it has required the kind of partnership capacity to keep itself together for as long as it is needed. Its partnership capacity must be strong enough to produce some end-products but not so strong that those products don't serve the larger policy agenda of establishing a multi-credit ecosystem services marketplace.

\section{Formation of the COTE WG}

From its inception in 2008, COTE WG was a project of WP and its NRCS grant. In many ways the grant-driven nature of the COTE WG provided both much needed structure to existing conversations and a degree of rigidity that continues to pose challenges for policy learning going forward. The original grant ran from July 1 , 2008 to June 30, 2010 and defined for the Willamette Partnership clear objectives, deliverables, and deadlines for the process which the partnership had formulated with its partners prior to submitting their grant proposal. The partnership was anxious not to repeat the mistake they made with the EPA-sponsored process. In contrast to that earlier process, the COTE WG had a well-developed problemdefinition with a clear set of objectives and deliverables which helped to communicate expectations to stakeholder participants.

The project was ambitious: to convene a special working group of stakeholders to develop and agree, by August 2009, to a multi-credit ecosystem services accounting system of credit calculation methodologies, protocols, assurances, and tools that would subsequently be tested in several markets in the Willamette River Basin. The project identified 4 crediting areas of concern: 
salmonids, water quality (specifically, temperature), wetlands, and upland prairie. Pilot-testing would begin in late summer of 2009 and continue for 2 years, with results available in summer of 2011 . The final version of the accounting system, including a web-based platform, was scheduled to be rolled out to the public in early 2010. That said, the expectation was that the pilot projects and the subsequent rollout of the accounting system in the Willamette River Valley would ultimately lead to larger scale marketplaces, covering a larger diversity of credit types (including carbon), in Oregon and elsewhere.

Recognizing the ambitious nature of the grant, its architects were deliberate in designing a process that would ensure the successful completion of the objectives on-time. Staff support was crucial throughout the process, starting with the process design. David Primozich, then-Executive Director of WP, and Bobby Cochran, thenProject Manager of the COTE WG and Market Analyst at CWS, essentially sheparded the process from the beginning. Both men had been actively involved in the ecosystems services marketplace community for a number of years. Primozich had overseen several management planning processes, including the Willamette Subbasin Plan, before helping to found WP in 2004. Cochran had worked on credit markets at Defenders of Wildlife before becoming market analyst at CWS. Their general approach to the COTE WG process was to anticipate and address significant obstacles before they materialized. The numerous judgments that went into the design and management of the process reflected a keen awareness on the part of Primozich, Cochran, and other members of the project team, of what was both 
practically and politically feasible. This appreciation of the policy context had been instilled through their educational trainings and experience working with agencies and other partners in similar market experiments and through their general familiarity with Oregon's environmental politics.

A legitimate concern Primozich and Cochran had was that the COTE WG process would appear to lack genuine participation. This concern applied perhaps especially to government agencies that were inclined to view the ecosystem services marketplace project with skepticism and even some confusion. To alleviate these concerns, WP invited Oregon Consensus, based at Portland State University, to assist them in setting up the process. Oregon Consensus's solid reputation as an impartial facilitator and mediator helped to reassure stakeholders that the process would remain open and fair. Debra Nudelman of Kearns \& West, a consulting firm specializing in facilitation and mediation, was subsequently hired to assist in setting up and facilitating the process. A "Project Team" consisting of Primozich, Cochran, Bartholomew "Mac" Martin, a water resource analyst at WP, Nudelman, her assistant Peter Harkema, and occasionally Bill Warncke of ODOT, began meeting in early 2008. Their first order of business was to identify the categories of stakeholders that should be involved in the COTE WG. These categories covered a range of natural resource agencies as well as private and civil interests. Once these categories were developed, individual candidates were selected. In selecting participants, the Project Team identified individuals who had both decision-making authority in their organization and a reputation for collaborating with others. The 
team recognized that the innovative nature of the project would require a willingness to consider other points of view and to think creatively about integrating those perspectives and concerns in the final set of products. This was especially the case for the regulatory agencies. The natural posture of these agencies is to defend their jurisdictional authorities, and the ecosystem services marketplace agenda was viewed by many as a problematic intrusion on that authority that carried risks of its own. To assuage some of these fears, Nudelman and the rest of the Project Team worked hard to communicate the boundaries of the problem space (especially regulatory) that the Working Group would cover, as one of the Working Group members reports:

There were some very early concerns by agencies, particularly in the regulatory realm. Some of those concerns never went away. They were going to get dragged into this collaborative process that was going to have them give up their regulatory authority, that all of a sudden they would be abdicating their responsibility to others. I think the facilitator - which is another key, that they brought in an independent facilitator so they could participate in the process - helped to really set up sideboards and boundaries to keep that from happening.

Given the general institutional skepticism, the team recognized it was also important that the participants were in traditional leadership positions that would enable them to secure the level of support from their home organizations and constituents necessary for wider scale adoption of the Working Group's products and recommendations. Once again, Primozich's and Cochran's familiarity with the policy community gave them valuable insight into which individuals from which organizations would work well together as a Working Group on this particular project. 
Once the list of candidate participants was drafted, Primozich and Cochran approached these individuals, described the NRCS grant project and its objectives, and asked them to join the COTE WG for the 2-year commitment. Recruitment was certainly facilitated by the fact that most of the individuals who were approached already knew Primozich and Cochran either through previous collaborations or associations or were at least familiar with WP's initiative. Indeed, several Working Group members had at one time or another served on WP's board or on one of its committees. Still, the recruiting process appears to have accelerated as more reputable names signed on. As one Working Group member remarked:

The other thing they did really well was bringing in influencers, bringing in folks who really have an influence in the natural resources arena. They brought in names that brought in other names. I could look at the list as I started to be involved and say, "We have Defenders Of Wildlife and the right person at Defenders Of Wildlife involved. We have people at top levels." You start to look around the table and say, "They're bringing in this level of people, we need to bring in a high level of participation."[...] Particularly for NOAA, I don't think NOAA ever felt comfortable being at the table. NOAA was very concerned if they weren't at the table, that they were going to be on the menu. I think part of what kept the regulatory agencies there is, "By God, we want to know what is going on. They're talking about programs we regulate." That was one of the issues was it's such a high profile that they didn't want to not be present.

NOAA was certainly not the only agency that was hesitant. Even so, agencies are not monolithic, and many of the same regulatory agencies that were wary of the ambitious project nevertheless saw it as supporting many of their own initiatives to innovate in the areas of implementation and compliance. The same Working Group member continues:

The other regulatory agencies, [Oregon Department of] State Lands, [Oregon Department of] Fish and Wildlife, I think those agencies are looking for new 
and innovative ways to implement their regulations. I think from their perspective, DEQ as well, those agencies were looking at it saying, "If this is going to help us do our job better and more cheaply, and more appropriately, we want to be involved in this process, and we want to be sure, just like NRCS does from the technical expertise end, we want to make sure what they're doing is up to a certain standard." That kept them at the table.

Initially, 25 representatives of federal, state, and local agencies as well as of specific environmental groups, farming and industry associations, and municipalities committed to participating in the COTE WG. ${ }^{23}$ Although some representatives have since been replaced, the composition of the COTE WG has been quite stable.

What followed was roughly 6 months of co-designing the process with the participants themselves. Nudelman and Harkema carried out a "convening assessment" consisting of interviews with participants asking them to identify their expectations, as well as potential obstacles for the process, including those related to internal approval processes, and suggestions for addressing them. The result was a set of "Operating Principles" which all agreed to from the outset. The thinking of the Project Team was that by agreeing to these principles before the process got underway, participants were more likely to feel bound by them going forward.

For the Project Team, this preparatory work was critical to improving the likelihood of producing a set of credit accounting methodologies and tools which the

\footnotetext{
${ }^{23}$ The original members of the COTE WG are: U.S. Fish and Wildlife Service, USDA Natural Resources Conservation Services, USDA Forest Service, U.S. Army Corps of Engineers, U.S. Environmental Protection Agency, National Oceanic and Atmospheric Administration, Oregon Governor's Office, Oregon Department of Agriculture, Oregon Department of State Lands, Oregon Department of Fish and Wildlife, Oregon Department of Transportation, Oregon Department of Environmental Quality, Oregon Watershed Enhancement Board, Oregon Department of Forestry, Oregon Department of Water Resources, Clean Water Services, City of Albany, City of Eugene, City of Portland, Cascades West Council of Governments, Institute for Natural Resources, The Nature Conservancy, Defenders of Wildlife, Ecotrust, Mud Slough Wetland Mitigation Bank.
} 
representatives and their constituents would be willing to test. As one of the Project Team members explains:

The other part is we spent a lot of time before we brought that Working Group together, we spent almost six months of meeting to make sure [...] that the right - people were there. We were setting it up in the right way. It was very clear the day that Working Group started and when it ended, exactly what we wanted in the end, exactly how each step was going to proceed throughout the whole piece. We spent a lot of time setting it up to the point some people were saying "get on with it," but I think spending that time was really helpful.

The "Operating Principles" identified fairly specific expectations around the decision-making process which reflected a concern with ensuring a relatively smooth process with minimal surprises. Its statement of expectations covered a wide range of concerns: the objectives of the process, including the signing of an agreement of principles governing a multi-credit ecosystem services marketplace, overall process structure, what constituted consensus, roles of participants, leadtimes for distributing agendas and decision items, meeting preparation, and crucially, keeping home organizations and constituents informed and in the loop throughout the process. A major risk for all the participants was that they would invest precious time and resources only to come to the end of the process and find that other members were unable or unwilling to sign the agreement. Indeed, the very presence of this risk could deter others from participating, as one Working Group member relates:

Some entities just work glacially, and so one of the threats is that at some point the bulk of the group just says, "It's not going to be implemented in a way that warrants the time and money I'm spending involved in this study." [...] I'm soft funded so I go down on my own time and it's very difficult for me to justify that time when I have all this grant funding that is paying for other 
work that is not being done. It's not like any money so much as: if stuff isn't happening it's not a priority, and if I'm having to go to five meetings because Army Corp of Engineers wants to do something but can't figure out how to do it internally, it's really difficult.

To address this, the Project Team and Nudelman made sure that the participants understood their obligations for participating. They recognized that the ambitious nature of the project required clear commitments upfront.

The Project Team modeled their process structure after the largely successful WEM by creating several supporting bodies to the Working Group that represented various inputs: a Stakeholder Coordinating Team; a Policy Group consisting of organizational leaders; a Practitioner Review Team consisting of likely buyers and sellers of credits to provide feedback on the usability of the accounting system and its tools; and a Technology Development Team to assist in the development and implementation of the ecosystem services marketplace. Figure 12 illustrates the structure of the COTE WG process as it was laid out:

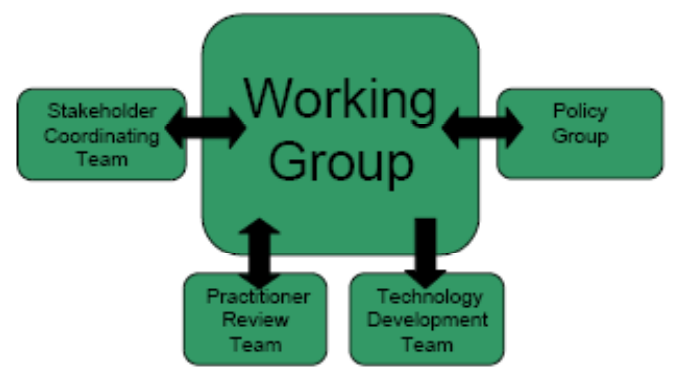

Figure 12: COTE WG Process Structure (Source: http://willamettepartnership.org/ongoing-projectsand-activities/wp nrcs project2pager-11-06-08-2 .pdf, accessed 10/26/10)

Although not obvious from the figure, arguably the most important component of the process was, and continues to be, the Stakeholder Coordinating 
Team. It was tasked with assisting the Project Team in ensuring that the process moved forward by facilitating communication between the Project Team and the overall Working Group. This has enabled the Project Team to anticipate issues before they became a significant problem. The (Stakeholder) Coordinating Team gave input on the process design itself before the larger Working Group convened. Since then, it has provided valuable feedback to the Project Team on agenda items and documents for upcoming meetings as well as on how the Working Group members felt about how the process was going. The individuals that comprise the Coordinating Team continue to act as two-way filters of information and perspectives between the Project Team and Working Group which requires them to make judgments about what types of communications and actions are appropriate and when. According to one Project Team member:

We [Project Team] would meet between meetings, two to three weeks in advance of a Working Group meeting, provide them [Coordinating Team] with a draft agenda, draft technical materials, and say, "Is this enough? Is this too much information?"... That Coordinating Team I think provided a key function of bridging the communications as well as just really being that sounding board where, "This is really strategically what we're thinking, keeping in mind all of the time frames and what we need to accomplish, given that this is what we're thinking in terms of framing up this meeting or that meeting," and using them as, "Does that sound right? Does that make sense? Will that be enough? Are we pushing people too hard? Can we push a little harder? What can we do, if we really need to get here, can we meet independently with this group, that group, because we know they're going to have concerns about X, Y or Z topic?"

In assembling the Coordinating Team, the Project Team made a point of inviting individuals like Cathy Macdonald of the Nature Conservancy and Yvonne Vallette of EPA who were comfortable in both the technical and policy worlds and who were 
recognized for their collaborative leadership. As one Project Team member

explains, these traits applied to all the Working Group members, but perhaps especially to those on the Coordinating Team:

...In starting our process we identified those people we considered first key gatekeepers to various constituents. As it turns out, this should not be surprising. Those gatekeepers are also those people that have vast technical capabilities, but can also operate very easily in the policy world. We created what we called our Coordinating Team. Those are people who do both, who have to manage, by necessity of the work they do, the technical world with the policy world. Those gatekeepers were essential to the process. Those are the people who are the true boundary spanners, the people who can operate really effectively in both worlds.

The Operating Principles included expectations regarding what representation entailed. The grant-driven nature of the project meant that stakeholder participation and therefore representation was more selective. For this reason, participants were asked to only represent their organization and constituents. But arguably the most controversial aspect of process design was the timeline. Many if not most of the agencies and organizations felt that it was going to be very difficult to achieve the stated objectives within 2 years, and there was sufficient skepticism during the initial meetings to nearly derail the process even before it had started. Sensing that participants were beginning to question the project's feasibility, one of the project leads responded quickly by enlisting the help of one of the Working Group members who was widely respected as a collaborative leader:

I turned to one of our gatekeepers, one of the people that was well respected by the various constituents that were there, and asked that person to bring us back home, why we were articulating, why we were doing the thing we said we were going to do. It wasn't because we got a grant and we said we'd 
do it so we better do it. It was because there was a real, clear need that everybody at the table had agreed to. There was one gatekeeper who had the ability to articulate that in a way that made a lot of sense. That person got up, at my request, when it looked like people were saying "Yes but, yes but, yes but..." I turned to this person and said, "Will you please just lay it out there why we're here? Why we have to do what it is we're saying we're doing?" She did. It was just like all the hot air went out of the room and people said, "Okay, we think it's going to be a lot of work and hard, but I'm willing to give it a shot."

It is likely that the project lead's recognition and skillful handling of the issue asking an influential policy leader to articulate the reasons for the COTE WG helped maintain group cohesion at an early stage in the process when that cohesion was still quite vulnerable.

Innovation of Boundary Objects

With the "Operating Principles" in place, the Project Team set to work in the fall of 2008 to develop credit calculation methodologies, protocols, and tools for each of the 4 banking areas (salmonid, water quality, wetlands, and upland prairie). The Working Group convened the first of 5 workshops in late November of 2008 to begin discussing how to develop an integrated ecosystem marketplace. To supplement and inform these discussions, the Project Team convened focus groups consisting of Working Group members and other stakeholders who had technical and regulatory expertise in each of the 4 areas. The primary objective of the focus groups was to build on existing approaches and tools while attending to the specific challenges of a multi-credit platform. During the course of these discussions, which spanned roughly 8 months, the Project Team, Working Group, and focus groups confronted numerous issues, including determining criteria for baseline 
assessments and weighting of credit indicators to account for liabilities and risks related to "temporal loss" of credit values.

The Project Team was able to build on recent innovations in credit calculation methodologies and supporting technologies in the areas of credit registry and project planning and management which provided much-needed legitimacy in the final project products. For credit calculation of wetlands improvements, the Project Team ultimately settled on DSL's Oregon Rapid Wetlands Assessment Protocol (ORWAP), which combines acreage and functional assessment methodologies and was by the fall of 2008 nearing completion. For water temperature, the team adopted DEQ's Shadelator, a credit calculator that quantifies water temperature reduction from shade restoration projects. The team could also draw on the "Synthesis Map" from the WEM project as a resource to identify high value shade restoration projects.

Developing methodologies and tools for salmonid and prairie was in some ways more challenging since there was less innovation on which to build. The focus groups and Project Team had to consider how the various aspects of banking for salmonid and prairie should be integrated across regulatory (e.g., salmon recovery plans) and ultimately ecological concerns. This entailed learning to talk across disciplinary and even linguistic boundaries. Minutes from one of the salmonid focus group meetings captures this dilemma with respect to developing an agreed-uponset of criteria for selecting bank sites:

One thing ODOT did was develop conceptual guidance for the limiting factors in the watershed. Some limiting factors are overall viability of the population, 
conductivity and disease. One concern is that everyone does not speak the same language and don't define limiting factors in the same way which may make them hard [to] determine (meeting minutes from February 23, 2009).

Assuming a common framework could be established, inputs to the tools baselines and limiting factors like population viability - would require information about the specific ecological context of a given site. In the case of salmon, this information is distributed in various databases, GIS maps, and fishery histories among different agencies and organizations ranging from the federal level (e.g., NOAA) down to the local (e.g., watershed councils). All of the tools, but perhaps especially the salmonid and the prairie tools, were going to require a level of information-, but also knowledge-, sharing between agencies and other stakeholders that had not previously existed.

Ultimately, the Project Team drew heavily on ODOT's and Parametrix's work and developed a Salmon Credit Calculation Method that proposed a functions-based methodology (covering 6 functions) that would assign or "release" credits, expressed in habitat-weighted linear feet, for restoration and conservation actions such as habitat improvement and floodplain restoration that benefitted salmonid species. The Prairie Credit Calculation Method measures credits in functional acres of upland prairie based on a weighting methodology that accounts for multiple factors, including a site's contextual value. This "prairie calculator" could then be used to release credits for actions that improved the habitat and survivability of listed species such as the Fender's Blue Butterfly and Willamette Daisy. 
The development of these credit calculation tools for pilot-testing entailed numerous technical and policy judgments that had to be negotiated among the Working Group members, focus group members, and the Project Team, as one the participants explains:

We had to take some shortcuts. I don't think they created any fatal flaws but maybe has handicapped us a little bit. But I still think that's probably just a relic of us having to do this at such a fast pace. I think we had some interesting alignments between the agencies on some of the policy questions. There were some contradictions in policy that had to be discussed. Some of them still need to be discussed.

Indeed, numerous issues with the salmon and prairie tools remain which can only be addressed in real-world policy experiments.

Testing Innovations

The significant level of uncertainty and risk associated with measuring and accounting for credits called for an iterative approach to tool development and testing. Versions of the tools were first tested in the Spring of 2009 in various test sites which were selected by the Project Team, the Coordinating Team, and the larger Working Group in consultation with the focus groups. Preliminary results from these tests were fed back to the each of the focus groups for comments and suggestions which were then incorporated by the Working Group to refine additional field-testing in May. Results of this second round of field tests were then fed back to the Working Group to inform their decision on a package agreement in August. The Project Team and Working Group identified sites that fit the basic criteria of high value restoration, willing participants, minimal regulatory conflicts, and available resources for carrying out the projects. Ultimately, 2 credit projects - 
Delta Ponds and Gales Creek - and one debit project - an ODOT project at Dairy Creek Bridge - were selected.

The iterative process spanned multiple meetings over a period of 8 months in which the Project Team would confer with the focus groups and identify areas requiring follow-up. Time between meetings would be spent collecting data, answering information requests, clarifying agency policies, and sharing information, findings, and perspectives with constituents and home organizations. One Working Group member reflects on the importance of these informal exchanges:

Even outside of our structured meetings in the Working Group, a great deal of behind the scenes discussions happened. It was good. Lots of the time it was done as preparatory work or follow-up work so that we could try to figure out a way to address these in a constructive way in order to move on to the next step.

Time that participants spent debriefing constituents and home organizations also provided an opportunity to field concerns and other relevant information that they could then relay back to the Working Group process. This required exercising some judgment about what was relevant to share and to whom, as one participant explains:

It's a two way communication. You needed the Working Group representatives to meet with their stakeholder groups, but also to bring what they were hearing back to help problem-solve and address the concerns that were arising and that may have arisen. I think that communication happened fairly efficiently and well throughout the process. Representatives would say "It's a great idea." [or] "We're never going to be able to support that. It's just not going to work. We can't be responsible for long term management of a piece of property without some sort of assurances of what that might look like." Each group, I felt, did a good job of bringing those concerns back to the table. It was a key component of saying "This is where the conversation happens. It has to happen here at the Working Group table." 
The sheer number and diversity of stakeholder interactions and inputs happening both within and external to the formal process posed a management challenge to the Project Team. Sometimes there was miscommunication between steps, for example, in reporting out from the focus groups to the Working Group:

I like the idea of the focus groups because they would be much smaller. They would be four, or six, or eight people. There is an opportunity to bear down more on specific parts of issues and return to a topic and work over a topic more than the big [Working] group. Did the information get translated back to the group? Not always. There is always translating. There are always transcription errors and translating errors, particularly if you don't have that background: "I think I heard you say this. I wrote it down and you didn't correct me. Then I transcribed it and I said it to the group." There's a little loss there. Maybe it's all inherent in the process.

With so many parallel processes occurring it was easy for the process to get

side-tracked or stalled at a particular step. One important process strategy the Project Team employed was a system of provisional "agreements in principal" which served to anchor progress at decisive steps along the way, not unlike the anchoring strategy familiar to rock climbers. Yet, the iterative nature of the process also meant periodically revisiting agreements to solve larger issues, with the ultimate goal of developing a comprehensive crediting package:

You do have all the technical information to support a decision but also the non-substantive input, the policy overlays and process overlays that weigh into whether you have all of the information, or sufficient information to move forward. At some level we did utilize "agreements in principle." Getting to a point you made a decision that was good enough for now, pending how, recognizing once you have an agreement on this piece and this piece, and this piece, once you pull it all back together, it still needs to work for everybody. At some level we took a piece-by-piece agreement: "Is this good enough for now? Is this good enough for now?" Then when you got to the final agreement, pulled it all back together and said, "Does the package still work?" 
Obtaining Institutional Support for an Ecosystem Credit Accounting System A major objective for WP and for the Project Team was securing statements of support from Working Group members and their organizational leadership for a package proposal. By the summer of 2009, the Project Team had assembled its "Ecosystem Credit Accounting System" (ECAS), a system of protocols, assurances, and tools, including templates for contracts and procedural documentation, that would enable ecosystem services credits to be traded in 4 different types of currencies corresponding to: salmonid habitat, water quality (water temperature), wetlands, and upland prairie habitat. Obtaining statements of support from the institutional stakeholders was crucial for several reasons. In a more immediate and practical sense, these statements of support removed any legal and administrative obstacles to pilot-testing the system on a meaningful scale. But they also continue to lend the ECAS a certain institutional legitimacy during the current pilot-testing phase when the policy innovation is vulnerable to skepticism and loss of momentum. On August 4, 2009, 25 members of the Working Signed an "Agreement in Concept" supporting the ECAS and its field-testing. A similar "Agreement in Principle" was signed by the corresponding organizational leadership in October of 2009.

As statements of support, in contrast to an official ratification of the ECAS, the agreements provided signatories sufficient exemption from any liabilities or obligations to make them feel comfortable signing, as one of the agency representatives explains: 
It's also helped that we haven't said, "We're going to agree to it all and do everything on this either," because it's still a pilot and we're still developing it. Even though all along I said, "I'm working on this and do everything, but if all of a sudden a red flag pops up and we can't work with this, and Willamette Partnership isn't willing to change it so we can work with it, we can still walk away."

The signing of these agreements represented a significant step forward in the development of an integrated ecosystem services marketplace. The formal process leading up to the agreements lasted less than a year; yet a significant amount of social learning occurred from the time the Working Group first convened until the agreements were signed and pilot markets launched. The social learning occurred at the technical, policy, and social levels, as new tools and policies were developed and new social relations of trust were built. In many important ways, the social learning within the COTE WG process simply built on the social learning within the larger policy network that preceded it. Nevertheless, these agreements were far from assured at the outset and would not have been successfully negotiated without the considerable effort on the part of the participants and the Project Team to challenge themselves and each other to consider other points of view while critically seeking integrative solutions. This boundary spanning took various forms within and outside of the formal process, but ultimately it centered on patiently balancing active listening and critical judgment within a context of policy experimentation and learning.

The COTE WG has not been an unqualified success, however. Four agencies NOAA, USDA, ODFW, and the City of Portland initially did not sign the agreements (although ODFW ultimately did), and there were disagreements that arose along the 
way that remain unresolved. The points of contention in part reflect the immense challenges of assembling an integrated credit accounting system. At the same time, they may also shed light on the important ways boundary spanning facilitates social learning. By critically examining where miscommunication occurred, we may come to better appreciate those practices that serve to enhance communication and coordination of social learning across technical, policy, and social boundaries.

\section{Boundary Spanning and Social Learning in the COTE WG}

What follows is an account of the social learning that has taken place as COTE WG stakeholders have worked to forge an agreement around an integrated ecosystem services accounting system, with particular emphasis on the various ways in which stakeholders have attempted to bridge differences in viewpoints, practices, policies, and ultimately language. Following the present framework, we should expect to find evidence of social learning where boundary spanning practices begin to take a definite shape. Boundary spanning is defined within the framework as any practice or process that facilitates the interaction of actors, ideas, and practices from different fields of practice, as well as the interaction itself. If we furthermore define social learning as the progressive organization of boundary spanning practices for a particular purpose, then we find evidence of several instances of social learning associated with the COTE WG process: the process design, the formation of group norms of interaction, the ECAS and associated innovations, and finally, the framing and organization of the larger policy network. 
Taking the first instance of social learning, the formal organization of the COTE WG process itself, we note that the structure and "operating principles" had to be negotiated and agreed to among the stakeholders before commencing the process. The Project Team certainly spearheaded the effort, guided by the diverse experiences its members brought from previous processes, but the Working Group ultimately had to agree to and abide by it. In cases where substitutes of representatives were later added, the Project Team and Working Group trained these substitutes to abide by the process structure as it was already laid out.

But the COTE WG's process design and “Operating Principles" provided only a general guideline with which to organize the process and in fact do not account for the precise pattern of interactions that were observed. The COTE WG process in fact consisted of a number of moving parts: the Working Group itself, the Project Team, the smaller Coordinating Team, the Policy Group consisting of the organizational heads, the focus groups, the Technology Development Team, and the Practitioner Review Team. In addition, the stakeholder communities that were represented or consulted also figure as "participants" in the process. Within each of these groups, boundary spanning played an important role in bringing together stakeholders from different disciplinary, professional, policy, and institutional backgrounds. In turn, these groups have played various roles within the larger COTE WG process, and the success of that process has depended on the effective communication of information and coordination of actions across these groups. 
This communication and coordination was not trivial. Often roles and responsibilities overlapped between groups or other ambiguities had to be addressed. Certainly communication within and between groups was complicated by language barriers that had to be overcome. As one Working Group participant observes:

Even though it [the COTE WG process] was innovative, it did create some potential for hiccups. The folks that had participated in the technical side were not always represented, or were not - they were represented but they weren't - a full participant in the Working Group. Sometimes the flow of communication within the agencies, or within the organizations between those folks that were sitting on the Working Group and making those policy decisions were different than those representing the technical side.

Miscommunication happened sometimes within those. If there was a way to fix it, I don't know. I can't fix it within even my own agency.

Participants often had to rely on a combination of technical, policy, and political judgments to decide what issues to raise and when, as well as what solutions to propose and when. To use a musical analogy, the process was improvised as much as it was orchestrated. One aspect of the informal nature of the negotiations has been the lobbying and positioning leading up to important decisions. As a Project Team member relates, Working Group members often talk to one another to gauge the level of support before casting an official proposal or vote:

As you know, the jungle telegraph tends to inform that process in a much more effective way than any formal process does. Individuals talking with one another...people calling each other. They say, "I'm really concerned about this. At this meeting I want outcome ZYZ. Are you with me?" That stuff happens on a regular basis.

These conversations involved a certain degree of political judgment that had to be learned in a new context of engagement. This learning happened as a matter 
of course in negotiating the ECAS. Parallel to this negotiation has been what Kolb and Williams (2003) refer to as the "shadow negotiation" of the relationships between the parties in which various claims to competencies, roles, responsibilities, and even identities are sorted out. The informal negotiation of these tacit rules of engagement, which usually entails building trust, is necessary for any social interaction between different points of view to be sustained over time. To the extent that we observe new patterns of interaction among the COTE WG members and their affiliated communities emerging outside of the formal process context we may infer some sort of social learning.

Thus, a major social learning outcome of the COTE WG process has been the strengthening of both personal and institutional bonds of trust among participants of the COTE WG process. One of the participants points out that WP has perhaps been the most direct beneficiary of the process:

I feel like the [COE] Working Group was just the vehicle, it was the base that got the [Willamette] Partnership to do what they needed to do. I think about the Working Group as that was a tool, that was all of us coming around the table, but the product, the thing we're all proud of is the Partnership. The Working Group was great. The Partnership is what it's all about. You're right, most anything I talk about here is the group came together and did the Partnership work. Which is different than the group existing for itself, which is probably different than you'll find with Deschutes and Walla Walla. They exist because they're putting projects on the ground. We existed to get the Partnership projects going and send them off on their merry way.

But the growth in trust resulting from the COTE WG has extended beyond the organizational boundary of WP. This trust has grown as stakeholders have learned about each other's interests but also about the constraints under which they work. 
This has, in turn, required each participant to learn how to listen and ask questions,

as described so well by 2 COTE WG members:

I may not be comfortable with something but I didn't have a solution. I have faith in the people that were leading the project. It's kind of going back to the trust thing where I knew they weren't trying to do things that were going to further push us back in terms of environmental improvement. You needed that flexibility in the Working Group to say, "I'm not comfortable with this, but I also see the benefit to it. It might not be that I understand it right now so I'm going to wait and see." You can't do that all the time. There definitely needed to be the same flexibility in the Working Group. This is uncomfortable stuff. It's something new not a lot of people have worked in. You're talking about offsetting or mitigating impacts to the environment that could be permanent. It's a scary space to be in. [...] When I started working in this area, I really had to change my thought processes and how I approached these things. You can have a healthy level of skepticism but when you're doing the boundary spanning stuff, you really have to get beyond your typical thinking or break down those barriers you might already have that are just part of who you are, your experience, that type of thing... $(105,176,208)$.

It's them getting to know me, me getting to know them personally and professionally, but also just amongst them I think some of the folks they don't deal with on a regular basis, they may have crossed paths before, but now they're interacting with them on a more frequent basis. I think that it definitely has helped relationships and also understanding other agencies' authorities and regulations, more knowledge. If you understand where somebody is coming from, you may not agree with them, but you at least understand. That has definitely helped a lot more with that understanding and knowledge of us as individuals, as members, but also of our agencies.

It is clear from the testimonies of participants that a vital ingredient for building trust has been the capacity and willingness of participants to challenge demands made of them, so long as it was done in a respectful manner. Indeed, this pushback not only provided others with useful information about the speaker's constraints, but it also seemed to communicate a sign of respect in its own right. An observer of the process explains: 
I think they really succeeded in building credibility with each other in that way, in their interests, or their approach of working to address each other's interests while pushing back on each other...It wasn't soft in any way. People feel passionate and strongly about these issues. It wasn't that people gave up and just said, "You can have your way." They pushed on each other and created a more resilient solution for that reason and respected each other all the more because of that.

This increase in trust spurred further disclosure of information about the institutional terrain which led to insights into how to improve inter-organizational coordination around multi-credit accounting. Interviews revealed that both the Policy Advisory Group and the Coordinating Team, because they are somewhat smaller and have met more often, have forged particularly strong working relationships.

The Coordinating Team emerged as arguably the hub around which the process revolved. It is in the Coordinating Team, more than any other group, where the intersection of technical and policy questions is first discussed. As a result, it has played a key role bridging the work of the Project Team and the larger Working Group. As already noted, the Project Team has relied heavily on the Coordinating Team to vet ideas, proposals, and agendas before presenting them to the larger Working Group. This has enabled the Project Team to anticipate issues ahead of key meetings or decision-points, helping to move the process along in a smoother and more constructive manner:

The biggest threat is either in my opinion a key agency either withdrawing, whether it's officially or not, they stop showing up or raising issues late in the game as opposed to early on. Some of that has been managed. The (Willamette) Partnership has tried to call up people, tie up loose ends, make more of an effort to say "You weren't able to come to this last meeting; you didn't respond to these emails..." They pick up the telephone, or they shoot 
you another email trying to get the information from you, whether it's verbally "Hey, let me explain to you what is going on with this..." or "We really need you to read this stuff." So more that one-on-one follow-up if they feel it's important that we need a particular agency's position and engagement.

Indeed, much of the "offline work" between and outside of meetings was carried out by the Project Team and WP staff. To this point, staff support helped ensure timely and consistent follow-through that was crucial in maintaining a steady level of participation and progress:

You'd almost need a diagram to see how it all played out between the small Coordination Team to the Working Group, then to the various focus groups to see how the flow of information came together. Luckily for participants like myself, the Willamette Partnership was the one that was keeping all these balls in the air at the same time. If we had relied on government to do this, it wouldn't happen. It would definitely have dropped a few balls. This was interesting in the fact that the Willamette Partnership had a specific motive with regard to meeting a timeline.

This staff support has made participation in what was already a risky and challenging process easier for representatives who are typically strapped for time and resources. Interview comments suggest that Working Group participants greatly appreciate it:

They would report back and before every meeting. Willamette Partnership would send out a packet of information that people would read through and tell what deliverables there would be, or what to read, or what to be prepared for. Then there would be follow-up afterward with meeting notes, an opportunity to comment on things. Then what the next steps were. They were very communicative throughout the process.

The (Willamette) Partnership did a lot of behind-the-scenes work. A lot of us, we can make the time to show up to a meeting, review some documents, but most of the true footwork was done by Willamette Partnership and their facilitator and their staff. Which really helped a lot of us that are more challenged with time and resources to devote it. We can review some information, show up and provide our input, tell them what we can do, what 
we can't do, suggestions in a day meeting. But again, writing up strawman documents, coming up to [...] meet the logistics of the program, the Willamette Partnership did most of that.

I found it one of the few enjoyable processes to have gone through. I enjoyed working with everyone, including the Willamette Partnership, but also appreciate how much thought they put into the process and what it took to really get the job done. They did a lot of work. In essence that made my participation much easier. I didn't feel as though the work they had done was leading me in any particular direction. You have to have a certain level of information in order to move on. They did the work to bring that information to the table for folks. It was a lot of work.

Interviewees also reported that the facilitation provided by Nudelman and Harkema helped to ensure that they stayed on topic and discussion moved forward in a constructive manner.

Project staff members have participated in nearly all the meetings of the Working Group and the sub-groups, which has facilitated "scanning" for and addressing contradictions or surprises in a consistent manner. Crucially, they have maintained a big picture perspective which has enabled them to prioritize issues and assign them to the appropriate context for discussion. But it is also clear that the relative cohesiveness of the policy network facilitated scanning for and addressing issues before they became more difficult. This monitoring system became more effective as relations formed in the COTE WG process:

You'll have Working Group members step up and say, "I'll go talk to this person," or "I'll go engage this group." You have Working Group members flagging issues, or questions we're getting from the broader stakeholder communities. If the wetland mitigation banking community is having an issue with how we're doing things, [Oregon] Department of State Lands and the [U.S. Army] Corps will let us know that and will invite us to work through those issues with them. I think the group kind of does it organically. There's not a system for doing it. We all have tight enough relationship that 
communication is pretty quick and fast. It's a nice part about Oregon, you can pick up the phone, or you see people around town pretty regularly.

An important source of surprise was the "policy drift" that sometimes developed between the representatives and their home base. This occurred either as a result of significant personnel turnover or representatives failing to adequately keep their constituents or relevant decision-makers in their home organizations in the loop:

People have been good within the group, but not necessarily so good reaching out internally in their organization, and I think it's because we built up all these good relationships there. They don't have those internal relationships, which is really difficult, especially for the larger agencies.

There's going to be a difference between John and Joe, even though they work for the same agency, have similar experiences. So trying to manage that to me was one of the challenges in keeping people part of the team and not letting things go on so long when you didn't hear from them [...] "Did this thing die?

The risk of "policy drift" appears to have been greater for the larger agencies than it has been for the more activist organizations that were involved. For a non-profit advocacy group like Defenders of Wildlife, it is expected that representatives will function as both advocates and leaders of their communities. They therefore carry a certain amount of boundary spanning authority. Representatives of government agencies are subject to a more traditional hierarchy of decision-making. Agencies' predominant defensive or "risk-averse" posture means that more experimental policymaking on their boundaries of competence and jurisdiction are, paradoxically, both less of a priority and a source of concern. More often than not, the initial interest of a government agency entering into such boundary spanning projects is to maintain rather than span those boundaries that would threaten its turf or even 
existence. Complicating matters, agencies often find themselves understaffed with respect to meeting their core obligations.

To be adopted, the ECAS required of course the institutional support of organizational management and leadership. Primozich and Cochran would frequently make visits with the representative to their home base to bring stakeholders and vital decision-makers up to date on the Working Group's progress and to field any concerns. Nevertheless, it is unlikely that the final agreement would have been endorsed by most of the organizational leadership involved in the COTE WG without Working Group members boundary spanning "across" with peers and "up" with authorities and influencers in their home fields, as a representative of a federal agency recounts:

I was at the table but I certainly wasn't just representing myself or just my specific part of the program. The tasks and the framework the Willamette Partnership wanted to address was wider than that. That meant I had to do a fair amount of coordination and communication with the folks up in Seattle that had those program areas. I think the same thing happened with National Marine Fisheries Service [NOAA] in that it served as a catalyst to get the conversation going further up the chain that then allowed, when those upper management representatives came to other forums, for the discussion to continue to happen. Yes, it just helped to open the door and keep the door open on the possibilities.

Interviews revealed that this education and outreach gradually evolved into an informal communication strategy that specified roles for each of the components of the COTE WG process:

The model was set up such that representatives briefed their own interest in the public face. The Working Group itself, all of the representatives never did a public forum, or never went to a Farm Bureau meeting to present something. I think the collegiality and the fact that folks felt comfortable in the Working Group was probably transmitted and communicated to the 
various stakeholder groups. I would say that David [Primozich] and Bobby [Cochran] presented a good, acceptable, and representative public face of the Working Group in reaching out to those different stakeholder groups. They really did the work of spanning those potential gaps.

In addition, the pilot projects have facilitated this education and outreach by providing a concrete context to involve implementation-stakeholders in testing the ECAS.

Often, instances of lateral boundary spanning within an agency or organization have spurred additional policy conversations and experimentations across organizational and community boundaries. These secondary, tertiary, and additional degrees of boundary spanning have taken place in a variety of contexts ranging from informal conversations to conferences and collaborative projects, such as the collaboration between the EPA and USACE in developing a more functionsbased approach to stream mitigation and mitigation banking. More generally, the ECAS and pilots have helped to provide a context for policy discussion and learning. Several Working Group members reported feeling that they could communicate with more confidence and clarity what a multi-credit ecosystem services marketplace might look like.

In some ways, the more important forms of lateral boundary spanning have occurred within coalitions of partially-overlapping interests. The trust and openness within these coalitions has provided a safe entry point for the COTE WG innovations to be discussed and diffused over a wider network of weaker institutional ties. The boundary spanning appears to have consisted of discovering 
and acting on interdependencies in those ties. As the representative of one federal agency explains:

Within this larger group there was smaller factions that have alignment. I think that is where the boundary spanning occurred such as we are in close affiliation also with Oregon Department of Environmental Quality. They have some influence over other resource agencies that are more on the development side, such as Department of Forestry, or Agriculture. In that regard the boundary spanning occurred within these areas of overlap. I think if I draw it out it might be easier to visualize, but it was how you are able to influence.

The diffusion of innovations emanating from the COTE WG to these other contexts was certainly facilitated by the existence of a relatively close-knit professional and personal network of actors working in fields related in some way to ecosystem services markets. An environmental activist involved in the COTE WG process describes an environmental policymaking community in Oregon where people and organizations know one another well enough to routinely call meetings held to discuss issues and projects as they arise:

Oregon seems to be a fairly tight-knit community in terms of keeping each other apprised of what is happening. Sometimes it's just one on-onemeetings. [Environmental organization] for instance will just request a meeting with Oregon Department of Ag[riculture], ODFW, and say, "We'd like to meet with you to tell you about these projects that we're working on," and generate interest and momentum in that manner. Everything we're involved in from my organization's perspective, which includes the Counting On The Environment and the [Willamette] Partnership, is incredibly collaborative.

At the same time it is clear that the COTE WG process has forged new relationships and forms of collaboration which have, if anything, increased the "readiness" of the larger policy network for its innovations. 
Primozich and Cochran seemed to have recognized that the accounting protocols, tools, and supporting framework being developed ultimately had to be validated by a community of market participants. This validation corresponds to what Rugkåsa et al. (2007) refers to as "downward boundary-spanning," in which innovations are communicated to the community of users for testing and refinement to ensure that those innovations are compatible with the local context of implementation. Of course, this downward boundary spanning to some extent occurred naturally within the putatively technical groups since the Project Team had originally recruited individuals who were either likely end-users themselves or were familiar with the technical and policy context within which the credit accounting methods and tools would be used. Moreover, "downward boundary spanning" seems to have been designed into the process in at least two important ways. As already mentioned, the pilot projects have enabled a community of users to test the implementation of the ECAS, while the Practitioner Review Team has given valuable feedback to the Working Group on the usability of its prototype methods and tools. In addition, the various efforts that the Working Group and Project Team members made to reach out to and update home organizations and constituent communities were important instances of downward boundary spanning.

Finally, there is little doubt that the success of the process depended to a great extent on the personalities and charisma of Primozich and Cochran:

A big part of it is the personal passion of the people. A lot of it is personalitybased. You have two guys leading this process who it's really hard to say "no" 
to. They're so excited and so convinced this is going to work. Part of it is their investment and involvement and excitement about it.

Their clear commitment, persuasive message, and dogged determination helped win over skeptics and convince Working Members and their constituents that a multicredit Ecosystem Credit Accounting System was not only important but achievable. It is also clear that, from the start, Primozich and Cochran could also draw on the support of influential collaborative leaders such as Sarah Vickerman and Bill Gaffee who helped them make their case to other COTE WG members. As this confidence was built, COTE WG participants became champions of the project as well, setting into motion the diffusion process described above. A key Working Group member summarizes this process:

It's a snowball effect. You start to get this core group of people having these conversations and all of a sudden an entirely different dialog, Senate Bill 513, or what we're doing in agriculture, with the Forest Service in forestry, you just start to trigger it. If you have the right people in the room, they're going to leave and go back to their agency, and when the right chance comes for an agenda item, or a speaker, or a conversation at the table, if they're good and take advantage of it, you start to feed that information into a bunch of different agencies. I think it's feeding, I would say it's feeding even better now than it was when the group was active, which is again why we had some of the challenges with getting folks to sign on at the end. I think since then, now that this thing is going, there's a lot more conversations going on than there were before because they're piloting, because there is another working group that has been established. It just moves that dialog down the road...You've got this whole set of 26 people running around saying, "We're not going to have a conversation about ecosystem services unless it involves what we came out of the Working Group with." That is how we ended up with Bobby [Cochran] and David [Primozich] on the Senate Bill 513 committee. People said, "You can't have a conversation without having these guys there." That is how you now have people like Sarah Vickerman, who are speaking to groups at the state and national level about what is going on with the Willamette Partnership. That group has ended and it's vested itself back into its own communities to get the word out about what happened and what 
has been developed. It's not formally the group itself. It's the members divesting themselves back into their own communities.

Testimonies of COTE WG participants reveals that policy actors have been quite skilled at capitalizing on the success of the COTE WG process to build a case for a multi-credit ecosystem marketplace. They will refer to the ECAS as a serious proposal endorsed by the major stakeholders in the policy area. They also point to the pilot projects to underscore the feasibility of their proposal. In doing so, so they seek to convert the social and political capital of their products and backing signatures- capital which will be greatly enhanced if the pilots are deemed successful - into institutional legitimacy which will ultimately lead to expanded funding and development:

The other thing we have been trying to do all along is try to make this thing sort of work in other places. When it initially started it was very, very, very focused on the Willamette. Bobby [Cochran] and David [Primozich] both have realized that in order to make this thing work, both from a funding perspective and other things, they have to move broadly. They have first been expanding other areas in this state. Then in the region we've been working with partners to try to expand it across the country, both using our network with Nature Serve and other Natural Heritage programs, but also with the federal government related to their creation of their new ecosystem services office [Office of Environmental Markets] in USDA.

From the inception they brought together the right people. They had the right agencies, the right organizations. They can now say, and they consistently say, "We have 26 or 28 organizations that have signed off and endorsed this thing." You walk that off to other folks and they say, "Wow," like I did when I sat down at the table: "You've got some players here." They've got players who have signed off. So you walk to a Conservation District. Or you go to another state, or you go to Eastern Oregon and say, "Here is what we did and who supported it." They have a lot of street credibility from that. They message it well. I told them at one point in time the same thing I told you: there are only three entities in the country I know of who are even going down this road. They say that constantly: "We're one of only three in the country. We're doing it this way." They've got this marketing down. They message appropriately. At the end of the day, a snake 
oil salesman can do the same thing. If they have a bad product, you know pretty quickly. At the core of it they have a quality product. They have tested it. They invested a lot of money. They went for a lot of grants to actually get the right product. You can't just BS your way through marketing and get people to do something if you don't have a good product to deliver.

Furthermore, it is clear that the COTE WG process is a vehicle for a nascent coalition of policy actors to promote a multi-credit ecosystem services marketplace. A Working Group member and prominent actor in this policy coalition relates how she has drawn on WP and the COTE WG process to tout the promises of an integrated ecosystem services marketplace:

They have enough notoriety that, for example, I spoke [...] on a panel for ecosystem services a couple of week ago. [...] As a result of that conversation, [U.S.] Forest Service had a National Leadership review a couple of weeks ago and added "ecosystem services" as an agenda item. I don't think they would have had it on their agenda before. I think a lot of that level got raised as well. We've had Willamette Partnership come and speak to our technical advisory committee, which is made up of Ag groups, state and federal agencies, so we can get them more informed about the process. They have done a good enough job that a number of us are using them to spread the word about ecosystem services to our constituents.

Another instance, then, of social learning is occurring at the larger policy network level and centers on reframing environmental restoration and conservation in terms of integrating ecosystem services. The COTE WG process established a new working framework on which subsequent policy conversations and experiments are already building. Several Working Group participants separately used the metaphor of class level to allude to this policy learning:

For example we have Senate Bill 513 Working Group. It has about five members of the Working Group [Coordinating Team] also on the 513 Group. They have so much experience with these markets, having gone through the Counting On The Environment process, that when they talk at the [Senate Bill] Working Group, they're talking at a level way past 101 on that stuff. I 
think that is a result of their experience. They can bring that experience with them to various other conversations. When people start talking about alternative methodologies, or verification, or registration, you have this core group of people that say, "We have been through this. This is what makes sense. What do you think? Do other people think that?"

While this reframing of policy conversations was catalyzed by the COTE WG process, it is more properly understood as being coincident with the emergence of the ecosystem services marketplace policy network itself. Along with the reframing has been a corresponding reorganization of policy fields with distinct collaborations and role definitions. Testimony from participants suggests that the COTE WG process has contributed significantly to this reorganization by enabling the stakeholders to negotiate their respective spheres of competence, influence, and authority in the new context of a multi-credit ecosystem services marketplace:

There's different decisions and different parts of this where different people are on first. In that sense the [Working] Group is fairly deferential in some ways for a given decision about really who is lead on it. There wasn't any formal piece, it just happened as people got to know each other. In some ways the boundary spanning was knowing when to step back and let someone else make a decision.

The crystallization of new norms of engagement has extended beyond the COTE WG to encompass various formal and informal contexts of policy development. The collaborative experiments in stream mitigation banking between USACE and EPA is just one example of Working Group members and other stakeholders taking their own initiatives to test notions of what is both feasible and desirable in ecosystem service markets:

You see some of those conversations spilling over into how to go about doing mitigation better for road projects or other things. I think you see, particularly among [U.S.] Army Corps, EPA, and [Oregon Department of] 
State Lands representatives, a tight knit subgroup forming there, which is nice to see. How that has evolved, I think it had the wetlands crowd coming into the first meeting, the upland broader conservation crowd, you had the water quality crowd, and then the fish streams crowd coming together. When we started off it was like, "In wetlands it's like this; in Endangered Species it's like this; in water quality we do it this way." How that changed is: "How do we take what our individual mandates are and put it into one that is a much broader focus and shift as we started going onto making the one?" You started seeing people talking in those terms.

I think the nice thing that has come out of this is other entities can see where their role is. While we're struggling with how does this actually look in the real world, OSU is now stepping up and saying, "We're going to do a study on how we get those aggregators together, how we set up ecosystem service districts. We see this concept and we like it, but we see a really big hole with people who can be the go-between between the buyer and the seller." They're stepping in and they're going to apply for a grant to really research that and figure out how it works. They wouldn't be having that conversation if they hadn't been part of the Working Group before.

Nowhere is the influence of the COTE WG on the larger policy network more apparent than in the SB 513 Working Group, whose primary concerns center on developing overarching policy goals of an integrated ecosystem services marketplace, clarifying the role of government, and identifying legislative opportunities. The membership overlap is striking, with 15 of the 26 Working Group members also participating in the SB 513 WG process. Moreover, the 513 WG is in many ways formulating the policy implications of the ECAS developed by the COTE WG. While the SB 513 WG was a legislative creation formally unrelated to the COTE WG, interviews revealed that key policy actors, including Sarah Vickerman, had a hand in ensuring that the two working groups would complement each other's work, as one of the boundary spanners participating in both working groups notes:

Fifteen of them [COTE WG members] have ended up on the Senate Bill 513 Working Group which is helping to implement what the Working Group was 
doing, so it's helping to scale up, setting the policies, setting the statutes, setting the framework in place to do the vision these guys had. That was not on purpose. It wasn't like the Working Group said, "OK now we have to form a policy group." The policy group with the governor and the legislature were formed totally independently of this working group, although Sarah [Vickerman] was stitching it together nicely.[...] It [COTE WG process] changed the dynamics of our policy conversation; our subsequent policy conversation is much better and much richer because many of us went through that first dialog with the Willamette Partnership.

The social learning of the larger policy network is arguably concentrated in the alignment practices between the Coordinating Team's work (particularly the pilot projects) and the SB 513 WG's higher-level policy work. The communication and coordination between the two working groups enables policymaking to be grounded in the practices and tools being developed while the final recommendations of the Coordinating Team in 2011 will be informed by the SB 513 WG's own policy findings. A key policy actor explains that this coordination improves the likelihood that the ECAS and associated tools will be adopted:

Every member of the (SB 513) Interagency Review Team is on the Working Group. In fact all of them are on the Coordinating Team. They are the key implementers of this process. If we move into the Counting On The Environment process as state policy, they will be the implementers. They're not going to inform the implementers; they will implement.

The efforts underway to develop an integrated ecosystem services marketplace simultaneously entails building an adaptive policy network of actors capable of asking and answering relevant questions bearing on the adaptive management of such a marketplace. This same actor describes how the policymaking around ecosystem services markets is decentralized, with numerous "working hypotheses" being tested in various policy experiments: 
I think the Working Group's innovations have given people the confidence they can do it. I think as other people start to do it, they will put together these processes and these protocols in a different way, which I think is healthy and appropriate for the development of nascent market activity here. I think it's important that we try multiple working hypotheses. It's probably a much better route than a command and control system at this point. How this spreads, I think there's a lot of people who are interested in not necessarily replication but building on the work that has been done here. I don't know. It will be interesting to see in the next couple of years what groups in the Pacific Northwest and other parts of the country begin to work toward this.

Just as important as the formulation of those working hypotheses has been the development of roles and responsibilities that organizes the social learning. On a very general level, at least, it would appear that much of the learning around operations and implementation of an integrated ecosystem services marketplace is clustered around the COTE WG and its members while many of the strategic and even constitutional questions are being primarily addressed by the SB 513 WG. Finally, the COTE WG Coordinating Team facilitates a kind of conversation between operational, strategic, and even constitutional concerns, at least through 2011, when the COTE WG officially dissolves. After that, it is less clear how social and policy learning will be coordinated. However, WP has emerged as a leading candidate to act as a third-party manager of a multi-credit ecosystem services marketplace, at least on a regional level (LaRocco \& Vickerman, 2007).

All that said, the road to social learning in the larger policy network has been uneven and is far from complete. Institutional change comes slowly and is often met with great resistance. For one thing, the cultures and practices of many agencies, including NOAA and DSL, remain biased against the kind of off-site mitigation 
envisioned in a robust ecosystem services marketplace. As one participant

observes, the transformation of attitudes and relationships at the Working Group level have not necessarily translated to larger-scale changes in institutional policy, culture, or relations:

I think the agencies have gone so far as when they're talking about ecosystem services, they're going to use this model [Ecosystem Credit Accounting System]. Yes, from that perspective when we're talking specifically in that realm, the Senate Bill 513 Working Group used the exact same model the Willamette Partnership did and the exact same facilitator. The downside is I don't think it stretched to the other natural resource conversations that are going on. Those conversations, it is still operating the way it used to operate where you fight over regulations, state regulations versus federal. I think in a year or two you'll start to see it feed into other conversations as well. I don't know if it has quite yet.

One of the surprises that the COTE WG has had to confront has been resistance from mitigation bankers who are concerned that the new credit accounting rules would result in losses to some of the investments they have made in restoration and conservation. In particular, many farmers view an ecosystem services marketplace as an additional layer of regulatory intrusion that creates more risks than it does opportunities. In the end, the USDA representative in the Working Group, Dave Wilkinson, did not sign the Agreement in Concept endorsing the ECAS. In retrospect, this resistance from bankers is perhaps less surprising, given the difficulty that the Project Team and the Working Group had in reaching out to landowners in general, and farmers in particular, as one of the Working Group members observes:

When we talk about ecosystem services, whether it's this group or the Senate Bill 513 Working Group, I think the voice that isn't as effectively heard is the voice of the people they're planning to do this work on their land. In part this 
group needed to form around the regulation, and they needed to form around the technical, setting up the right systems. I think they ran into a challenge that when you set up the right systems, [when] you don't necessarily have those strong agricultural producers on board, you're going to run into some challenges. At the end, in part maybe because they didn't build that as well up front, at the end they had challenges with Department of Agriculture not wanting to sign off on the agreement.

The USDA represents a large constituency of landowners whose participation or at least support will be critical to the success of any integrated ecosystem services marketplace. WP has been able to funnel some EPA funding to work with the NRCS to reach out to farmers and educate them on the proposed crediting protocols and tools. But farmers, like many landowners and developers, remain wary. Despite the sincere attempts by WP and the COTE WG to provide clarity around a concrete proposal, numerous questions about accounting and assurances remain which can only be addressed through policy trial-and-error. This creates somewhat of a chicken-and-egg dilemma for those seeking to foster a wider adoption of the new accounting approach.

The COTE WG faces several important hurdles to wider adoption of its ECAS. Of course, as mentioned, much will depend on the outcome of the pilot projects. Pilot results will be used by the Working Group to modify the ECAS as needed. Gaining the support of farmers, developers, and other landowners will depend on the ability of the Working Group to address ease-of-use, liabilities, and other concerns in those pilots and in the modified accounting system. In addition, some interviewees felt that promoters of the new approach will need to do a better job of reaching out to the developers and other landowners who would buy credits to 
offset planned impacts. As already noted, much of this education and outreach will center on downward boundary-spanning.

In addition, COTE WG stakeholders will need to continue to work with agencies like NOAA that remain skeptical of an experimental accounting system's ability to help it meet its minimal regulatory requirements. Where many landowners and bankers see precision, some regulatory agencies perceive a liability stemming from rigidity. Discussing the problem he sees with the salmon tool, one agency representative notes the difficulty in developing precise accounting of ecosystem services that change over time:

Streams are really dynamic. Maybe you were there and it was a wet year, or a dry year. There were floods. You thought you measured everything but you didn't measure that well. I thought there was a bias toward this analytical static classification approach and not something that would make a leap to something that would be more relevant to me, something that would go after a scale idea in a different way, or interconnectivity ideas in a different way that would be simpler and a little more dynamic, somehow not as labor intensive, not as transactionally intensive, but I wasn't successful in supporting that. "Let's analyze it to death" kind of carried the day. The thing they came up with was much more analytical.

The representative's comments also reflect a frustration that, from their point of view, the development of the salmon tool was merely building on Parametrix's earlier work rather being open to new approaches:

That was an approach that seemed to me that had already been tried and hadn't really worked out. We had our small work group and that was reintroduced and hashed over again. It wasn't productive. Instead of it being a real opportunity to try some new ideas it was, "We're going to rehash this; can we get some support?"

Indeed, several Working Group participants who were interviewed felt that the COTE WG process was in some ways driven by WP's own agenda. But the more 
common sentiment was that WP and the Project Team had done an excellent job of creating a fair, inclusive, and open process:

I think the Willamette Partnership has been very careful to try to be inclusive as we continue to work on things and not to run the risk of imposing their will without input, or something that would be contrary to another agency's policies or rules.

I'd have to commend, back to the Willamette Partnership and their facilitators, trying to keep things on a professional level, and keep things moving, and making sure they maintained a high respect and professional atmosphere with all of us. If somebody had something to say, they were given the opportunity to convey that to the group.

Sometimes when you have those collaborative groups come together, you have groups that are at different places in the process. You have people that are versed in this stuff every day. They get it. It's easy. They understand it. You have other people that are still trying to get their head around the concept. I think that they did have to do some shift through the process in how they were going to approach some things because of that feedback. They were very adaptive throughout the process, which I thought is critical because then people feel like they're listened to. [...] I thought they did a good job of that.

Summarizing this discussion of social learning in the COTE WG, the formal process design and "Operating Principals" which the Project Team and the Working Group members developed certainly provided a framework that organized interactions among a diverse set of stakeholders. In this respect, they are direct evidence of social learning. Second, alongside the formal rules of engagement, Working Group members and other stakeholders participating in the process had to collectively negotiate more tacit rules governing interactions both within and outside of formal meetings and discussions. Gradually, the participants have developed a sense of judgment about what topics are appropriate to raise in which context and when. This judgment is itself dependent on there being a certain degree 
of trust that communication is relatively undistorted by hidden agendas, that information and perspectives are being shared as claimed.

And finally, we find evidence of social learning in the formation of a policy network organizing itself around the development and management of an integrated ecosystem services marketplace. Perhaps the most concrete evidence for this is the development of the Ecosystem Credit Accounting System. The crediting methodologies, protocols, assurances, and models that comprise the ECAS can be thought of as boundary objects, that is: social-technical innovations that embody and reinforce new patterns of social interaction bringing together different fields of practice, in this case: the buyers and sellers of novel credits and the intermediaries that facilitate, credentialize, and monitor their exchange. Furthermore, the ECAS has provided a new framework with which to organize subsequent policy conversations and experimentation, particularly the pilot projects and the SB 513 Working Group's ongoing policy formulations. Nevertheless, our description of social learning at the network level would be incomplete without considering how this reframing has itself both precipitated, and been facilitated by, a corresponding reorganization of institutional roles and relations. As policy conversations and experiments have assumed greater focus, problem areas have become more clearly defined, and institutional actors are stepping in to address them. The "division of policy labor" is certainly more improvised than it is scripted, since the statutory and other policy reference points on which this division depends continue to evolve. Yet, a picture is already emerging of a new joint field of practice at the policy system 
level, complete with its roster of players and processes, which will influence the negotiation of roles and responsibilities going forward.

Now that we have documented the major instances of boundary spanning and social learning in the COTE WG process, we are confronted with a problem about how to classify them. The complication arises from the fact that it appears that the emergence of the COTE WG coincides with the emergence of the larger policy network. Our theory of convergence starts with boundary spanning practices and an institutional ecology and proceeds to map their convergence; they are inputs of the model. But in the case of the COTE WG, the 2 convergence processes - one centered on the emergence of the COTE WG and the other centered on the emergence of the policy network to which it belongs - are related. We have, in other words, no clear baseline against which to measure convergence. Our case study concerns the COTE WG so our account of its formation must take care not to include processes strictly associated with the formation of the larger policy network. Otherwise, we falsify our explanation by treating processes of different orders as if they belonged to the same order. To take one example: should we interpret the observed convergence of policy thinking and practices between the COTE WG and the SB 513 WG as evidence of the formation of an as-yet-not-fully formed "COTE WG partnership" or as evidence of the formation of a regional ecosystem services policy network to which both working groups belong, as just 2 of many "working hypotheses," as one of the interviewees characterized it? In the first interpretation, the boundary spanning between the groups amounts to Social Learning I (i.e., 
formation of a particular joint field of practice), whereas in the second, the boundary spanning practices are the objects of selection and organization of a still more complex instance of Social Learning I.

This dilemma points to a limitation in the methodological framework. According to it, social learning can only be classified "after the fact," as it were, that is, in terms of the partnership capacity that it produced. Once we can ascertain a pattern of boundary spanning practices, we have a stable system-level-of-reference against which to classify social learning and the boundary spanning practices associated with it. The problem in this case is that until the convergences are complete we have no clear criteria for assigning boundary spanning and social learning to the various bins in our general typologies. Still, while we may not be able to definitively classify the boundary spanning practices and social learning associated with the COTE WG process, a preliminary assessment of the increasing capacity of both the COTE WG and the ecosystem services policy community to organize their respective boundary spanning may nevertheless shed some light on the 2 related social learning processes.

\section{Assessing Partnership Capacity of the COTE WG and Larger Policy Network}

From the standpoint of Mandell and Steelman's (2003) typology of interorganizational processes, the COTE WG is a temporary taskforce operating within a larger network structure. In the more limited sense of the taskforce, it would appear that the COTE WG is accomplishing its stated objectives to produce and test an integrated ecosystem credit accounting system. To do so, it has had to 
organize a process that coordinates diverse activities, perspectives, and objects of knowledge such as models and other tools. In addition to the formal process design, there is evidence that norms of engagement have already begun to form among the Working Group members and "supporting actors." But because the COTE WG is not yet completed as of this writing, it is not possible to determine whether in fact the COTE WG has the capacity to complete its task, that is, has Partnership Capacity Type I. It is the temporary nature of taskforces like the COTE WG that their PC I status can only be assessed after the fact. Their transitory and problem-focused nature also means that they can never have any higher level of partnership capacity.

But we have also seen how the COTE WG process has spawned new institutional ties of trust and cooperation that extend beyond the formal process and which will be critical to the successful implementation of its products. The larger network structure is still taking shape, as policy actors continue to define the problem domain and their respective roles and responsibilities within it. The ECAS and pilot projects are giving policy deliberations a sharper focus, and it is clear that the innovations associated with the ECAS have already begun to influence larger conversations and experimentations. As this influence increases, the COTE WG process has accrued a certain degree of cache which Working Group members are beginning to strategically employ for their own projects and programs.

However, WP and the COTE WG have in a certain important sense been a victim of their own success, for while the process' cache has facilitated diffusion of its innovations to wider policy circles, this diffusion has in some ways begun to 
dilute that cache as elements of the ECAS have been applied to contexts somewhat

at odds with their original intention. One of the project leads points out the dilemma of promoting the adoption of COTE WG's innovations while protecting the "brand" of COTE WG:

As soon as we got our agreement, one of the initial threats to it actually is people would pick different pieces of the whole package of metrics and processes and call it "Counting On The Environment," or hint that it might have been subject to this Agreement. We were very narrow with the scope of what we asked people to agree to. So when people picked different pieces of it, it started making some of the agencies nervous. At the same time, it's kind of the reality if you have an innovation and it's better than something else, people want to try and bring that. The balance is saying, "We want the innovation disseminated as widely as possible. We do think it's better. People should be using it." But at the same time being true to that agreement to test it, and also to protect the brand of the Counting On The Environment standard of if you say "Counting On The Environment," it means something explicit...

In addition to concerns over legitimacy, there has also been the concern that if marketplace experiments were not made subject to some kind of standardizing process, it would be difficult to achieve the kind of scales needed for marketplaces to work. As one of its members relates, the SB 513 Working Group was formed in large part to prevent this fragmentation of policy learning:

What [the SB 513 Working Group] did was encourage agencies and organizations to work together as they build these markets for ecosystem services. The premise behind it is, "We're really concerned that there is a lot of momentum gaining around these markets." We were worried agencies were going to get hold of something and run with it without consulting everyone else that has been working on this for a long time in the state.

To the extent that boundary spanning facilitates standardization of innovations, we may presume it plays a central role in the SB 513 Working Group's work. 
Our framework proposes that innovations of a joint or partnership field can be thought of as boundary objects that hold value to the extent that the boundary spanning practices they embody are valued by a larger community of practice. The implication is that PC I partnerships have established some system of capital exchange in which forms of capital, be they "local" or "non-local," are converted into alternative forms in a way that generates value. Given this, the struggles of the policy network to regulate the uses of its innovations suggests that the network has not quite stabilized as a partnership field. This conclusion is supported by the simple observation that, to date, no wide-scale integrated ecosystem services marketplace has been established in the Willamette Valley or in Oregon. Certainly the successful establishment of such a marketplace would require a multi-sector partnership having what the current framework classifies as PC I.

\section{Conclusion and Recommendations}

When we compare the social learning occurring within the formal COTE WG process and the social learning associated with the reframing and reorganization of larger policy fields, we find at least some evidence of convergence in which the institutional relations are beginning to mirror one another. The SB $513 \mathrm{WG}$ process has adopted many elements of the COTE WG process, including Nudelman's facilitation, and there is significant overlap in the membership between the 2 groups. Even more important than the convergence of formal processes has been the convergence of informal processes and relations. For one, the COTE WG process has strengthened ties between certain agencies that have spawned collaborative 
efforts like the EPA and USACE's joint work on developing a functions-based instream mitigation program. We also find evidence of the kind of capital exchange that the framework theorizes drives such convergence. The NRCS grant provided the seed financial capital to fund the COTE WG process which, in turn, generated social capital in the form of trust, teamwork, and boundary spanning competencies. These competencies were ultimately embodied in a set of agreements, processes, and tools which have generated, among other things, the political capital to influence larger policy and legislative processes to favor the diffusion of these innovations. Finally, policy actors have shown a willingness and an ability to tap into the institutional legitimacy of the COTE WG process and its products - a legitimacy which will be enhanced by the successful conclusion of the pilot projects - to secure additional funding for the development and expansion of integrated ecosystem services markets both in the Willamette Valley and beyond.

Nevertheless, the co-emergence of the 2 joint fields of practice complicates our analysis of the formation of the COTE WG. Some of the boundary spanning we observe that are associated with the mutual adjustment of the COTE WG and policy efforts in other contexts may or may not, properly speaking, be a part of the formation of the COTE WG. Until the larger ecosystem services policy network is established, classification of these boundary spanning processes remains tentative at best. 
Table 4 summarizes the various boundary spanning practices that were observed in the COTE WG process. The table's structure follows the methodological criteria contained in Table 2: Typology of Partnership Processes." 
Table 4: Boundary Spanning Practices in COTE WG

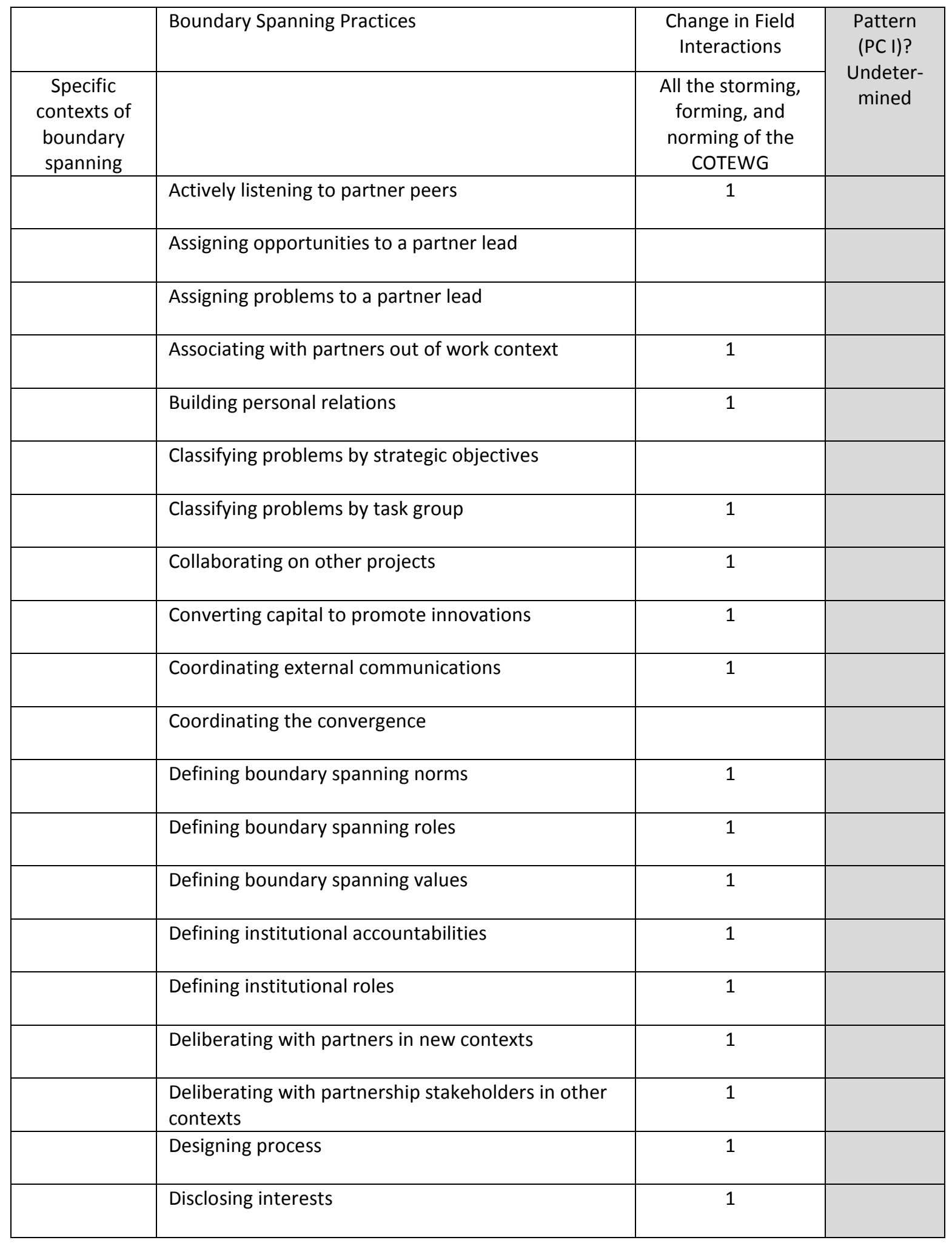




\begin{tabular}{|c|c|c|}
\hline & Education & 1 \\
\hline & Extending favors to partners & \\
\hline & Facilitation & 1 \\
\hline & Framing innovations in terms of need & 1 \\
\hline & Framing need in terms of innovations & 1 \\
\hline & Influencing across policy sub-networks & 1 \\
\hline & Innovating (paradigmatic boundary spanning) & 1 \\
\hline & $\begin{array}{l}\text { Integrating boundary objects/innovations } \\
\text { (standardization) }\end{array}$ & 1 \\
\hline & Making government rules and regulations & 1 \\
\hline & Managing process (budget, conflicts, surprises, time) & 1 \\
\hline & Outreach & 1 \\
\hline & Pilot-testing innovations & 1 \\
\hline & Pitching to decision-makers & 1 \\
\hline & Prioritizing problems & 1 \\
\hline & Protecting brand/integrity of innovations & 1 \\
\hline & Respectfully pushing back (disclosing constraints) & 1 \\
\hline & Ritually enacting boundary spanning & \\
\hline & Scanning environment and reporting issues & 1 \\
\hline & Seeking input from relevant constituents & 1 \\
\hline & Seeking input from relevant decision-makers & 1 \\
\hline & Sharing risks & 1 \\
\hline & Staff collaborating across organizations & \\
\hline & $\begin{array}{l}\text { Staging group decisions (lobbying, building } \\
\text { readiness, gauging support, vote counting, timing) }\end{array}$ & 1 \\
\hline & Strategically aligning partnering organizations & \\
\hline
\end{tabular}




\begin{tabular}{|l|l|c|c|}
\hline & Task-mastering & 1 & \\
\hline & Testing ideas/Vetting & 1 & \\
\hline & Translating across technical/disciplinary boundaries & 1 & \\
\hline & Translating between task groups & 1 & \\
\hline
\end{tabular}

As far as the larger policy network is concerned, we find evidence of Social Learning I (SL I) as the network continues to develop a community of practice around an integrated ecosystems services marketplace. To do so, it will need to expand the original vision of the NRCS grant to articulate a coherent statement of values and principles that will organize otherwise disparate conversations and experiments under a unifying framework. Constitutional questions, however, cannot be addressed separate from these conversations and experiments but rather through them in an iterative process of convergence. For example, the seemingly pedestrian question of public financing of banking activities carries implications for the role of the state in such marketplaces. Similarly, the crediting tools leave many questions unanswered, such as how to assess baselines and compensate for such things as "temporal loss." The innovations associated with the ECAS are challenging state policy and even law. In turn, the policy responses of the SB $513 \mathrm{WG}$ and others are redrawing the boundaries for subsequent marketplace experiments.

The convergence of the COTE WG innovations and the larger policy community that must occur in order to establish a multi-credit ecosystem services marketplace is to a large extent driven and mediated by exchanges occurring between the COTE WG Coordinating Team and the SB 513 WG. It is in these 
exchanges of findings and recommendations, conversations, and questions that much of the mutual adjustment between local experimentation and policy and statutory framing is taking place. WP and the COTE WG have also begun converting the institutional legitimacy and success of the COTE WG process into alternative "currencies," including grants, which are used to promote the continued development and adoption of their innovations. But it is also clear that policy actors are also taking initiatives of their own to drive the ecosystem services marketplace agenda, sometimes in directions somewhat at odds with the intentions of its original architects. Concerns voiced by prominent leaders in the policy network over the misuse of the "COTE WG brand" are more than about a name. The stakes involved center on nothing less than the organization and standardization of a new joint field of practice on which an integrated ecosystem services marketplace will depend. 


\section{Chapter 5}

\section{Regional Water Providers Consortium}

\section{Background}

The Portland Metropolitan region (2002) covers an area of 462 square miles spanning the states of Oregon and Washington, 7 counties, as well as 23 municipalities, including Beaverton and Hillsboro on the west side of the Willamette River, Gresham on the east side of the river, the City of Portland spanning the river, and Vancouver, WA on the north side of the Columbia River. As of 2010, the population of the metropolitan area was over 2.2 million (Portland State Population Research Center). The Bull Run watershed, draining from the Cascades to the east, supplies much of the region's drinking water, and is renowned for its pristine water quality. Perceived threats to this quality has at times been a catalyst for intense citizen mobilization that has led to numerous legislative acts over the past century to protect the watershed from timber harvests and other activities that might negatively impact that quality. These efforts culminated in 1996 and 2001 in the Bull Run Act which features a unique agreement between the City of Portland and the U.S. Forest Service to cooperate in the management of the watershed and its resources. But the region is blessed with a diverse range of water sources, including the Tualatin and Trask rivers to the west and the Clackamas River to the east. There are numerous ground water sources, as well, including the Columbia South Shore Well Field, an aquifer located under the confluence of the Willamette and Columbia Rivers that is Oregon's largest supply of municipal ground water. As of 1996, there 
were roughly 26 surface and groundwater sources being tapped, including the 4 major ones. These supply sources provided an estimated delivery capacity of 413.8 million gallons per day (mgd) with an estimated usable storage capacity of 11.4 billion gallons. At the time, regional water supply was sufficient to meet the region's peak-day demand of roughly 370 mgd (Water Providers of the Portland Metropolitan Area, 1996).

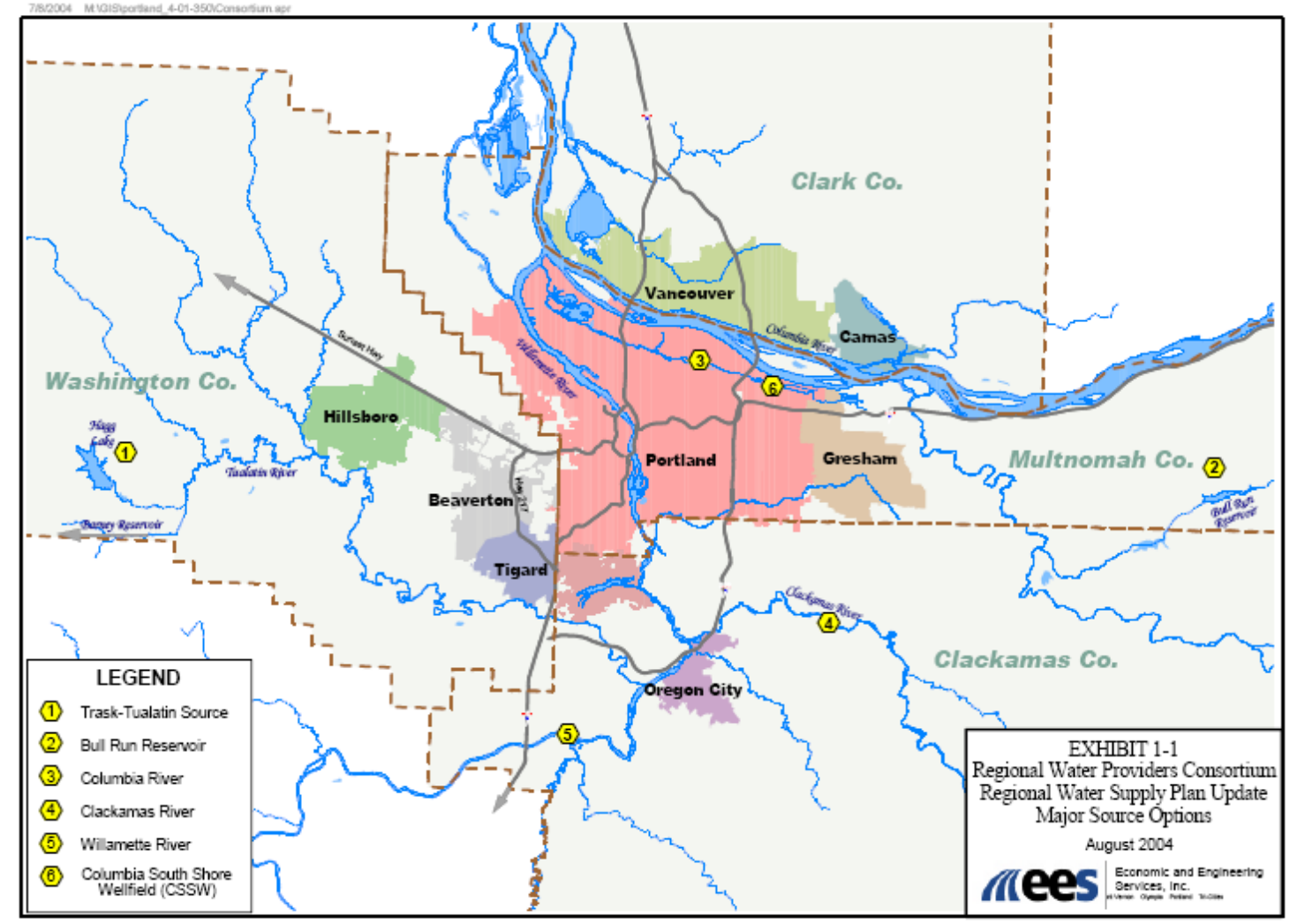

Figure 13: Actual and Potential Drinking Water Sources of the Portland Metropolitan Area in 2004 (Source: Regional Water Providers Consortium)

Perhaps in part because of this supply abundance, by the late 1980's, water supply in the region was largely feudalistic and fragmented. There were roughly 65 
water suppliers, including 27 major ones, comprised of cities, public utility districts (PUDS), and other special water districts, serving, at the time, a regional population of 1.5 million people. Figure 14 is a map of the major water providers, as of 2010.

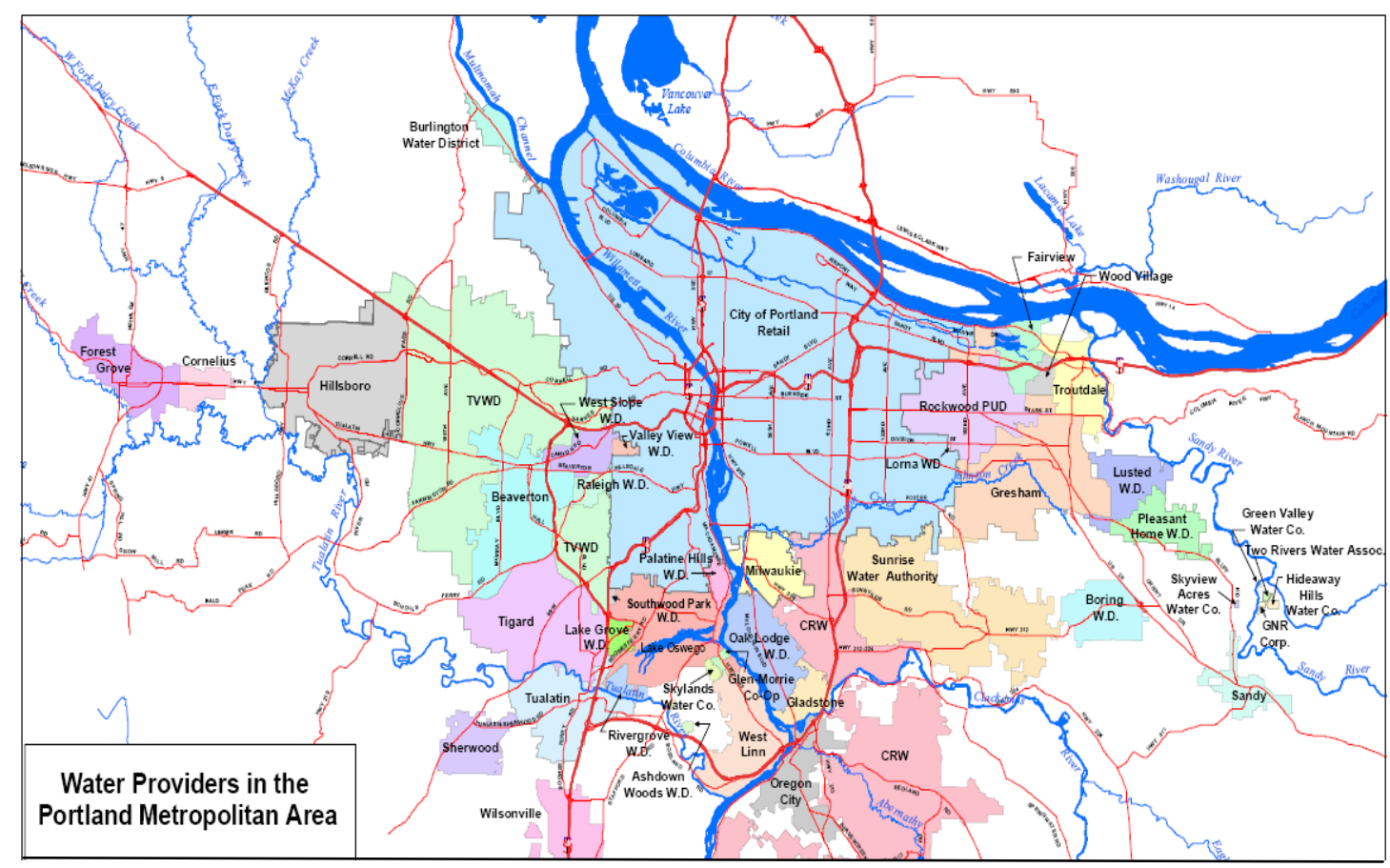

Figure 14: Water Providers in the Portland Metropolitan Area in 2010 (Source: Regional Water Providers Consortium)

Each was governed by a body of officials ranging in form from city councils and commissions to boards that were elected by local rate-payers. Water suppliers owned and operated facilities largely independent of one another, even though many bought Bull Run water from the City of Portland as wholesale customers. Political scientists have noted that politics has become local, and certainly by the 1980's, water had become framed as a local issue in the Portland Metropolitan 
region. Rate payers, citizen activists, neighborhood associations, and advocacy organizations like “Citizens for Safe Water," “Citizens Interested in Bull Run," and "Friends of the Reservoirs" demanded local control of water sources, and suppliers defended their turf vigorously against encroachment, real or perceived.

In many respects, the localism was a form of resistance to what was widely perceived by many surrounding communities and suburbs to be Portland's unjustified dominance within the region. Portland had been the center of political and economic power in the region for decades, which created a fair amount of resentment in surrounding communities that felt beholden to Portland's demands in a wide range of policy areas. This general condition of dependence certainly framed water politics and likely colored the interactions between the Portland Water Bureau (PWB) and the many cities and districts that bought Bull Run water from it. Over the years, Portland had come to regard itself as the rightful owner of the coveted source. Portland began selling water through wholesale contracts as early as the 1920's. The first formal 25-year contracts were signed in the 1970's, and many wholesale customers complained that the terms were often onerous. On a more interpersonal level, several interviews with current and former water provider officials and staff reported that directors of the Bureau had for a long time treated their counterparts with an air of arrogance and disrespect. Many of the more public stories recounting Portland's treatment of wholesale customers had become political fodder for advocates calling for greater local control of water supply. "Citizens for Safe Water," for instance, ran a R. Gregory Nokes' article from 
the Oregonian recounting Tualatin Valley Water District Board President Jim

Duggan's recollection of one such run-in with the City of Portland:

Duggan said, for example, that former Mayor Frank Ivancie once dropped a proposed contract in front of his Beaverton counterpart, demanding "Take it or leave it." (The Oregonian, September 13, 1999).

With privileged access to Bull Run water, widely considered the best quality water in the region, the City of Portland appears to have had little motivation to negotiate the terms of the contracts.

But the increasing resentment among the surrounding cities and districts also reflects shifting expectations that coincided with an increase in the economic and political influence of surrounding communities. Demographically, the suburbs were by then growing faster than Portland, introducing changes in the political dynamics within the region. These demographic movements also brought with them shifting tastes that increased demand for local control over water sources. While many water suppliers were still buying Bull Run water from Portland by the late 1980 's, there was a growing drive to tap alternative local sources, largely in an effort to alleviate their dependence on Portland.

The precise form that this localism assumed, however, varied between the two sides of the river. The east side, especially Clackamas County, was plagued by feudal disputes that fragmented water supply. Starting in the late 1980's, several municipalities split off from the Clackamas River Water District (CRWD) to escape what they viewed as excessive rates and general mistreatment by the CRWD. The schisms resulted in several new water suppliers, including Oak Lodge Water District 
(OLWD), Happy Valley, Demascus, and Gladstone, the latter 3 of which would later form Sunrise Water Authority (SWA). A legacy of this revolt was the addition of a fourth intake and treatment plant on the Clackamas River, with 4 intakes all within only a few miles of one another. In 1997, SWA joined with Oak Lodge WD to form the North Clackamas County Water Commission which also expanded service to the City of Gladstone. But even after these consolidations, today there are 5 surface water intakes on the Clackamas associated with: the City of Estacada, Clackamas River Water, North Clackamas County Water Commission, South Fork Water Board (Oregon City and West Linn), and the City of Lake Oswego.

The west side was a different story. Companies like Intel and Nike provided not only a stronger economic base but supported a culture of relative affluence that struck a markedly different tone with respect to water. Residents in Washington County, especially, were willing and able to pay a premium for good drinking water. It appears that this affluence, combined with resentment toward dependence on Portland's Bull Run source, provided a political opportunity for sub-regional cooperation among water suppliers on the west-side. As the region's second-largest water agency, the Tualatin Valley Water District (TVWD), based in Beaverton, emerged during this period as a leader in the sub-regional effort, which also included Forest Grove, Hillsboro, Tigard, Tualatin, and Wilsonville, to diversify water supply. A centerpiece of this effort was a campaign to tap the Willamette River for drinking water. TVWD sponsored water quality studies attempting to alleviate public concerns that water treatment would not be sufficient to address 
human health risks stemming from decades of industrial and municipal pollution of the river. The campaign drew stiff resistance from Portland and Metro, both of which eventually rejected the Willamette source option in a regional vote on the matter in 1995. Nevertheless, it appears to have galvanized sub-regional cooperation on the west-side. The Joint Water Commission (JWC) was an Intergovernmental Agreement (IGA) originally formed by the cities of Hillsboro and Forest Grove in 1976. Motivated in part to prevent forfeiture of its $130 \mathrm{mgd}$ state water right to the Willamette River, the TVWD joined the JWC in 1994. Then-TVWD manager Jesse Lowman spearheaded an effort to find partners to develop a Willamette source, and the Cities of Beaverton and Tigard subsequently joined the JWC. The resulting alliance eventually developed sources from the Tualatin, Trask, and Willamette Rivers.

The campaign to diversify water supply on the west-side, while rooted in a sub-regional resistance to Portland dominance, ironically planted the seeds of a regional cooperation in water supply between the City of Portland and local water suppliers. For one, the JWC provided a kind of model for the formation of the Regional Water Providers Consortium (RWPC). On a more substantive level, the Willamette source controversy influenced the way policy discussions around regional water supply were framed. The campaign to source the Willamette helped raise awareness around the region's vulnerabilities stemming from what its proponents considered to be excessive dependence on Bull Run water. But it also helped establish the conditions for its formation, in part by supporting the TVWD as 
a counterweight to the PWB's regional dominance in water supply. Although the water quality studies of the Willamette were criticized by some - many of the studies were carried out by firms like Montgomery Watson Americas Inc. that were likely to benefit from contracts to develop a treatment plant - they convinced enough rate-payers, outside of Portland at least, that there were credible options to buying Bull Run water. The respective bargaining positions of the various water providers were beginning to shift. Just as importantly, regional water supply was being reframed to emphasize diversification of sources rather than enhancement of the Bull Run source. And rooted as this reframing was in the local and sub-regional resistance to Portland hegemony, the diversification of water sources began to carry political connotations around gaining independence from Portland. A discourse of "regional water supply" was beginning to form that was premised on the strength of local and sub-regional partners. Thus, while a nascent sense of regional cooperation in water supply was beginning to emerge, many factors limiting the extent of that cooperation were already in place.

The sheer number of water providers in the metropolitan area presented an immense challenge, but there were also barriers that prevented mergers of water providers. Some of them were legal. Mergers required the approval of the Oregon legislature and the Boundary Commission, and this process could be cumbersome. Although Portland did absorb several water districts as it expanded eastward during the 1980's, many cities were also reticent to annex abutting districts, for fear of losing their flexibility in tapping water funds for other needs. An additional 
barrier to regionalization of water supply was the preponderant participation of municipalities in water supply. Municipal administration of water supply and treatment, by its nature, tends to politicize water, greatly complicating any efforts to integrate water supply planning and management on a regional scale. This is the case even in Portland, where the commission-form of government is designed to limit more provincial political influences. Finally, the proliferation of surface and ground water sources greatly added to the technical complexities of water supply in the region. When one considers the interaction of technical and political interdependencies, the complexity of the problem represented a formidable barrier for regional water supply planning and management.

Against this backdrop came the regulatory and demand drivers that pushed the region's suppliers to consider working more closely together. Updates and stepped-up enforcement of the Endangered Species Act and the Clean Water Act in the mid-1980's began to put pressure on cities and districts to upgrade water supply (including storage and transmission) facilities. Many of the water providers, especially the smaller ones, were not likely to be able to afford the upgrades. But even Portland was going to need sufficient rate-payer and voter buy-in to finance any improvements to the Bull Run system, including building a filtration plant and/or $3^{\text {rd }}$ dam. Another regulatory driver was the updating of Oregon's statewide land use planning law (SB 100) granting Metro the authority to do water planning and administer water provision. Many local water providers, particularly the special utility districts, viewed the authorization as a direct threat to their existence, 
but many constituents also feared tax levies. At the state level, the Oregon Water Resources Department (OWRD) was, by the 1980's, beginning to impose greater restrictions on obtaining and extending unexercised water rights, signaling to cities and districts that they were going to have to learn to do more with less. The Portland Metropolitan region was beginning to experience significant growth, increasing demand for water even as additional supplies were becoming less readily available. By the late 1980's there was a growing sense of urgency within the region's water supply community to coordinate planning and management before it faced a water supply crisis. The preponderance of common threats helped the community coalesce around a sense of shared fate even as any regional identity remained subordinated to local and sub-regional interests. Ironically, the increasing strength of local providers gave them sufficient confidence to overcome their concerns for Portland dominance, at least enough, to start thinking about regional cooperation.

\section{Formation of the RWPC}

Spanning River Spanning Visions

By the late 1980's there was therefore growing awareness, even readiness, for the need for better regional coordination in water supply planning and management. Given its historical prominence, it was natural that the actual initiative should originate in Portland. City Commissioner Mike Lindberg's hiring, in 1980 of Ed Tenny as Administrator of the PWB in some ways served as the spark that set this readiness into motion. 
It was Tenny, more than any other person, who first formulated a vision for what a regional coordination of water supply might look like. By accounts, he envisioned something like a regional water supply authority that would own and operate a water supply system on a regional level. Although precedents could be found in institutional experiments like the Metropolitan Water District of Southern California, the San Diego Water Authority, and, later in Colorado, the Metro Water Conservation, Inc., they were relatively scarce, particularly in Oregon. Building the vision would mean overcoming significant institutional and public skepticism.

Tenny recognized along with Lindberg the importance of improving Portland's relationships with Portland's wholesale customers and set to work reaching out to local providers with a new tone of mutual respect. His outreach efforts were significant. He made numerous visits to his counterparts like Lowman and Charles Harrison, General Manager of the Clackamas River Water District (CRWD), as well as with mayors and other elected officials, slowly establishing bonds of trust and even friendship. These relationship-building efforts by Tenny and his successor Mike Rosenburger established important conditions for the formation of the RWPC, especially in raising the profile of district managers whom city managers traditionally tended to dismiss. There were a number of personal bonds that proved especially important. Tenny soon became acquainted with Gene Seibel, a charismatic figure who helped build the TVWD up from the Wolf Creek and Metzger Water Districts and who later served as President of the AWWA. Seibel's 
involvement proved important for promoting regional water supply thinking, as a former manager observes:

Seibel created TVWD and was a really insightful big picture guy. He was perfectly capable of setting aside his self interest and saying, "I think this is a better way of thinking about the region, whether it puts us out of business or not." He was really the only one that was. He was such a leader from the wholesale customer group that he could bring people along. We made a fair amount of progress for a while largely because of that.

Tenny also began working with Gary Cramer, who headed what is now Clean Water Services (CWS), and Dale Jutila, who worked at the PWB before heading the CRWD. These men, especially Seibel, Cramer, and Jutila, all shared Tenny's vision, and their friendships began to link water supply policy on both sides of the Willamette River. In addition to these executive officers, it appears that middle managers played a key role in promoting regional coordination in water supply planning and management. This included facility engineers and operators like Van Burris, Water Plan Superintendent for the JWC, who was especially influential in convincing his counterparts in Clackamas County to join the effort. Removed as they were from the political vagaries of water politics and ensconced instead in the daily operations of the system, these engineers and operators, more than most others, could see the need for greater regional coordination. Indeed, not only were they familiar with the daily conditions of local operation, they were more likely to move around the system throughout their careers assuming positions and responsibilities that spanned the many aspects of the regional system. Along the way, they built a social network of professional and personal relations, and their loyalties tended to reside 
with the system, as opposed to a particular administration, professionally but also personally.

Nevertheless, the ambitious nature of regional coordination required someone of sufficient stature and visibility like Tenny to launch it, and Tenny, Seibel, Lowman, and Jutila were especially instrumental in getting local water suppliers to come to the table. Lowman and Seibel, in fact, had participated a few years earlier in the negotiations between the JWC and PWB to build a 60" gravity-fed pipeline connecting the Bull Run system to Washington County. The Washington County Supply Line Project, completed in 1983, set an important precedent for regional cooperation, and showed some skeptics, at least, that Portland could be a reliable partner in water supply. On the east side, Jutila was a factor in getting the eastside providers to come to the table by, among other things, reassuring them it wasn't just a Portland ploy to continue dominating regional water supply. Jutila saw that his board was at least receptive to the idea of more regional planning and then pitched it to them. They also presented the idea to some of their neighbors like Sandy. Thus, board members of local providers such as the Clackamas County Water Providers Board of Commissioners were also important in some cases in backing the efforts of Jutila and others. But it seems fair to say that middle-managers like Van Burris helped pave the way for these lobbying efforts through their own version of lobbying, although there is no evidence the lobbying was coordinated.

Summarizing, it would appear that the collaborative leadership of especially Tenny, Seibel, Jutila, and later Rosenberger was critical in building support for the 
idea among the region's water provider managers. Much of this leadership, it appears, depended in turn on the persuasiveness and charisma of these individuals. But it seems also likely that as the social network of managers developed from a network of loose professional ties to stronger bonds of trust and even friendship, the commitment among managers for regional cooperation increased, which in turn, increased the effectiveness of their message to recruit other managers.

These early conversations coincided with a policy discourse centered on "integrated water resource planning" (IWRP) that was beginning to influence the larger water policy world. The concept of IWRP states that water resources are multidimensional, encompassing physical processes on multiple temporal and spatial scales. Its calls for addressing water demand through a combination of proactive measures, including conservation, that head off the need for more expensive solutions. More robust notions seek to integrate physical processes with economic and social processes. The American Waterworks Association (AWWA) and its research foundation arm AWWARF were carrying out studies of IWRP around the same time as these early conversations, and many of its strongest proponents were active in the influential Pacific Northwest Section (PNWS) of the AWWA, including Jutila and Seibel. As the region struggled to address the looming water supply shortage, many of these leaders saw IWRP as a framework with which to organize discussions of greater regional cooperation. Still, at the time, IWRP was a largely untested concept, at least on the scale envisioned by Tenny and others conducting an IWRP in the Portland metropolitan region would be a true policy 
experiment. Eventually, these informal conversations assumed a more formal shape. The PWB organized a series of meetings around 1990 to discuss developing a regional water supply plan using an IWRP approach. The meetings were facilitated by Tenny and Jutila, among others. This group of managers eventually put together an IGA between 27 of the region's water providers to form a Regional Water Providers Advisory Group (shortened to RPAG), charged with commissioning, funding, and producing a regional water supply plan. Interviews with observers of the process at the time also suggest that elected officials of the various municipalities and districts were eventually able to secure the support of Metro through such channels as the influential Metropolitan Policy Advisory Council (MPAC). Metro signed the IGA to join the management of the RWSP.

Integrated Water Resource Planning Process

The planning process fell into two phases. The first phase, completed in 1992, consisted of carrying out a regional inventory of water source options and estimating future demand. But when the RWPAG suggested that the Willamette River might serve as a source option for drinking water, the public and political backlash was significant, particularly among Portland residents and organizations like "Citizens for Safe Water" that feared compromising the quality associated with the Bull Run drinking water. The Willamette source option bore the hallmarks of the TVWD and the JWC and represented a compromise of sorts with the PWB, but the ensuing controversy nearly split the uneasy partnership within the RWPAG. In the end, local political pressure, from Portland and Metro especially, moved RPAG to 
drop explicit reference to the Willamette River as a source option. The backlash was so strong, in fact, that the Portland City Council eventually adopted an ordinance passed with the future Consortium IGA - that identified Bull Run as the City's primary source. It was the first of several political controversies over water supply sourcing that would eventually temper the ambitions of policy actors promoting a regional water supply authority.

The second phase of the IWRP began in 1991 with the development of a Regional Water Supply Plan (RWSP) to supply the region's water until 2050. The plan was ultimately adopted in 1996 by the 27 major water providers in the Portland Metropolitan Area, and Metro was also a signatory. Overseen by a steering committee co-chaired by Rosenburger and then-Hillsboro city manager Tim Erwert, the planning process itself seems to have strengthened ties among the different water providers. The regional source water and demand studies were jointly commissioned and paid for by the water providers comprising the RWPAG. The studies were ambitious in scope and cost, costing the participating water providers $\$ 2.2$ million in capital or donated staff-time. The planning process therefore entailed a significant degree of risk-sharing among the water providers, as a participant of the process recalls:

I think some of the unique aspects of that was it was all trust-building. It was all about involvement, and stakeholder involvement. They all had a stake. They were all paying. They all had a say in how these studies were going to be done. We went through this bidding process and we used a scope for a regional water supply plan to come up with a budget. You really didn't have a clue how much this was going to cost. 
The successful completion of these studies, on-time and on-budget, therefore represented an important early success in collaboration and bolstered the water providers' confidence in their capacity to work together on a significant scale.

But the planning process was also important for producing a staff infrastructure centered on staff time donated by the PWB that would provide an important model for the future Consortium. Lorna Stickel, a former Multnomah County planner who was hired by the PWB in 1990, led a small team of staff, organized around a RWPAG Subcommittee, in managing the contracting and reporting. It was through this core staff work - first in the context of RWPAG and later under the Consortium - that the PWB was able to establish itself as an organizational, if not visionary, leader in regional water supply planning.

Designing an Implementing Entity

The Regional Water Providers Consortium (RWPC) was formed largely from the recognition within the RWPAG that there was a need for a body to implement the RWSP. This decision marked a decisive movement away from the conventional one-off planning that had characterized much of planning and closer to adaptive management that takes into account the changing social, economic, and political contexts of implementation. Erwert was one of the members to propose the need to form a more durable planning and management entity. Furthermore, managers like Erwert were concerned the implementation of the ratified plan would entail numerous political decisions that the RWSP could not anticipate. After some 
discussion among the managers, it was decided that such a group would require the participation of elected leaders representing the various cities and utility districts.

While placing elected officials on the Consortium board fostered conditions for a decision-making body that could lead in regional water supply policy, such leadership never really materialized. One of the visionaries involved in the early design of the RWPC argues that elected officials were brought into the design discussions too soon, before its architects had had the chance to develop a more detailed proposal to which the officials could respond. Without a robust proposal framing discussions that identified sideboards and relevant issues, the resulting uncertainty led water suppliers and their legal counsels to raise issues about all sorts of possible transgressions, real or imagined. According to him, the talks got lost in the weeds of turf politics:

You can't get elected officials involved in things like that. You have to give them a package they can react to one way or another. Elected officials are terrible at making sausage. They're great at eating it, but you don't ever let them make it.

As a result, we find evidence that, from the very start, the board of elected officials felt more beholden to their local constituents than they did to any vision behind the RWSP. Thus, the IGA reflects a preoccupation with ensuring equality and fairness among the providers. An internal document that was circulated to the respective boards of elected officials of the various water suppliers outlined the reasons for joining the RWPC. In it one can discern an "expansionary" frame emphasizing the mutual benefits of joining while playing down any references to 
potential costs or risks. As one of the PWB staff members involved in the formation explains:

The thought was that the Consortium could help when it was asked. It was agreed upon that the things they were going to do were beneficial, not getting in people's ways. The idea was that sub-regional efforts were probably much more likely.

It was especially important to its architects that the RWPC not appear as an instrument of the PWB and Portland to dominant the other water providers. This preoccupation with equality and fairness, or at least with maintaining the appearance of equality and fairness, tended to limit the vision of the RWPC to procedural matters and program outputs that could be more easily verified, as opposed to regional outcomes that were both more difficult to assess and fraught with political risk. The staff member continues:

Because every time you go to a council or a government and say, "Pass this," an IGA under ORS190 is very much the same as a contract so it gets the same kind of scrutiny. All of them have their legal people, whether they're consultant legal or their in-house staff look at these. We knew we couldn't do this unless it was all identical; they had to be the same. That took months to get through that process.

The architects of the RWPC appear to have been driven to a large extent by political pragmatism, taking pains to make the IGA palatable to local constituents in order give the RWPC the best chance of being adopted. This pragmatism extended to the language of its resolution, which used the weaker term "endorsement" rather than "adoption," which would have been more binding and, its designers feared, therefore more difficult to pass. This decision seemed to be driven by a recognition, 
resignation even, that regional water supply planning and management was going to continue to be driven by local interests.

In some ways, this was an accurate assessment of the state of metropolitan water policy at the time, and it would appear that the realistic approach taken by the early architects of Portland's regional water supply planning and management helped increase the likelihood that the RWSP would be accepted and implemented. Indeed, it appears that many of the smaller providers saw the RWPC as perhaps their best opportunity to limit Portland's regional dominance. As a manager of a water district on the east side points out:

Portland is perceived as the big gorilla in the room that nobody wants to wake up. That may even have been part of the initial reason for various members to join and participate, if for no other reason than to neutralize Portland.

An IGA was drawn up specifying a board of elected officials representing the participating water providers, along with an executive committee, a technical committee, and a technical subcommittee. A separate staffing IGA was also drawn up specifying that the City of Portland would provide staffing for Consortium functions. Over the course of 1996 and early 1997, the IGA was endorsed by 26 of the 27 entities on the Oregon side of the metropolitan region. The exception was Troutdale, which decided its wells gave it sufficient ground water supply to obviate participation in regional coordination and the risks (real or perceived) that that entailed. Concerned about the potential conflicts between Oregon's and Washington's water laws and policies, the Washington state entities of the metropolitan region, Clark County PUD and the City of Vancouver, opted not to join. 
State boundaries proved too significant. Regardless, the RWPC obtained the minimum signatories to enact the IGA by early 1997 . With a self-funding and administrative mechanism in place, the RWPC began its fiscal year on July 1, 1997.

\section{Boundary Spanning and Social Learning in the RWPC}

Final Push for a Regional Water Supply Authority

Although many of the institutional conditions that limited the RWPC's scope and reach were already in place by the time it formed, the election and appointment of Eric Sten as Commissioner of the PWB in 1996 paved the way for one more push to make the Consortium a robust regional water authority. Tenny was introduced to Sten through a mutual friend in Washington, D.C. and asked Sten for political backing in the effort to regionalize water supply. Sten was initially enthusiastic, and soon started working on a vision of a regional water supply agency that would own and manage the Bull Run system to meet the region's water needs. Sten's expectation was that local water providers would be willing to help fund the agency's expansion of the Bull Run system, including construction of a $3^{\text {rd }}$ dam, in exchange for the coveted water, but he seems to have underestimated the political volatility of water supply. For one, local providers and their rate-payers equated an expansion of the Bull Run system with increased economic and political dependence on Portland. During this time, in fact, the TVWD and its partners continued their campaign to build a water treatment plant on the Willamette River. The TVWD hired Kevin Hanway, a former lobbyist, in 1996 to spearhead the campaign, and he eventually organized local water providers interested in sourcing the Willamette 
into a group called the Willamette Water Supply Agency. Tenny, who was by then working as a consultant, actively supported the idea, helping the TVWD get a pilot plant to determine whether the treated water would meet safe drinking water standards. Lowman also became an outspoken advocate for the proposed treatment plant. Testifying before the TVWD board in July, 1999, he argued that the plant represented "a window of opportunity to solidify Tualatin Valley Water District's role as a leader in the industry in this area" (Oregonian, September 13, 1999). Eventually, the TVWD and the Cities of Tigard, Tualatin, and Wilsonville approved plans for a $\$ 92$ million state-of-the-art treatment plant on the Willamette River. When Sten, backed by Portland-based advocacy groups like "Citizens for Safe Water," challenged the city councils' decisions, the Consortium found itself in an awkward position. Many of its members were irked by what they saw as Sten's heavy-handed approach. The matter went before voters in ballot measures in Tigard, Tualatin, and Wilsonville. As one Consortium board member recalls, it was a tense time for the RWPC as it waited to see which way the public would vote:

I think really what happened was everyone was waiting to see if Portland and Eric [Sten] could really control water politically. If you can control it politically, you can functionally and physically control it...The hard part is getting everyone to agree with what you want to do. The technical, physical part is easy. I think everyone was holding their breath to see what was going to happen. Once we saw them fail, we all spoke in Wilsonville's favor: "This is Wilsonville's choice; it's not Portland's choice." Once we saw the people really able to overcome Eric's involvement, then we thought "Okay, there is some sense about this."

The referenda on the Willamette treatment plan were also a referendum on Sten's vision for a regional water supply agency. When Wilsonville voters approved the 
bond measure to build the plant, many observers, including those within the Consortium, sensed that the political tide on regional water supply was shifting decisively to local control. Not surprisingly, it was a pivotal moment for the Consortium as well, as the board member continues:

That [referendum] came a breath away from disintegrating the whole Consortium. The Consortium looked at it as the City of Portland trying to dictate who is going to drink what water and when. It doesn't sound like that big of a deal in real life. In politics it was a huge deal. It was a huge loss for Eric Sten when Wilsonville voted and in fact did build a plant. It was a huge loss politically for Eric. He thought he had the power politically to stop it. He didn't. That came very close, a lot closer than a lot of people think...

Framing Regional Water Supply in Local Terms

Emboldened by their victory at the polls and sensing a political opportunity, 12 of the local 27 water supply agencies - Beaverton, Gresham, Portland, Tigard, Tualatin, Clackamas River Water District, Clean Water Services, Rockwood Water District, Powell Valley Road Water District, Sunrise Water Authority, Tualatin Valley Water District and the West Slope Water District - came forward to propose a variant of Sten's vision: instead of jointly owning and managing the Bull Run system, the region's water providers could pool their diverse water rights into a regional agency. Since these water rights covered not only Bull Run, but also the Clackamas, Tualatin, Trask, and Willamette rivers, such a proposal effectively diversified water supply for the region as a whole. Sten came out in favor of the proposal, and the group of agencies soon organized under what they called a “Regional Drinking Water Supply Initiative," which included several public hearings on developing criteria for the proposed regional agency. But here too, it seems Sten 
underestimated the political backlash, this time from his own constituencies, many of whom wanted to protect their Bull Run drinking water from being pooled with other sources, especially the Willamette. Others balked at the notion, at the time still only in development, that the proposed agency's board might be appointed rather than elected. Sten's political capital was further diminished when Rosenberger became embroiled in an accounting scandal at the Bureau that ultimately forced him to resign in 2001. Around this time, many wholesale contracts also came up for renewal, and these one-on-one negotiations, which spanned a 4-year period between 2002 and 2006, tended to distract attention from bigger picture issues. The vision of a regional water supply agency soon lost political momentum and was never realized.

It would seem, then, that the fierce localism of water supply politics in the Portland Metropolitan region posed boundaries that proved daunting enough, at least, to frustrate plans for a robust regional water supply agency. But this assessment is only half of an explanation, since it begs the question: what boundary spanning did take place that helped to shape the RWPC into the partnership that it did become? Part of the answer can be found in the constitutional design of the Consortium, where we find that an abiding concern for nominal equity and consensus imposed certain limitations on the organization's ability to experiment and innovate. Instead of creating a regional water supply agency, the IGA preserved the independent authorities of local providers to carry out their own planning and management of water supply. Significantly, local providers retained their full 
authority to own and operate their facilities; no such authority has been given to the Consortium or similar entity. Furthermore, the IGA states that each board member receives one vote. The one-member-one vote rule has helped to mitigate undue influence that Portland or even the TVWD (the second largest provider in the region) might otherwise have while giving smaller providers a significant degree of leverage, both individually and as a coalition, to influence regional water supply policy. In addition, the IGA lays out a dues structure that assigns dues based on current and projected demand for water. ${ }^{24}$ Both of these measures have the effect of instituting a policy of equity and fairness among the providers. Other clauses were written in as well - pushed by the provider's respective lawyers - to protect providers against liabilities from activities. This had the effect of reducing risksharing and therefore the need for trust.

Convergence of expectations

On a less formal though equally important level, the board members have embraced a consensus-based culture. Although majority rules are observed if necessary, every effort is made to achieve consensus on decisions. Over time, this has meant that the Consortium tends to avoid especially contentious issues. Initially, this meant Consortium officials avoided issues that would divide their constituencies. But as the Consortium evolved and its members developed bonds of friendship and trust, their "local" interests and identities became increasingly tied to the fates of one another and to the Consortium as a whole. Board members also

${ }^{24}$ The growth portion of the dues structure was removed in an IGA amendment in 2004. 
recognized early on that they were more likely to influence larger regional and state policy questions if they could present a united front. It would appear, at any rate, that the RWPC slowly built a reputation as a regional water supply planning and advisory group that Metro and the state could refer to on issues ranging from planning to compliance. For these agencies, the RWPC vastly simplified their work by reducing the number of stakeholders and associated transaction costs. The convergence of expectations and roles has been driven as much as by the politics of perception as by reality. As one Consortium staff person points out:

[Metro] come[s] to us when there's issues involved with the latest round of urban reserves, and cost of service, so we have become the go-to group of entities when these collective things come forward. We gained a boatload of goodwill and points with the state, with the State Water Resource Department, DEQ. [...] Nonetheless, the fact you do these things gains you this aura of "the whole of you is greater than the sum of the parts." Whether this is perceived or real doesn't matter. It is the perception that really makes the difference.

Given the ever-present threat that Metro's water planning authority represents, the favors of Metro and the state have only reinforced the Consortium's dependence on maintaining its image as an effective and consensus-based organization. In a sense, the RWPC has had to allay the concerns of 2 opposing interests: on one hand, it has to demonstrate to Metro and the state that it is an effective regional water supply planning organization, while, on the other, deferring to local control. Seen in this light, and given the public nature of its meetings, the Consortium's consensus culture can be understood as an institutional strategy to keep internal differences away from the public eye. In 2004, the same year it updated its 5-year Strategic Plan, it made a constitutional change to its IGA that significantly reduced the scope 
of its dispute mediation section to cover only internal organizational disputes. The change communicated a clear policy that the Consortium was no longer going to be in the business of engaging in larger public controversies. Over time, then, the RWPC has evolved into a kind of clearinghouse and forum for convening local water providers to share information and discuss issues relevant to them, as opposed to a policymaking body that would lead the region's water providers with a strong vision for regional water supply and management.

\section{Consortium's Legacy}

This is not to downplay the Consortium's significance. After all, local water providers did not previously have such a place to meet to share information and perspectives on any regular basis. The Phase I source water-, regional demand-, and Portland conservation studies were the first of their kind for the region and led to what was probably the country's first IWRP on that scale. Since then, the Consortium has commissioned numerous studies, including: conservation impact assessments, an update of the RWSP, 2 regional transmission and storage studies, the development of a source water protection participation strategy, and even assessments of water supply and demand impacts from climate change. More generally, the Consortium's growing resource of studies, models, and monitoring all have vastly increased the metropolitan area's ability to plan for water supply issues before they materialize. The Consortium regularly updates both its RWSP and its 5year strategic plan, ensuring that the region's water providers stay abreast of and respond to developments as they arise. 
But it's also clear that boundary spanning played a role in helping the Consortium navigate the treacherous waters of regional water politics. The RWPC developed and adopted a public involvement plan that, following the IWRP framework, was largely driven by an interest in balancing water supply concerns with questions of demand. The region's water suppliers recognized that improving conservation and efficiency was going to require broad public participation. Questions of water demand turned out to be much less contentious than questions of supply which consequently made boundary spanning between the water providers easier. They also recognized the potential cost efficiencies of pooling their resources to reach the region's media market. Here, outreach efforts have been more robust and more successful. The Consortium has successfully sponsored focus groups and surveys, and partnered with businesses and local media in both identifying their target market and shaping their messages and programs to fit that market. Their successful media campaign "Conserve $\mathrm{H}_{2} 0$," for example, has helped raise the public's awareness of the importance of conservation. Through the Consortium, water providers are able to leverage participation in these otherwise expensive media campaigns.

Water suppliers have also discovered an opportunity for collaborating in the area of emergency supply planning. The Consortium carried out a study on regional system interconnections, transmission, and in-town storage which revealed vulnerabilities from disruptions in local and regional supply caused by earthquakes, terrorist attacks, or other emergencies. Just as importantly, the study showed a 
political readiness to consider a regional response to the problem, suggesting that the public was more willing to think as a region to address acute supply crises. Here was a water supply issue that seemed less controversial which the Consortium could address. And, as with conservation media campaigns, the RWPC discovered there were efficiencies in pooling resources. For instance, the RWPC has secured 2 Urban Area Security Initiative (USAI) grants, 1 of which funded the purchase of several portable emergency distribution systems. Eight such systems were brought online in 2008. And building on its 2000 Regional Transmission and Storage Strategy, the Consortium completed a more detailed GIS-based assessment of regional transmission and interconnection that was funded by a grant totaling over $\$ 90,000$.

Given the existing political legitimacy of the issues and the cost-efficiencies of regional coordination, it is perhaps no surprise that water conservation outreach and emergency supply planning remain the Consortium's 2 most important programs. The conservation program, which was formed after folding the Columbia/Willamette Conservation Coalition into the Consortium in 2000, has been the most successful and popular program among the members. Directed by a Consortium Conservation (Sub-)Committee, the program has grown to around $\$ 400,000$ in annual expenditures out of a total budget of around $\$ 700,000$, consuming over $60 \%$ of the annual budget with 2 dedicated FTE staff positions, as of 2010. Similarly, an Emergency Planning (Sub-) Committee formed in 2001 to oversee the Consortium's emergency planning program, eventually producing a 
Regional Emergency Water Distribution Plan that outlines strategies and agreements for coordination among water suppliers and regional emergency managers. Together, these programs have enhanced the capacity of the Consortium's members to not only respond to problems but also to discover and capitalize on opportunities.

The Consortium, then, has become largely a value-added to the region's providers rather than the other way around, much as the original lobbying documents had framed it. In fact, these programs are a major reason why providers continue to participate in the Consortium. As a manager of a smaller water district on the east-side explains:

I see people really accepting the fact that this regional entity has value. This is something we want to participate in. They always say when you're doing something good, you don't have to shove it down people's throats; they'll steal it. When people began to accept this organism as their own, you know you have arrived.

Water providers continue to enjoy the flexibility to adopt the Consortium's programs, modeling tools, and other innovations as they see fit. An important feature is a flexible dues structure that accommodates the specific scope, capacities, and needs of each member. For example, the City of Newberg pays just enough dues to participate in the conservation portion of the Consortium's activities. While this flexibility appeals to the individual water providers, it also means that participation in the Consortium is somewhat inconsistent. This, in turn, impedes the adoption of certain innovations which, in a kind of Catch-22, rely on larger-scale implementation 
to be successful. For instance, some of the Consortium's integrated forecasting and planning tools like "Confluence" remain largely unused.

As a value-added entity, the Consortium has also proved to be a fairly effective lobbying arm for local providers when needed. The Consortium has worked with outside agencies and the state legislature on various issues, as for example, when the state proposed changes to the way providers could impose System Development Charges for connecting to local water systems. Many of these lobbying initiatives have been successful. The RWPC helped pass legislation to better regulate pesticide use and disposal. Consortium members also participated in a statewide commission to build a state-bonding capacity for districts. However, there are also indications its influence is limited. For many of the state's lawmakers, for example, the Consortium remains a somewhat obscure entity. In fact, it seems the smaller and more homogeneous Oregon Water Utility Council (OWUC) has been a more effective lobbying arm in many cases. Still, when one considers the fact that many of the Consortium's members also serve on the OWUC, the Oregon Water Resources IWRS Policy Advisory committee, and other trade organizations, its influence becomes more significant. In fact, members of the Consortium's Emergency Planning Sub-Committee were instrumental in developing the Oregon Water/Wastewater Agency Response Network (ORWARN), which provides a statewide framework for inter-agency coordination in emergencies.

The RWPC has built relationships of trust and communication at all levels of governance that has undoubtedly led to some significant institutional changes in 
regional water supply as well. For one thing, the Consortium seems to have stimulated the formation of numerous sub-regional agreements. Consortium's influence is especially evident on the eastside, where various capital projects point to increased risk-sharing and collaboration. Mt. Scott and Damascus, for instance, have formed a joint water authority, while the Clackamas River Water Providers Consortium is modeled in many respects after the RWPC. In some cases, the Consortium has defined the specific policy context for sub-regional cooperation. A framework for sub-regional interties is currently informing the cooperation between Gresham and Rockwood on a major ground water project that will include jointly held and managed wells. These developments would have been unthinkable let alone doable before the Consortium formed. As a representative of one of the 2 agencies observes: "Ten years ago we wouldn't have sat at the same table."

The RWPC has similarly influenced experimentation at larger levels of governance which serve to reinforce its innovations. Currently Metro relies on the RWPC to help meet its chartered requirements for a Regional Framework Plan, particularly with regard to water supply and storage. At the state level, the OWRD has adopted the Consortium's Conservation Program as a policy standard for the industry. The OWRD's Division 86 planning requirement calls for water providers to produce a water management and conservation plan that is largely modeled on the Consortium's program as a condition for extending unexercised water rights. In addition, the OWRD has largely used the Consortium's RWSP as a template for its own planning efforts. 
Beyond the state, the RWPC has enjoyed less direct but nevertheless significant influence. Its architects, including Rosenburger, Jutila, and Seibel, have used their professional and social networks to actively promote the Consortium's approach as a general model for regional water supply management. Stickel has been approached by her counterparts in other regions to be interviewed or present on the Consortium's work. Many of the groups showing interest in the Consortium have been concentrated in the west, such as the Cascade Water Alliance, the Seattle Public Utilities, and the Puget Sound Water Forum in the Seattle area. Cities and water providers from San Francisco, Sacramento, and Denver have also approached the Consortium. But the RWPC has attracted national attention as well, whether through associations like the AWWA, or through more personal ties. After leaving the PWB, Rosenburger joined CH2MHill and eventually transferred to Atlanta, where he invited Stickel to give a presentation to city officials and water providers. These presenters reported that other regions and entities were often interested in different aspects of the Consortium's approach. Many have wanted to explore emulating the constitutional innovation of including a board of elected officials. Others have taken more of an interest in the Consortium's programs, offering, for instance, to buy TV ads associated with its "Conserve $\mathrm{H}_{2} \mathrm{O}$ " media campaign. These institutional reinforcements essentially generate value in the policy innovations that encourage their diffusion and enhance overall credibility in the Consortium. In some cases, they have emboldened the Consortium to further promote itself and its innovations. For example, when the PWB rewrote its wholesale contracts in 2006, it 
added a stipulation that wholesalers serving over 1500 customers submit a water conservation plan. Participation in the Consortium's Conservation Program partially met this new requirement; thus, the change in the wholesale contract boilerplate effectively solidified continued support for one of the Consortium's most important programs.

But these boundary encounters with the larger water supply community have also served to reinforce a particular identity for the Consortium's members. The very act of talking about and presenting on the Consortium - particularly after being invited to do so - instills in both the presenters and in the audience a certain level of awareness that is crafted through an ever-evolving narrative. The narrative itself - the story of the Consortium - takes shape gradually as presenters hone their message and as audiences hone their expectations of what they will hear, particularly to the extent that these audiences have been linked through various social and policy networks. Events and developments that occur between these storytelling encounters surely influence the path the narrative takes; so long as there is a Consortium, the story of the Consortium never really ends. Nevertheless, there is good reason to suspect that these encounters have had an effect on narrator and audience alike. Furthermore, to the extent that we observe a convergence of the Consortium and the Portland Metropolitan Region around a particular vision for regional water supply planning and management, we may surmise that these storytelling encounters played a role in that convergence.

Tinkering at the Edges 
The evolution of the RWPC structure also reflects a growing dependence on staff that suggests the subordination of visionary leadership to program development. Initially, policy directions were made by the Board for staff development before heading to the Executive Committee for consideration. Often, the Executive Committee would comment on drafts of plans or program recommendations for further refinement by the staff, until the Executive Committee was satisfied and passed its recommendations onto the Board for final approval. Thus, staff has always played a fairly important role. As the Consortium was being formed, staff members, particularly Stickel, worked to flesh out the various implications of the RWSP by articulating outstanding questions - such as how would the Consortium finance itself? - and identifying the kind of information that was needed to answer them. But this role has expanded as institutional trust among the water providers translated into trust in staff. As one staff person explains, it has become somewhat difficult to get adequate direction from the Board:

In fact, sometimes it's like pulling teeth to get [to] staff direction. And as you build your trust over time, they [Consortium Board] generally think you're going to do a good job as staff in presenting stuff to them for further action and whatnot. So sometimes after a while you don't get as much input.

The Board does continue to provide general direction on important matters like strategic planning, the annual work plan, and the budget, and its meetings now regularly include proposing a set of topics for future discussion and deliberation. The Executive Committee will work, in turn, with the various sub-committees to schedule agency staff, elected officials, consultants, and other sources from outside the Consortium to present on a given topic before the Board. Thus, Consortium staff 
influence should not be overstated. Nevertheless, evidence suggests that their role has expanded since the partnership's inception, placing greater reliance on boundary spanning among staff.

Especially, the cost-sharing agreement in the Staff IGA requires pooling dues among the water providers to compensate staff, many of whom are partially administered by different entities and staff policies. PWB personnel, for instance, enjoy more benefits than do staff affiliated with some other providers, raising issues of equity within the Consortium. Key staff members like Stickel and Rebecca Geisen, who manages the Consortium's Emergency Preparedness Program, have also had to learn to wear multiple hats as they divide their loyalties, attention, and energies among different organizational roles. It takes a good deal of boundary spanning skills to negotiate these differences without raising issues of conflicts of interest, as one Consortium staff person explains:

I think over time the consortium staff in general, all of us, have established a trust relationship with all of the entities, more so with some than others at various times. [...] We're very careful about what staff we select. It's not that there has been a huge turnover but the fact we have been able to grow the staff and have staff that recognizes that we're working for a many-headed master and it requires a certain degree of skill and finesse to do that.

As the water providers have learned to trust the Consortium staff more, they have given them more leeway to develop policies and programs, increasing their influence on the organization as a whole.

Even so, lessons of trust and respect have to be continuously relearned as both the Consortium and its members experience staff-turnover, changes in political leadership, policy shifts, and other changes. The RWPC has at least provided an 
institutional context for regular negotiation as issues arise. This context has not

only fostered interpersonal and interorganizational ties but also, as one board

member relates, the political skills necessary for reaching and implementing

agreements:

When we need to, we make a few calls out and around and line up the votes. Some people get a little annoyed with that but that's just good politics. You have to know where the votes are when you go to the meetings. [...] We know who has ties. For example, if there's a particular district or manager that is having difficulty with a budget issue, we know who they're friends with and we know who can talk sense to them. And so we just make a few calls. You can call it what you want. Some days we just call in a few favors. It's just like, "Look, we've got to get this budget passed, and we're just not going to do anything different." We just take care of that. We have to. Conservation is not a hit-and-miss program. You can't advertise and you can't promote conservation one year, skip a year or two, promote it for a year, skip a year or two. It's a consistent message. You can't just take time off and think you're going to gain back the ground that you lost. You just can't do that.

Even with relatively stable entities, Consortium members may interact with several points of contact ranging from board members and managers to technical and program staff that don't necessarily communicate consistently with one another.

For Consortium staff, this means continuously reassessing the terms of social, professional, and political relationships, which requires, in turn, the ability and willingness to appreciate other points of view, as one Consortium staff person observes:

You better have thick skin. [...] You'd better not be too defensive because it's a fairly good size group of people and they do shift over time. [...] I have become tolerant. I wasn't always that way in my career. I would say the other thing is not having your own agenda, and being honest without being too opinionated. [...] I think one of the characteristics I and several people I work with have that I think puts you in pretty good stead to be able to deal with this kind of difficult organization is that you tend to try and look on the 
good side of everything and not ascribe evil motives to people. I know this may sound like pop psychology but these are lessons I have learned over decades. It's always put me in good stead.

Several Consortium members that were interviewed spoke especially highly of

Stickel's ability to negotiate the shifting and complex partnership terrain:

Lorna [Stickel] is really politically savvy. She may not agree with everything the politicians have to say, but she's smart enough to know which ones to work and which ones to not. There's a couple of people you have to have on your side. You need the president of the board. You need a couple members of the technical committee and a couple of key board members. Once you have those, they can take care of the rest of the business. They just align themselves with the right people. You make sure you know politically what the program is, what these people are interested in. [...] So politically you have to be smart enough to figure out early on what is going to fly and what's not. That's the key thing, if you happen to know a couple of people you can call - "I'm thinking about A or B, what do you think?" - in an hour you can find out if it's going to fly or not and where the votes are. [...] And like I said Lorna is really good at that.

She gets something in her sights, she knows generally she has consensus. She has the ability, whether it be by intimidation or whatever it takes, to get the ones that are lying out there that really don't know what they want to do, she's got a real way of convincing them this is for the good. [...] She's got that knack that she's really smart but everybody respects her. Some are afraid of her. I'm not afraid of her at all, and I would say most of the managers aren't. But there are some that are. I would say everybody that knows Lorna respects Lorna. She puts out work like you wouldn't believe. She's just a machine at putting out work. It's quality work. It's not just throwing papers in the air. It's good stuff. I'd say of anybody she's the star.

The increasing reliance on staff more generally is reflected in the

Consortium's emphasis on its programs as opposed to framing regional water supply issues. Participation also reflects this growing reliance on staff. In the early heady years, the Consortium enjoyed the participation of top management. However, interviews and meeting minutes show that top management participation at both the Executive- and Technical Committee levels has steadily decreased, while 
Board meetings have decreased in frequency from quarterly to every 4 months. The attrition of top management reflects the decreasing relevance of the RWPC in directing new policy. Instead, the Consortium has largely become a program institution tinkering with policy innovations at the edges of program development and implementation.

With this evolution we see a corresponding shift in boundary spanning. Early on, it appears that the boundary spanning at the top management level was significant. But the early involvement of elected officials introduced a degree of risk-aversion and turf mentality that tended to blunt more ambitious efforts by managers to develop a robust regional water supply system. This isn't to say that top managers were more inclined than staff or elected officials to think in terms of regional interests. As already stated, most top managers also tended to be protective of their independence as well as their jobs, and relations between managers were strained before the Consortium formed, particularly on the east side of the Willamette River. Still, there are indications that top managers were starting to build relations of trust during the RWSP process. But those bonds were always vulnerable to the political vagaries of the officials and administrations for whom these managers worked. Nevertheless, to this day, general and district managers provide an important "vertical" boundary spanning function by filtering policy deliberations that occur at the Executive, Technical, and sub-committee levels and relaying only the information and perspectives that they judge will help inform decision-making. As a general manager of one of the smaller districts relates: 
If there is something I think is a hot issue that my board member is going to vote on, then I see it as my responsibility to prep them and give them the benefit of my thinking and a breadth of the discussion that went on so when they get to the [Board] meeting that evening, they're prepared.

To the extent that top management represent the link between operational and bigger picture concerns, the subsequent atrophy of their support and participation has left a vacuum of the kind of collaborative leadership needed to articulate a strong vision that would shape regional water supply policy. The attrition of top management within the Consortium is perhaps most significant among the municipalities, where water must compete with many other priorities. Without top management participation in the Consortium, these cities are unlikely to lead on water supply policy. Furthermore, poor or inconsistent top management participation means that utility districts that focus on water may find it difficult to collaborate with their municipal counterparts lacking a similar focus. As a result, the Consortium has been relegated to relatively narrow programmatic and other operational concerns, where the boundary spanning of staff, middle-managers, and occasionally elected officials then become important. For example, the Boring and Sunrise water districts recently faced budgetary constraints that threatened their ability to pay their membership dues to the Consortium. In a series of negotiations that speaks to the personal and institutional loyalties within the Consortium, the remaining members offered to cover the dues of Boring by using contingency funds. ${ }^{25}$

\footnotetext{
25 The loss of dues from the financially strapped Sunrise WA was much greater, and the Board voted to increase their own dues rather than cut the funds out of the budget and reduce activities. The 


\section{Partnership Capacity of the RWPC}

The RWPC could properly be classified as "Permanent and/or regular coordination" under Mandell and Steelman's (2003) typology of interorganizational innovations. The IGA and Staff IGA provide a formal framework for collaboration around regional water supply planning and, to a lesser degree, management. Membership is limited to water supply authorities operating within the Portland Metropolitan Region, and members pay dues according to a dues structure that accounts for different capacities and needs. The partnership's scope is restricted to a defined range of programmatic and strategic concerns, and membership commitment and risk-sharing is correspondingly limited. Most of the coordination is centered on planning, information-sharing, capacity-building, and development of Consortium programs, while each member retains full control over their respective operations, including implementation of any Consortium programs or other initiatives.

As we saw in the cases of the COTE WG and the UDRP, Mandell and Steelman's typology is useful in gauging the scope of the RWPC's partnership, but it leaves us with little sense for the resilience of that partnership. The IGA and Staff IGA that structure the RWPC are clearly interorganizational innovations, as is the IWRP framework that guides its water supply planning. Beyond this, it is clear that the RWPC has provided an institutional - that is to say, normative - context for

Board provided an Ex-Officio status to both Boring WD and Sunrise WA for the time they were not able to pay their dues. The Sunrise WA returned to full status one year later when a 4-part payment plan was approved (Lorna Stickel, personal communication). 
engagement across technical, policy, and social boundaries concerned with water supply planning and management. Within a few fairly well-defined policy areas anyway - regional water supply planning, including aquifer storage and recovery and interconnections and transmission, conservation education and outreach, and emergency planning - boundary spanning among the region's water supply agencies has become fairly routine. Not only is there a well-defined process for decisionmaking, but a host of often-tacit rules of engagement and attendant social technologies ranging from phone trees to planning models help to reduce the uncertainties associated with the interaction of different and often conflicting actors, ideas, and practices. These rules of engagement are composed of normative and ideological expectations about what the proper roles of various agencies, elected officials, managers, and staff are in specific contexts of interaction, both within and between public meetings. Together these rules form an institutional system for responding to various classes of problems, whether it concerns system supply vulnerabilities, the inability of one of its members to pay their dues, or a legislative threat emanating from Salem. Arguably the most fundamental rule of the partnership operates through a culture of consensus and goodwill that steers the Consortium away from problems it deems to be too divisive.

Having surmised that the RWPC meets the minimal conditions for PC I, it is natural to ask whether its institutional capacity rises to the level of PC II? Here the answer is less clear. On the one hand, the Consortium carries out a number of distinct functions centered on regional water supply planning, conservation 
education and outreach, and emergency planning. However, the integration of these functions remains limited. The RWPC Strategic Plan, renewed every 5 years, does address specific links between the major programs. And the work flows between the various committees and the Board allow for boundary spanning across operational, strategic, and even constitutional levels. These structural and programmatic elements are key ingredients for PC II. But as effective as the RWPC's programs have become, the lack of a compelling vision driving the Consortium means that these programs remain largely separate from one another. More generally, the implementation of the Consortium's initiatives and programs is largely left to the discretion of the individual agencies. One water supply manager from Washington County who participates in the Consortium expresses a sentiment expressed by many of his colleagues that the Consortium today has limited influence in shaping regional agenda on water supply:

When we did the original [regional] Water Supply Plan, we made sure that our water sources were in it. But since that time, if I'm honest with you, we are still doing our own thing, and it [the Consortium]'s not driving an agenda. The Tualatin Basin Water Supply Project is not talked about in the Consortium. We're not doing that. So to be honest, I don't know what is driving the agenda. I don't think it's implementing it either.

While some flexibility on implementation is critical to assure local adoption of the partnership's innovations, too much freedom leads to uneven and largely uncoordinated implementation. The alignment of partnership and community practices can only occur if there is a definite context of implementation that can lend both technical and cultural salience to those innovations. A context of 
implementation grounds the innovations in a community of practice and makes the various partnership functions accountable to one another. For instance, a problem which the RWPC has yet to completely address is: how to reconcile conservation objectives with agencies' revenue models that depend on provisioning water to wholesale and rate-paying customers? And because water supply systems are owned and operated by separate agencies and rate-paying communities, inefficiencies associated with transaction, opportunity, and related costs between these agencies translate to rates and taxes that a unified regional constituency would probably not tolerate for long. Some observers point to the Scoggins Damraising project on the Tualatin River, estimated to cost $\$ 1$ billion, as an example of a mega-project born from system-wide inefficiencies and missed opportunities. A general manager of one of the smaller water districts summarizes the dilemma that arises when a partnership empowers the individual members to the point of compromising the partnership itself. He points out, among other things, that an information clearinghouse is arguably only useful if there is a visionary framework to translate that information into a plan for collective action:

I'm speculating here, I haven't fleshed this out in my mind: there may even be this notion that I can go in and get this information, access this information, participate, but then I can take my bone back to my corner. "I don't want to be bothered by you unless I ask for it. I have the resources now to fend for myself, to keep the big state away from me," kind of thing. If you mean boundary in that context, that is something we haven't yet solved because like five water entities pulling out of one river, the river is oversubscribed. Here Clackamas River water sits with excess capacity and people are talking about building new treatment plants. What is wrong with this picture? You've got Portland having a pretty good source. There are a lot of wells and stuff. Tualatin Valley is talking about building a larger storage facility because they don't want to pay what Portland wants to charge for it. Rather than sit 
down and figure out how we collaborate and do all these other things, "we're just going to do our own." We haven't crossed that bridge as successfully as we should be, in my opinion. Some of that is because of the success of the Consortium. [...] In the sense that the Consortium does allow you to get all this information and this data. The thing I was talking about, if you're not the big fish, that allows you to take your bone to your corner. You don't have to come out and play with everybody. [...] It's like great strengths make great weaknesses. I don't think we have actually thought about the other side of the coin in the sense that because we're doing such a good job here, it may be the laws of physics. You don't want to mess with this because it will screw this one up and vice-versa.

The decentralized structure of the RWPC to some extent has empowered the individual agencies, particularly the smaller ones, but the partnership itself is neither inclined to grapple - nor capable of grappling - with coordination problems of greater complexity than the individual functions which it provides. As a result, it remains vulnerable to changes in socio-technical or policy conditions that currently allow these inconsistencies and inefficiencies to go largely unnoticed. For example, the region's relatively abundant water supply has, to date anyway, tended to mitigate impacts from missed opportunities or system-supply vulnerabilities, at least in the short-term. As one district manager observes:

We always like to talk, in order for something big to happen there has to be a crash. Then we do stuff in America. We never do anything in advance of anything. We wait until it destructs; then we say "We have to go do something!" There wasn't that here, which may explain why we don't have a regional water supply authority.

Another cause and effect of the Consortium's limited partnership capacity is its heavy reliance on staff, which has been evident from the RWPC's inception. It seems the boundary spanning of the staff, especially Stickel, has been crucial in making sure that the decision-makers have access to information, models, and 
perspectives needed to make decisions. Perhaps more importantly, staff help to identify gaps in data and knowledge which may inform policy discussions and learning at the executive and board levels. But this reliance also makes the RWPC vulnerable to staff-turnover, as several Consortium member representatives discussed in connection with Stickel's impending retirement in 2011. The Board and even Executive Committee have come to entrust in Stickel and her staff the capacity to make decisions which require a combination of technical and political judgments only experience can give. This investment has evolved into a particular operational strategy for adapting to changes at various levels of resolution. Indeed, perhaps the most important operational strategy concerns the set of largely unwritten rules determining which changes or issues belong to which level. Over time, Stickel and her staff have internalized this strategy, enabling the smooth functioning of the organization. Given the reliance of the Consortium's operations on staff, there is the risk that the loss of that trust from staff-turnover will cause the organization to lose some of its flexibility, in effect "freezing up" its operations.

Finally, the Consortium consensus culture has helped it stay together in many ways. Clearly, the boundary spanning among its members to gauge which battles or issues are worth taking up as a consortium versus as individual providers has helped it stay together. But there is the real risk that deeper conflicts will resurface and become unavoidable or that the Consortium will drift from its constituencies as their positions evolve. As a result, the region remains vulnerable to surprises, especially "long emergencies" like another economic crisis or climate 
change, that impact water supply. Indeed, the renegotiation of 25 -year contracts currently underway risks bringing simmering differences to the surface. In some instances, the renegotiations have provided an occasion for constituencies to openly question whether their district should remain in the Consortium. Many cite the familiar issue of local control over water supply, but some observers argue that a more fundamental issue is poor regional management of existing water supplies. Indeed, perhaps most insidious of the long emergencies is the inefficiency in water supply which threatens the region's economic development and quality of life. The silence around regional management issues - indeed, its almost complete lacuna in public debate - reflects the subordinate status of regional water supply policy and supports the conclusion that the RWPC's role in those policy deliberations has been more accommodating than visionary.

\section{Conclusion and Recommendations}

In conclusion, then, it would appear that the RWPC has limited Partnership Capacity Type II. The Consortium carries out a number of distinct functions centered on regional water supply planning, conservation education and outreach, and emergency planning. Within each of these policy areas, the RWPC has developed policies, programs, and tools that represent true innovations in regional water supply cooperation. The Consortium has provided a forum for sharing technical information and resources that have enhanced the capacities of its individual members. Perhaps most significantly, this forum has cultivated bonds of trust and goodwill that carry direct and indirect implications for regional water supply. 
Certainly the region as a whole is more informed and better prepared to address regional supply issues because of the Consortium, particularly with respect to acute crises or emergencies. In addition, these bonds have translated in some cases into policy experiments with sub-regional development, ownership, and operation of water supply.

But in many ways, the Consortium has reinforced norms of conflict avoidance among the region's water providers that has tended to vitiate regional policymaking in water supply. The absence of a compelling vision of regional water supply means that ownerships, authorities, and responsibilities remain largely uncoordinated. Along the same lines, the lack of risk-sharing in the Consortium's institutional design and operations reflects (and reinforces) persistent turf mentality and distrust. As a result, the Consortium's programs and functions remain to a great extent disconnected from one another, while implementation is uneven. Additional signs of limited partnership capacity include missed opportunities, persistent system-wide inefficiencies, and organizational vulnerability to staff-turnover. There is, in another words, little evidence to suggest that the Consortium and its members have established strategies for adjusting core practices so that programs talk to one another and strategic plans both anticipate and inform local water provider actions. We don't find much evidence of a unique pattern in alignment practices that would indicate PC II.

Let us now summarize our assessment of the RWPC's capacity to manage institutional processes of varying degrees of complexity. Table $\mathbf{5}$ summarizes the 
various boundary spanning practices that were observed in the RWPC process. The table's structure follows the methodological criteria contained in Table 2: Typology of Partnership Processes." 
Table 5: Boundary Spanning Practices in the RWPC

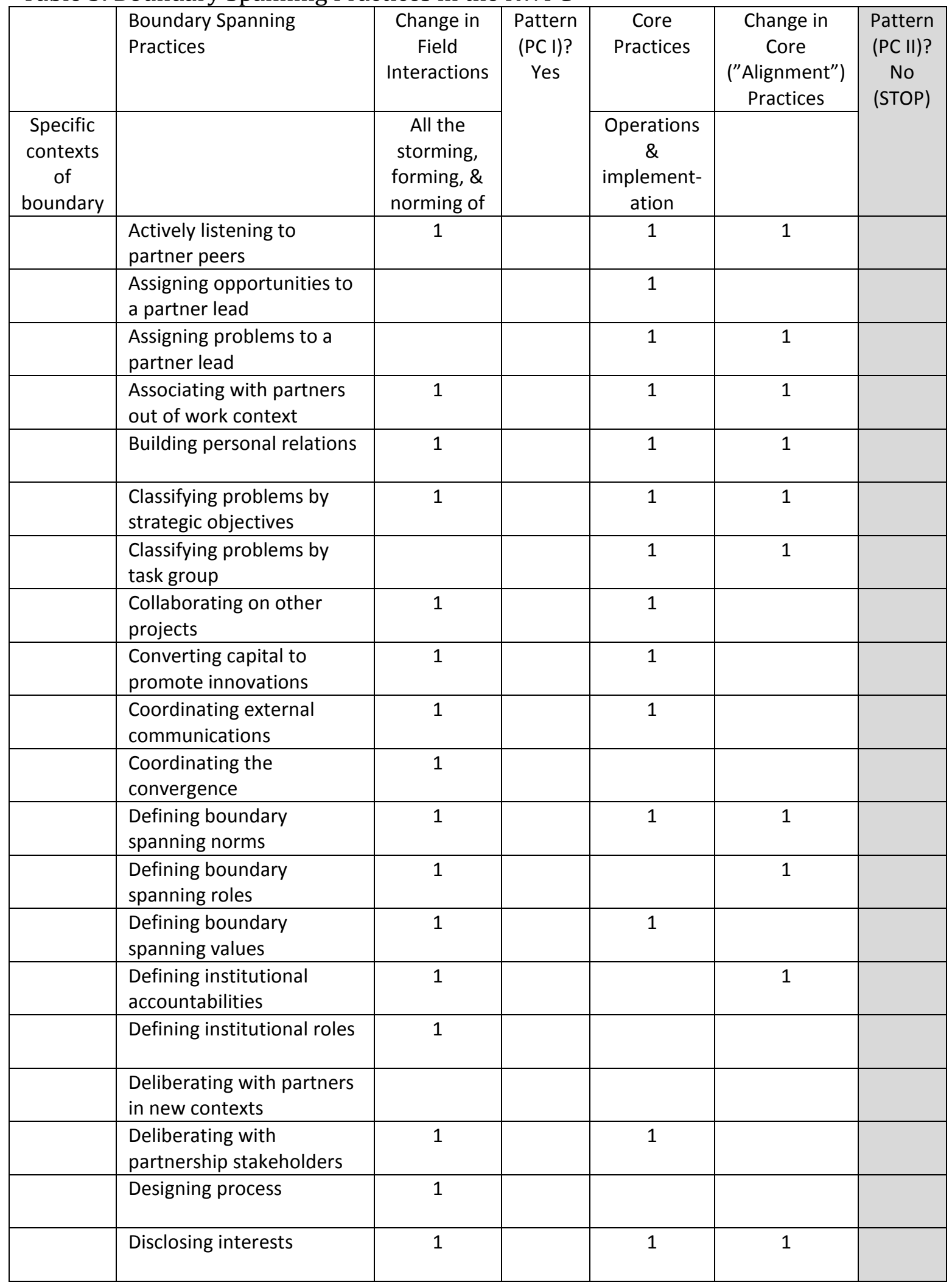




\begin{tabular}{|c|c|c|c|c|}
\hline Education & 1 & 1 & & \\
\hline $\begin{array}{l}\text { Extending favors to } \\
\text { partners }\end{array}$ & & 1 & & \\
\hline Facilitation & 1 & & 1 & \\
\hline $\begin{array}{l}\text { Framing innovations in } \\
\text { terms of need }\end{array}$ & 1 & 1 & & \\
\hline $\begin{array}{l}\text { Framing need in terms of } \\
\text { innovations }\end{array}$ & 1 & & & \\
\hline $\begin{array}{l}\text { Influencing across policy } \\
\text { sub-networks }\end{array}$ & 1 & 1 & 1 & \\
\hline $\begin{array}{l}\text { Innovating (paradigmatic } \\
\text { boundary spanning) }\end{array}$ & 1 & 1 & & \\
\hline $\begin{array}{l}\text { Integrating boundary } \\
\text { objects/innovations }\end{array}$ & & 1 & & \\
\hline $\begin{array}{l}\text { Making government rules } \\
\text { and regulations }\end{array}$ & 1 & & & \\
\hline $\begin{array}{l}\text { Managing process (budget, } \\
\text { conflicts, surprises, time) }\end{array}$ & 1 & 1 & 1 & \\
\hline Outreach & 1 & 1 & & \\
\hline Pilot-testing innovations & & 1 & & \\
\hline $\begin{array}{l}\text { Pitching to decision- } \\
\text { makers }\end{array}$ & 1 & 1 & 1 & \\
\hline Prioritizing problems & 1 & 1 & 1 & \\
\hline $\begin{array}{l}\text { Protecting brand/integrity } \\
\text { of innovations }\end{array}$ & & & & \\
\hline $\begin{array}{l}\text { Respectfully pushing back } \\
\text { (disclosing constraints) }\end{array}$ & 1 & & & \\
\hline $\begin{array}{l}\text { Ritually enacting boundary } \\
\text { spanning }\end{array}$ & & & 1 & \\
\hline $\begin{array}{l}\text { Scanning environment and } \\
\text { reporting issues }\end{array}$ & & 1 & 1 & \\
\hline $\begin{array}{l}\text { Seeking input from } \\
\text { relevant constituents }\end{array}$ & 1 & 1 & 1 & \\
\hline $\begin{array}{l}\text { Seeking input from } \\
\text { relevant decision-makers }\end{array}$ & 1 & 1 & 1 & \\
\hline Sharing risks & 1 & 1 & & \\
\hline $\begin{array}{l}\text { Staff collaborating across } \\
\text { organizations }\end{array}$ & & 1 & 1 & \\
\hline $\begin{array}{l}\text { Staging group decisions } \\
\text { (lobbying, building }\end{array}$ & 1 & 1 & 1 & \\
\hline $\begin{array}{l}\text { Strategically aligning } \\
\text { partnering organizations }\end{array}$ & 1 & & & \\
\hline
\end{tabular}




\begin{tabular}{|l|l|c|c|c|c|c|}
\hline & Task-mastering & 1 & & 1 & 1 & 1 \\
\hline & Testing ideas/Vetting & 1 & & 1 & 1 & 1 \\
\hline & $\begin{array}{l}\text { Translating across } \\
\text { technical/disciplinary }\end{array}$ & $\begin{array}{l}\text { Translating between task } \\
\text { groups }\end{array}$ & 1 & & 1 & 1 \\
\hline
\end{tabular}


If the RWPC were to address some of the outstanding issues that have been identified here, it would need to present a visionary framework that translates those issues into actionable items for the Consortium of water providers. This would require, in turn, building a culture that not only tolerates but welcomes frank discussion of deeper policy differences among its members. By surfacing these deeper differences, members may collectively develop a framework that places those differences in a particular context for collective action. System-wide inefficiencies and other costs would be "discovered," while other differences may lose their relevance. Programs and initiatives would build more naturally on one another, while implementation would be simultaneously coordinated and appropriate to local context. The social learning to achieve PC II is not trivial. It would require expanding ownership of the region's water supply problem whatever form that ownership may take - to a more encompassing entity. As we have seen, such an expansion would hinge on significant political will and visionary leadership. 


\section{Chapter 6}

\section{Upper Deschutes River Partnership}

\section{Background}

A Brief History of the Deschutes River Basin

The Deschutes River Basin covers a vast area of 10,700 square miles in central Oregon. The drainage is set off to the west by the Cascade Mountains, to the south by lava plateaus, and to the east by the Ochoco Mountains and plateau between the Deschutes and John Day Rivers, and heading north to its confluence with the Columbia River approximately 170 air miles from the headwaters of the Deschutes River. The Basin features a wide variety of climatic and ecological zones, ranging from wetland and mountain forest to sage and juniper rangeland and high desert. A significant part of this climatic and ecological diversity stems in fact from the basin's geology. Most notably, on the west side, which includes the Deschutes River mainstem, porous volcanic soil and lava tubes help to absorb snowmelt and runoffs into the vast aquifer which gives rise to springs and drainages that naturally replenish river flows. Historically, the result was a remarkably stable flow regime. On the east side, in contrast, particularly in the canyons that feed into the Crooked River, the Cascade rain shadow and more impermeable basalt rock combine to create more variable flows from season to season and year to year (NWPCC, 2004).

The Basin has been home to human settlements for thousands of years, including ancestors of the Warm Springs and Wasco Tribes who subsisted on Chinook and sockeye salmon, steelhead trout, and resident fish. White settlers 
brought with them beaver trading and livestock grazing that began to significantly impact the landscape and ecology, particularly in riparian and wetland areas. By the late 1800 's, agriculture, forestry, and urbanization were impacting flow regimes, water quality, and habitat on which many species, including salmon and steelhead, depended. In some cases, historic floodplains, which afforded critical ecosystem services such as groundwater recharge and habitat connectivity, were lost while other areas flooded. Perhaps most significantly, irrigation diversions and eventually reservoirs were created to meet water demand from irrigation and municipal use that reduced flows to the point where some of the reaches became seasonally dewatered. By 1914, filings for water use rights in the Upper Deschutes River north of Bend amounted to 40 times the river's annual flow (NWPCC, 2004). Hydroelectric dam projects, which started in the early 1900's to meet the region's power needs, threatened fish passage for anadromous fish, as did of course diversions, culverts, and other structures associated with logging, road construction, and development. Finally, water quality in some reaches became degraded. Reductions in river flows and riparian shade increased temperatures while pollution from municipal waste, agricultural run-off, and other economic activities contaminated streams and lakes. By the mid-1990's, a number of sections of the Basin were in violation of state water quality standards for temperature, dissolved oxygen, and phosphorous (Moore et al., 1995a).

The cumulative impact on anadromous fish populations was significant. Already by 1880, Oregon Fish Commissioners were reporting that salmon 
populations in the Deschutes River had dwindled to the point that Warm Springs Indians were forced to travel to the Clackamas River for their winter supply of fish (NWPCC, 2004). The licensing and construction in the 1950's and early 1960's of the Pelton-Round Butte Dam complex on the confluence of the Deschutes, Crooked, and Metolius Rivers by Portland General Electric (PGE) created Lake Billy Chinook and, with it, fish passage problems on an unprecedented scale which were never completely overcome. This project, combined with USACE projects that straightened channels in Wychus Creek and other critical reaches, hastened the demise of wild salmon and steelhead populations in the Basin. In 1999, the summer steelhead was listed as Threatened (the resident bull trout was listed as Threatened in 1998).

In the 1980's, the Basin began to experience an influx of visitors and new residents who were attracted to the region's natural beauty and recreational opportunities. Much of the influx has been concentrated in the middle to upper reaches of the Deschutes River Basin. Until recently anyway, Deschutes County, which includes the city of Bend, led the state in population growth for many years, increasing by over 53\% between 1990 and 2000 (NWPCC, 2004). In 2009 the county's population was estimated to be almost 159,000, compared with just under 75,000, 20 years earlier (NWPCC, 2004). Jefferson and Crook Counties have similarly experienced tremendous demographic growth. In contrast, between 1990 and 2000, Sherman and Wasco Counties farther north grew by only $0.8 \%$ and $9.7 \%$, respectively. Indeed, the story of water in the Basin has more recently been driven 
by urbanization in and around the cities of Madras, Redmond, Sisters, and Bend which has changed land use patterns, the economy, and the political culture of the Basin. In this south-central part of the Basin, the lumber industry has been replaced to a great extent by construction, retail, and service industries like tourism, while irrigation district land is being converted to municipal development, bringing increased pressure on ground water resources. On the eastern side of the Basin, by contrast, the cattle industry and agriculture continue to be important sources of employment, although here too we find evidence of social change, as cities like Prineville are becoming suburbs or even bedroom communities to larger cities like Bend and Redmond.

Birth of the Idea of a Basin-wide Entity

The resulting geographic, demographic, economic, and urban contrasts have given rise to cultural and political differences through which water conflicts have been framed and negotiated. Irrigation districts and communities farther north must contend with water shortages and related issues stemming at least in part from consumption by Basin water-users upstream of them. The natural scarcity of water farther east, particularly in the Crooked River Subbasin, has been exacerbated by the growing socioeconomic rift between the increasingly affluent and urbane Deschutes County and the more rural (although increasingly suburban), conservative, and poorer Crook County. These socioeconomic, political, and cultural differences translate to contrasting and often conflicting attitudes about water resources and how to manage them within the Basin. 
These differences have proved daunting in the absence of a unifying institutional water resource management framework. While about $50 \%$ of the Basin is owned by the federal government (primarily USFS and BLM), fully $42 \%$ is private, while most of the remainder is owned and managed by the Confederated Tribes of Warm Springs Reservation (CTWSR). As with many basins, the Deschutes River Basin is comprised of a diverse set of stakeholders ranging from federal, state, and local agencies, counties and municipalities, and special districts, to landowners, businesses, utilities, environmental interests, and the CTWSR, each with their own set of interests, authorities, and obligations. Treaty rights of the CTWSR, for instance, include use rights of water and fisheries that extend far beyond their reservation, making the CTWSR a key stakeholder in the management of the Deschutes River Watershed (Moore et al., 1995b). They have played an active role in the Northwest Power and Conservation Council's (NWPCC) Columbia River Fish Management Plan, including the NWPCC's Deschutes Subbasin Plan (NWPCC, 2004). Perhaps most relevant to the current case study, the CTWSR are co-licensees with PGE of 2 of the 3 dams of the Pelton-Round Butte Dam Complex and were central to the negotiation over relicensing in 2001 (Moore, et al., 1995b).

The CTWSR have also formed partnerships with environmental groups and government agencies to develop management plans that identify and monitor water resource problems within the Basin. In 1995, the CTWSR co-published a report with the Environmental Defense Fund (EDF) entitled Restoring Oregon's Deschutes River that carried out a fairly comprehensive survey of the planning processes and 
institutions in the Basin that were engaged in addressing resource management

problems in the Basin. ${ }^{26}$ The report's authors concluded that:

...there is presently no single organization within the Deschutes River Basin that provides an arena in which all of the region's stakeholders can discuss management of the Deschutes River and the other natural resources in the Basin. None of the existing institutions has the regulatory authority, financial resources, or institutional capacity to plan and manage the natural resources in the Basin on an ecosystem basis (Moore, et al., 1995, p. 116).

The authors called for a "Basinwide entity" which would combine legal, fiscal, institutional, and ultimately social capacity to develop and implement a comprehensive adaptive management plan, and they concluded that an interstate compact was probably the most appropriate institutional structure, particularly given the need to coordinate the otherwise sovereign interests of the federal government and the CTWSR (Moore, et al., 1995b).

Although an interstate compact has not materialized, Restoring Oregon's Deschutes River nevertheless laid out a strategic framework that has since informed watershed management in the Basin. Perhaps most importantly, the EDF and CTWSR argued that the issues of water quantity, water quality, and fishery health were intertwined and needed to be addressed in a strategic and integrated fashion. It proposed that the Basin-wide entity adopt market-driven policy mechanisms that

\footnotetext{
${ }^{26}$ The planning processes and institutions that were operating in the Basin in 1995 included: The Deschutes Basin Resources Committee, and advisory group to the City of Bend and the Deschutes County Board of Commissioners; the Deschutes Mitigation and Enhancement Committee, charged with reviewing ODFW's mitigation and enhancement plans for the Central Oregon Irrigation District's hydroelectric project; the Deschutes Basin Alliance, an intergovernmental organization formed by, and largely to serve the interests of, the 7 irrigation districts in the Upper Deschutes Subbasin; the Deschutes Provincial Committee, part of President Clinton's Forest Plan for the Pacific Northwest, two separate Wild and Scenic planning processes, one for the Deschutes River and one for the Metolius River.
} 
would expand opportunities for the private sector to more efficiently and effectively participate in environmental restoration and protection. Such mechanisms included: voluntary leases of irrigated land and transfers of water to restore instream flows, incentives for water conservation, an exchange to trade pollutiondischarge permits or "credits," and user fees to finance environmental restoration. The report added that the science and policymaking around water quantity was more developed and should receive greater initial emphasis until water quality science and management, particularly concerning non-point source pollution, was developed enough to support market-driven policy mechanisms. Many of the report's recommendations were ultimately realized in the Basin's water transactions programs that were implemented in the 2000's, including the Oregon Water Resource Commission's (OWRC) Deschutes Ground Water Mitigation Program and the Bonneville Power Administration's Columbia Basin Water Transactions Program (CBWTP).

The report owes much of its influence to the pioneering work of its authors, including Zach Willey, a prominent economist who was then working at the EDF. Willey collaborated with policy thinkers such as Jim Noteboom, then an attorney for the CTWSR and a partner in the Bend-based law firm Karnopp, Petersen, Noteboom, Hubel, Hansen \& Arnett, Gail Achterman, an environmental lawyer who specialized in natural resources and environmental law at the Stoel Rives law firm, and Bruce Aylward, a world-renowned water economist who was recruited from Washington, D.C. This group of innovative thinkers - starting with Willey and Noteboom, who 
were later joined by Achterman and Aylward around 2000 - began working on a policy and legal framework that would incorporate voluntary, market-based policy mechanisms to begin to address the Basin's water quantity, quality, and fisheries issues (Gail Achterman, personal correspondence, August 10, 2010). Willey and Noteboom, along with Jim Manion of the CTWSR and Ron Nelson formerly with the Central Oregon Irrigation District (COID), were especially pivotal in the formation, in 1996, of the Deschutes River Conservancy (DRC), a non-profit organization set up to handle water transactions for the express purpose of restoring instream flows in the Deschutes River Basin. In many ways, the DRC grew out of the report's recommendations, and to this day its instream restoration strategy centers on water leases, transfers, and conservation projects. Indeed, the DRC was a response to the report's call to form a working group that would identify and evaluate pilot water leasing projects, and which would eventually evolve into a Basin-wide entity. As a DRC staff member explains:

What we used to do was we would do pilot projects. We'd say, "What happens if we save some water, we put it back in and get the state to certify? Is that okay? Did anybody get hurt? What is our comfort level with that?" Most of the things I described to DRC in the early phases as being research and development.

Willey and his colleagues built on a task force comprised of the Basin's 7 irrigation districts (the "Deschutes Basin Alliance"), the Oregon Water Resources Congress, the BLM, the CTWSR, and the EDF to form the "Deschutes Basin Working Group," which subsequently received legislative authorization in 1996 to become the DRC. Thus, it appears that the DRC was conceived by its founders very much 
with the Basin-wide entity in mind: a consensus-based, multi-stakeholder organization that would concentrate on restoring instream flows through a Basinwide approach that remained at least attentive to the economic and social issues related to water quality, habitat, and fishery health. This broader strategic approach was shared by the DRC's diverse board members like business leader Mike Hollern and Stuart Shelk. The DRC's board ties with the EDF and CTWSR, but also with BPA, PGE, Bonneville Environmental Foundation (BEF) and the National Forest Foundation (NFF) would later prove important in securing funding and support for building a strategic partnership around a specific initiative.

Incremental Policy Experiments with Vision

More generally, the growing awareness of the Deschutes River Basin watershed during the 1990's helped to spur regional thinking and provided fertile ground for the emergence of strategic partnerships. An important groundwater study of the Basin carried out by the USGS and the OWRD in the late 1990's revealed that surface water flows were directly linked to the aquifer and aquifer discharge. The study's findings, famously captured and circulated in local newspapers and other publications as the "blue whale" hydrograph - so-named because its shape resembles a blue-whale - helped to raise awareness of the watershed-scale processes. This awareness was given a new level of urgency when the OWRC, obligated by the amended Scenic Waterway Act to regulate the impacts of new groundwater use on the Lower Deschutes River, imposed a moratorium on new groundwater permits. The study and ensuing moratorium effectively linked 
previously disparate issues ranging from fisheries to real estate development and spurred various interests to begin to think of themselves as common stakeholders in a broader watershed community. One important result was the OWRC's Deschutes Ground Water Mitigation Program (DGWMP), adopted in 2002, which enabled developers and other landowners to secure temporary or permanent groundwater permits by purchasing mitigation credits through an approved mitigation bank such as the DRC that would finance water transfers, aquifer recharge, storage release, and water conservation projects. In addition to the DGWMP, several Columbia Basin-wide initiatives coincided to further stimulate water banking in the Deschutes. In 2002, the Columbia Basin Water Transactions Program enabled the BPA and the NWPCC to redirect previously unavailable money through the National Fish and Wildlife Foundation to fund water transactions while the amended Pacific Northwest Electric Power Planning and Conservation Act (“Northwest Power Act") authorized funding instream restoration.

Achterman, then ED of the DRC, and her colleagues saw an opportunity in the different interests of irrigators, municipalities, and environmentalists to create a marketplace for buying and selling water credits that would meet those otherwise competing interests. Achterman's own outreach efforts with landowners and other stakeholders helped to build readiness for participating in conservation and restoration efforts that would support a water transactions program (Gail Achterman, personal correspondence, August 10, 2010). As a DRC staff member 
explains, the solution certainly had a technical aspect to it, but it ultimately

depended on the alignment of policy, social, and political concerns:

I don't know if we would have formed a bank, or had water existing without the city's role. The districts would have never agreed to set up a bank simply for river restoration. They ultimately were willing to set up a bank to provide water to cities. Then we put the two concepts together. Essentially we have two buyers for the bank. One is a restoration buyer that doesn't want to have any other consumptive use. It just wants to retire water rights to increase flows. We have another that wants to have a new consumptive use. They're mitigation buyers who are very important. In fact the restoration efforts really ride on the coattails of mitigation. Mitigation is what really drives district boards to participate.

In addition, the NWPCC's Deschutes Subbasin planning process, part of the NWPCC’s Columbia River Basin Fish and Wildlife Program, certainly has helped to move the disparate conversations about Basin-wide management closer to a concrete regional agenda. Undertaken in 2001, and subsequently reviewed every 3 years, the process convened a Deschutes Coordinating Group (DCG) that brought together stakeholders representing environmental groups, businesses, watershed councils, cities, counties, soil and water conservation districts, irrigation districts, hydropower operators, and state and federal natural resource management agencies (NWPCC, 2004). Moreover, the DRC served as the DCG's fiscal agent, underscoring the important role it has played in fostering Basin-wide management.

It was from the Deschutes Subbasin planning process that the Deschutes Water Alliance (DWA) was formed in 2004 to plan for long-term watershed management that would balance the needs of fisheries, agriculture, and municipalities. In many respects, the DWA share with the DRC many of the attributes of "Basinwide entity" first envisioned by the EDF and the CTWSR in their 
Restoring Oregon's Deschutes River, suggesting that the Basin's policy thinkers were in some sense experimenting with different institutional structures to realize their vision. The DWA in many ways grew out of the earlier task force: its current organizational membership - the Deschutes Basin Board of Control (formerly “Deschutes Basin Alliance”), CTWSR, DRC, and the Central Oregon Cities Organization - overlaps strikingly with that of the former task force. As one DRC staff member recalls:

One of the things that the DRC has really had to do a lot to implement the water part of this proposal we worked on is to attempt to create something we're now calling the Deschutes Water Alliance. It's an expansion on the concept of the DRC board, which has representation from both private and public stakeholders. When it gets to the public side, its representation is limited because it's not trying to represent every county and every city, every irrigation district, every public entity. It's trying to have a representative sample of those even at the state and federal levels as well...We felt we needed an additional forum where everybody's voice was at the table, all seven irrigation districts and all eight cities, three counties, plus three state agencies. For the moment we have left the federal agencies off knowing there has to be engagement with them, but the purpose was mainly to see if there was a way to get all these jurisdictions to come more on the same page with the notion of: "How do we manage water more efficiently and more effectively for mutual benefit in the basin?", instead of the traditional way it has been, which is each jurisdiction simply has its blinders and takes care of its own. With a resource like water, it's all connected. You can't do something in one area without affecting another.

In addition, the DRC has since transferred its water mitigation bank to the DWA.

Still, these institutional efforts to build a "Basin-wide entity" have been met with persistent resistance from more parochial interests and concerns, underscoring an ongoing tension between regionalist and more local approaches to planning and management. As already discussed, this tension has taken particular historical and geographical shape related to the urbanization of the Upper (and 
Middle) Deschutes River Subbasins. The primary interest blocs that comprise the DWA - environmental, agricultural, and municipal - have much to gain from regional cooperation in water resource management. Still, the DWA has struggled to hold together its alliance. Irrigation districts, for instance, remain wary of ceding their autonomy with respect to water use rights as their land and revenue base is lost to urban development, particularly since the economic downturn. And there are important internal differences, as, for example, in the competing claims and interests of irrigators and irrigation districts. The upper basin's senior water right holders tend to hold land that is considered agriculturally less productive than their junior counterparts farther north. The DRC has struggled to get senior water rights holders to free up some of their water to irrigators to the north and thereby free up reservoir water to better manage seasonal fluctuations in instream flows. Cities such as Bend and Prineville also compete with one another for groundwater and differ in their economic and environmental policy priorities. These differences have been complicated by lingering scientific uncertainties about the physical, biological, and ecological factors contributing to watershed "health," legal uncertainties related to the implications of Oregon's water laws on water transactions, and institutional uncertainties related to monitoring and compliance. As one DRC staff member summarizes:

...it's all about the hydrology of the area and how the water is moving. There's a whole technical side of looking at what happens when you move the water right somewhere else. What are the impacts? Have you injured anybody and looked at your return flows? Ultimately, based on a scientific assessment, what should you be able to protect instream if you're moving water to land for instream purpose? There was a lot of technical work there 
that goes into having the (Oregon) Water Resources Department feel comfortable that its interpretations of the statute were not going to get them into trouble. You've noticed an evolution of their thinking. Things we did in the beginning, some of them they say, "We reserve the right to get smarter."

The DWA tried to address a number of these concerns in a series of reports it presented at a "Water Summit" in 2006. In 2007, it convened a "Deschutes Basin Water Management Consensus Process" with the aim of finally developing a comprehensive Basin-wide plan under which various water management efforts would be coordinated. As noted in a summary from one of the early meetings:

Ultimately, there was consensus that while numerous tools exist for addressing water management and restoration issues in the basin, these tools aren't integrated into an overall coordinated plan that is supported by all. Even if the group were to commit to address specific problems as they arose, as suggested by some, it wouldn't have any context, in terms of an agreed-on goal or goals, for doing so (Meeting Notes, 1/23/07).

By 2010, the DWA was struggling to hold a quorum, much less promulgate a unified management plan for the Basin.

The DWA is not the only partnership whose trials illustrate the challenges of developing a Basin-wide approach. During the first 5 or 6 years of its existence, the DRC struggled to work with the various soil and water conservation districts, which tended to view the DRC's attempts to work with landowners and irrigators as infringements on their domain. The DGWMP has similarly struggled to enjoy broader support and participation. In 2005, the program was held up in appeals court until its champions, including Martha Pagel of the water law practice group Schwabe, Williamson \& Wyatt, were able to get the program approved by the Oregon Legislature later that year. Even so, a February 2008 report evaluating the 
public's perception of the program found that a cumbersome groundwater permitting process, uneven enforcement, and a lack of information about the program were negatively impacting participation in the program (Lieberherr, 2008). The DRC and its partners have worked with the OWRD to streamline water rights transfers, but, as with many instances of administrative rule-making, these changes have come about incrementally through collaborations on multiple mitigation projects over a period of years. As one DRC staff member recalls:

Our job was not to create new policy but for the first time test existing statutes and rules at the state level that had really never been tested. The conserved water statute [authorizing the Allocation of Conserved Water Program] went on the books in 1987 along with the Instream Water (Right) Act. The first conservation projects didn't happen for ten years. Nobody had really used this. Nobody even really knew how to use it. The laws were way ahead of the social norms and the cultural acceptance, so nothing really happened. Fifteen years later we're generating an enormous number of project opportunities. We had to go through Oregon Water Resources Department and say, "We have this conservation project. We have done this. What are you going to do? What do we actually get? How does this work? How does this really work?" That was the policy. It became more perfecting, or some rule-making. They had the rule-making advisory committees. A number of those were happening when I joined. It was really an interpretation of, "How are we going to do this?" A lot of that happened in the early days.

As part of implementation of an interstate compact, the NWPCC's Deschutes Subbasin Plan required federal agencies including the BPA to develop management plans that adhered to it. Thus, the Deschutes Subbasin planning process was an important context for the relicensing of the Pelton-Round Butte Dam Complex in 2001. Five years earlier, in 1996, PGE and CTWSR filed competing intents to renew the Pelton-Round Butte Dam license. What followed draws a striking contrast to a similar conflict that unfolded farther south in the Klamath Basin around the same 
time. In the latter case, the conflict between the Klamath Tribes, PGE, irrigators, environmentalists, municipalities, and other stakeholders escalated into litigation, threats of violence, and community division. But in the Deschutes River Basin, it appears that the presence of local alliances, such as the aforementioned task force, the Deschutes Basin Working Group, and eventually the DRC, had at least a mitigating effect on the conflict between PGE and the CTWSR. ${ }^{27}$ Their presence indicates that the Basin was already developing cross-cutting social and institutional ties between the major interest blocs (and sectors) that in all likelihood facilitated the formation of a partnership between PGE and CTWSR. The two parties negotiated a settlement agreement to share the license in 2004, which FERC approved the following year.

A key stipulation of the license agreement requires the dam complex to address impacts to salmon and steelhead by restoring fish passage that connects populations to their historic runs upstream of Lake Billy Chinook. Although the license strictly speaking confines liabilities to the dams' design and operation, the legitimacy of the license, and of the partnership underlying it, became tied to the successful reintroduction of salmon and steelhead in the Middle and Upper Deschutes Subbasin. Reintroducing the populations after a greater-than- 40 year absence was going to require a comprehensive campaign to simultaneously address fish passage, instream flow, water quality, and habitat. To support the effort, PGE and the CTWSR established a Pelton-Round Butte Fund totaling $\$ 21.5$ million to be

${ }^{27}$ It is worth noting that the competing intents to renew the license were filed the same year that the DRC was legislatively authorized. 
awarded through 2020 to support water rights leases and transfers and habitat improvements to fish migration, spawning, and rearing grounds. The fund added to a funding stream that included the CBWTP, the DGWMP, and various OWEB programs. This funding served to reinforce Basin-wide partnerships like the DRC and DWA while infusing into these partnerships a new emphasis on salmon and steelhead reintroduction. Moreover, the funding stream was beginning to catalyze the formation of partnerships specifically organized around the reintroduction effort.

Contingent Shaping of the Reintroduction Narrative By the mid-2000's, then, the institutional context of the Deschutes River Basin was such that, while no Basin-wide entity or framework was in place to organize regional watershed management, there were a number of umbrella organizations, the DWA and DRC in particular, that provided a social network of personal and institutional ties which could be mobilized around more specific opportunities, usually on a more local or subbasin level. In the context of diminishing rural economic opportunities and increasing state and federal fiscal constraints, alternative funding streams such as the Pelton-Round Butte Fund were beginning to exert greater influence on local watershed efforts through granting criteria that established parameters on the purpose and scope of efforts and redirected resources through matching contribution initiatives.

Thus, for example, in 2006, the BEF entered into a partnership agreement with the Upper Deschutes and Crooked River watershed councils committing 
$\$ 300,000$ to implement and coordinate a 10-year Model Watershed Program (MWP) focusing on restoration and monitoring of three subbasins: the lower Crooked River, Whychus Creek, and Lake Creek. The latter 2 watersheds are considered especially important for the successful reintroduction of steelhead and Chinook salmon, while Lake Creek, a reach of the Metolius River, itself a tributary of the Deschutes River, was also one of only two reaches in Oregon that historically supported sockeye salmon (the "Suttle Lake sockeye").

But the BEF MWP was by no means the only partnership entity. In fact, urbanization and immigration to the Basin brought with them an explosion in the number of local, regional, and national non-profit and private organizations working on issues tied in one way or another to water. The prevalence of organizations, many of them advocacy in their orientation, exacerbated the lack of regional coordination and presented challenges for organizing higher-level partnerships, as more entities competed for overlapping funding streams. For example, the Upper Deschutes River Coalition (UDRC) consists primarily of landowners and neighborhood associations who focus their efforts on management of, and raising awareness around, wildfires and habitat in the subbasin. It emphasizes that the reintroduction efforts should not be at the expense of private property, real estate, and rural economic development interests. In the context of the struggles to define the Basin's management priorities, the UDRC represents an alternative perspective to the dominant reintroduction narrative. Over the past few years the UDRC has 
also received funding from OWEB, as well as from BLM, the Central Oregon Irrigation District, and the NFF, among others.

The emergence of these partnerships - and, by extension, the policy context that favored their formation - was neither purely grassroots nor manipulated by higher-level policy actors. Instead, it appears that policy actors and coalitions across multiple levels of governance engaged in a kind of mutual adjustment of ideas and practices as policy-relevant events and conversations, many of them exogenous to the process, unfolded. One such catalyzing event was the relicensing of the Pelton-Round Butte Dam complex. The competing intents by PGE and CTWSR and the resulting mitigation mandates could, by themselves, have had the effect of further splintering the Basin community, as happened in the Klamath Falls Basin. But the subsequent Pelton Round-Butte Fund dedicating $\$ 21.5$ million to water rights and habitat improvements was a seismic event that expanded opportunities for collaboration and helped to recast watershed management in the Upper Deschutes in terms of salmon and steelhead reintroduction. As one of the partners of the Upper Deschutes River Partnership puts it:

When the re-licensing settlement agreement was signed with the Warm Springs Tribe, General Electric, and all of the folks that were involved in the re-licensing, it became clear at that time that there was going to be significant funding associated, and that being habitat funding associated with the reintroduction effort. That is what really galvanized what you see as the Partnership today. That is what it was. Simply the availability of funding and that's kind of a crass statement, but for us, again, the funding helps us accomplish conservation that we wouldn't otherwise be able to do. 
We may well ask whether the relicensing accelerated the conversations and experiments about basin-wide (or at least subbasin-wide) management or whether those conversations and experiments helped to frame the relicensing in the larger context of salmon and steelhead reintroduction. The 2001 relicensing of the PeltonRound Butte dam complex coincided with the NWPCC Subbasin Planning Process and, more generally, with a heightened awareness of the plight of wild Pacific salmon and an increased interest in finding local and collaborative ways, as championed by Gov. Kitzhaber in his Oregon Plan and similar initiatives, to address the state's growing environmental issues. On the other hand, the case will be made that boundary spanners, initially working through a partnership between the EDF and the CTWSR and later through mediating organizations like the DRC and DWA, saw the concurrence of the Subbasin Planning Process and the dam relicensing as an opportunity to join 2 policy discourses, one centered on the substantive issue of salmon recovery and the other stemming from the results-based environmental governance movement that was by then emerging. Gradually a new policy agenda emerged proposing to reintroduce salmon and steelhead in the Upper Deschutes River Subbasin through local, consensus-based and market-driven solutions. The new policy context defined a specific need - the reintroduction of salmon and steelhead in the Upper Deschutes Subbasin - which favored innovative partnerships that could coordinate restoration of instream flow, water quality, and habitat on a watershed scale. But the development of this policy context was not strictly agentdriven. Historical records and informant testimony captured in interviews reveals 
that these boundary spanning individuals and organizations changed in the process of shaping the policy context. The engagement of funders, organizations, and constituents in novel contexts like the DRC, DWA, the dam relicensing, and the Subbasin Planning Processes was transformative for the participants. For approximately 10 years, between circa 1995 and 2005, policy conversations and experiments facilitated the gradual alignment of expectations so that, by the time the Pelton Round-Butte Fund was formed, organizations like the DRC which had participated in those conversations and experiments, were in a position to respond.

But the convergence of innovative policy practices and funding environment didn't stop there. In the absence of a strong regional policy framework, there was more room for local boundary spanners to define the specific shape of these partnerships and indeed to influence the policy context itself in ways that have tended to reinforce the direction of social learning in the Upper Deschutes Subbasin. The 10-year Model Watershed agreement between BEF and the 2 watershed councils is a case in point. Furthermore, there is some evidence suggesting that as partnership experiments like it produce promising results, they are spurring the formation of partnerships with a similar strategic focus and approach. In 2007, OWEB launched a Special Investment Partnership (SIP) Program that resulted in a SIP agreement between OWEB, The Upper Deschutes Watershed Council (UDWC), the Crooked River Watershed Council (CRWC), DRC, and the Deschutes Land Trust (DLT) that committed $\$ 4$ million in dedicated funds over 2 years toward the 
restoration of the Whychus Creek watershed. ${ }^{28}$ Early successes in the reintroduction efforts have already attracted attention and additional funding to the partners. As we shall see, these funding initiatives and ensuing media and institutional attention have tended to reinforce the collaboration between and among these organizations and their partners working on reintroduction-related issues in the Upper Deschutes Subbasin. At the same time, many issues like rural economic development, which are of course part of the watershed story, have tended to lose visibility to the extent that they remain removed, in policy discourses anyway, from reintroduction efforts.

But these partnership experiments have also impacted the funding environment that supports them. In some very significant ways, both the Deschutes MWP and Deschutes SIP have become models for their sponsors as they look to reproduce their success in other basins. There has been, in other words, a kind of convergence of innovative partnership practices in the Upper Deschutes River Subbasin and a more "global" institutional ecology of watershed management. Furthermore, this convergence has operated through, and on, a vast network of policy actors that has enabled divergent practices to be compared and progressively aligned to one another. In the process, the network itself has changed. Thus, the implementation of their respective partnership agreements has recast the relationship between, for example, the BEF and OWEB at the same time that the links between the partnering entities have acquired a new dimension. This study

${ }^{28}$ The DLT uses a strategy of land acquisition for conservation purposes that is modeled after water trusts like the DRC and Oregon Water Trust (OWT). 
proposes to use the informal label “Upper Deschutes River Partnership” (UDRP) to refer to this new dimension of coordination centered on the reintroduction of salmon and steelhead in the Upper Deschutes River Subbasin. ${ }^{29}$ Figure 15 is a map of the Upper Deschutes Subbasin area where the UDRD has focused their work.

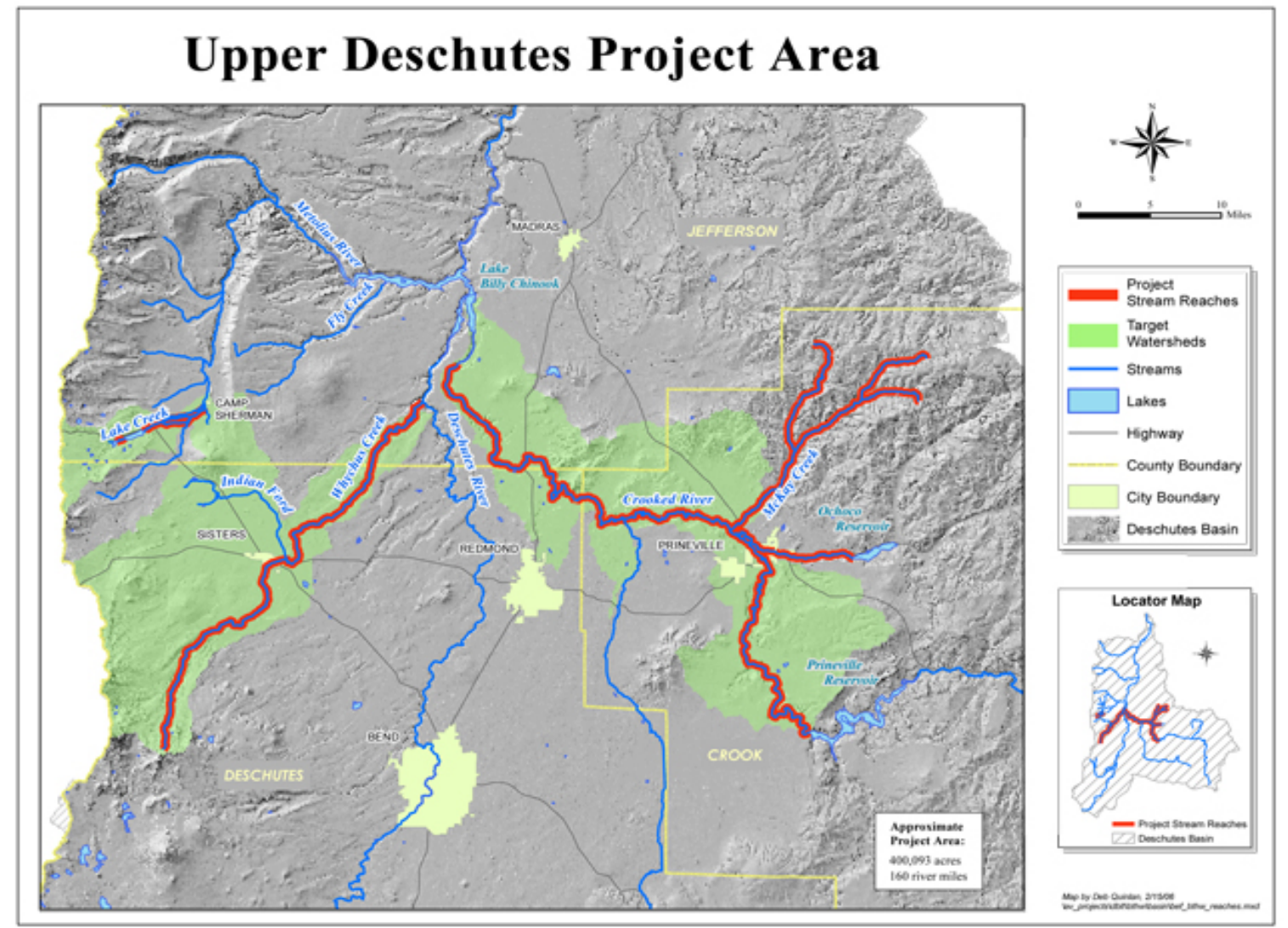

Figure 15: Upper Deschutes River Basin (Source: OWEB)

The moniker is intended as an analytic construct to help make sense of a particular set of partnership processes. It should be noted that informants in interviews never

${ }^{29}$ I use the term "Upper Deschutes" to refer to the drainage area upstream of Pelton-Round Butte Dam complex and Lake Billy Chinook. In many literatures, this area is further divided into the Middle Deschutes Subbasin, typically defined as the drainage area between Lake Billy Chinook and Bend, and Upper Deschutes Subbasin, typically defined as the drainage area generally south of Bend. 
referred to an "Upper Deschutes Partnership," per say, although informants would sometimes refer to "the partnership" when discussing collaborations around the reintroduction effort. However, the term is meant to suggest that there are partnership processes that transcend the specific partnership agreements (and perhaps the awareness of policy actors) that nevertheless animate and give a definite shape to the imagination and practices of a cluster of policy actors working in the Upper Deschutes Subbasin. The "Upper Deschutes Story" of the salmon and steelhead reintroduction is being recounted with greater frequency and with greater institutional salience, and there is evidence to suggest that actors are capitalizing on it to create new opportunities for themselves and their partners. There seems to be something like an "Upper Deschutes River Partnership," which has achieved a currency in certain policy circles. But the convergence into a coherent Upper Deschutes River Partnership is by no means complete or assured. In many ways, we find evidence of the same sorts of struggles to balance different interests and needs under a common Subbasin management vision framework as we do in the larger Basin. Unless or until the larger Basin community's narrative achieves greater coherence, the fates of the two stories will probably be tied to one another.

\section{Formation of the Upper Deschutes River Partnership}

\section{A Programmatic Context Emerges}

The twin convergence of innovative policy practices and policy context - one at the Basin level and one at the Subbasin level - is in many respects encapsulated in 
the story of the Deschutes Land Trust's "Back to Home Waters Program." Like the DRC, the DLT had board ties with both PGE and CTWSR, as well as with other important entities involved in the negotiations, including ODFW, and thus served as an informal, albeit important, mediating organization during the dispute over competing intents to renew the dam complex license. Led by its charismatic and visionary Executive Director, Brad Chalfant, the DLT launched a program in 2001 called "Back to Home Waters," whose name evoked the image of salmon and steelhead returning to their historic spawning and rearing grounds. The development of the program coincided with both the relicensing negotiations between PGE and the CTWSR and the NWPCC's Deschutes Subbasin Planning Process. The DLT's ties to both processes meant that it was influenced by them. But conversations leading up to the Back to Home Waters program actually preceded both the Deschutes Subbasin Plan in 2001 and the settlement agreement in 2004, which suggests that the DLT became an important programmatic context for getting the reintroduction of salmon and steelhead on the Basin's policy agenda. Indeed, as one DLT staff person relates, the DLT's involvement in the development of this agenda dates back to the mid-1990's when, anticipating the dam complex relicensing, the CTWSR and EDF articulated an alternative vision in their Restoring the Oregon Deschutes River that soon led to the formation of the DRC. Policy entrepreneurs behind the vision became keenly aware that the relicensing and Deschutes Subbasin Planning Processes represented a unique opportunity to leverage mitigation obligations on BPA, PGE, and others for funding their work: 
Those efforts began in probably 1995 with the knowledge that those dams would need to be re-licensed. At that point in time, shortly thereafter a number of the groups that are now involved in the partnership began working either in a focused way, which was the case with us, or [...] they were dabbling in reintroduction or focused on it. I think the Land Trust was probably more focused on it. We were more involved in the actual licensing issues. Early on in about 2000 saw the potential for bringing all of these groups together. At the time we didn't have a concept of what all these groups meant. But bringing everyone together to focus on this reintroduction effort, and the opportunities we thought it would bring in terms of accomplishing conservation and restoration work. [...] So we initiated in 2001, sort of formally, as formal as anything we do in terms of our conservation work, a program we call "Back To Home Waters," which is exactly that: it's conserving habitat and restoring habitat to support the reintroduction of salmon and steelhead.

Although Back to Home Waters was ostensibly a DLT program, one can discern the influence, if not the direct hand, of the CTWSR, EDF, and DRC in the development of the program.

Chalfant hired Brad Nye to head the program in 2001. Here too, social ties played an important role. Nye had worked previously with the CTWSR and served on the Upper Deschutes Watershed Council (UDWC), while his wife, Lisa Nye, had served as the DRC's first Executive Director. Although the DLT had worked sporadically with both the DRC and UDWC, the Back to Home Waters program catalyzed their working relationships with one another and with close funding partners around a new focus on salmon and steelhead reintroduction. Until then, many of the young organizations that were just starting to work in the Basin struggled to find a niche around which to organize their efforts. By all accounts, this appears to have been the case for the DRC, DLT, and the UDWC. The lack of strategic focus meant that programs tended to overlap among the organizations. For 
example, all 3 organizations carried out various kinds of restoration work. As a result of this programmatic overlap, the organizations tended to regard each other as competitors for limited funding. A DRC staff person recalls:

I also noticed that we had a Land Trust that viewed itself in various sundry ways. It protected land. It did habitat restoration on its land. They each had water rights. They had water. They were an organization that did conservation in a specific but also general way. They talked about themselves in a more general way. I noticed watershed councils were very technical and very interested, and very good at habitat restoration. I looked at the DRC, which had been a very innovative and creative organization. People described my predecessors as basically innovating. Throwing stuff against the wall, what would stick, what wouldn't? We did carbon sequestration, we were going to do water leasing, water banking. We had all sorts of innovative concepts. It was much more of a research and development group, which had developed a couple of solid programs. [...] We had overlapping programs, not fully but enough.

The Back to Home Waters program started to change that. The first project, started in 2000, was the land purchase and conservation easement centered on Camp Polk Meadow on Whychus Creek that was partially funded by PGE's Habitat Restoration Fund. In what would become a model for future work, the Land Trust proceeded to lease and permanently transfer water rights to both the DRC and the Oregon Water Trust for instream flow. It's clear that from the very start the DLT envisioned the Back To Home Waters program as the basis for building a strategic partnership around land conservation, restoring instream flow, and habitat restoration. The DLT staff person continues:

An example of that is our Camp Polk property we purchased in 2000. We did a water transaction on it, as we mentioned, to get water into the stream knowing that was important with the DRC. From the time we bought the property we were looking for someone to restore it... 
But finding the right partners to carry out the actual habitat restoration initially proved difficult:

...that was a challenge I faced in the Back To Waters thing. I had talked to facilitators back in 2001 about "This is what we want to do; how should we do it?" The obstacle then was the list of partners we were looking at was very imposing. There was probably 20 or 30 groups. The challenge was how "Do we get a core group?"

Coordination would in some senses be easier with fewer partners, but it would also be important for the partnership to be sufficiently representative of relevant interests. The UDWC, like most watershed councils, specializes in watershed restoration projects, such as removing culverts, stabilizing streambanks, restoring channels and wetlands, and improving habitat. The UDWC seemed a likely candidate, given its charter and its local ties to both the DLT and the DRC, but it lacked sufficient capacity. The PGE Habitat Restoration Fund, and later the PeltonRound Butte Fund, provided critical support to build that capacity. The Camp Polk Meadow project on Whychus Creek established a model of coordination - the DLT purchasing land, the DRC leasing or transferring water rights, and the UDWC carrying out the restoration - that would eventually form the framework for a strategic partnership between the 3 organizations.

From New Friendships Comes a New Partnership

The simultaneous hiring of key managers at all 3 organizations also shifted the interpersonal dynamics and catalyzed the development of the partnership. In 2001, the same year Brad Nye started heading the Back to Waters Program at the DLT, the UDWC brought on board Ryan Houston to lead the organization as its 
Executive Director, while Tod Heisler succeeded Achterman as the DRC's new ED 3 years later in $2004 .^{30}$ As new hires, the 3 men were less tied to the historical politics of the organizations and more inclined to view the reintroduction efforts with a fresh set of eyes. As one of them recalls:

The writing was on the wall that the fish would be coming back at some point. With that was a historic opportunity that many places in the West never get to work with. So for people interested in rivers, watershed, and fisheries, the chance to restore populations of fish that have been gone for almost half a century, it's really exciting. It's career changing kind of work. With that we also knew, and this is the self interest side I think is important, we also knew there would be a ton of opportunity for each organization to better implement its mission, be more successful because there would be more money available. There would be funders, partners. People would see this historic opportunity and want to be part of it. We basically said - and these were informal coffee/beer kind of conversations between Land Trust, DRC, Watershed Counsel where we said - "We've been fighting for a long time. Thankfully some of us are new so we don't carry the baggage of fighting as much. We carry some of that baggage but not as much of it. This opportunity is coming and if we don't get ourselves together, and grow up, and be professional, and work out our differences, we are going to squander this opportunity."

Accounts differ on the degree of "fighting" between the organizations that preceded the new hires. Regardless, personality appears have been a factor, since in many ways the strategic partnership grew out of these informal meetings between 5 individuals: Chalfant, Houston, Heisler, and Scott McCaulou, DRC's Program Director. Many testify that Tod Heisler, especially, was inclined to see the benefits of a strategic partnership, in part due to the organization he represented, but this proclivity also stems in part from his own personality, as several colleagues report:

I also think Tod thinks more on a partnership level than the rest of us, probably by his personal nature but also by the nature of the way they do

${ }^{30}$ Achterman left the DRC in July, 2003 and Aylward served as interim ED until Heisler's hire in 2004. 
their business. He's got a lot of different partners. He understands the need to work together expanding that sort of energy.

My relatively brief time here interacting with Tod Heisler with the DRC, he's pretty broad-visioned and probably looked at "How can we bring this together? What different strengths do different organizations have to do that?" I would expect he would have been...there was a lot of behind-thescenes stuff; I think he's a pretty big player.

The timing of the intersections of the arcs of these men's careers probably also favored institutional change, since all of them were relatively young or still building their careers.

In 2002, the DRC and UDWC moved into the same office complex in Bend. The close physical proximity of staff facilitated the kind of impromptu exchanges on which deeper relationships of trust are built. As the trust grew, so did the social learning: communication became more open, revealing problems that had not been apparent before. As staff members of both organizations recount, it became apparent that the 2 organizations shared many interests and even functions, but that this overlap was haphazard and even counterproductive:

About the same time in 2002 the Watershed Council and DRC decided to move in together and share this office. Things started to change. We started to say, "We have to work together. We have to figure this out. This competitive nature, this stepping on toes, this jockeying for position...is not smart. We're all trying to do the same thing; we're competing with each other." That was the context.

We also had this Deschutes, DRR, Deschutes Repair and Restoration effort. We had a program, one of our key program people who sat right next door, we're all in the same building. It took me a little while to figure out there was social coordination in the office, everybody liked each other. There was some professional engagement, but very little of it was very meaningful. 
It is also undoubtedly the case that the physical proximity placed a greater premium on nurturing the social relationships since any issues in those relationships had more immediate consequences for the parties involved. At any rate, interviews reveal that Heisler and Houston started having conversations in 2003 exploring ways to work together in a more strategic and coordinated fashion. One of them recalls:

We put forward the notion, and the timing of this was critical, we knew that through the re-licensing of the Pelton Roundbutte, there was now an obligation by the Tribes and by PGE to mediate. They were spending a huge amount of money on a fish passage facility up there at their dam. They were also investing \$20-\$25 million that was spread out over 10 to 15 years on habitat development and restoration for the reintroduction of steelhead and salmon. We knew those were about to happen. Those were about to be funded. I put forward the idea that we're going to be so much better off if we go together, if we look like, if we're playing together, if we have a joint strategy. We know the outcomes we're seeking. We understand the roles each of our institutions play. We can put that forward as an initiative rather than us going in with our projects, our dots on the map. Our project over here, this project over here, which ultimately looked like competitive efforts where we're disassociated and with our own blinders on we put our own projects through a project window. I said, "We have to look at this not as a project window but as an opportunity to drive a major initiative with funding that is about to come on. Basically we can make the pie much bigger by telling a much bigger story and having a much larger vision, and still being able to drill it down to the pieces."

In many ways, Houston served as a natural catalyst of the initial meetings, since he had by then fostered closer working relationships with both the DRC and the DLT through various restoration projects and was therefore in a position to set up meetings between Heisler, McCaulou, Chalfant and Nye. The first meetings were somewhat awkward, as one of the participants recalls:

It was [the $5 \mathrm{men}$ ] literally just sitting around figuring that stuff out. It was just classic. They say you never want to see laws or sausage made; you don't 
want to see partnerships being formed. It was a lot of talking about things and figuring things out, saying, "Your organization currently does this. What you're doing is really offensive to us because it treads on our territory. We need you to stop doing that." It was that kind of thing.

For all their enthusiasm and vision, relatively unshackled by historical baggage, these boundary spanners still had to work through many issues related to institutional differences and conflicts between the organizations and constituents they represented. Despite the significant programmatic overlap, the organizations differed in their histories, missions, and operations. The DLT was a privately funded advocacy organization answerable to a distinct interest group concerned with land conservation and preservation. In contrast, both the DRC and the UDWC had been formed to represent a broad range of stakeholders to tackle the many controversial and context-sensitive aspects of water and watershed management. Almost by their very nature, they tended to be more process-oriented than the DLT, which only needed to answer to their private community of members and funders. The DRC and UDWC often found the DLT's independent streak frustrating, as, for example, when the DLT decided its administrative independence was more important than any potential cost-savings associated with moving into the same building with the other 2 organizations.

But the rub ran in multiple directions. The DLT, for instance, perceived the DRC as too "development-friendly" in its water transactions program, and it argued that many of those transactions had the unintended effect of reducing restoration opportunities by precipitating the breakup and development of streamside farmland. In addition, the DRC had served as a funding entity distributing federal 
appropriation and other dollars to various conservation and restoration projects that were, in many cases, carried out by the DRC itself. This created an ambiguous relationship between the UDWC and the DRC, which functioned alternately as both funder and competitor to it.

But, despite these significant differences in both the missions and approaches of the organizations, the staff tended to share a common vision around restoring and conserving the basin's natural resources and wildlife, as a staff person at the DLT recalls:

We all work differently. The Land Trust is a privately funded and much more private entity. The [Upper Deschutes] Watershed Counsel has, on its board, county commissions and those sorts of things. Their thing is to pick across the social and political landscape to get broad representation. We try to do that too but it's not anything formal. We want the most effective board we can have. The DRC is similar to the Watershed Counsel in terms of that they need to have a board comprised of various interests. In that sense the organizations are different but on a staff level we pretty much do the same sort of thing. [...] On a staff level we all speak the same language; we all have the same interests conservation-wise in most cases.

Another key factor in overcoming these differences appears to have been the somewhat serendipitous confluence of motivations drawing the parties to the negotiating table. All 3 relatively young organizations were struggling to define their missions and build their capacities, and this soul-searching was catalyzed by the arrival of new staff in management positions. Houston had already approached the BEF to fund the DRWC efforts to restore the Whychus Creek in what would have been Oregon's first Model Watershed Program, but the BEF decided the DRWC did not have sufficient capacity. Nye had approached some professional facilitators to put together a partnership of organizations to carry out the Back to Home Waters 
Program and got a similar response. And finally, Heisler soon found himself struggling to explain to his finance department and board why the DRC carried unused funds. This, in turn, stimulated some critical reflection, and Heisler came to the conclusion that the problem was a lack of social capital in the DRC's relations with key stakeholders, especially the irrigators, which prevented successful completion of many of their projects.

Thus, when the men finally sat down to discuss ways to work more effectively together, each was already motivated to do so and was thinking of ways their organization might benefit from such a partnership. As already stated, the early meetings were not always pleasant. But it was perhaps precisely this frank communication - combined with a demonstrated intention to listen and learn from one another - that fostered enough trust among the managers to take some chances in changing their own organizations. Thus, for example, Heisler recognized that the DRC would actually be more effective if it transferred much of its restoration work to the UDWC. As one of the participants of those early discussions recounts:

Each organization had to do a little bit of reflection on itself and decide, "What is my niche? What do I really want to do given that I am now somewhat accountable to these other parties? I need to pay attention to what these other people think." The DRC shifted some of their programs, and they canceled one of their programs that is a program that we do. It had been an overlap. In the nonprofit world overlap means competition. It had been an overlap and to their credit they said, "We're not the best ones to do this. You guys are. We're going to cancel our program." They not only canceled their program, but they gave us some of the money they had in their program because they wanted to invest in us being successful. There were things like that where the boundary spanner in that case might be someone like Tod (Heisler), who recognized it's in his own organization's long term interests and the watershed's long term interests for him to cancel a program and give money to someone else. I think it's pretty cool in terms of that situation 
where he saw 10 or 12 chess moves ahead and knew it was a good thing to do, even though the short term meant, "cancel program and give up money."

Heisler set to work reorienting the DRC from a largely research and development organization that funded pilot projects ranging from carbon sequestration trading to habitat restoration to one focused primarily on restoring instream flow. At the same time, he envisioned the DRC "outsourcing" much of its work on water quality and habitat restoration through strategic partnerships. And because a consensus view was by then emerging that instream flow was an important determinant of water quality, Heisler could still make the case that the DRC had not abandoned its core concern for water quality. Heisler approached his board on the matter and proposed to add a key criterion - is there genuine stakeholder buy-in? - for selecting projects and programs. By modifying the DRC's project filter, Heisler proceeded to change his organization's boundary condition. What is striking is that Heisler not only articulated a problem, but he proposed a solution which the board could then deliberate on. When the board approved the strategic change, new opportunities for collaboration emerged. As a DRC staff member recalls:

All the time was spent by our staff and us saying, "How do we now take things we piloted and scale them? Can we get the agreements? When we do, this will turn absolutely around and we will have too many projects chasing too few dollars." That is where we are today.

Convergence on Multiple Governance Levels

It remained for the managers to make their case to their respective boards, and initially there was pushback from some of the board members. At least initially, the ongoing negotiations around the relicensing and Subbasin Planning processes 
created a context of tension if not distrust for the boards, particularly given the DRC's and DLT's historical affiliations with the CTWSR and PGE, respectively. More generally, there was a natural inclination for the boards to want to protect their respective programs and interests, as one of the managers recalls:

There were plenty of side conversations and back conversations expressing frustration, and "Why do we have to give up this much? Can't they give up more?" All that negotiating kind of stuff. In the end, when we said - "Historic opportunity, we don't want to blow it by bickering with each other. We have to come together; in order to come together we have to give up a little" - I think they got that.

It is to the credit of the organization's boards that they were willing and able to reflect on their core purposes and cede some of their functions and potential funding streams to better realize them. This was especially the case for the multistakeholder boards of the DRC and UDWC, where social learning within the organizations had gradually produced board members who were more inclined to think in terms of relationships and collaboration. A staff member of the DRC explains:

We have board members who go to Salem on a regular basis. They're on opposite sides of the issues lobbying hard for the legislature to create new policy statute where they're in absolute and utter complete disagreement. They come to our board and now they actually behave themselves and they know their job is not to go in and try to grandstand, or make a point on principle, or try to persuade somebody to go down some narrow path. Their job is to listen to other people and to say, "Am I okay? Is this a way I think is an acceptable way for us to resolve, work on a long standing issue?" That turns a whole different way of viewing things. It's been remarkably successful. It's allowed us to do what I was saying before, which was to take non-agreement, the whole too many dollars chasing too few real projects it's allowed us to reach the larger universe, a larger bounds of agreement, which then enables implementation at a larger scale. 
Furthermore, as the managers continued to meet with one another, their messages

gradually became more consistent and reinforcing. As one of the managers

remembers:

I think what we all did, quite honestly, is we all were staff at our organizations, we all had to sell this stuff to our board. I saw how Tod sold some of his. I saw how I presented some of mine. I didn't see much of how the [partnering organization] presented theirs, but presumably everybody had to sell it and market it in a way that fit with their constituency. I think what I remember Tod saying is, "We're here for the whole, and in order for us to be successful, our partners need to be successful. This is a program that has kind of been a ball-and-chain for us. It's kind of been a pain-in-the-butt, so it's appropriate for us to cancel it." If it was their best program, their favorite program, they probably wouldn't have done it. They were somewhat relieved to be done with it. I think for all of us the main thing that we shared with our boards was all of our boards are committed to collaboration, in spirit. In practice it's always challenging because you have personalities, baggage, politics and all that. I think when you stand in front of your board and you say, "I'm working with several organizations, we're going to gain a lot but we have to give up a little," any board is going to go along with that. They have to. That's their job is to rise above it in that environment. Frankly I think a lot of people were tired of the bickering. It's kind of embarrassing from a professional standpoint. It's just silly. Why should the water people be arguing with the fish people? We're all on the same team. I think everybody had that in the back of their mind: "Come on guys, this is pretty ridiculous." It all sort of came together and gelled. I think the driving force was that opportunity and the fact that everybody knew they would be better off if they joined.

The partnership required of course internal changes in the organizations that introduced a fair amount of stress and uncertainty for staff as well. The manager leading the partnership effort had to learn how to communicate these changes to staff, making judgments about what to communicate to whom and when. It entailed the development of a particular set of skills for boundary spanning downward from high-level strategy to day-to-day operations. 
These talks coincided in 2003 with the DLT's capital campaign to raise $\$ 3$ million to purchase a 1,240 acre forest tract from Weyerhauser Industries that was one of the last tracts along a critical reach of the Metolius River still in private hands. The capital campaign mobilized critical matching support from the NFWF, OWEB, and the Orvis Company, among others, and enabled the DLT to exercise their purchase option just before it expired later that year. The resulting Metolius Preserve created an opportunity for the DLT, DRC, and its partners to begin largescale monitoring and restoration work to prepare for the reintroduction of salmon and steelhead. Here too, capacity became an issue, and it took some time for the DLT to convince the UDWC to take on such a large project. But once again, the nascent ties among the organization's new management proved pivotal in moving the organization's board toward a partnership, as one of the DLT staffers explains:

I know we went to their board meeting and suggested they adopt the Metolius River as part of their jurisdiction because of its importance. We did things like that. We never really pulled the partnership together. I can show you. I worked on it with Ryan (Houston). I think I probably presented to his board flow charts of what is "Back To Home Waters" and how do we all fit into it?

The "Back to Home Waters" Program provided a programmatic context for the development of the partnership between the 3 organizations, both providing opportunities to test ideas as well as to formulate new ones to discuss. For Heisler, a key concern of outsourcing overlapping functions was ensuring the UDWC and the CRWC had the capacity they needed to carry out the restoration functions that the DRC was now ceding to them. The partners saw an opportunity to extend DRC's role as fiscal agent by formalizing administrative and funding agreements with each of 
the watershed councils that would essentially "seed" the capacity for writing grants to sustain their own capacity over time. One of the partners explains that the DRC and the watershed councils developed individual MOU's that reflected the unique objectives and conditions of each relationship while serving a larger strategic objective:

It starts with all of our highest level objectives of our mission to restore flow and improve water quality, which really requires restoration at a high level in the watershed. You break those higher level objectives down to these pieces. You see it's the integration of them that gets you there. That is level one, the partnership. And then you can now go into each segment and see a whole other universe. My universe is very different from Ryan's and very different from the Land Trust's.

As the partnership grew, the reconfiguration of relationships at the staff level

translated to broader institutional changes at the board levels. For board members, each successful iteration of the partnership gave them more political cover to span their own boundaries at higher governance levels. An UDWC staffer explains:

I think that because in the "Deschutes Partnership" we started working together and we started reconciling some of the competitive issues and things like that between the partners that existed in the late 90s and early 2000 , I think what that did to the next tier of people, those stakeholders, communities of interest, I think what it did was it sort of released them from taking sides. The Land Trust connected into its network, DRC its network, the Watershed Counsel its network. If the Land Trust, DRC, and Watershed Counsel were bickering with each other, inevitably those networks that were connected into those boards and were sort of staunch supporters of that organization kind of took sides, but kind of had to. They were like "I'm a founding board member of $X$ organization, and so this organization is right." Once the bickering went away and we said, "We're working together," I think that went away. The relationship between that outer network and the core organizations, I think improved. Then I think when you step outside the nonprofits and you have those folks out in that network, I would assume their relationships evolved a little bit. There was no longer this allegiance situation. 
It is noteworthy that improving board relations coincided with both the successful relicensing negotiations between PGE and the CTWSR and the NWPCC's Subbasin Planning processes. This study did not examine the precise causal relationship, if any, between the 3 processes. However, we have evidence to suggest a convergence occurring between staff and board level relations and practices; it is reasonable to suspect that a similar convergence was occurring between the boards and these higher level negotiations. However and whenever it started, the warming of relations between the major interest blocs, once these networks were connected, appears to have been self-reinforcing.

The convergence accelerated in 2004 when the partnership work between the 3 organizations got the attention of Todd Reeve at BEF. As already mentioned, Houston had already unsuccessfully approached the BEF about selecting Whychus Creek as a Model Watershed. But in the intervening 2 or 3 years, 2 critical developments now improved the chances for such a Model Watershed: first, it was by then apparent that a relicensing settlement agreement between PGE and the CTWSR was going to feature a significant initiative (and funding streams) to reintroduce salmon and steelhead to the Middle- and Upper Deschutes River Subbasin; and second, the UDWC could point to an incipient, grassroots partnership with the DRC, DLT, and CRWC that was already resulting in significant restoration projects in reaches like Whychus Creek and the Metolius River tributary. Later that year, Reeve told Houston and Heisler that he thought that the partnership was ready to apply to form a BEF Model Watershed. In an important instance of boundary 
spanning, Houston invited the CRWC to join in the application, and Jason Dedrick, ED of the CRWC, set to work planning how to include the Crooked River Subbasin in the Model Watershed Program.

It is clear from interviews that a grant deadline for receiving 10 years of support to carry out a comprehensive watershed scale restoration spurred the partners to accelerate their strategic planning and partnership development, as one of the partners recalls:

In a way what it all came down to was we needed a deadline to kind of get our act together. It's one thing to talk about working together, it's another thing to actually work together. [...] Then what happened is they [BEF] saw the reintroduction of the fish happening. They saw this partnership forming, and BEF started saying, "Maybe this is right." They started saying, "We think it's time for you guys to apply." [...] What we had to do at that point was produce something and what BEF said to us is, "As part of your application we want to see a ten-year plan of work for what you guys are doing collectively." We looked at each other and said, "There is our deadline." We developed what we call the Watershed Restoration Matrices, which were basically a ten-year work plan for what we would do collectively in Whychus Creek. That is really what got it rolling was that deadline to apply for BEF.

Reeve's decision to encourage the partners to apply amounted to a moment of selection - a validation of a set of still-unnamed boundary spanning practices - that nudged the partnership in a specific evolutionary direction. But BEF's influence did not stop there. To help the organizations prepare for applying, Reeve offered to facilitate capacity-building workshops for the partners to develop their strategic restoration and monitoring plan for the Crooked River and Whychus Creek watersheds. In addition, Mary Vass of the NFF, who was already looking for partnership opportunities in the Deschutes National Forest, took an interest in the partnership and offered to help co-facilitate the process. Reeve and Vass came 
down to Bend and facilitated planning meetings over roughly 6 months. The result was by all accounts a strong application that had thought through and addressed many of the technical, institutional, and social capacity issues that often frustrate implementation. In 2005, the 2 watershed councils signed an MOU with BEF committing a minimum of $\$ 250,000$ over 10 years to monitor restoration of the Crooked River and Whychus Creek watersheds.

The offer by Reeve and Vass to come down and assist the partnering organizations in preparation for applying to BEF's Model Watershed Program reflects a remarkable appreciation for addressing capacity issues before committing funding. But it is also remarkable for the convergence that it facilitated. A significant socio-technical innovation that came out of the application process was a series of matrices that organized the roles, actions, and responsibilities of the organizations around a set of concrete and measurable outcomes concerned with instream flow, water quality, habitat restoration, and education and outreach. Working backward from outcomes enabled the organizational partners to more strategically coordinate their activities and functions over time. In that sense, the matrices served more as a framework than it did an action plan to guide the selection, design, and implementation of projects as opportunities or problems arose. As one of the partners explains:

"What are we actually going to do and how do we spend our money?" That is what requires us mostly to come back together. Different opportunities, and things are always changing because we have project concepts, big pipeline of stuff. The question is: "What is coming up for whom? How does it fit?" In those conversations sometimes what will happen is we'll see, "You really have that going now; we ought to ramp up our activity. We're going to focus 
some more time now that we know you're that ready. Maybe there was some critical dependency that that landowner needed to be brought on." When that landowner came on, that was going to create an opportunity for Ryan's group to do some habitat restoration on that property. That would be a classic example.

This approach provided the partners with the kind of flexibility required to carry out a 10-year restoration and monitoring plan, while the emphasis on outcomes gave monitoring a central role in the adaptive management of the watersheds.

It also flipped the problem of capacity on its head: by dividing up the various roles and responsibilities to achieve a desired outcome, the capacities of the partners ultimately came to depend on, rather than subtract from, one another, as 2 of the partners explain:

We basically said in those restoration matrices: "We are not so concerned about how many trees we plant, or how many widgets we build. We're concerned about the long term ecological outcome." We don't want to measure activities, which are sort of really measures of busyness: "I planted a million trees." "Great, you're really busy. Did you actually accomplish anything? Did you have an ecological outcome? Did those million trees actually change whatever? Bird habitat, or bird populations, or whatever?" That focus on ecological outcomes was, and still is, a core theme. That, at least from the audiences we talk to, they see that as an innovation. I don't know if it really is; it's really simple. [...] But when we go to funders and say, "We have this 10-year program of work, it's loose, it gets edited all the time, it's not perfect, but it's focused on outcomes, and in order to achieve those outcomes, all of us need to be effective," [...] they say, "That's incredible, no one has ever done that."

Basically what we said is, "The collection of activities is very ecologically significant and they drive these outcomes. Aren't these the ones you want to see? Fish habitat? Fish passage? More water in the streams? Us protecting this area from development encroachment? Isn't this what we're all about? Yes." Then it became less about "this project is better than that project," or "should we be trying to go through this exercise of prioritization of all these activities to see which should come first and which is ecologically more important?" Get away from that and say, "Together they're very ecologically significant." Now we can overlie opportunity. First you have strategy; then 
you have opportunity. "Where are you ready to move?" [...] We're at cultural, social, and political agreement. "Where does that exist?" You go to those places.

While the development of the matrices was certainly a collaborative process, one can detect the guiding vision of Heisler, particularly in its emphasis on prioritizing and sequencing projects according to the level of support they enjoyed from landowners and other key stakeholders. This approach was consistent with the strategic planning Heisler was doing for his own organization. For Heisler, the way to expand capacity was to secure the social and political agreements that would expand the number of projects that could be feasibly implemented. The DLT and the 2 watershed councils enjoyed ties to many important stakeholders, particularly landowners. The DRC's strategic partnership with the other 3 organizations expanded its opportunities accordingly.

At the same time, it is also clear that Reeve and Vass provided critical input and support as the partnership prepared their MWP application. Knowingly or unknowingly, Reeve and Vass acted as policy entrepreneurs working to give a local partnership innovation a particular shape that conformed to the program's broad parameters, essentially outlining the relevant problem domain and the generally appropriate policy response. As one participant of those meetings remarks:

I think Todd Reeve in particular spent a lot of time thinking about the partnership. Mary Vass was helpful in facilitating things and putting stuff on board. I think Todd is very well equipped in terms of thinking about "OK, what is the dynamic here?" So, yeah, [...] they were a good team.

And yet, to the extent that the partnership, particularly the Back to Home Waters program, influenced larger policy conversations and processes, it is reasonable to 
suspect that some alignment of expectations and practices between the partnership and BEF was already in place before the formal application was submitted. In other words, it is likely that BEF was to some extent, at least, conditioned to look for partnerships bearing some resemblance to the partnership that was forming between the 3 original organizations. At any rate, it is clear that the BES-and-NFFfacilitated application process hastened this convergence.

Nevertheless, the convergence took time and, for a while, was by no means assured, as there were plenty of controversies to work through. One of them was naming the partnership. Discussions about naming a partnership carries with it implications for ownership. Ownership itself is premised on a unified vision that is held together through bonds of both trust and mutual accountability. In the absence of self-governance, partnerships are prone to one or more partners exploiting the partnership brand for their own benefit, often to the detriment of the others. ${ }^{31}$ Interviews of UDRP stakeholders reveal in fact that discussions over the naming of the partnership were often fraught with concerns over ownership, suggesting that those bonds of trust and mutual accounting were not yet developed. Over the course of the Polk Meadows and Metolius Preserve campaigns, the Back to Home Waters program had become associated in people's minds with both the DLT and the broader partnership, causing consternation among some of the partnering stakeholders. Several interviewees involved in the negotiations over what to call the partnership recalled questioning whether the partnership effort was really worth it.

\footnotetext{
${ }^{31}$ The dilemma is not unlike those described by the Prisoner's Dilemma and Tragedy of the Commons.
} 
But the common refrain that emerged from the interviews was that early funding provided critical feedback to the managers, staff, and boards that the process was indeed worth the effort. As one DLT staff member relates:

When something like SIP funding comes up and you all of a sudden get a dedicated funding source because of the existence of it, and then you see these more positive day-to-day interactions, you start to think, "Hey" - and I did say this to my board at the last board meeting - I said, "I'm glad [...] some folks on our board were pushing saying, 'Hey, we need to do this.' They got a little reward out of that.

As the last quote suggests, board members encouraged managers to continue with the deliberations when they may have felt like giving up. Interviews with those involved in the early formation of the partnership also revealed that Heisler was especially important in reminding parties that they were better off working together than apart. Regardless, with the exception of the CRWC, what started out in large part as a staff- and management-driven initiative came to be owned by the respective boards, whose buy-in was critical for investing staff resources and time in the process and for making the structural changes necessary to implement the partnership's strategic plans. In contrast, however, the CRWC's board questioned whether the partnership benefitted them. One of the board members recalls the lack of buy-in to the partnership idea:

Originally when the Partnership first started in this BEF foundation, our director at the time seemed to have worked with the Partnership to come up with our plan. Then when the board saw the plan, they were like, "What? This is awful." We've had to come from that point.

This resistance is rooted in a complex interaction of organizational, historical, and ultimately social processes that continue to carry implications for the partnership's 
capacity, as will be discussed below. Regardless, ultimately Dedrick's successor, Max Nielsen-Pincus, was able to put together a strategic plan which the board would endorse.

Shaping Policy Readiness for their Innovations

The initial BEF award also encouraged the partnering organizations to present their framework and plan to funders and partners who were beginning to line up behind the salmon and steelhead initiative. The partnership recognized that, in order to succeed in their Model Watershed plan, they were going to need to partner with others in a variety of areas ranging from skilled and unskilled "boots on the ground" to data collection and knowledge-sharing on the various reaches of the Crooked River and Whychus Creek watersheds. Here, the organizational affiliations with funders proved especially helpful. They reached out to the CTWSR, ODFW, and the Deschutes National Forest, among others. But although prospective partners lauded the partnership's strategic approach, they did not adopt the matrices as part of their own work perhaps as some of its creators would otherwise have hoped.

In the context of a fragmented policy landscape dotted by silos, innovative approaches that integrate previously disparate perspectives and practices often struggle to achieve wider-scale adoption. This appears to have been the case here, even though the matrices enjoyed institutional sponsorship by BES and were generally warmly received. The lack of a regional management framework into which a partnership initiative like theirs could plug themselves meant that there 
was as yet no developed community of practice to adopt it, even with local modifications. The boundary spanners promoting their product seemed to have been aware of this contextual constraint, and matched their expectations accordingly. If anything, according to one of them, by not trying to push their matrix approach too hard, the partners were at least able to avoid active resistance to it. Given their pragmatic focus on outcomes, the partners were less concerned that the matrix was not broadly adopted:

There was sort of this acceptance on both parties that those outside parties could look in on our program of work, or matrices and say, "That looks good, good stuff. " They didn't own it, and we didn't try to force them to own it. [...] We said, "Good enough, these things don't have to be perfect. We'll just keep working. We'll just keep doing it." That comes back to that philosophy focus on the outcomes. We need enough process to get to the outcomes, but we don't need a God-awful amount of process that gets in the way of our outcomes.

The partnering organizations also recognized that they now had a product they could present to various funders to expand the scope of their work to reintroduce salmon and steelhead in the Upper Deschutes River Subbasin. They worked on their message and developed an effective PowerPoint presentation to hone that message to prospective funders. Wittingly or unwittingly, these policy actors developed a novel set of communication practices that were boundary spanning in their own right:

From my standpoint these outcomes, these measurable outcomes drive everything. Instead of selling tasks, we were going to sell the outcomes in the strategic process. Then we had people who take responsibility, in some cases it was a joint responsibility, most of them were joint responsibilities. We got to this level and created a PowerPoint. We created a four-page color printout that distilled all of this into the executive summary-type piece: "This is what we're all about, why we've come together." We started to shop that. 
What was perhaps most innovative about their message was that they often came unsolicited to funders and defined the problem for them using a language of outcomes and proceeded to propose a well-developed strategy for meeting their objectives. They challenged funders to stop evaluating proposals strictly through project windows and instead work backward from desired outcomes. In doing so, they started to upend the entire review process:

We all joined as a team and said, "Our job is not to bicker about whose job is more important. Or job is to get projects out that fit our strategy that [...] we're confident will drive our outcomes." All of a sudden this review thing was turned on its head: it was essentially a self-governing effort among the partners where our incentive was to drive the maximum number of projects to capitalize on as many opportunities as we could. Basically all of them in our minds were equal: "We're not going to argue about whose is more important. They're all important. If this one is ready, let's do it. We can follow later with a project." That was an interesting evolution.

After their BEF award, the partnership drew on the DRC and DLT's connections and approached PGE and CTWSR. One of the partners describes how they approached them:

For me, I guess I really categorize it as: it's one thing to talk about; it's another thing to actually have a tangible product. That BEF application was the first product. Once we did that we realized there are other people interested in this. [...] We were able to take that application and shop it to other people. We took it to the Pelton Roundbutte Fund, which is run by PGE and the Tribes. That is a special funding application dedicated to supporting reintroduction. We basically said to them, "We know you guys are going to spend about $\$ 5$ million at this next funding cycle on reintroduction-related projects. Here in Whychus Creek, our three nonprofits, we are the primary people doing work. Here is our ten-year plan-of-work. This looks like the obvious thing for you to invest in." We started shopping it. 
Each funding success seemed to embolden the partnership to reach out to other funders. As one of the partners explains, it wasn't always easy to bring the parties together and transition into a working partnership, but each grant success provided critical feedback to the partners that they were onto something worthwhile. This soon led to a virtuous funding cycle in which funding increased both the confidence and credibility of the partnership, which attracted, in turn, more institutional interest and funding. The partner continues:

What happened was one would join, the next would join, the next would join. I was looking at the list the other day and it's actually up to about 12 funders who have all said, "We like what you're doing." At that point we started getting the positive feedback loop that was saying, "This works." In the end we kept seeing these rewards. We said, "We have to stick with this." That is what I think it has been, there has been this cost/reward kind of thing, but the reward has outweighed the cost significantly. So it's this constant process of having that feedback.

The early 2 successes with BEF and the Pelton-Round Butte Fund encouraged the partners to approach OWEB in 2006. As one of them explains, the partners brought their innovative approach to the table, framing the reintroduction problem as a coordination problem requiring a partnership response guided by outcomes rather than by project outputs:

At some point the reviewers realized we were completely driving the boat. We would sit down and say, "Here is our strategy, here are the projects. Here is why we're doing them." The questions change. [...] It moved completely away from OWEB's normal process of this microanalyses at a project level, which in many cases is not relevant or very difficult to do.

OWEB was so impressed with the partnership's approach that they decided to form a separate funding program called "Special Investment Partnership" that was largely modeled on the strategic approach taken by the partnership. Indeed, as an officer of 
OWEB explains, the partnership actually worked with OWEB to put together the basic approach that would drive the program:

The things they have done that are unique in the Deschutes is to create a whole upper basin vision, and to explicitly sit down with their partners and say, "What do we envision this place, the upper Deschutes, to look like in the future? What are our various roles in achieving that?" That form of coherent visioning around the reintroduction of anadromous fish into the Upper Deschutes Basin has put them in a position where they could come to us and say, "Look, we have a vision for the future. We would like you to invest in that vision." Very few groups put themselves in that place where, "If this kind of funding is available, here's what we have to match with it and here is the outcome." They were organized in a way that resonated; they were able to speak directly to the core mission of the agency for investment. They worked with us to enhance the idea of targeted investments, which led to them becoming a Special Investment Partnership that we're quite proud of.

In 2008, OWEB awarded its first SIP award to the partnership, committing \$ 4 million for the 2007-2009 biennium. The Deschutes SIP subsequently received an additional \$ 4 million for the 2009-2011 biennium.

It should be noted that, despite the significant support that OWEB's SIP program provides the UDRP, the partnership is not a creature of the state. On the contrary, in the programmatic outlines one can detect many instances where the program was designed with the UDRP in mind. On a general programmatic level, OWEB's SIP aims to build the capacity of partnerships that have already formed, or are forming, "on the ground." As a December 2007 OWEB memo states:

OWEB's contribution will be critical, not only to funding the effort, but also to attracting the other support and catalyzing the action necessary for achievement of the objectives. In particular, a SIP investment will tend to launch important efforts that otherwise have been stalled or delayed (OWEB memo, December, 2007). 
Among the criteria used to assess eligibility for SIP funding, partnerships must demonstrate a minimal level of "ripeness:"

To receive a funding allocation from the Board, a Partnership: (a) needs to be ready to form and begin functioning to finalize objectives and a work plan; (b) must have a likely time frame for implementation and completion that is reasonable and fits OWEB's needs; and (c) must be at the point developmentally where it both needs and can take advantage of the OWEB funding commitment to further the project (OWEB Memo, December, 2007)

But while OWEB appears to have been influenced to some extent by the UPRP, it is also clear that these selection criteria were very much driven by the agency's own practical and political considerations, including minimizing - or at least appearing to minimize - state government's involvement in local watershed management. In the context of the state's budgetary woes and uncertainties, state agencies and programs like OWEB that are funded by legislative appropriations from the Oregon State Lottery Fund are under pressure to fund those projects and programs that are more likely to please lawmakers. Typically this translates into higher-visibility projects that show immediate results but do not necessarily address long-term problems. Partly to address this systemic bias toward band-aid solutions, OWEB developed a SIP program that would dedicate a portion of its funding to facilitate partnerships to work in areas where "the ecological impact, significance of the issues addressed, and the anticipated outcome(s) are large" (OWEB memo, December, 2007). The memo also reflects the agency's preoccupation with high-visibility projects, but this preoccupation appears to be driven by an appreciation of the local as well as state-level political conditions of sustaining partnership work, arguing that such projects can capture the public's 
imagination and raise awareness around watershed enhancement more generally. It goes on to note that partnerships with "robust" funding sources not only provide opportunities for funding leverage, but that they are more likely to see programs and projects through to their completion. Moreover, the SIP program requires awardees to include a comprehensive monitoring system to ensure that periodic assessments of progress can be used to modify implementation as needed.

The alignment of principles behind the UDRP and OWEB's SIP program is evident in these policy promulgations. For example, the program's section criteria reflect an abiding concern with implementation and outcomes. In addition to "ecological significance" and organizational "ripeness," OWEB's SIP program seeks projects that take a "triple bottom line" approach balancing ecological, economic, and social concerns. The same theme was taken up by the DRC 10 years previously. Some of the alignment can surely be explained by situating this theme within the larger outcome-based environmental governance movement sweeping national and international environmental policy since the 1990's. But there is at least one instance in the OWEB memo that suggests the agency was adopting a lesson already learned from the DRC's work in the Upper Deschutes Basin: the memo notes that feasible projects produce "benefits that sustain themselves over time because they've become a part of local custom and culture" (OWEB memo, December, 2007). One can almost hear Heisler's admonition to secure real social commitment from implementing stakeholders prior to funding projects. 
OWEB's SIP program marks the emergence of the UDRP as a legitimate institutional process with programmatic corollaries. This matching of programmatic criteria and partnership attributes resulted from a mutual adjustment of boundary spanning practices and policy-environmental "demands" that took place in a variety of formal and less formal contexts, but included facilitated workshops, discussions, conversations, presentations, RFP's, grantwriting, and, of course, awards. These policy deliberations operated through a social network of relations, many of which could be described as communities of practice in their own right. Thus, for example, OWEB participated in many of the conversations in the public and private funding community that took place in the 1990's and onward that began to emphasize "environmental performance" and ways to measure it (thereby improving programmatic performance). OWEB therefore was already beginning to develop a "search image" of partnerships it wanted to invest in. Gradually, this image assumed a more concrete shape in conversations with other funders like BPE and PGE. And, as the state agency charged with funding and supporting the state's watershed councils, it doubtlessly followed the UDRP with interest as it began to make its round of proposals to these funders. Interviews of participants of the early meetings between OWEB and the partners suggest that the original intention was to explore funding the UDRP. But as they continued to talk, the conversation moved to a higher level of program design. The partnership solicitation for support and the development of an OWEB partnership program became part of one and the same process. 
The emergence of the UDRP was fed by outreach and funding efforts in another sense: for the very act of going out and presenting to audiences had the effect of solidifying a sense of partnership identity that became more defined as the conversations and messages evolved. In encounters with others we come to know ourselves, and this appears to have been the case here as well. Over time, the partners became more self-aware of the partnership "as a unit," as one of the presenting partners describes it. Moreover, as their identity developed, the partnership became more efficient at finding and acting on funding opportunities by quickly relaying relevant messages and tasks to the appropriate partner:

I think because we have had to actually do funding proposals together, and basically do work together, whether we have to present as a unit to the OWEB board, or we have to present a funding application as a unit to the $\mathrm{BEF}$, what we then basically do is we have a loose but effective system where we pretty quickly say, "Who is going to be the lead on this thing?" It's typically a self-nomination process where somebody says, "I'm the best lead because it's most up my alley. I know this person well; I will follow up on it." Then it's that person's job to basically be the lead, communicate to the partnership, and bring them in that direction.

The development of partnership identity entailed the development of boundary conditions for an emergent joint field of practice, which enabled the partnership to begin to scan its environment for - and respond to - problems and opportunities of relevance to it.

\section{Boundary Spanning and Social Learning in the UDRP}

The emergence of the UDRP was not a single event but rather a process of convergence that spanned roughly 5 years from 2003 until 2008 with the funding of OWEB's SIP. This account does not include the many years leading up to the "Back 
to Home Waters" program when policy actors and communities strove to build their vision of a Basin-wide watershed management entity. Their efforts provided the conditions that favored partnership formation at the Subbasin level. The social learning that went into building the UDRP has already been documented, but it is worth summarizing the previous discussion. First, we can observe a convergence on 2 levels, one at the Subbasin level and the other at the Basin level. At the Subbasin level, the "Back to Home Waters" program appears to have been the original unit of selection for early funders, especially BEF. Furthermore, there is evidence that funders came to adopt criteria that drew on valuable lessons that the partners had learned from their previous work in the Upper Deschutes Subbasin. At the same time, the partners showed a willingness and ability to learn from and accommodate funders and other interests, as illustrated in the capacity-building workshops that were jointly facilitated by BEF and NFF. The partnership also astutely did not push their matrix approach on other potential partners, recognizing that there was no Basin-wide framework in place to adopt it. At the Basin level, we note that the boards of the partners generally - with the possible exception of the Crooked River Watershed Council, which is discussed more below - came to throw their support behind the partnership. From this observation, and from interview testimony on the subject, we may infer - albeit cautiously - some alignment of perspectives and interests among the major Basin actors that operate in the outer layers of the partnership. Some of this alignment was surely prepared by the initial experimentation by the DRC with federally appropriated restoration funds and later 
accelerated by the positive turn of events in the Pelton-Round Butte Dam relicensing negotiations as well as in the NWPCC Deschutes Subbasin Planning Process. But there is also evidence to suggest that the formative partnership work in the Back to Home Waters Program and subsequent campaigns helped push the salmon and steelhead reintroduction to the forefront of the watershed agenda in the larger Deschutes River Basin. The partners used their extensive social network of members and affiliations to promote their agenda, as one of them recounts:

...When fish were being released, we brought people out. We got the news reporters out here. We did all the stuff. We organized a big thing at Camp Polk. The people releasing fish, the Tribes [CTWSR] and ODFW, they didn't necessarily want, not that they didn't want, but their goal is not to do outreach about it. I think by all of us being out there and talking to the community about it, we have been by far the main source of information about this. Then I think all of a sudden other people are starting to realize what is happening. I think from any way you view it, just from any press and any press interest in this has largely been initiated by either the Partnership as a partnership or by the individual partners talking about the Partnership, talking about our work. We used to struggle to get people aware of it. We had coverage in the Oregonian, we had articles in the New York Times. Now the local community is pretty knowledgeable about it. I think that probably runs throughout those outer layers, that folks are aware of this and dealing with. Other conservation groups are making that a priority. Certainly the National Forest Foundation has launched their national campaign on Wychuse Creek and Metolius. I don't think that would have happened without us having raised the profile of reintroduction to where it is.

The convergence of policy conversations and practices at these 2 levels facilitated by boundary spanning across social networks - helped pave the way for larger institutional support for the UDRP. The development of OWEB's SIP program marks, in some ways, the completion of this convergence, as the UDRP became a template of sorts for a state-funded watershed partnership program that now includes the Sandy River Basin Partnership. 
Evidence for the formation of a partnership we are conveniently calling "UDRP" can also be found in the routinization of boundary spanning practices between the 4 organizations. That is, we can observe a differentiation of roles, actions, and responsibilities that reflects deeper coordination across organizational boundaries. The partnership agreements have given the partnership a definite structure - a "prism," as one of the partners calls it - that drives the questions - e.g., "does the restoration project enjoy landowner support?" - and their collective response to them. Because they are driven by higher-level strategic objectives, the partners are able to make adjustments ranging from project design to project sequencing as conditions change. A DLT staffer illustrates this coordination with an example of work being conducted along McKay Creek:

We have pretty much weekly discussions on strategy for McKay Creek making sure there is a restoration strategy there before I go in and do land conservation because I want to make sure what I do and my agreement with the landowner is going to allow for the type of restoration that is going to need to be done and that it's going to sequence well with what the DRC might be doing in terms of water rights and how it works with the agricultural components and demands. That is a big change. I don't know that it's due entirely to the Partnership or if it's the evolving nature of our work and communications. I would attribute quite a bit of that to us having taken the step of being partners formally and saying, "This is how we're going to approach it." I think that has been a huge change in the way all of us do business.

The strategic approach enables partners like OWEB to outsource the project development function to the partnership itself. As a self-governing entity, it is able to develop, evaluate, fund, implement, and monitor projects that attend to the evershifting requirements of the local context. For funders, especially government agencies, this model is of course convenient from a practical standpoint, since it 
reduces the number of entities with which they must interact. But it also insulates them somewhat from the politics of funding and managing individual projects.

The coordination extends beyond outsourcing to communication to the larger community. As already mentioned, the partnering organizations have shown a capacity to not only track down and effectively respond to RFPs, but they have also created funding opportunities through carefully crafted strategic proposals to prospective funders and partners. The UDRP is creating, in other words, its own system of capital exchange that rewards partnership work modeled after it. Beyond that, the partners have developed a communication strategy to ensure that the messages they convey to various audiences, whether they concern project reporting or big picture visioning, are aligned or at least do not conflict:

To keep ourselves straight when we communicate, whether it's in a newsletter, a fund-raising letter, our annual report, we're all clear about how we talk about what we do so as to be honest. "We participate in a partnership that produces these outcomes. What we do is this portion of it." So we remain honest to each other about what we're claiming and how we communicate that to our constituencies.

Respondents in interviews also refer to instances, including referenda, where the Partnership managed to either maintain consensus on or avoid altogether contentious issues facing the Basin community. In the face of outside political pressures, this is no small feat.

Another evidence for social learning concerns the demonstrated capacity of the organizations to mobilize their resources and messaging to support one of the partners when it confers little or no direct benefit, or even imposes a cost, to the others. This was the case when, in 2008, the partners learned that Trout Unlimited 
(TU) was preparing to launch a reintroduction campaign of their own in the Basin. While TU's programs overlapped the most with the UDWC, the other partners nevertheless helped provide a united front both in confronting and ultimately negotiating with TU. As a result of those meetings, the partnership was able to develop a common understanding with TU that the 2 different campaigns would support, rather than simply compete with, one another. Interviews of the managers of the partnering organizations suggest that DRC and DLT rallied behind the UDWC mostly out of a sense of loyalty as opposed to any narrower strategic interest. Such gestures of loyalty are investments in the relationships rather than in a particular cause and suggest that the partnership has salience for the partners themselves.

\section{Partnership Capacity of the UDRP}

The UDRP can be properly classified as "permanent and/or regular coordination," using Mandell and Steelman's (2003) typology of interorganizational innovations. The Partnership is organized around a well-defined purpose involving material commitments from each organization that are delineated in formal agreements; nevertheless, financial, political, and institutional risks to each organization are largely confined by those partnership agreements. The UDRP does evince many of the characteristics of Mandell and Steelman's definition of a "coalition" to the extent that the coordination of activities and actions is well developed. However, the material and political commitments, and therefore risks, for each organization are more restricted in scale and closer to those associated with "permanent and/or regular coordination." This classification is made while 
bearing mind instances, albeit sporadic, where partners made some risks above and beyond what would be expected in "permanent and/or regular coordination."

While this classification is a start, it leaves us with little sense for the capacity of the UDRP to manage changes of varying orders. As an interorganizational innovation, is there any evidence to suggest that the UDRP has any significant influence in defining watershed management problems for the larger Basin community in ways that maintain its own relevance? In other words, does it have the capacity to both serve and lead the Basin community on watershed management issues? Beyond that, what evidence is there that would suggest the Partnership can reinvent itself to meet policy problems that are for all intents and purposes surprises?

The case has already been made that the UDRP meets the minimal definition of a partnership having, using the present framework, Partnership Capacity Type I. It has demonstrated a capacity to organize boundary spanning practices around a specific purpose and set of objectives centered on the reintroduction of salmon and steelhead in the Upper Deschutes Subbasin. The successful return of adult Chinook salmon to the Upper Deschutes River in 2010 was an historic milestone both for the Basin and for the Partnership. And we can observe an alignment of perspectives, interests, and practices between the UDRP and the larger institutional context. Indeed, the UDRP has become a model for partnerships in other basins. The Partnership received the Department of the Interior's Cooperative Conservation Award in 2007. The state of Oregon has also recognized the innovative nature of the 
Partnership as it prepares its Integrated Water Resource Strategy. OWEB is even funding the partners to help tell their story to a broader audience, with the ultimate aim of leveraging additional funding. In addition, private foundations like the NFF and the Ford Family Foundation have drawn on the UDRP model to explore partnership-building in places like the Deschutes National Forest near Sisters as well as in the John Day Basin. Members of the UDRP report being approached by some of these groups to share their lessons and perspectives. So long as this broader institutional support holds, the UDRP has a good chance of remaining viable.

Nevertheless, there is evidence to suggest that the Partnership is vulnerable. For one, interviews with staff and board members revealed that many of the rules of interaction that guide day-to-day operations of the Partnership remain unspoken and inaccessible. The boundary spanning competencies that enable the Partnership to function - for instance, making on-the-spot decisions about which funding opportunities to pursue and who should take the lead - are largely embodied in the practices of the founders and certain segments of the staff and board that are more intensely involved in the Partnership's affairs. Until these core practices and rules are more fully inculcated in each of the partnering organizations, the Partnership is vulnerable to personnel changes, particularly at the management level. In addition, while the Partnership has grown in operations over the past several years from roughly $\$ 3$ million in outlays annually to over $\$ 10$ million, it is likely to encounter 
significant challenges to scaling up further until those partnership practices are institutionalized.

More significantly, a deeper examination of the Partnership reveals fissures between the CRWC and the rest of the Partnership that reflect social tensions between the Crooked River and Upper Deschutes Subbasin communities. This is not surprising since, watershed councils by their very nature are bound to represent the community they serve. In the present case, the conflicting perspectives and interests of the 2 subbasin communities manifest themselves in conflicts over priorities and practices within the Partnership.

An issue of contention is the prioritization of fish, farmland, and rural development, more generally. Many in the Crooked River Subbasin are concerned that the emphasis on the reintroduction of salmon and steelhead is directing attention away from the issue of rural and community development. Until recently, anyway, the combination of land and water use restrictions along with various incentives has shifted the economic equation against full-time farming and in favor of specialty and hobby farms, recreation, and real estate development. A former rancher, himself a recent transplant, is struck by the changes in lower Crooked River Subbasin over the past 40 years, estimating there are now "probably only 2 legitimate, true agricultural land owners on the whole valley." For him, it comes down to simple economics:

One thing is your land use, how they're zoned. That has a huge effect on what you're going to do with your property. In fact it's probably one of the major ones if you're close to Prineville or whether it gets into your land planning. That's probably a major thing that happens. Like I said before, it's plain old 
economics. You're not going to survive on a 200-acre farm raising 40 head of cows. That's just plain old hard facts whether you like it or not.

The former rancher adds that these changes also present opportunities under the right circumstances:

...All of a sudden this land here may not be sold as a little farm, but it might be sold as a nice recreational area too down the line. And I think you're seeing a lot of that now. I lease my duck-hunting out. I think you'll see a lot of that. I would love to see this [Crooked] river - now that we've got the regulations, if it's going to be so regulated - let's have some Chinook salmon in it and some steelhead and go for it.

The changes in relationship to the land carry consequences for the

institutional and community context, as more traditional agricultural interests must vie with competing interests for a political voice in local watershed management. Traditional agricultural agencies and entities like the Farm Service Agency, NRCS, soil and water conservation districts, county extension agencies, and irrigation districts struggle to develop relationships with immigrating landowners no longer dependent on agricultural production. At the same time, entities like the DRC seeking to do projects in the Crooked River Subbasin have met resistance from landowners and communities that remain distrustful of outside intervention. As one resident of Prineville remarks: "People here don't like people from Bend telling them how they should do stuff." She recalls the controversy that ensued, before the Partnership was formed, when the DRC tried to purchase some prime agricultural land for a permanent water transfer. Many in Crook County balked at what they saw as a threat to their agricultural interests. For the DRC the lesson was to work through local partners like the CRWC. Nevertheless, the experience stirred a 
wariness in many local residents about any outside initiatives, especially those coming from Bend, that has mitigated the influence that the Partnership has had in the Crooked River Subbasin. In fact, interviews with ranchers, residents, and policy actors in the subbasin reiterated the general sentiment that the Partnership had very little salience for them.

Caught somewhat in the middle of this struggle has been the CRWC, which, as a receiver of OWEB and SIP funds, has emerged as a significant player in the Crooked River Subbasin. In many ways, the CRWC is an organizational site for this institutional struggle, and its capacity depends to a large extent on its capacity to span the economic, political, social, and ultimately cultural boundaries of distinct communities of practice. Here, the diagnosis is somewhat troubling. Staff turnover has been an issue. The CRWC has had 4 ED's in about as many years. To the extent that the ED is the locus of boundary spanning - on multiple levels, including between staff and board, between the UDRP and the Crooked River Subbasin community, and ultimately between different interest blocs - this turnover reflects a deficient organizational capacity for articulating and leveraging differences for a larger purpose. Instead of expanding opportunities, these differences have to a great extent deteriorated into power struggles. Perhaps the observation most relevant to this discussion concerns the degree to which the UDRP has been out of step with the CRWC board. As already mentioned, the board initially rejected Dedrick's proposal to join the Partnership. When Dedrick finally left, subsequent ED's were naturally less invested in the Partnership. There was one with whom the 
partners felt they could work, but the CRWC board quickly concluded he was not a match and let him go after only 6 months. More recently, the CRWC hired new staff, including an ED, Craig Carr, and moved out of the building they shared with county agencies and other entities, complicating efforts by the CRWC to find its footing in its own community. As one of the board members observes:

We had our first Watershed Counsel meeting [since the move]. They were there and I went: "who are those people?" They're our employees. I thought, "Since we're not all in the same building, we need to learn what each other are doing just here, let alone the Partnership."

The limited boundary spanning capacity of the CRWC carries implications for the Partnership capacity of the UDRP. Most obviously, a partnership is only has strong as its members, as the DRC has discovered in trying to carry out water transactions on the Crooked River. Several managers also reported that, not surprisingly, partnership work has been frustrated by the turnover in the CRWC ED position. But the relationship between the capacities of a partnership and its constituent parts is not necessarily linear. In this case, the DRC and the larger UDRP face a kind of paradox in building the capacity of the CRWC to the extent that its legitimacy, and therefore effectiveness, in the eyes of the local community depends on the autonomy and even influence it enjoys with respect to the Partnership. Indeed, the CRWC brings with it certain technical and local knowledge as well as social capital that could be valuable assets to the UDRP. For instance, the CRWC's institutional and perhaps cultural inclination to look at the land as opposed to just the water gives it an important perspective on watershed management that is 
sometimes lost in the greater Basin's focus on salmon and steelhead reintroduction, as the board member explains:

We believe the beginning of getting more water in the stream is by working from ridge-top to ridge-top. That involves removing invasive juniper. We like to work on upland projects and that is where a lot of our expertise and a lot of our knowledge, and a lot of our interest is in this Watershed Council. That is different than what the other two groups are doing. That can be good but I don't think we want to lose that focus by being brought into the Partnership. We want to have that focus and be part of the Partnership.

To a great extent, the strength of the Partnership will depend on the extent to which the CRWC is able to maintain a focus that is appropriate to their basin and community context. This means giving the CRWC a greater voice within the Partnership. The board member continues:

I don't know what we do with Upper Deschutes [Watershed Council] - they do the same kinds of things we do over there - besides getting expertise, and they primarily just work on instream stuff. A lot of our expertise is in the uplands and they don't seem to work in the uplands. It doesn't seem they come to us and ask us, "How should we control juniper in our county?" If they did that, I think board members would appreciate that. There's no interaction.

That lack of interaction translates to missed opportunities for mutual learning. For instance, the CRWC has not taken full advantage of the UDWC's expertise in monitoring. Of course, the board member is quick to point out that, before there is any productive interaction between the CRWC and the other partners, it will first need to establish its bearing with respect to its own subbasin community. But it would seem that even here the Partnership can make a difference by following the DRC's lead and reaching out to the CRWC, especially the board, for more input in developing reintroduction priorities and strategies. Such a gesture would, at least 
initially, probably be more significant for what it communicated about the relationship between the 2 subbasin communities than it would be for any technical or policy learning that resulted from it.

Contemplating such a change in partnership stance brings our attention to another potential limitation in the UDRP's institutional capacity: its dependence on reintroduction funding. The grant-driven nature of the Partnership limits its resilience in several ways. Perhaps most superficially, it is vulnerable to any unexpected disruptions in funding streams linked to the reintroduction efforts. This would perhaps not pose such a risk if the Partnership had the capacity to link into alternative policy narratives and associated funding. But the UDRP is in a certain sense a victim of its own success: each funding success has spurred the Partnership to invest its limited resources and time in the refinement of the reintroduction partnership niche, a niche which it has helped to shape in its own image. The convergence of practices and viewpoints has been such that funders and grantees have become mutually invested in the "the UDRP story" and in the enactment of their respective roles in that story. On the one hand, the UDRP has been a convenient policy vehicle for institutional supporters and funders like OWEB that are looking to invest in community-based efforts without having to incur the political risks or transaction costs that attend the messy work of partnershipbuilding and maintenance. These institutional sponsors rely on the cultural-political and technical legitimacy of the Partnership for the political cover to outsource that 
work to the Partnership itself. ${ }^{32}$ For their part, the partners are, with each funding success, incentivized to maintain their story as an effective, self-governing and egalitarian partnership. And as the financial investments grow, so too do the political, institutional, and psycho-emotional investments. This is particularly the case for multi-year contracts like those envisioned in the SIP and MWP. For all the strengths of these programs, the ever-present confirmation bias which guides each reporting and review tends to become more compelling over time, for sponsor and beneficiary alike.

\section{Conclusion and Recommendations}

In conclusion, then, it would appear that the UDRP has Partnership Capacity

Type I. Its matrices and system of decision-making allow for some flexibility in addressing changes in funding and project opportunities and priorities. But its strategic concern - the reintroduction of salmon and steelhead - is fairly narrow in scope. We need only look to the controversy surrounding the naming of the Partnership to appreciate that the Partnership's capacity to organize around a bigger story has been limited from the start, as one of its founders admits:

...We have always asked, "Do we create an alliance, a formal alliance with a brand that we all fit under?" That has never really worked. The fact is we work together. We have an overlapping enough mission that we all outsource to each other. That is really a model that's working.

\footnotetext{
32 This outsourcing has the empowering effect of "seeding" an indigenous system of capital exchange whereby the partners themselves judge the merits (whether technical or cultural-political) of projects and project sequences based on criteria they devised, assigning social value, in essence, to various local innovations. The problem being raised here, however, is: how to ensure that the judgments embodied in project-vetting reflect the values of community they are supposed to serve?
} 
This is not to say that the reintroduction story is not big or that the scope the Partnership took on was not ambitious: the Partnership was and remains innovative. It is simply to say that the innovation we are calling the UDRP addresses only a small part of the story of Deschutes River Basin.

But even staying within the restricted scope of salmon and steelhead reintroduction, to the extent that institutional funding and support depends on the partners maintaining appearances of both consensus and effectiveness, the UDRP's capacity for honest discussions about deeper differences, particularly between the Upper Deschutes and Crooked River subbasins, remains underdeveloped. So far, at least, the UDRP does not demonstrate a general inclination or capacity to ensure that its objectives are aligned with those of the "larger community of implementers." The DRC's emphasis on obtaining social agreements before initiating projects is a step in the right direction, but we do not find a pattern of (meta-)boundary spanning practices linking everyday practice with strategic and even "constitutional" questions that would give a robust indication of Partnership Capacity Type II. Instead, we find evidence that the partners often get stuck, not in the weeds, but in the clouds:

What we struggle with is that is where people's fears and apprehensions come out. Inevitably high-level ends up talking about big-picture fundraising, it talks about big strategy and organizational identity, things like that. It sort of re-opens some of those sensitivities. And because we're not talking about details, it's very easy for people to bring their fears to the table and you could have four people around the table, each one is thinking you're talking about a different thing because you're not actually talking about something specific. 
Lacking a larger narrative to frame strategic discussions, these discussions tend to devolve into disagreement over distractive or even false issues. Until this problem is addressed, it seems likely that the Partnership will be vulnerable to deeper Basin issues, including the question of where the reintroduction of salmon and steelhead fits in the larger management agenda. Unless it can influence, if not lead, the discussion on such deeper questions, the UDRP will be mostly subject to the vagaries of socio-economic and political change.

We are now in a position to say something about the capacity of the UDRP and larger policy network to manage changes of various orders. Table 6 summarizes the various boundary spanning practices that were observed in the UDRP process. The table's structure follows the methodological criteria contained in Table 2: Typology of Partnership Processes." 
Table 6: Boundary Spanning Practices in UDRP

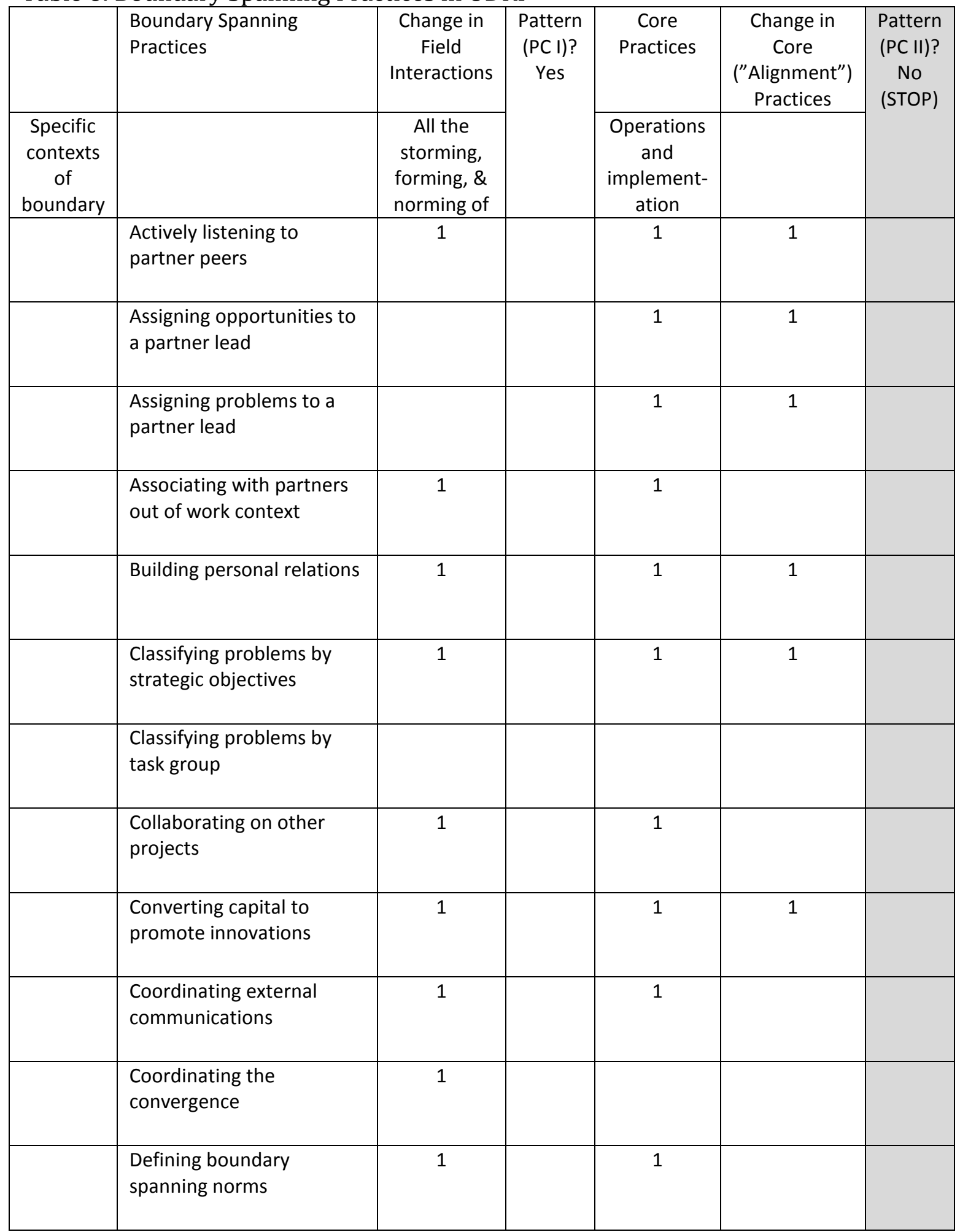




\begin{tabular}{|c|c|c|c|}
\hline $\begin{array}{l}\text { Defining boundary } \\
\text { spanning roles }\end{array}$ & 1 & & \\
\hline $\begin{array}{l}\text { Defining boundary } \\
\text { spanning values }\end{array}$ & 1 & 1 & \\
\hline $\begin{array}{l}\text { Defining institutional } \\
\text { accountabilities }\end{array}$ & 1 & 1 & \\
\hline Defining institutional roles & 1 & 1 & \\
\hline $\begin{array}{l}\text { Deliberating with partners } \\
\text { in new contexts }\end{array}$ & 1 & 1 & \\
\hline $\begin{array}{l}\text { Deliberating with } \\
\text { partnership stakeholders } \\
\text { in other contexts }\end{array}$ & 1 & 1 & 1 \\
\hline Designing process & 1 & & \\
\hline Disclosing interests & 1 & 1 & 1 \\
\hline Education & & 1 & 1 \\
\hline $\begin{array}{l}\text { Extending favors to } \\
\text { partners }\end{array}$ & & 1 & \\
\hline Facilitation & 1 & & \\
\hline $\begin{array}{l}\text { Framing innovations in } \\
\text { terms of need }\end{array}$ & 1 & & \\
\hline $\begin{array}{l}\text { Framing need in terms of } \\
\text { innovations }\end{array}$ & 1 & 1 & \\
\hline $\begin{array}{l}\text { Influencing across policy } \\
\text { sub-networks }\end{array}$ & & 1 & \\
\hline $\begin{array}{l}\text { Innovating (paradigmatic } \\
\text { boundary spanning) }\end{array}$ & & & \\
\hline
\end{tabular}




\begin{tabular}{|c|c|c|c|}
\hline $\begin{array}{l}\text { Integrating boundary } \\
\text { objects/innovations } \\
\text { (standardization) }\end{array}$ & & & \\
\hline $\begin{array}{l}\text { Making government rules } \\
\text { and regulations }\end{array}$ & & & \\
\hline $\begin{array}{l}\text { Managing process (budget, } \\
\text { conflicts, surprises, time) }\end{array}$ & 1 & & \\
\hline Outreach & & 1 & 1 \\
\hline Pilot-testing innovations & & & 1 \\
\hline $\begin{array}{l}\text { Pitching to decision- } \\
\text { makers }\end{array}$ & 1 & 1 & \\
\hline Prioritizing problems & 1 & 1 & 1 \\
\hline $\begin{array}{l}\text { Protecting brand/integrity } \\
\text { of innovations }\end{array}$ & & & \\
\hline $\begin{array}{l}\text { Respectfully pushing back } \\
\text { (disclosing constraints) }\end{array}$ & 1 & 1 & \\
\hline $\begin{array}{l}\text { Ritually enacting boundary } \\
\text { spanning }\end{array}$ & & & \\
\hline $\begin{array}{l}\text { Scanning environment and } \\
\text { reporting issues }\end{array}$ & & 1 & \\
\hline $\begin{array}{l}\text { Seeking input from } \\
\text { relevant constituents }\end{array}$ & 1 & 1 & 1 \\
\hline $\begin{array}{l}\text { Seeking input from } \\
\text { relevant decision-makers }\end{array}$ & 1 & 1 & \\
\hline Sharing risks & 1 & 1 & \\
\hline $\begin{array}{l}\text { Staff collaborating across } \\
\text { organizations }\end{array}$ & & & \\
\hline
\end{tabular}




\begin{tabular}{|c|c|c|c|}
\hline $\begin{array}{l}\text { Staging group decisions } \\
\text { (lobbying, building } \\
\text { readiness, gauging }\end{array}$ & & & 1 \\
\hline $\begin{array}{l}\text { Strategically aligning } \\
\text { partnering organizations }\end{array}$ & 1 & 1 & \\
\hline Task-mastering & & & \\
\hline Testing ideas/Vetting & & 1 & \\
\hline $\begin{array}{l}\text { Translating across } \\
\text { technical/disciplinary } \\
\text { boundaries }\end{array}$ & 1 & 1 & 1 \\
\hline $\begin{array}{l}\text { Translating between task } \\
\text { groups }\end{array}$ & & & \\
\hline
\end{tabular}


For the partnership to obtain deeper resilience, the kind described by Partnership Capacity Type II, it will have to help create a story of a different order, one that imagines the Basin after the successful reintroduction of salmon and steelhead, one that integrates reintroduction objectives with until-now either disconnected or competing community concerns such as upland restoration and forest health, agriculture, recreation, energy, service sector growth, and rural, urban and suburban development. Such a story would enable the partnership to navigate the complex web of networks and partnerships that comprise the social fabric of the Deschutes River Basin without losing its coherence. In the current state of affairs, the partners struggle to juggle their various commitments without working at crosspurposes. The converging fates of the Upper Deschutes and Crooked River subbasins will tend to lend greater importance to boundary spanning within organizations like the CRWC as well as place demands on partnerships to develop strategies to move between different levels of governance. By extension, the DWA and the region face a similar dilemma with respect to the state's Integrated Water Resource Strategy initiative: innovate or become obsolete. It is perhaps the central dilemma of the "Networked Society. 


\section{Chapter 7}

\section{Walla Walla Watershed Alliance}

\section{Background}

The Walla Walla River Basin spans 2 states, Washington and Oregon, draining west and north from the Blue Mountains in the eastern Cascades to form the Walla Walla River which is joined by its tributary the Touchet River before its confluence with the Columbia River (see Figure 16). "Walla Walla," is a Cayuse Indian name meaning "many small waters," which is an apt description of the valley's many small springs, streams, and tributaries that feed the Walla Walla River. The Cayuse, Umatilla, and Walla Walla Tribes subsisted in the Basin for centuries before white settlers began arriving in the early 1800's. Agricultural settlements brought with them irrigation diversions and, soon after, the establishment of "water rights" as early as the 1860 's. Among the larger settlements, the City of Walla Walla experienced a population boom associated with the Idaho Gold Rush and soon became the largest city in the Washington Territory (Siemann \& Martin, 2007). In 1855, the 3 Tribes signed a treaty with the United States ceding more than 6.4 million acres of land, including the entire Walla Walla River Basin. In the treaty, the Tribes retained a piece of land in the Umatilla Basin in Northeast Oregon as the Umatilla Indian Reservation while retaining rights to fish, hunt, and gather throughout their historic territory. The Tribes subsequently became known as the Confederated Tribes of the Umatilla Indian Reservation (CTUIR). 
Rapid settlement dramatically increased diversions, resulting in chronic water shortages and conflict. Already by the 1880 's, the amount of water appropriated by water rights on the Walla Walla River exceeded the total flow at certain times in the year, resulting in a seasonally dewatered river. The scarce supply and persistent conflicts led to an increasing number of court adjudications of water rights, culminating in the state of Washington filing suit against Oregon in 1936 for what it deemed transgressions against its citizen's water rights. The Supreme Court found in favor of Oregon, ruling that Oregon could divert all of the water from the Walla Walla River mainstem. The case divided farming communities across the state line, while disputes over water rights divided communities within state lines. Moreover, the Treaty of 1855 and subsequent white settlement had sown the seeds of deep antipathy and distrust between farmers and the Tribes. The Tribes' isolation on the Umatilla Indian Reservation only added to their sense of alienation from the Walla Walla Basin community. Thus, already by the middle of the last century, the Basin had a history of water shortage and conflict going back almost 100 years, and the many cross-cutting boundaries were its legacy. 


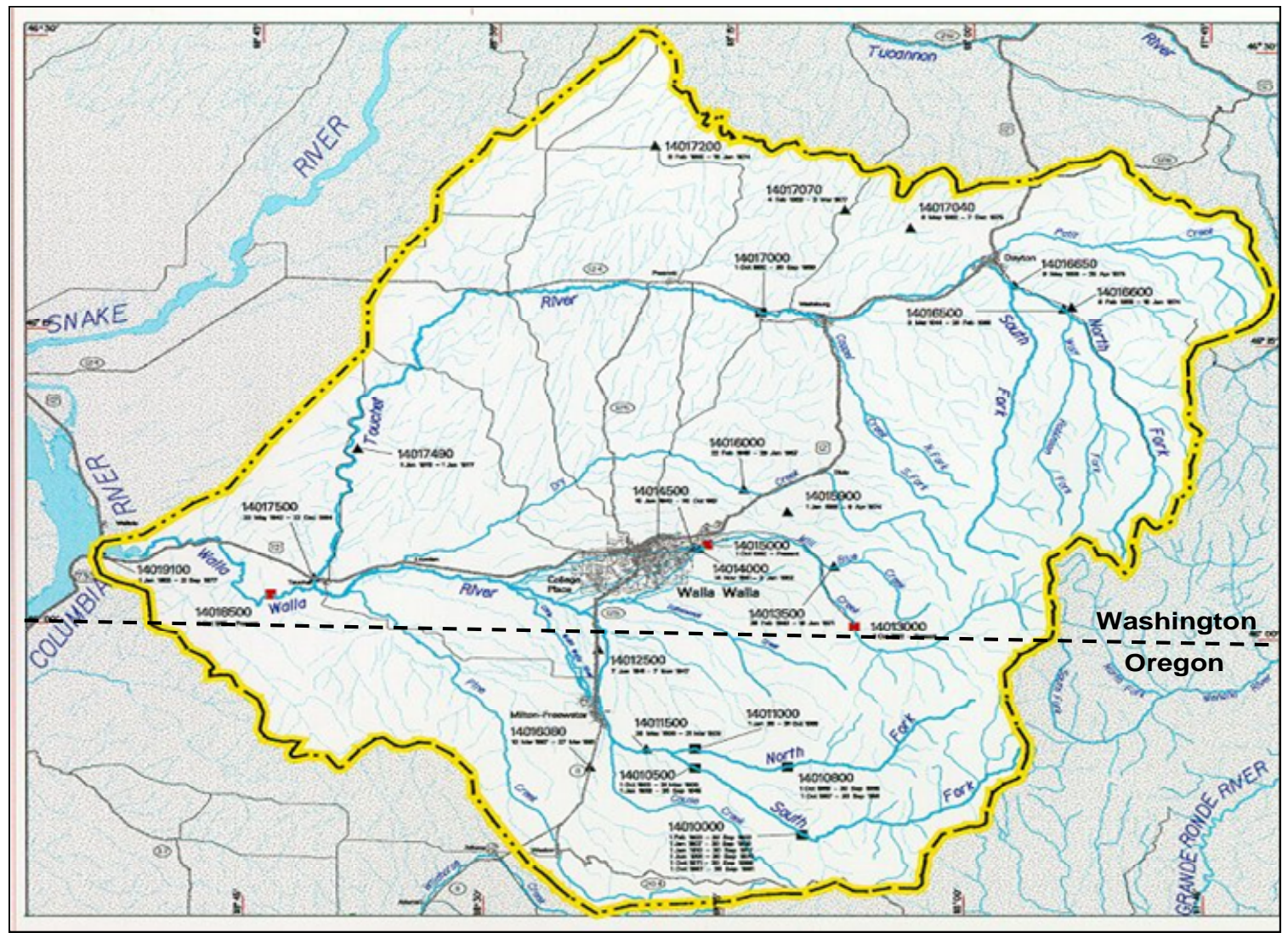

Figure 16: Map of the Walla Walla River Basin (Source: Curtis, 1997)

Complicating the water shortage and conflicts was the progressive depletion of fish populations and related species. Historically, the Walla Walla River supported significant populations of spring Chinook salmon and summer steelhead as well as resident bull and rainbow trout. Smaller numbers of fall Chinook, chum, and Coho salmon were also likely present. But the combination of seasonal dewatering and reduced fish passage from numerous activities, including irrigation diversions, is believed to have extirpated the Basin's salmon runs by 1925 (Siemann \& Martin, 2007). The slew of federal environmental laws in the late 1960's and early 1970's ushered in state-level regulation as well. On the Washington side of the 
Basin, for instance, the Department of Ecology ("Ecology") established the Water Resources Program Rule which seasonally closed most streams and rivers and limited future water withdrawals (Siemann \& Martin, 2007). The U.S. Fish \& Wildlife Service (USFWS) listed the bull trout as Threatened under the Endangered Species Act (ESA) in June 1998, and in March 1999, the National Marine Fisheries Service (NOAA) listed the Middle Columbia River summer steelhead as Threatened under the ESA. In January 2000, the USFWS served a notice-of-intent-to-sue 3 irrigation districts - the Hudson Bay District Improvement Company and the Walla Walla River Irrigation District on the Oregon side, and the Gardena Farms Irrigation District \#13 on the Washington side - for potential violations of the ESA stemming from their water delivery operations. The potential consequences for the irrigation districts and farmers were significant: stiff fines, forfeiture of water rights, and even incarceration. And given the Basin's heavy reliance on agriculture, the injunction had ripple effects that spared practically no one living in the Basin.

\section{Formation of the Walla Walla Watershed Alliance}

The federal injunction, by its very scope, spurred boundary spanning across the state line. Before the notice was served, the irrigation districts had been working relatively independently of one another. The social and political division across the state line had historical roots in the 1936 Supreme Court ruling, but irrigation districts, by their nature, also tended to operate as autonomous entities. By some accounts irrigation districts on the Oregon side were less conservative politically, but the recent influx of relatively sophisticated wine growers from 
California had begun to soften the distrust of outsiders which had characterized the valley's communities. Reactionary and progressive elements within the agricultural community combined in their response to the common threat represented by the USFWS injunction. Initially led by conservative leaders like Dick DuCharme, they formed a legal defense fund that sought to fight the injunction. As one of the participants of the early meeting of farmers recalls, the palpable threat to people's livelihoods mobilized the irrigation communities on both sides of the state line:

It is pretty easy to rally people around that because the threat was we were just going to lose our water. Anyone who is serious about their water, which is anybody who owns a water right or holds a water right, you're serious about it. That part was really easy to get together. I think, if I remember correctly, everybody threw $\$ 100$ in the pot and we started this fund. There were probably 35,40 people at the original meetings.

On the plaintiff side, the notice-of-intent was actually served by the USFWS along with a coalition of state, regional, and national environmental groups, including the Washington Environment Council (WEC) and the Center for Environmental Law and Policy (CELP), led by environmental lawyer Rob Caldwell. ${ }^{33}$ Given the Basin's historical and cultural context, the USFWS injunction was incendiary and, indeed, lines were already being drawn in the sand. But surprisingly to many Basin observers and even residents, instead of litigation, the various parties eventually opted to negotiate a settlement agreement that resulted in new commitments to protect both water and water rights. The story behind this shift is a story of

\footnotetext{
${ }^{33}$ Other environmental groups involved in the injunction included: American River, WaterWatch of Oregon, Friends of the Earth, Institute for Fisheries Resources, Pacific Coast Federation of Fisherman's Associations, Trout Unlimited, and EarthJustice.
} 
boundary spanning which laid the groundwork for a more collaborative approach in the Basin, including formation of the Walla Walla Watershed Alliance.

\section{A Bi-State Friendship}

Throughout this story, we find evidence of moderating forces working to deescalate tensions, often working on both sides simultaneously. Within the irrigation community, the budding friendship of 2 community leaders, Bob Rupar of Nelson Irrigation and Ron Brown of the Walla Walla River Irrigation District on the Oregon side, proved especially important. Both men are, according to interviewees, highly regarded within their respective communities both for their technical and business acumen as well as for their personal integrity, as several excerpts from interviews attest:

Bob was really important with his background in irrigated ag[riculture] and just his overall business acumen. He's a very articulate guy and well connected.

Ron was someone very caught in the middle of the water crisis and a good spokesman for the issue just because he lived it every day. He and his family get their living from irrigated agriculture. The fact orcharding being their main source of income, they couldn't go a year without water. They would lose all their trees and have to start from scratch across all their farms they operate. I think he was really passionate and knowledgeable to be able to speak to federal agencies, to speak to elected officials and bring together a boarder coalition.

There's a high level of credibility with the people that are involved amongst their peers. We were very fortunate that the people that came together have a very high level of integrity, respect, low egos, and just a sense in the community that "If Bob says this is an important thing to do, I'm going to trust Bob. There must be something - I trust his judgment - there must be something about this that is good." 
Both men, it seems, also hold a great deal of faith in the ability of local communities to come together to creatively solve their own problems. This twin faith in technical innovation and collaboration had cultural roots in the Walla Walla River valley, but was now being given new expression in the context of the USFWS injunction. Rupar and Brown felt that, by partnering with community stakeholders on improving efficiencies and other measures, the irrigation districts could reduce diversions while retaining most of the irrigation districts' water rights. Testimony from one observer familiar with the early discussions suggest that the Alliance was born largely from an urge on the part of irrigators to avoid not only litigation but future regulatory intervention. This impulse gave the Alliance a somewhat defensive posture that was consistent with the independent character of the agricultural communities from which it emerged:

Bob and Ron, in looking at this, it was a mechanism in their minds to be able to take control here locally and try to establish a reputation where we were doing the right things to help deflect the agencies' more punitive measures they might take. It was really a defensive-oriented: "If we're actively thinking through these issues, working with the stakeholders, it's going to work. We'll be able to make progress. That will allow us to have more ability to manage our own water problems and not have the agencies be so actively involved."

Building Trust between Farmers and Environmentalists

While the idea of local management may assume a natural, almost inevitable, quality to it in retrospect, at the time of the injunction, a negotiated settlement was far from assured. In fact, the moderation of political views within the irrigator's legal defense fund depended on serendipitous convergence of several historical developments. For one, the steady shift in agriculture away from water-intensive, 
lower margin crops like alfalfa to more profitable wine production, which requires less water, created an incentive for farmers to conserve water. As already mentioned, this shift to wine production also tended to bring with it a somewhat more progressive group of farmers, many of them veterans of California's water conflicts, who were more inclined to experiment with new methods and technologies.

Second, the overall political climate of environmental policy was already shifting to favor more creative and collaborative approaches over litigation. Around the same time as the injunction, Klamath Falls was emerging as a cautionary tale of the destructive effects of litigation. There, farmers tried to fight the ESA and lost while the Klamath Basin community experienced heart-wrenching conflicts. Neighboring Methow Valley had a similar tale to tell, where a Notice of Violation was served to the Methow Valley Irrigation District in late December 2001 that resulted in drawn-out court battle with the Department of Ecology. But neighboring Umatilla Basin was a study in contrast. There, the CTUIR had begun cooperating with irrigators, agencies, and other stakeholders in managing the basin's water resources. Early on, Walla Walla's irrigators invited Senator Gordon Smith down to discuss their options. Interviews with irrigators who were present reveal that Smith told an assembled group of farmers and irrigators that ESA was probably here to stay for the foreseeable future and that they would be better off learning to work with, rather than against, it. Moreover, Smith pointed out, as co-managers of salmon resources and holders of rights to half the fish as well as holders of federal water 
rights, the CTUIR were major stakeholders in the ESA issue. No agreement would stand without their participation. Smith pointed to neighboring Umatilla Basin as evidence that such collaboration was indeed possible.

Boundary spanners also worked to moderate views on the other side of the USFWS injunction. Local environmental interests, most notably Kooskooski Commons and its founders Judith Johnson and Kevin Scribner, were not part of the injunction, but they were familiar enough with the shifting political winds in the Basin to sense that farmers were at least ready to consider ways to collaborate to address the ESA listings, and they conveyed this to their regional and national environmental counterparts that were party to the suit. Johnson's and Scribner's role was important, for, as one irrigator points out, without their fingers on the local community's pulse, these larger environmental organizations were not themselves in a position to sense the opportunity for collaboration.

He [Scribner] had the ear of some of the people from Washington Center for the Environment if I understand it right, at that time was an umbrella group that a lot of different environmental groups basically were kind of under the umbrella of that and Kevin was kind of plugged into those people. [...]Where some areas you are not lucky enough to have a Kevin Scribner out there because if they don't know your area, and they're coming in the big boys from Seattle and there is no connection here at all, then they immediately jump over anything that might be a reasonable approach to this thing and go right to a lawsuit. And so somehow Kevin got engaged and he's a very friendly guy and very gregarious, [but] very unlikely a guy like him and I would ever have any reason to talk to each other. And then all of a sudden we did. Then he finds out maybe I'm not that bad a guy. And I find out he's not that bad a guy. He's pretty easy to engage with. [...] He did a real good job I think in liaising with the environmental people so that they had a level of comfort here. Because we were talking, and they were saying, "Hey, this is pretty interesting that we can even talk to you guys." 
As the quote suggests, personalities played a role too. In addition to Scribner, Rupar and Brown demonstrated a willingness to consider alternatives points of view that may have led to their friendship. Several interviewees also testified to Caldwell's penchant for developing "out-of-the-box" solutions to water management problems. He was therefore already inclined to think in terms of collaborative solutions. Lisa Pelly, who was affiliated with the Washington Environmental Council and enjoys considerable legitimacy in the eyes of state and even national environmental interests, also eventually championed a negotiated settlement.

Johnson and Scribner in some ways facilitated the first cautious steps toward negotiation by setting up the first meeting between regulators and environmentalists and farmers. One of the interviewees recounts the often-told story of the first meeting, pointing out how close the injunction came to becoming a lawsuit:

They met at [Ron Brown's] boardroom, his business, apple-packing business. They sat around a table and alternated, the outside environmentalist with the local guys. They had this big basket of juicy apples at the table. What the farmers were able to tell the environmentalists was: "Work with this, if you don't, you're going to lose your best partner in all of this to make things happen." They actually had an injunction letter in their briefcase. They set it down and said, "We will work with you." That was a significant moment. They didn't do that out of a vacuum but they were encouraged to do that, the guys from outside the basin.

Indeed, the bringers of the suit were encouraged to consider negotiation over litigation for a number of reasons. The decline in federal dollars for regulatory enforcement compelled federal and state agencies to begin collaborating with local communities in both the planning and management of watersheds. For 
environmental groups and even Native American tribes, litigation had served as an effective policy tool for bringing development, agricultural, and other interests to the table, but cases like the Klamath Basin also showed them that it was not a longterm solution. The alternatives to negotiation were not appealing for either party.

Caldwell and the USFWS were struck by the "sincerity" of the farmers and decided that it was worth giving this proposal a chance, thus commencing negotiations that would ultimately lead to what would be called the "Settlement Agreement." It seems likely that the reputation of Caldwell and Pelly helped allay fears among environmental interests at least enough to buy time to reach a settlement agreement. In addition, Gail Achterman, who was at that time a lawyer for Stoel Rives, attended one of the meetings and, according to one farmer who was present, helped convince the USFWS solicitor to grant the farmers a chance to come up with a local solution.

A "Final Amended Civil Penalty Settlement Agreement" between USFWS, the irrigation districts, and the city of Walla Walla, which was brought in to address its intake on Mill Creek (among other things), was reached in June 2000, restoring 1820 cubic feet per second (cfs) of flow to the Walla Walla River on the Oregon side and $15 \mathrm{cfs}$ on the Washington side. The agreement included a commitment from farmers and irrigators to take long-term measures to reduce withdrawal, including improving irrigation efficiencies, piping canals, and drilling new wells. In all, the districts gave up roughly $30 \%$ of their water rights. Most significantly, the reduced 
allocations were transferred back to the river as instream water rights through the Oregon Conserved Water Program and the Washington Water Trust Program. Formation of the Walla Walla Watershed Alliance

Reaching out to the Tribes

The Settlement Agreement set an important precedent in granting more flexibility to local water users and managers to comply with state and federal laws. But while the agreement succeeded in averting a lawsuit, several important issues remained that threatened to surface again if they were not addressed. For one, inconsistencies in state statues caused "protected" instream water rights on the Oregon side to be usurped by senior water rights holders on the Washington side. At the same time, smaller irrigators and farmers on the Washington side who relied on spring branches were beginning to suffer shortages as a result of Oregon irrigators returning more water to the Walla Walla mainstem. But the Settlement Agreement also exacerbated existing divisions within irrigation communities, as a staff person from the WWBWC explains:

The irrigation districts were dealing with a lot of controversy. They had patrons on their district saying, "Why aren't you serving me all of my water rights like you have been doing for the last 50 or 70 years?" There were threats of lawsuits within the district. "You can't reduce my water right," yet the board members are saying, "The federal agencies could shut off all our water if we don't give them some." There was this internal dispute going on within the districts. Then this external dispute of irrigation districts and individual irrigators down in Washington were joking they were having the best water availability they'd ever seen. Here is this water being left instream at this huge sacrifice of dollars where people are making their systems more efficient as they matched state and federal grant money, and the water is going downstream and getting used by others. 
Finally, the CTUIR were not included in the agreement and were therefore not fully vested partners in its implementation. Early in the negotiations, Caldwell reiterated Senator Smith's admonition to the farmers that they reach out to the Tribes to be partners in any agreement. But it was perhaps Scribner, more than anyone else, who helped start a conversation between the farmers and the Tribes. Scribner had ties with the CTUIR through his work with Kooskooskie Commons, but he also had connections to the farming community through his acquaintance with Rupar's son-in-law John Warinner, a geologist. The 2 men recognized that the USFWS injunction was the symptom of a much larger problem and therefore required a more comprehensive solution. They decided it may be time to try get farmers and the Tribes to work together to come up with a more comprehensive solution.

Later that year, Rupar invited Scribner to Thanksgiving dinner. The invitation itself was a significant gesture, and afforded the two men an opportunity to get to know one another and discuss water issues in a more informal setting. Scribner suggested that the farmers approach the Tribes to be partners in an alternative solution to litigation. He offered Kooskooskie Common's "open space technology" - a facilitated forum to explore and learn about different perspectives through storytelling - as a resource to help start the conversation. Rupar was initially skeptical. But one of the stakeholders working with Rupar reports that Scribner left a positive enough impression that Rupar was at least willing to listen:

It happened in a social setting where Bob and Kevin have dinner at Bob's house. Bob was very skeptical of environmentalists. We were talking a 
couple days later. He said, "Man, I enjoy this guy. He's got some really interesting thoughts." The relationships I think were in some ways nonexistent because there hadn't been communication. They were not particularly positive. There was more skepticism but when there were actual discussions and people got to know each other more on a - it was away from a meeting kind-of-a-structure - I think that also helped.

As the trust between them grew, Scribner eventually helped Rupar (and Brown) reach the same conclusion: the USFWS injunction had been more than just about irrigation and fish. Unless the Basin's major stakeholders came together to address more systemic problems related to the Basin's water shortage, future injunctions were all but certain. Rupar, Warinner, and Brown started to organize a group of farmers to invite the Tribes to talk about partnering in the management of Walla Walla’s “Many Small Waters.”

To be sure, it took some time and effort for the men to convince their fellow farmers to reach out to the CTUIR; after all, they had to overcome centuries-long prejudices and histories of water conflict. As in most cases where moderating forces work to move stakeholders closer to a center, it appears that much depended on the individual reputation of these men. Caldwell and Pelly faced a similar dilemma talking with their environmental colleagues, as did Scribner and Johnson in approaching the Tribes. But it appears that many elements within these separate interest blocs were beginning to feel it was time to start talking to one another to at least explore ways to proactively address the Basin's chronic water shortage and fish issues. The convergence was also aided by the motivation, shared by the farmers and the Tribes, at least, to minimize further state and federal intrusion. Still, it took some time for the new partners to adequately define the nature and scope of 
the management problem to begin to imagine what their partnership might look like. The founders were themselves changed by their conversations with other stakeholders and, of course, the organization naturally evolved in the course of reaching out and recruiting members.

It was in this context that Kooskooskie Commons organized the first in a series of "confluences," as the open-space community circles were called, between the farmers and CTUIR. Scribner was unable to attend the first meeting, which was held at the CTUIR. Caldwell, however, did help prepare the farmers for the meeting, while Scribner helped prepare the Tribes. A great deal of thought went into the design of the meetings. It was symbolically important, for instance, that the farmers reached out to the Tribes; it was similarly significant that the Tribes offered to host the first meeting at the Umatilla Indian Reservation. One of the irrigators recounts that first emotional meeting between two worlds:

There were twelve of us that went down and they sat around their Tribal Trustee deal and they were pretty stiff, and we were pretty stiff, and nobody - it was pretty tense, actually. [...] There were some four generation of farmers there and all the way down. [...] It was a good cross section of the farm community. And somehow we just started talking about the situation and the Tribes immediately, they responded to this because they said basically, you know, they didn't trust the federal government any more than we did. They trusted it even less because [of] the Treaty of 1855 and how the ceded land deal, and how they lost the water, their land, the whole entire thing. And they said basically "We really sympathize with your plight because we think the government is going to try to screw you too." So then all of a sudden we're talking, it actually became a - believe it or not - a tear-jerking experience for everybody that was at that. Because we discovered right there that not only from the environmentalists' standpoint but from the farmers' standpoint and the tribal standpoint that we basically all wanted the same thing. We're all for the fish. We're all for the environment. We're all for the economy. We're all for farming. We're all for preserving the culture. There 
wasn't anybody who had any difference there. And so all of a sudden it was kind of like "We don't know" at that point in time because it's so shocking.

But by the end of that first meeting the parties had discovered something extraordinary: their interests were tied to one another.

Birth of the Walla Walla Way

That first meeting set the tone for subsequent confluences, which Kooskooskie Commons helped facilitate. Interviewees also reported that Caldwell was instrumental in coaching the parties to concentrate on the " $75 \%$ " of values that they agreed on - preserving the natural resources for generations, protecting family farming, and so on - while avoiding the " $25 \%$ " where the differences were too wide to negotiate, at least until more trust was built. The confluences were not limited to the farmers, irrigation districts and Tribes, but instead sought to include all relevant stakeholders in the basin that were tied to water and water use, including: the City of Walla Walla, which is also a significant water user; the Walla Walla County Conservation District, which provided important technical assistance to farmers; and the Walla Walla County Commission. During these confluences, individuals like Mark Wagoner of Gardena Farms Irrigation District, Pat McConnell, a Walla Walla County Conservation District Supervisor, and Commissioner Greg Tompkins continued to work to bring other constituents on board. But the confluences were not the only settings where boundaries were spanned. Other formal and less formal settings were also important, as a board member recalls:

The Tribes invited Bob [Rupar] early on to come to their Root Fest[ival] and Bob and Sid went over there, and I think Ron [Brown] was involved in that. And then up at the [Walla Walla] Community College early on, the 
Community College invited the Tribes to come in and they had a ceremonial day, I think even, or maybe it was a half-day, and we were all there.

On the Tribes side, Kat Brigham emerged as an important collaborative leader. An elected Councilmember of the CTUIR, Brigham was, like many, initially skeptical. But, as a fellow Alliance board member attests, Brigham eventually came to embrace collaboration, particularly after her positive experience working in the Umatilla River Basin:

I think Kat, a very well-spoken tribal board member - who had participated in very heated discussions over fish management in the U.S. versus Canada fish management discussions regarding anadromous fish but also in negotiations between the Tribes in Oregon - [with] her experience with that, she's a great negotiator but also realized the irrigation community are her neighbors and she was able to keep that in mind and work across boundaries to find common ground.

Once she overcame her own skepticism, Brigham's next challenge was to bring other members of the Tribal community on board. Her efforts were helped by the positive precedence set in the Umatilla River Basin. Moreover, according to interviews, many Tribal members were moved by the farmers' overtures and were willing to give talks a chance.

These confluences planted the seed of what would become known as the "Walla Walla Way," a set of principles centered on community self-determination that balances the triple-bottom-line of environment, economy, and culture. In December 2001, the Walla Walla Watershed Alliance (WWWA or "Alliance") was incorporated as a bi-state 501(c)3. The WWWA was formally created by Rupar and Brown with the initial intention of helping with the implementation of the 
Settlement Agreement, but it's also clear that the men's vision for the Alliance was broader in scope. Their interest in local control, basin-wide thinking, and a more balanced approach to the management of water and fish resources overlapped with those of the CTUIR. And, inspired by Johnson and Scribner, they imagined a forum modeled after Kooskooskie Commons' community circles through which common values and interests could be found. On May $8^{\text {th }}, 2002$, the Alliance hosted a gathering of prominent community members, including representatives of the irrigation districts, the CTUIR, and local businesses and governments, and, in a signing ceremony, made a "Walla Walla Promise:"

On this day, March 8, 2002, the undersigned pledge to work together, within the forum of the Walla Walla Watershed Alliance, to restore and maintain the ecological, cultural, and economic health of the Walla Walla Basin. We make this commitment on behalf of the future for the next seven generations and beyond. A promise made, to ourselves and to our children, is a promise kept (Ruckelshaus Center, 2007).

Signatories included Lisa Pelly and Megan Clubb, a prominent member of the business community whose family-owned bank Baker Boyer, had been in operation in the valley for 140 years. The involvement of such a broad swath of community stakeholders signaled a truly comprehensive approach to water. Old wounds and rifts were being mended as a new vision for the Basin began to take shape. What started as a legal defense fund to fight a federal injunction was evolving into a community-based watershed management partnership.

Convergence around the Walla Walla Way

Critical to this convergence was the progressive investment of key collaborative leaders and their constituents in the collaborative process. Much of 328 
this investment was rooted in the friendships that were formed. As one board member puts it:

At least here in Walla Walla it seems the success is built on the relationships that are built. I don't know if it's like that everywhere, but the more time you spend with someone, the more likely you are to develop an understanding of what is important to them. It comes down to family in a lot of cases. You heard Kat [Brigham] at the meeting the other day say "I'm a grandma again!" That is the level at which these people relate. They didn't initially, but after you spend years and years working for it, you become very familiar with what is going on in people's personal lives. I think this is key.

Representatives like Rupar, Brown, and Brigham started out primarily as advocates for their respective communities, but in the process of building new relationships, their own views began to change and new identities began to form. As their thinking began to align, these community leaders came to view the process not simply in terms of advocacy but also in terms of discovering and realizing joint benefits.

But the convergence in thinking was no doubt also aided by more official planning processes that were partially informed by these early conversations. On the Washington side, work on the Walla Walla Watershed Plan began in 2000 and was overseen by Ecology's Watershed Improvement Area (WIA)-32 Planning Unit in accordance with the Washington State Watershed Management Act. While the Planning Unit was carrying out its various assessments of water quality, flow, and storage, it also partnered with the WWWA, the Walla Walla Basin Watershed Council (WWBWC), and other entities to form the Bi-State Habitat Conservation Coordinating Committee charged with developing a Habitat Conservation Plan (HCP) for the entire Walla Walla Basin that would address incidental take of 
federally listed fish. The WRIA 32 Planning Unit also partnered with the WWBWC on a Walla Walla Subbasin Plan, sponsored by the Northwest Power and Conservation Council, to address habitat impacts from hydropower facilities on the Columbia and Snake rivers. Finally, the Snake River Salmon Recovery Plan, working under the Washington State Governor's Salmon Recovery Office, prepared a recovery plan for the Walla Walla and Middle Snake River basins to address a variety of issues ranging from hydropower to hatcheries and habitat. On the Oregon side, the Oregon Department of Environmental Quality (DEQ) worked closely with the WWBWC in developing its water quality plan for the basin. In addition, the Oregon Plan for Salmon and Watershed, administered through the Oregon Watershed Enhancement Board (OWEB), has sponsored numerous projects in the Basin. One example is the Hudson Bay Aquifer-Spring Restoration Project, where the Alliance partnered with the WWBWC, the Hudson Bay District Improvement Company (HBDIC), the CTUIR, Oregon and Washington state agencies, OSU, and technical consultants to test active recharge strategies. In that project, a monitoring team was set up that included a sub-group to examine the specific interaction of groundwater levels, flow, and fish runs. Among other things, the WWBWC worked with local landowners to use their wells as data points.

These processes stimulated discussion among the Basin's disparate stakeholders about basin-wide management and helped build personal and institutional ties across technical, policy, and social community boundaries. Some observers bemoaned the lack of coordination between these various planning 
efforts (Siemann \& Martin, 2007). Nevertheless, in 2006 the Walla Walla Watershed Plan completed its Detailed Implementation Plan which guided subsequent funding and work on both the Walla Walla Subbasin Plan and the Snake River Salmon Recovery Plan. The HCP similarly brought in the counties to funnel federal appropriation dollars to address irrigation inefficiencies and fish passage issues. According to interviews, in most of these planning efforts, the Alliance played an important role in bringing together funders, regulators, local government, implementing entities, and other partners to identify and address the Basin's issues in a fair and balanced way.

The planning processes also stimulated awareness of the need to reform existing state water statues to allow for more effective coordination of water management across the state line. Hydrological models of the Basin, especially, showed complex and dynamic dependencies between ground and surface water levels that spanned the two states. The research of the WWBWC's hydrologists Warinner, Bob Bower, and their colleagues has been important in this regard. These studies and discussions raised critical awareness of watershed-scale processes and pointed to the need to approach management on the same scale. But the planning processes were, according to participants who were interviewed, also characterized by a good deal of advocacy science, as different interests presented studies that tended to support their point of view. For many of these participants, the HCP and WIA-32 processes underscored the need for stakeholders to learn about the deeper interests and values behind each other's stated positions. The hope was that by 
doing so, stakeholders might discover both the opportunities and limits for collaboration. Of course, in the course of learning about and relating to others, stakeholders themselves would be transformed, sometimes shifting the cost-benefit calculation in subtle but profound ways.

Lawyers and Policy Entrepreneurs

The story of the Alliance's formation is to a great extent a story of "happy confluences" of like-minded individuals with the talent, resources, and institutional capacity to stitch together an innovative institutional process to address the Basin's water issues. In no small way, these confluences were made possible by social networks spanning multiple sectors and governance levels. A key part of this story centers on the initiative of outsiders whose own policy interests came to be aligned with those of the Alliance and its partners. After the Settlement Agreement was reached, Caldwell joined the law firm Gordon Thomas Honeywell LLP based in Tacoma, Washington, where Dan Evans was already working. Evans had significant public service experience, having worked as state director for Democratic Senator Patty Murray before working for various congressional representatives in Washington, D.C. James Waldo was (and is) a partner in the firm with over 20 years of experience in negotiating regional agreements over contentious natural resource issues. Waldo, a lifelong Republican, was also serving as then-Governor Gary Locke's Water Policy Advisor from 2001-2004 and developed a reputation for working effectively across the aisle. He was also a graduate of Whitman College in Walla Walla and was therefore already familiar with the basin community. At the 
time Caldwell joined Gordon Thomas Honeywell, Waldo was heading up a group within the firm that was experimenting with alternatives to litigation for addressing natural resource disputes. Waldo pulled Evans and Caldwell into the group. The firm's group began functioning as an important node in a social and policy network of innovative thinkers, many of them environmental lawyers including Gail Achterman, who had been having informal conversations for a while about the need to move beyond the traditional regulatory approach to a "next-generation" of policy tools that was science-and performance-driven, flexible, streamlined, and economical.

Another member of this network of thinkers was Jay Manning, with whom Evans had collaborated in several important contexts. Manning was Chairman of the Board of the WEC when the USFWS injunction was served, and was part of the decision to withhold the lawsuit. Evans had worked with Manning during Manning's years at WEC. In fact, together, Manning and Evans studied the Puget Sound for ways to do mitigation that was smarter, faster, and cheaper. Their proposals included an incentives-based mechanism for developers to help pay for the mitigation. Manning championed this approach as Christine Gregoire's assistant Attorney General for Natural Resources. In addition to mitigation banking, a second area of policy innovation that the group worked in was reforming Washington's onerous and complex water laws. A central problem with the statutes was a relinquishment clause that stipulated water users would lose the portion of their water rights that were not put to "beneficial use." The clause effectively created a 
disincentive to conserve water. To make matters worse, water rights holders who were otherwise motivated to make management changes were disinclined to work with Ecology for fear - a fear borne out by experiences with the Washington State Department of Fish \& Wildlife's Cooperative Compliance Program - that any additional unused rights would be discovered (Siemann \& Martin, 2007; Weber, et al., 2007).

Given their experience with the Walla Walla Basin, Manning, Evans, Caldwell, and their associates recognized that the Basin offered an opportunity to develop and test an innovative approach for managing water on a watershed scale. But the motivation was also economic: the group within Gordon Thomas Honeywell was particularly interested in developing a business model for the firm that was based on providing advocacy, capacity-building, and earmarks services to clients. Caldwell and the firm approached the Alliance and proposed to work with it to obtain the kinds of funding and legislative reforms they needed to realize their vision for local and flexible management of water. In 2003, Governor Locke visited Walla Walla in the first of many tours of prominent political leaders which the still-forming partnership of stakeholders, guided by Kooskooski Commons, would lead. As a result of that visit, Waldo was able to procure a state appropriation to support the inter-state aquifer recharge study.

Manning's “Challenge"

Gregoire's election in 2004 and her subsequent appointment of Manning to the Director of Department of Ecology ("Ecology") created another political 
opportunity to work on water management reform in the Walla Walla Basin. Manning was already familiar with confluences from his work with the EDF. And during one of his visits to the Walla Walla Community College's Center for Enology and Viticulture, he had been impressed by the unusual alliance of stakeholders that were working together to meet the Basin's multiple water needs. According to interviews, early in his tenure, Manning met with senior staff Hedia Adelsman and Walla Walla's widely respected water master Bill Neve, who strongly encouraged Manning to go down and visit the Basin as Director of Ecology. Thus, it appears that senior staff who were well acquainted with conditions on the ground helped push for more senior-level boundary spanning. At the same time, members of the Alliance and their constituents were beginning to recognize the need to include Ecology in the confluence discussions they were holding. As Washington's lead agency for enforcing state and federal water rights, standards, and laws, it was clear that Ecology would need to be part of any long-term Basin management agreement. Manning made several visits, typically for about 2 days, spaced 6 to 9 months apart. The visits proved to be pivotal for building trust between Ecology and the Basin as well as for developing a strategy for collaboration. Local watershed managers, led by the Alliance, explained to Manning that if they could be extended some flexibility in the water laws, then they could find a long-term water management solution that addressed the needs of farmers, fish, the Tribes, municipalities, and the Basin as a whole. Impressed by what he saw, Manning subsequently invited key members of the Alliance up to Olympia, where he made his 
by-now famous proposal: Walla Walla would be granted flexibility in administering state water laws provided 2 conditions were met: first, that water quality and flow was sufficiently restored to the Walla Walla River to support fish; and second, that any conflicts that came up would be peacefully resolved within the community. After receiving a positive response from this smaller circle of leaders, Manning issued his challenge to the Basin community at a public hearing in Walla Walla on January 25, 2006:

Do you want to push on the edges of the existing law and regulatory system for water? [Or, do you want to do] something far more radical than that, which is, let's forget about the existing system of laws and regulations and let's replace it with an approach that is unique to this basin. And you decide-you come up on a year-to-year basis based on that year's precipitation. [...] We're going to maintain this flow in this wet year, we're going to maintain this flow in this medium precipitation year, and this lower flow in a dry year. We're going to maintain that flow for fish, for recreation, for other instream values. And the rest of the water, we're going to manage amongst us users (Ruckelshaus Center, 2007).

The proposal by Manning was a significant moment in the evolution of the WWWA, for it provided a state-sanctioned template for a watershed management partnership - encapsulated in the phrase "Flow from Flexibility" - around which the stakeholders could organize. The convergence of boundary spanning practices and the larger policy community took an important step forward.

Piloting a Vision

To accomplish such an ambitious policy agenda, the WWWA decided it had to secure funding to carry out studies and pilot projects, including monitoring projects, that would help build additional support for the bold initiative. Even before Manning issued his challenge, Evans and Scribner went to Washington D.C. to meet 336 
with Senator Murray, a Democrat, and Representative George Nethercutt, a Republican, to seek financial and political support to explore basin-scale management that addressed the Basin's diverse needs. Interviews with participants of those meetings indicate that the lawmakers, in turn, wanted to be sure that there was a "critical mass of support" for the Alliance before they backed it. By organizing presentations and tours of the basin, Evans and Scribner were able to eventually show that the partnership had the backing not only of the Tribes, farmers, and environmentalists, but also of local governments, industries, and businesses. The lawmakers threw their support behind it. Nethercutt, especially, was taken with the initiative and secured a couple key early appropriations, including a $\$ 500,000$ block grant through the National Resource Conservation Service (NRCS) designed to foster policy innovation. With this funding the Alliance partnered with the WWBWC in a bi-state effort, led by Warinner, to carry out aquifer recharge and monitoring studies. The partnership between the Alliance and the WWBWC, which also included the HBDIC aquifer recharge project, helped to raise awareness around shallow aquifer recharge across the state line. The NRCS project was a policy innovation in and of itself, with the Alliance funneling federal but also Washington state funds to a project that was implemented by an organization on the Oregon side.

But funding did come with strings attached, including procedural requirements associated with receiving and distributing federal money. These requirements introduced, in turn, potential legal and ethical liabilities for the 
partnership. The Alliance's community role as fiscal agent and grant administrator also carried with it political risks. The early years were a time for the Alliance to define who they were both within their community and to the outside world. Initially, many local organizations and interests were skeptical of the group, and there was some resentment that came up when occasionally the Alliance, in its effort to promote itself to the outside world, took credit for accomplishments which other groups felt was not theirs to take. And to the extent that the Alliance implemented projects of its own, the Alliance was also seen by watershed councils and other implementing entities as a competitor for funds.

It took time and some mistakes, but eventually the Alliance built trust with local partners. Specific measures, like holding public meetings and sharing meeting minutes, helped. The community reputation of its board members also helped. But just as importantly, as the Alliance started bringing major funding into the basin, it became clear that the group was a net asset to the Basin, particularly to the extent that it distributed this funding to local groups. Indeed, this "pilot project phase" was important in several respects. Mistakes associated with project and fiscal controversies spurred the Alliance to shift its focus away from implementing projects to its core strengths: raising awareness and raising funds. It is not a coincidence that the Alliance started shifting away from project management and implementation just as the Basin community was completing its Detailed Implementation Plan as part of its Walla Walla Watershed Plan. A 2007 report by the Ruckelshaus Center and Martin Consulting Service notes that a number of the 
Basin's significant policy actors, including the Alliance, were considering ways to change their missions and strategies to better align with the major planning efforts (Siemann \& Martin, 2007). And even though the Alliance eventually abandoned ownership of individual projects, the projects raised awareness of the Basin's hydrology and fish biology while testing innovative methods for restoring fish passage and stream flow. Finally, the projects themselves not only cultivated particular working relations, but they also served as models for future collaboration. Branding the Walla Walla Way

Eventually, the Alliance became in many respects the public face of the Basin community. For one, it drew on its board's formidable political ties to host highprofile visits by powerful officials and representatives. Typically stakeholders from the major interests were invited to meet dignitaries and share their stories and perspectives. Often, visitors came away with the impression of an otherwise diverse community united by a common vision. The description by an Alliance member of Representative Nethercutt's visit illustrates how a personal connection was used to first invite the dignitary, how he was prepped beforehand, and how the organizers used the open space forum to allow the official to experience "the Walla Walla Way" firsthand. The experience often left a lasting impression; in Nethercutt's case, it brought significant funding:

We invited Congressman Nethercutt - the connections to George [Nethercutt] were through the Rupar family. My friend John Warinner and Ron [Brown] were briefing George on what to expect, but also who is going to enter into our space. One of the requirements of being in open space is a dedication to keep the space open. We informed him, "You can't just come in and glad-hand, drop some wisdom and jet. You have to come in and listen to 
us." He came into the circle - I ended up talking to one of his staffers later and we were reminiscing about it. They just didn't know what they were going to discover there. They didn't know if they were coming in to get lynched - we put George in the circle, then just went around, everybody saying why they were there and - which is one of the patterns of open space - by the time it got around to George, it couldn't have been scripted any better. It wasn't farmers over here and others over there. It was a mosaic of perspectives, and people being hopeful and optimistic. He said, "I just can't believe this." He got to experience that firsthand and then became a champion of the Walla Walla efforts firsthand back in D.C.

By acting as the greeter and convener of outside visits and tours, the Alliance assumed a kind of gate-keeper role in both directions. As far as the Basin community was concerned, the Alliance came to represent the access point to political and financial capital. To the larger policy world, the Alliance came to stand for a unique set of values and processes captured in the evocative phrase, "the Walla Walla Way." To a great extent, the development of the Alliance centered on the cultivation of "the Walla Walla Way" brand.

Successful tours led to new opportunities to tell the Walla Walla story to a larger audience. In June, 2005 the Chair of President Bush's Council for Environmental Quality visited the Basin and was so impressed that he nominated the Walla Walla effort to be 1 of 32 select case studies to participate in Bush's Collaborative Conservation Initiative. Brigham, Brown, Scribner, and Cathy Schaeffer, who was then Watershed Planning Director for Walla Walla County, formed the core of the group. At the first conference in St. Louis in August, the presentation given by the group made a lasting impression on attendees and put the Walla Walla on the national map of environmental collaboration. In many ways this group formed the core of the Alliance as it became the public face not only for the 
Alliance but for the other collaborative processes already underway in the Basin. Local groups could see that they were going to have to work with the Alliance in order to be successful or risk alienation and de-funding. Similarly, partnership initiatives with the Alliance imprimatur gave elected officials and other institutional sponsors the political cover to support them. Eventually, the Alliance found its role, namely: as a voice and advocate for a unique vision of basin-wide management premised on the principles of local control and flexibility, innovation, the triplebottom line, and a fair and open process.

While the Alliance's standing within the Basin rested on its unique ability to secure outside support, its standing with the larger policy world depended on holding together a coalition that could claim to represent the diverse interests of the Basin community. The many tours of high profile officials and leaders ritually underscored this claim. More generally, it seems that in many ways the Cooperative Conservation group and the Alliance's larger connections - and the confidence they enjoyed from political leaders - gave the Basin's planning processes a degree of autonomy that was rather unique. In contrast to other watershed planning processes in Washington, Ecology's Planning Unit overseeing WAI-32 decided early on to reserve voting rights for only local representatives while relegating state and federal regulators to the role of observer (Siemann \& Martin, 2007). In 2007, the Walla Walla Basin became 1 of the first 5 Watershed Innovation Zones ("Walla Walla Valley Innovation Partnership Zone") sponsored by the state that brought $\$ 4.7$ million to the Basin over the 2007-09 biennium. The planning process itself was 
inclusive throughout, from problem exploration and plan formulation to implementation. The final plan consequently came to enjoy broad-based support.

Realizing its Vision

But arguably the Alliance's most influential role to date has been sheparding the development of the pact between Ecology and the Basin, which came to be called the Walla Walla Water Management Initiative ("Water Management Initiative"). Responding to Manning's challenge, the Alliance started the work of elaborating a basic vision of a Walla Walla Watershed Management Partnership"(WWWMP) into a concrete institutional design. But even here, the Alliance benefitted from assistance. Gordon Thomas Honeywell, especially Caldwell, was critical in providing the Alliance the capacity to advocate for legislative reform and appropriation, as was Manning. But there is good reason to suspect that these policy entrepreneurs had a hand in the conceptual development of the WWWMP as well. Another important institutional champion was Bill Ruckelshaus. His Ruckelshaus Center provided technical assistance in researching and developing the proposal for the WWWMP (cf. Ruckelshaus Center, 2007; Siemann \& Martin, 2007 ). Federal and state support was also important. The support of Senator Murray and Representative Nethercutt was of course crucial. At the state level, the Basin was fortunate enough to be represented by a delegation of 3 strong leaders in the Washington legislature: Mike Hewitt, Democratic Senate Minority Leader; Bill Grant, the \#3 Republican in the House, and Maureen Walsh, a moderate House Republican. Grant, especially, became a champion of the Alliance and the Water Management Initiative and here, 
too, serendipitous connections played an important role, as an Alliance board member explains:

He had a lot of respect for the people who were involved in the Alliance locally and was friends with most of us and really understood it. He was a producer too. He wasn't an irrigated producer but he was a farmer. That was a good thing too.

Grant, a popular bipartisan leader, died during the legislative session that included the WWWMP bill, which only solidified support for the legislation.

But arguably no individual put more thought or effort into developing the WWWMP than did Cathy Shaeffer. Shaeffer drew on the Ruckelshaus reports and other sources and assembled a WWWMP proposal for a "local and flexible water management program" that enabled the multiple watershed managers to work together through a bi-state "governance structure with clear authority and function" to meet local, state, and federal water policy goals (Adelsman, 2008). It called for a board to oversee the WWWMP, a "Policy Advisory Group," and a "Water Resources Panel" of technical experts. Ecology would participate in the latter two groups while sharing oversight responsibilities with the WWWMP board. In addition, the proposal outlines "Flow from Flexibility" pilot projects to test a more flexible and local management regime whereby water users creatively change water usage without going through conventional Ecology review and permitting. In this way, water users can voluntarily participate in various conservation and management strategies that restore flow while preserving groundwater and aquifer storage, all without jeopardizing their water rights from relinquishment or other rule. Finally, the proposal describes a "Walla Walla Water Bank" that would accept and protect 343 
agreements by water users to return water to the river on a temporary or permanent basis as a result of conservation and management activities. It imagined the Water Bank eventually handling a full range of both public and private water transactions and markets. The institutional design of the WWWMP reflects an abiding faith in the ability of local and voluntary policy mechanisms to address stubborn socio-technical and policy complexities where, the proposal argued, interstate compacts and other mechanisms would either be too expensive or likely fail (Adelsman, 2008).

Initially, the proposal was met with a great deal of skepticism by some of the watershed managers who suspected the WWWMP was an instrument of one interest bloc or another or who felt that their roles, jurisdictions, and funding were threatened. One particularly contentious issue centered on exempt wells, which are wells that can draw water without a permit. An attempt within the proposal to restrict exempt wells met with stiff resistance from developers, builders, and other real estate interests. But relationships between Alliance members and between their constituencies had strengthened to the point that differences could be aired and compromises found. Those who could help resolve differences, like Commissioner Tompkins, were either members of or affiliated with the Alliance in some way, making it more likely that compromises would be found. Furthermore, the major interests that were represented by the Alliance were able to provide a unified message endorsing the proposal that tended to be reinforced as that message made its way through different channels, as one of the board members explains: 
So as we were forming that [WWWMP] and I'm explaining to the conservation district supervisors, "This is not a grab by the county, or anyone else," well, so Greg Tompkins, who is a county commissioner is in his county commission meeting saying "Well guys, this really would be a good idea because of this and this and this and this." And "yes, we'd lose some county funding that is doing this, but it would make this process way more efficient, and the conservation district is on board."... And without the county, the district, and 15 other entities supportive of it, it would have never happened. If any one of us -- if Greg Tompkins, who is a county commissioner would have called a legislator and said "Hey, this is going to be bad for the county" or if I would have called a legislator and said "this is going to be bad for the district," you know it potentially would have derailed that whole deal.

The proposal also underwent a public involvement process, and Shaeffer and her colleagues were able to incorporate comments and ideas into the final proposal. They subsequently translated the proposal into a legislative outline and presented it to Washington's House of Representatives for consideration in the fall of 2008. The House introduced a variant of the proposal as HB 1580 which was unanimously approved - a feat unto itself in the context of an economic crisis and polarized political climate - and signed into law by Governor Gregoire in 2009. The pilot program (codified as RCW 90.92) amounted to a social contract between Walla Walla and Ecology that the Basin's watershed managers had 10 years to meet water quality and flow standards through a local partnership program they deemed appropriate. Among its responsibilities, the program's governing body would manage and resolve its water disputes internally. If Ecology found that sufficient progress toward the program's goals was not being met, ESA injunctions and other actions could be imposed. The USFWS injunction continues to hang over the Basin like a distant storm cloud. 
As a legislatively authorized partnership, the WWWMP represented the institutionalization of the Alliance's Walla Walla Promise. It carried with it the added legitimacy of including Ecology as a partner in local watershed management. The WWWMP was of course not merely a creature of the Alliance: it was driven as much by the other major planning actors and processes, including the Detailed Implementation Plan, as it was by the Alliance's own agenda. It's more accurate to say that the Alliance principles and practices converged with ideas and practices of other policy actors through a process of mutual adjustment to form the WWWMP.

Success begets success. The 2009 legislative triumph solidified the reputation of the Alliance and the "Walla Walla Way" brand both within and outside of the Basin. The same year, Walla Walla Community College (WWCC) President Dr. Steven VanAusdale, County Commissioner Greg Tompkins, and Rupar were able to secure additional funding to expand and operate the renamed WWCC William A. Grant Water and Environmental Center. The speed with which they were able to secure funding for the center - about $\$ 8.5$ million total plus $\$ 500,000 /$ year operating budget - particularly in the context of an economic and budgetary crisis, speaks to the prestige of the Alliance's work. Indeed, during one of the Alliance's board meeting in the spring of 2009, VanAusdale reported that state officials wanted to explore turning the Water and Environmental Center into a state center for water policy research and development (personal observation, June 10, 2010). In late 2010, the center was the recipient of Governor Gregoire's Workforce and Economic Development Best Practices Award. 
The Alliance's Choice

These achievements ironically brought with them an existential challenge for the Alliance, as its role championing the concept of a local watershed management partnership became less clear now that the WWWMP and the Water and Environmental Center were realities. For some board members, including some of its founders, the Alliance had clearly fulfilled its mission. For others, the Alliance still had an important role to play in bringing awareness, funding, and political support for the local watershed management efforts, particularly the WWWMP. Coinciding with these discussions, the U.S. Army Corps of Engineers (USACE) and CTUIR were finalizing a list of alternatives for a Stream Flow Enhancement Project on the upper reach of the Walla Walla that seeks to restore salmon runs without jeopardizing water rights of irrigators and other water users. At the time, the USACE seemed to favor a more expensive source water pump exchange option that envisioned pumping Columbia River water to irrigators to replace bypasses of their diversions on the Walla Walla. Cost estimates had steadily climbed and, by June 2010 , had reached $\$ 400$ million. The latest price tag was beginning to reveal fissures in priorities among the Alliance's members. From interviews, coupled with personal observation of the June 10 board meeting, it appeared that several representatives of the agricultural and business communities were beginning to balk at the price tag, saying it ran counter to their philosophy of private sector innovation and small government. But while the CTUIR were also frustrated with the glacial pace with which the USACE moved, they reiterated that the project should go forward, even if 
the pump exchange option was ultimately selected. The return of salmon was paramount. For the CTUIR, the Stream Flow Enhancement Project needed an organization like the Alliance to use its considerable political influence to secure support for the project. The Stream Flow Enhancement Project was beginning to acquire notoriety in the Basin, and discussion of the Alliance's future was being increasingly framed in its terms.

Mike Bireley, the Alliance's ED, guided the Alliance Board through a decisionmaking process that lasted 6 months and at least 4 board meetings. Bireley wanted to ensure that the board members understood what their options and implications were before they made their decision, rather than after. Essentially, the board members had to decide to either step up the Alliance's visibility as the Basin's water policy leader or ramp down operations and assume more of a supportive role, either loosely or just individually. On June 10, 2010, the board met to discuss a proposal to dissolve the 501(c)3 structure. Proposers of the motion contended that the recent establishment of the WWWMP obviated the need for the Alliance, particularly as a legal body subject to liability. They felt that the administrative strictures were hamstringing the members from doing what they do best, which was to lobby for outside support. Several, including Ron Brown, pointed to increasing personal and business commitments that made it difficult for them to continue participating in the Alliance. Yet, Brigham, among others, pointed to the need for the Alliance in significant efforts like the Stream Flow Enhancement Project. The discussion that ensued, while perhaps not always comfortable, reflected a kind of frankness that is 
evident in groups bound by trust and goodwill (personal observation, June 10, 2010). At one point, Clubb pointed out that the Alliance's true value was that it offered a unique forum where diverse stakeholders could continue to meet, build relationships, share perspectives, and learn from one another. The meeting concluded with an adoption of a motion to formally dissolve the Alliance's 501(c)3 status while retaining its function as both a lobbying arm and forum for discussing local watershed management in the Basin.

\section{Boundary Spanning and Social Learning in the WWWA}

The codification of the Walla Walla Promise signaled the emergence of the WWWA. But for such processes of social learning to translate to wider institutional and social change (and to prevent "drift" of leaders from their communities), it is critical for collaborative leaders to continue to communicate and share their learning with their constituents, not so much to bring them aboard as to bring the wider communities into greater alignment with one another. In such processes, social learning is iterative: boundary spanners "report back" their learning to stimulate conversations and social learning within their respective communities, and this learning is then communicated back to the partnership to be mixed and integrated with the learning reported back by fellow boundary spanners, and the

cycle repeats. The theory suggests that the social, technical, and policy agreement between the group and the larger community(ies) will tend to increase with each iteration. 
We see this in the way early conversations between Rupar, Brown, Caldwell, Scribner, Brigham, Clubb, and others transformed the participants themselves. And ultimately each major interest bloc - whether they be farmers and irrigators, the Tribes, environmentalists, regulators, municipalities, or other stakeholder group made concessions, not only within the context of the Water Management Initiative, but within the contexts of the other planning processes as well. This speaks both to the ability of the founding members to learn from one another, but also to communicate that learning to their constituents even as they relayed important information and perspectives back to the group. This ability depended, in turn, on the emergence of a particular group culture within the Alliance centered on frank and respectful communication. As one board member says:

We got to the point in relationships where we were able to have really serious, robust conversations on issues that were challenging but there was enough positive emotional bank account built - there was enough positive there - that even though you might cause some damage, people understood we have differences by this time. It was just part of the deal.

In many ways the Alliance's members came to embody the Walla Walla Promise they made. Given the politically volatile context in which it formed, it is doubtful that the Alliance would have lasted long if it hadn't.

There was probably some path dependence to the evolution of the Alliance as well: specific relationships like the friendship between Scribner and Warinner led to personal and professional introductions that not only opened or foreclosed opportunities but also shaped subsequent thinking. As with other cases of partnership building, the partnership effect of the WWWA was certainly significant, 
as each member placed their indelible print on the organization's mission and practices. But there were also important "affiliates" who helped cultivate and develop the Alliance. Caldwell, working in conjunction with a close circle of water policy entrepreneurs, actively supported the deliberations that ultimately led to the WWWMP and the fulfillment, in many respects, of the vision which he and his colleagues had been developing. For Caldwell, Manning, and others, the Walla Walla Basin presented a unique opportunity to test their ideas - and business model - in a specific policy context. These individuals also used their considerable political capital to secure funding and support for the Alliance and its initiatives.

In the case of Manning, the story of his challenge to the Basin is particularly illustrative of convergence. Interviews reveal that Manning in fact proposed his challenge to a close circle of stakeholders (including Alliance members) in Olympia before making his public challenge to the Basin community in early 2006. By first discussing his challenge with a group of Basin leaders, Manning increased the likelihood that his proposal would be well received. But it also afforded the Basin leaders a chance to influence Manning's proposal and therefore the direction of convergence between state regulators and the Basin community. Caldwell and others similarly helped the Alliance pitch their message to the larger policy world. In the process, the partners learned to cultivate an image of themselves and to derive political and economic capital from the resulting "Walla Walla Way" brand. After all, by the time Manning made his now-famous speech, the Alliance had already garnered significant national attention as a Cooperative Conservation 
Awardee. In the end, Ecology's challenge to the Basin was as much the Alliance's as the Alliance's Water Management Initiative was Ecology's. The timing of the Alliance's shift to a more strategic role in the Basin - which coincided with the WRIA 32 Planning Unit's Detailed Implementation Plan and with an increased awareness among the Basin's major watershed managers to more strategically align their priorities, resources, and efforts - suggests that similar instances of convergence between the Alliance and the larger community were occurring in other, and partially overlapping, planning and policy deliberations as well. Indeed, interviews of policy actors that participated in the concurrent planning processes depict a policy community of partially overlapping networks, as a prominent member of the Alliance explains:

There was a few of us that crossed in to different groups. I wasn't part of the watershed but being part of the irrigation district, I had twofold going on. I had not only what was happening with the Alliance so I could bring whatever was happening in the district side with negotiations basically on a plan we had to work out before we did the HCP. And so I was connected by a lot of knowledge. And so being on different groups then, I brought some stuff to the table. I was probably the most connected of everybody because of the irrigation district that was being sued by U.S. Fish and Wildlife. There was a few other people though too. Hudson Bay (District Improvement Company), Ray Williams was connected then through the watershed. And so he was giving them information. Cathy [Shaeffer] was eventually part of the HCP, and she was connected by being the head of the watershed group on the Washington side. So we had these people that were kind of interconnected with what was going on and so people were getting to hear different sides of the story and bringing it together.

Given the centrality of the Alliance in the Basin's network structure, it is likely that it became a locus of convergence in water policy thinking and practice. For all its innovation, then, the Water Management Initiative had been thoroughly vetted. 
The social learning reflected in the legislative authorization of the WWWMP can be interpreted in at least 2 ways, depending on our level of analysis. On one hand, the "Flow from Flexibility" that drives the WWWMP can be seen as a kind of codification of the "Walla Walla Promise" around which the Alliance first organized. In this respect, the WWWMP can be seen as a triumphant institutionalization of the Alliance's boundary spanning vision. However, some of the elements that comprise the WWWMP, particularly the water bank and the envisioned water transactions market, cannot be readily attributed to the Alliance, but rather to other actors and initiatives. More fundamentally, as a manager and implementer of projects, the WWWMP fulfills a role that the Alliance has progressively abandoned over the past 5 years. To be sure, there was significant overlap between the two boards (at least until the Alliance dissolved its board in June 2010), suggesting some degree of shared governance. But the shared governance between Ecology and the WWWMP carries legislative authority and is more significant, particularly since the Alliance was dissolved. Any discussion of the boundary spanning and social learning associated with the WWWMP should be told in a story that is larger than our story of the Alliance.

The dissolution of the Alliance as a 501(c)3 is, however, part of our story, for it demonstrates a willingness and capacity of the partnership to adapt its form to fulfill different functions as the policy environment demands. The question remains whether the Alliance is acquiring a general capacity to learn (i.e., Social Learning III). 
In fact, there is no evidence to suggest this. Instead, the Alliance's recent decision to dissolve its 501(c)3 structure was largely driven by specific operational conditions, especially the lack of inclination or resources to commit the time, money, and risks that were required to operate a 501(c)3.

There is some evidence to suggest the Alliance has been able to adjust its operations in response to specific policy triggers, including the Detailed Implementation Plan, WWWMP, and even the Stream Flow Enhancement Project. Yet, the changes we observe in the WWWA do not even merit classification of Social Learning II, for we have no evidence - yet, anyway - that the alignment of the Alliance and larger Basin community is stable, that is: that the alignment practices follow a particular pattern. The Alliance's innovative ideas and practices have not been widely adopted by the larger Basin, particularly along some of the tributaries and upper reaches of the Walla Walla River. Indeed, interviews with stakeholders suggest that the Alliance is in many ways less known within the Basin than outside of it. There is still a significant need to raise awareness and reach out to stakeholders to participate in the WWWMP, the HCP, and similar initiatives that the Alliance has sponsored.

\section{Partnership Capacity of the WWWA}

Using Mandell and Steelman's (2003) typology, the WWWA was, until its dissolution, a kind of hybrid of "permanent and/or regular coordination" and a "coalition." Its formal organization and dedication of time, staff, facilities, and other resources were attributes of permanent and/or regular coordination. However, its 
purpose - to help build a local watershed management regime in the Walla Walla Basin - was ambitious and called for long-term commitment from its members. The partnership also entailed a significant amount of resource- and risk-sharing. ${ }^{34}$ It is interesting to speculate that the seeds of the Alliance's struggle to define itself over the years may have been planted in its incorporation as an organizational hybrid of two different and somewhat conflicting interorganizational innovations.

Analysis of the boundary spanning and social learning processes suggest that the WWWA possesses Partnership Capacity Type I. Its boundary spanning ideas and practices have assumed a definite shape over the years, culminating in the Walla Walla Promise and, to a great extent, the WMI. But last year, the Alliance dissolved itself as a 501(c)3, opting to assume a more low-profile role in supporting existing efforts, particularly the WWWMP. The challenge for the Basin is to develop a unified watershed management framework that will enable large-scale adoption of the policy innovations that have been developed. Studies of the collaborative capacity of the Basin suggest a greater readiness among farmers to work with agencies and other partners to adopt innovative management practices, like fish screens on diversions, compared to neighboring basins (Weber, et al., 2007). Still, efforts to improve fish passage in the Walla Walla Basin have fallen short of program and policy goals.

Similarly, in the case of the Stream Flow Enhancement Project, the pump exchange project alternative would appear to solve many water flow problems all at

${ }^{34}$ Bob Rupar and Ron Brown seeded the Alliance with their own money, not to mention a
considerable amount of time and effort that went into building the partnership and its initiatives. 355 
once, and this makes it attractive to many stakeholders who have since grown wary of the burdens of local governance, particularly in enforcing against their neighbors. But it's largely a technical and expensive fix, one that may not address more entrenched problems. As one Alliance board member observes, the Stream Flow Enhancement Project is a test of the innovative spirit that has driven the Alliance's vision. For him, the kind of questions the Alliance asks of the project reflects its own level of thinking. It's one thing to question the costs or accounting of the USACE pump exchange option; it's quite another to question whether it should be an engineered solution that is overseen by a federal agency like the USACE to begin with:

Are they [the Alliance and its partners] evidencing an interest and capacity to see this big water project in a larger spirit as a chance to innovate? Because we're going to come to these boundaries.[...] If we need a project on this scale - and what people are saying is, "We do," but then they balk at the price tag for it, but then they say "Well, is the price tag because it is now being countenanced as a public works project that is going to be managed by the federal government?" - Well, should we stop at that? Should that be our sole question, or can there be another way to get the project done? Does it have to be that federal agency? Can it be a public/private partnership? Can it be private money? There's a will of the Alliance to ask those questions and we already have of the Corps [USACE].

Whichever Preferred Alternative is finally selected on the project, it will reflect on the commitment of the Alliance to ask the harder questions, or at least on the Alliance's capacity to influence how major management issues are framed. We will then be in a better position to ascertain the extent to which the Alliance's capacity rises to the level of PC II. 
Finally, a more indirect measure of the Alliance's partnership capacity, although not derived from the current methodological framework, is the return of salmon. The CTUIR, working in partnership with the USFWS, began releasing adult spring Chinook salmon in 2000, with the first successful adult returns beginning in 2004. Since then, the number of returning salmon has increased from roughly 200 to over 1,100 (Walla Walla Watershed Management Partnership, 2010). The recovery was enough to enable the CTUIR to open, from June 18 through June 21, 2010, their first fishery of spring Chinook salmon in almost a century. The returns have held a great deal of significance for the Tribes, but also for the entire Basin, which held its second annual "Return to the River" celebration at the Water and Environmental Center on August 28, 2010. The site of that celebration, it should be added, underscores the Center's increasing importance as a hub of social learning for the larger Walla Walla Basin.

\section{Conclusion and Recommendations}

The convergence of perspectives and practices that led to the formation of the WWWA and finally the WWWMP was by no means a foregone conclusion at the outset. When the USFS served its notice-to-sue the 3 irrigation districts in 2000 over potential ESA violations, the Basin had already experienced a long and bitter history of water conflicts that divided communities and states. The Walla Walla River was over-appropriated while the Basin community lacked the social, political, and economic capital to sufficiently address its many water-related issues. Yet, despite its apparent similarity to the bi-state conflict that was developing in the Klamath 
River Basin around the same time, the Walla Walla Basin took a different path. The two "cases" are not independent, since it is clear from interviews and other testimonies that the Klamath conflict emerged fairly quickly as a cautionary tale for other Northwest basins, including the Walla Walla. Neighboring Umatilla Basin, in contrast, served as an inspiration. Nevertheless, interviews with residents suggest the innovative spirit of the Walla Walla River Basin may have played a role in encouraging boundary spanning across the public and private sectors. The second regional cultural characteristic that interviewees identified is the tendency of folks in the Basin to deliberate more before taking decisions. This more thoughtful approach, paired with the painful lessons of the Klamath and neighboring Methow and Yakima valleys, may partly explain why stakeholders, faced with the ESA injunctions, opted for a different approach.

Still, our case study does not concern the Walla Walla River Basin per say but rather the WWWA. Clearly, the Walla Walla River Basin ended up looking quite different from these other basins, but our theory of "convergence" suggests that, if anything, the Alliance was both a cause and an effect of the Walla Walla Basin's environment. For a more complete explanation of the Alliance's formation and evolution, we must examine processes endogenous to the Basin's social learning process.

The coincidence of other important planning processes within the Basin certainly facilitated convergence: by raising general awareness of Basin-scale issues; by increasing direct engagement between different stakeholders; and by increasing 
the probability that those engagements would overlap and thereby reinforce one another. During the negotiations leading up to the Settlement Agreement, arguably the most important boundary spanners were those individuals that, due to their unique social position, were able to approach both parties simultaneously and thereby de-escalate tensions. But convergence does not imply consensus - only that the boundary spanning practices of a few boundary spanners begin to align with the fields from which the boundary spanners are drawn. In this case, we see how Rupar, Brown, Scribner, Clubb, Brigham, and a handful of others came to embody a set of practices that was eventually ascribed to an entire basin community with the label "the Walla Walla Way." Of all the different social and policy processes that were underway in the early 2000's, starting with the ESA injunction, how did the Basin come to adopt "the Walla Walla Way" idea, and how did that idea eventually achieve legislative authorization in the WWWMP?

The story of the Alliance's formation is in many respects a story of personal ties and professional associations. A good deal of serendipity came into play, not only in the path dependence of member recruitment, but also in the coincidence of inclinations, capacities, and opportunities - the election of Washington Governor Gregoire and her subsequent appointment of Manning as head of Ecology is just one example - that facilitated the convergence of innovative thinking and practices. Networks formed that enabled different forms of capital to be combined in unique ways. The Alliance board itself was an example. Convergence was set into motion once these actors learned how to market their product - the Walla Walla Way brand 
- to the larger world. But the case study also shows how the Alliance and its boundary objects were transformed in the process. It is not simply that the there was "pushback" from community stakeholders. Interviews suggest that much of this pushback was relayed back to the board meetings for more deliberation. These pushbacks were compared to one another, enabling the board (mostly unwittingly) to construct a kind of composite mental map of the Alliance's standing in the larger Basin community from which new actions would be taken, and the social learning cycle would repeat. A kind of conversation ensued between the Alliance and the community about its proper role in it; it is a conversation that has been going on for 10 years.

While we find evidence of the kind of convergence of boundary spanning practices to suggest the Alliance has achieved minimal partnership capacity (PC I), there is no clear evidence that the conversational structure between the Alliance and the Basin community has achieved the kind of closure we would associate with a more resilient community partnership. That is, there is no indication that the Alliance and larger community agree on under which circumstances the Alliance should reorganize itself and what that reorganization should look like. Although the case study reveals instances of alignment between operational, strategic, and even constitutional concerns, we find no evidence of a pattern of alignment practices that would indicate PC II.

Let us now summarize our assessment of the WWWA's capacity to manage institutional processes of varying degrees of complexity. Table 7 summarizes the 
various boundary spanning practices that were observed in the WWWA process. The table's structure follows the methodological criteria contained in Table 2: Typology of Partnership Processes." 
Table 7: Boundary Spanning Practices in the WWWA

\begin{tabular}{|c|c|c|c|c|c|c|}
\hline & $\begin{array}{l}\text { Boundary Spanning } \\
\text { Practices }\end{array}$ & $\begin{array}{l}\text { Change in } \\
\text { Field } \\
\text { Interactions }\end{array}$ & $\begin{array}{c}\text { Pattern } \\
(\text { PC I)? } \\
\text { Yes }\end{array}$ & $\begin{array}{c}\text { Core } \\
\text { Practices }\end{array}$ & $\begin{array}{l}\text { Change in } \\
\text { Core } \\
\text { "Alignment" } \\
\text { Practices }\end{array}$ & $\begin{array}{l}\text { Pattern } \\
\text { (PC II)? } \\
\text { No } \\
\text { (STOP) }\end{array}$ \\
\hline \multirow[t]{20}{*}{$\begin{array}{l}\text { Specific } \\
\text { contexts } \\
\text { of } \\
\text { boundary } \\
\text { spanning }\end{array}$} & & $\begin{array}{c}\text { All the } \\
\text { storming, } \\
\text { forming, \& } \\
\text { norming of } \\
\text { the WWWA }\end{array}$ & & $\begin{array}{l}\text { Operations } \\
\text { and } \\
\text { implement- } \\
\text { ation }\end{array}$ & & \\
\hline & $\begin{array}{l}\text { Actively listening to partner } \\
\text { peers }\end{array}$ & 1 & & 1 & 1 & \\
\hline & $\begin{array}{l}\text { Assigning opportunities to a } \\
\text { partner lead }\end{array}$ & & & 1 & & \\
\hline & $\begin{array}{l}\text { Assigning problems to a } \\
\text { partner lead }\end{array}$ & & & 1 & & \\
\hline & $\begin{array}{l}\text { Associating with partners } \\
\text { out of work context }\end{array}$ & 1 & & 1 & 1 & \\
\hline & Building personal relations & 1 & & 1 & & \\
\hline & $\begin{array}{l}\text { Classifying problems by } \\
\text { strategic objectives }\end{array}$ & 1 & & 1 & 1 & \\
\hline & $\begin{array}{l}\text { Classifying problems by task } \\
\text { group }\end{array}$ & & & & & \\
\hline & $\begin{array}{l}\text { Collaborating on other } \\
\text { projects }\end{array}$ & & & 1 & & \\
\hline & $\begin{array}{l}\text { Converting capital to } \\
\text { promote innovations }\end{array}$ & 1 & & 1 & & \\
\hline & $\begin{array}{l}\text { Coordinating external } \\
\text { communications }\end{array}$ & 1 & & 1 & & \\
\hline & $\begin{array}{l}\text { Coordinating the } \\
\text { convergence }\end{array}$ & 1 & & & & \\
\hline & $\begin{array}{l}\text { Defining boundary spanning } \\
\text { norms }\end{array}$ & 1 & & 1 & 1 & \\
\hline & $\begin{array}{l}\text { Defining boundary spanning } \\
\text { roles }\end{array}$ & 1 & & 1 & 1 & \\
\hline & $\begin{array}{l}\text { Defining boundary spanning } \\
\text { values }\end{array}$ & 1 & & 1 & 1 & \\
\hline & $\begin{array}{l}\text { Defining institutional } \\
\text { accountabilities }\end{array}$ & 1 & & 1 & 1 & \\
\hline & Defining institutional roles & 1 & & 1 & 1 & \\
\hline & $\begin{array}{l}\text { Deliberating with partners } \\
\text { in new contexts }\end{array}$ & 1 & & 1 & 1 & \\
\hline & $\begin{array}{l}\text { Deliberating with } \\
\text { partnership stakeholders in } \\
\text { other contexts }\end{array}$ & 1 & & 1 & 1 & \\
\hline & Designing process & 1 & & 1 & & \\
\hline
\end{tabular}




\begin{tabular}{|c|c|c|c|c|c|}
\hline & Disclosing interests & 1 & 1 & 1 & \\
\hline & Education & & 1 & & \\
\hline & Extending favors to partners & & 1 & & \\
\hline & Facilitation & 1 & 1 & 1 & \\
\hline & $\begin{array}{l}\text { Framing innovations in } \\
\text { terms of need }\end{array}$ & 1 & 1 & 1 & \\
\hline & $\begin{array}{l}\text { Framing need in terms of } \\
\text { innovations }\end{array}$ & 1 & 1 & & \\
\hline & $\begin{array}{l}\text { Influencing across policy } \\
\text { sub-networks }\end{array}$ & 1 & 1 & & \\
\hline & $\begin{array}{l}\text { Innovating (paradigmatic } \\
\text { boundary spanning) }\end{array}$ & 1 & 1 & & \\
\hline & $\begin{array}{l}\text { Integrating boundary } \\
\text { objects/innovations }\end{array}$ & & 1 & & \\
\hline & $\begin{array}{l}\text { Making government rules } \\
\text { and regulations }\end{array}$ & & 1 & & \\
\hline & $\begin{array}{l}\text { Managing process (budget, } \\
\text { conflicts, surprises, time) }\end{array}$ & 1 & & 1 & \\
\hline & Outreach & 1 & 1 & & \\
\hline & Pilot-testing innovations & & 1 & & \\
\hline & Pitching to decision-makers & 1 & 1 & & \\
\hline & Prioritizing problems & 1 & 1 & 1 & \\
\hline & $\begin{array}{l}\text { Protecting brand/integrity } \\
\text { of innovations }\end{array}$ & 1 & 1 & 1 & \\
\hline & $\begin{array}{l}\text { Respectfully pushing back } \\
\text { (disclosing constraints) }\end{array}$ & 1 & 1 & 1 & \\
\hline & $\begin{array}{l}\text { Ritually enacting boundary } \\
\text { spanning }\end{array}$ & 1 & 1 & & \\
\hline & $\begin{array}{l}\text { Scanning environment and } \\
\text { reporting issues }\end{array}$ & & 1 & 1 & \\
\hline & $\begin{array}{l}\text { Seeking input from relevant } \\
\text { constituents }\end{array}$ & & 1 & 1 & \\
\hline & $\begin{array}{l}\text { Seeking input from relevant } \\
\text { decision-makers }\end{array}$ & 1 & 1 & 1 & \\
\hline & Sharing risks & 1 & 1 & & \\
\hline & $\begin{array}{l}\text { Staff collaborating across } \\
\text { organizations }\end{array}$ & & 1 & & \\
\hline & $\begin{array}{l}\text { Staging group decisions } \\
\text { (lobbying, building }\end{array}$ & & & 1 & \\
\hline
\end{tabular}




\begin{tabular}{|l|l|l|l|l|l|l|}
\hline & $\begin{array}{l}\text { Strategically aligning } \\
\text { partnering organizations }\end{array}$ & & & & 1 & \\
\hline & Task-mastering & & & 1 & & 1 \\
\hline & Testing ideas/Vetting & & & 1 & 1 & 1 \\
\hline & $\begin{array}{l}\text { Translating across } \\
\text { technical/disciplinary }\end{array}$ & 1 & & 1 & & \\
\hline
\end{tabular}


It appears that the Alliance's - and by extension the Basin community's - struggles stem from the lingering misalignment of its core values, especially the ideals associated with local governance, and the practical realities of its implementation. The state of Washington has certainly extended unprecedented regulatory flexibility to the Basin. Oregon has also worked with its local partners, although it has not made as many concessions. The federal government has been even less flexible, which, owing to its size, culture, and remoteness, is perhaps not surprising. Other funders bring their own agendas and constraints as well. When it was implementing projects, the Alliance was frustrated by many of the procedural requirements that accompanied funding and which it felt unduly limited its ability to innovate new watershed management practices. The entrepreneurial spirit of the irrigators especially has helped drive much of the innovation in the Alliance's work. But this same spirit also translates to an impatience with bureaucratic procedures and processes that occasionally puts the Alliance at odds with stakeholders with whom it must work if it wishes to see those innovations adopted on a larger scale. As important as technical hurdles are to watershed management, they pale in comparison to the socio-economic, political, and cultural differences between the communities that share a watershed. For one thing, a local governance structure, even one like the WWWMP that relies heavily on incentives, has to devise an enforcement mechanism that doesn't exacerbate community divisions. Interviews reveal that the Walla Walla Basin community is currently struggling with the dilemma that arises when neighbors enforce against one another. How will the 
Basin come together to solve this problem now that regulators or water masters cannot be as conveniently called upon to serve as "the bad cop" against which the community can unify?

Dissolving the 501(c)3 structure is one thing; but the Alliance and its partners must still learn to work with both outside constraints as well as internal differences if it wishes to continue to have a significant impact on watershed management within the Basin. The Alliance has demonstrated a willingness to change its structure to respond to circumstances, but the question remains whether the newly streamlined Alliance will help meet the Basin's new challenges.

The Alliance, but also the Basin, finds itself at an important juncture in its social learning. Now that much of the Alliance's innovations have become institutionalized in the WWWMP (and related initiatives), a significant challenge will be to achieve implementation on a meaningful enough scale to realize the vision expressed in the WMI. Here it seems that the Alliance has a role it could play. Interviews suggest that the Alliance has developed a network of personal and professional ties that makes it more likely that the innovations it helped spawn will be adopted. As one board member explains, the Alliance itself has gained a certain institutional legitimacy that expands its sphere of influence beyond its formal members:

They're consistent and they're trusted conduits of information. I think it's gotten way more effective over time. A lot less effort has to go into that dissemination process now because the pathways are built, you know? [...] Now it is more a conversation of "the Alliance - we talked about this, it's my opinion that this is this, or this needs to be this way," or whatever and they're more inclined to go, "Okay," because that trust level has been built up over 
time. Then I don't have to go tell the other five guys; he's going to. They also have gained some trust. That's just a really small example about one conservation district board, but I'm telling you, I'm sure that exists behind every one of the Alliance members, that their pathways for dissemination have become trusted and consistent and acknowledged as pretty important. So I think the process is just a lot easier.

As the Basin community strives to scale up the WMI, it would do well to use the social capital that the Alliance and its partners have built over time.

Given its position as a boundary spanning organization, it seems that the Alliance has a unique opportunity to help the WWWMP realize its vision by establishing alignment practices that introduce the innovative programs and practices to the various communities within the Basin while facilitating discussion and learning about the issues associated with implementation in specific contexts. As one Basin observer notes:

I think their (the Alliance's) role is spreading the word, using the tools we have to help get the word out, coordination in the community. Communication is very important. If you don't understand it, you can't support it.

In fact, if the Alliance is able to establish itself as a true community forum where values and interests - and even the differences - can be explored, then it would rise to the level of PC III: a learning partnership that facilitates social learning in general. But in order to play such a role in the Basin, the Alliance would have to shift its emphasis away from advocacy and focus instead on process, on, say, "the Walla Walla Way" on a basin-wide scale. Doing so, of course, would require a fundamental change in the culture of a partnership that has demonstrated far more comfort with innovation than it has with process, and it would entail the Alliance assuming a 
much more public and perhaps even democratic, role than it has, until now, assumed.

Finally, the WWCC Water and Environmental Center can serve as an important center of social learning for the Basin community. Several interviews also suggest that both the Center and the Alliance are perhaps the two vital links between the CTUIR and the larger Walla Walla River Basin community. The expansion of the Center that is currently underway therefore represents an important opportunity for the Basin. Given the importance of the CTUIR for the Basin's successful watershed management, the center and the Alliance are probably unique places of social learning and should be supported as such. 


\section{Chapter 8}

\section{Discussion}

\section{Significance of Study Aims}

The present study builds on this fundamental insight by proposing a framework centered on the design view of systems that treats partnerships as processes organized in a nested hierarchy of boundary conditions. Events are a function of thresholds which serve to regulate these processes, but as instances of change, they can also communicate something about the processes that "triggered" them. This all suggests that partnerships are composed of boundary spanning processes that are organized into a system of communication. That is, they are organized into distinct orders, each one communicating something about the order of processes nested directly within it: the direction of control is, as it were, "downward" (D. T. Campbell, 1974). Viewed this way, communication is a management act, and partnership work is communicative. This means, in turn, that boundary spanning is not only fundamental to partnership processes but also to social learning. It suggests, among other things, that social learning entails learning how to span boundaries in a new way and, furthermore, that this "way" refers to a more encompassing boundary condition.

Several important methodological implications flow from this discussion. First, if communication entails the management of change (or uncertainty), then the communication problem we face as scientists or modelers or storytellers seeking to explain social processes like partnerships is isomorphic to - is structurally identical 
to - the management problem partnerships face. Thus, we are as beholden to the laws of communication (and consequences of our errors) as practitioners are beholden to the laws of management. Indeed, as a piece of communication, our model of a partnership is fundamentally no different from the strategic actions which its managers take to change its course. ${ }^{35}$ Our theoretical and methodological disputes are more closely related to the dramas of the communities we study than we might like to think: cases of partnership failures should serve as cautionary tales of poor modeling, while success stories have something to teach us about the rules of sound explanation. To get our account right, then, we are compelled to identify, and remain true to, the system-level or model boundary that will serve as our reference. Once we do, we are in a position to evaluate the significance of boundary spanning practices with respect to the order of change they represent.

The framework therefore proposes a new typology of boundary spanning processes which is grounded in the twin problem of communication and change. The typology builds on the open systems view to posit 3 levels of boundary spanning: operational or "core practices" (sub-systemic), strategic or "boundary spanning practices" (systemic), and "alignment practices" that coordinate operational and the strategic practices (meta-systemic). A fourth type of boundary spanning concerns the coordination of alignment practices over a still more complex interface. In systems terms, alignment is akin to self-regulation. Thus, coordination of alignment practices refers to the coordination of multiple, self-regulating systems

35 If done correctly, the topologies of our mapping of the two processes would be indistinguishable. 370 
and is communicatively equivalent to (on the same order as) meta-systems or institutional design.

With this general typology of boundary spanning processes in place, it becomes possible to derive types of partnership processes according to their capacity to accommodate boundary spanning processes of varying orders: Partnership Capacity I (PC I) is a rudimentary capacity to organize boundary spanning processes around a set boundary condition and function; Partnership Capacity II (PC II) refers to the capacity to adjust routine boundary spanning between 2 or more boundary conditions in such a way that the adjustments anticipate one another, i.e., the adjustments are themselves boundaried; and Partnership Capacity III (PC III) refers to the general capacity to reorganize boundary spanning practices as needed (a fourth type - the capacity to generate PC III structures - is implied but not explicitly examined here). This typology suggests, in turn, a typology of social learning of corresponding orders: Social Learning I (SL I), Social Learning II (SL II), and Social Learning III (SL III).

In addition to shedding more light on the nature of partnership formation and resilience, this study proposes a general way of measuring partnership capacity and social learning: PC I can be measured in terms of some pattern of boundary spanning practices; PC II can be measured in terms of some pattern of alignment practices; and PC III can be measured in terms of some pattern of institutional design practices. A primary aim is to test the validity of these measures and the underlying methodology. 
A general methodology for measuring boundary spanning, social learning, and partnership capacity enables us to begin to compare their associations across cases. This is because, as already discussed, while the particular forms of knowledge, communication, and learning will vary, there are fundamental, epistemological conditions of their production and management which will not. If Bateson (1972) is correct that the basic unit of information is "difference which makes a difference," then by focusing on the problem of change as opposed to meaning, we can devise a methodology to generalize across cases and specific contexts. In this way, we can side-step many of the limitations and controversies associated with more hermeneutic approaches. A second aim, then, is to test our specific theories of convergence and partnership capacity by evaluating their predictions. And finally, given the infancy of our inquiry, a third contribution this study hopes to make is to document the many varieties and associations of boundary spanning practices in partnership work. By shedding light on the roles that various boundary spanning practices play in the communication and management of change, students of partnership processes may begin to identify patterns in those associations. Insights into patterns will help, in turn, practitioners to identify strategies for intervention to foster partnership resilience and social learning.

Findings

Exploratory Findings 
To assess the methodological framework we want to see how well it covers the range of boundary spanning practices we observe. A second indication of the methodology's usefulness is whether our mapping of our observations yields any new insights into the relationships, if any, between boundary spanning, partnership capacity, and social learning. First, let us summarize the results of the exploratory portion of this study. Table 8 summarizes the observations of boundary spanning practices that were made in the 4 case studies, showing their associations with different orders of partnership processes. A " 1 " indicates that a boundary spanning practice was observed for a particular partnership and process. The grayed out column reflects the fact that the COTE WG is still undergoing SL I (as of this writing): 


\section{Table 8: Observations of Boundary Spanning Across Cases and Orders}

Boundary Spanning Practices

Actively listening to partner peers Assigning opportunities to a partner lead Assigning problems to a partner lead Associating with partners out of work context Building personal relations

Classifying problems by strategic objectives Classifying problems by task group

Collaborating on other projects Converting capital to promote innovations Coordinating external communications Coordinating the convergence

Defining boundary spanning norms Defining boundary spanning roles

Defining boundary spanning values Defining institutional accountabilities Defining institutional roles

Deliberating with partners in new contexts Deliberating with partnership stakeholders in other contexts

Designing process

Disclosing interests

Education

Extending favors to partners

Facilitation

Framing innovations in terms of need Framing need in terms of innovations Influencing across policy sub-networks Innovating (paradigmatic boundary spanning) Integrating boundary objects/innovations (standardization)

Making government rules and regulations Managing process (budget, conflicts, surprises, time)

Outreach

Pilot-testing innovations

Pitching to decision-makers

Prioritizing problems

Protecting brand/integrity of innovations Respectfully pushing back (disclosing constraints)

Ritually enacting boundary spanning

Scanning environment and reporting issues Seeking input from relevant constituents

Seeking input from relevant decision-makers

Sharing risks

Staff collaborating across organizations

Staging group decisions (lobbying, building

readiness, gauging support, vote counting, timing)

Strategically aligning partnering organizations Task-mastering

Testing ideas/Vetting

Translating across technical/disciplinary boundaries

Translating between task groups

TOTAL

Average for each process

\begin{tabular}{|c|c|c|c|c|c|c|c|}
\hline \multicolumn{4}{|c|}{ Social Learning I } & \multicolumn{4}{|c|}{ Partnership Capacity I } \\
\hline COTE WG & RWPC & UDRP & WWWA & COTE & RWPC & UDRP & WWWA \\
\hline \multirow[t]{3}{*}{1} & 1 & 1 & 1 & & 1 & 1 & 1 \\
\hline & & & & & 1 & 1 & 1 \\
\hline & & & & & 1 & 1 & 1 \\
\hline 1 & 1 & 1 & 1 & & 1 & 1 & 1 \\
\hline \multirow[t]{2}{*}{1} & 1 & 1 & 1 & & 1 & 1 & 1 \\
\hline & 1 & 1 & 1 & & 1 & 1 & 1 \\
\hline 1 & & & & & 1 & & \\
\hline 1 & 1 & 1 & & & 1 & 1 & 1 \\
\hline 1 & 1 & 1 & 1 & & 1 & 1 & 1 \\
\hline \multirow[t]{2}{*}{1} & 1 & 1 & 1 & & 1 & 1 & 1 \\
\hline & 1 & 1 & 1 & & & & \\
\hline 1 & 1 & 1 & 1 & & 1 & 1 & 1 \\
\hline 1 & 1 & 1 & 1 & & & & 1 \\
\hline 1 & 1 & 1 & 1 & & 1 & 1 & 1 \\
\hline 1 & 1 & 1 & 1 & & & 1 & 1 \\
\hline 1 & 1 & 1 & 1 & & & 1 & 1 \\
\hline 1 & & 1 & 1 & & & 1 & 1 \\
\hline 1 & 1 & 1 & 1 & & 1 & 1 & 1 \\
\hline 1 & 1 & 1 & 1 & & & & 1 \\
\hline 1 & 1 & 1 & 1 & & 1 & 1 & 1 \\
\hline \multirow[t]{2}{*}{1} & 1 & & & & 1 & 1 & 1 \\
\hline & & & & & 1 & 1 & 1 \\
\hline 1 & 1 & 1 & 1 & & & & 1 \\
\hline 1 & 1 & 1 & 1 & & 1 & & 1 \\
\hline 1 & 1 & 1 & 1 & & & 1 & 1 \\
\hline 1 & 1 & & 1 & & 1 & 1 & 1 \\
\hline 1 & 1 & & 1 & & 1 & & 1 \\
\hline 1 & & & & & 1 & & 1 \\
\hline 1 & 1 & & & & & & 1 \\
\hline 1 & 1 & 1 & 1 & & 1 & & \\
\hline 1 & 1 & & 1 & & 1 & 1 & 1 \\
\hline 1 & & & & & 1 & & 1 \\
\hline 1 & 1 & 1 & 1 & & 1 & 1 & 1 \\
\hline 1 & 1 & 1 & 1 & & 1 & 1 & 1 \\
\hline 1 & & & 1 & & & & 1 \\
\hline \multirow[t]{2}{*}{1} & 1 & 1 & 1 & & & 1 & 1 \\
\hline & & & 1 & & & & 1 \\
\hline 1 & & & & & 1 & 1 & 1 \\
\hline 1 & 1 & 1 & & & 1 & 1 & 1 \\
\hline 1 & 1 & 1 & 1 & & 1 & 1 & 1 \\
\hline 1 & 1 & 1 & 1 & & 1 & 1 & 1 \\
\hline \multirow{7}{*}{$\begin{array}{l}1 \\
1\end{array}$} & & & & & 1 & & 1 \\
\hline & 1 & & & & 1 & & \\
\hline & 1 & 1 & & & & 1 & \\
\hline & 1 & & & & 1 & & 1 \\
\hline & 1 & & & & 1 & 1 & 1 \\
\hline & & 1 & 1 & & 1 & 1 & 1 \\
\hline & 1 & & & & 1 & & \\
\hline 39 & $\begin{array}{l}36 \\
33.7\end{array}$ & 29 & 31 & 0 & 35 & 31 & 42 \\
\hline
\end{tabular}


The first observation to make is the sheer number of boundary spanning practices that were identified. No attempt has been made here to collapse these varieties under larger groupings, although it is likely that there are significant relationships between many of the practices that would justify such a lumping and perhaps reveal some interesting patterns. It is true too that the practices could have been coded in an infinite number of ways. What is important is that a set of criteria is selected and adhered to. As described in the Methods section, the present framework defined boundary spanning as any interaction between 2 or more practices, ideas, entities, and objects hailing from different fields of practice, or any process or practice that supports such interaction. The codings were as descriptive as possible to aid in interpretation and validation of the observations. Future research could further validate or invalidate the findings in at least 2 ways. First, the textual data from interview transcripts, meeting observations, and secondary data could be revisited with this new list of boundary spanning practices serving as a kind of codebook. Revisiting the data with these categories in mind may change the results as some observations are discovered while others are dismissed. Second, interviewees and other sources could be re-queried about the specific categories of boundary spanning practices, again producing somewhat different results.

The second general observation to make is that the data are noisy. While there a number of boundary spanning practices demonstrating some variance across cases (highlighted in orange), a cursory scan suggests no obvious differences across cases. Furthermore, boundary spanning processes that may have some 
correlations with partnership processes built into their definition have been highlighted in yellow. Any associations with these processes should therefore probably be dismissed. But before we dismiss the data entirely, a couple points need to be made. First, the variables represented in the matrix are binary - either an observation was made or it wasn't. While such a gross level of resolution is probably necessary at this stage until our measures become more accurate, it also means that subtler correlations will be missed. The second point is, of course, that we have only 4 cases, which makes it difficult to discover any meaningful relationships that might exist. And finally, while the distribution of boundary spanning practices appears to be fairly uniformly distributed, either with respect to cases or with respect to processes, some of this uniformity may suggest that boundary spanning practices are more universally applicable to cases and processes than might be expected. In other words, part of the uniformity may stem from the fact that most of the boundary spanning strategies are being employed, regardless of context.

Still, the noisiness of the data makes any signals we do detect both more suspect but also potentially significant. Observations of boundary spanning that vary by a ratio of $1 / 3$ or more, either between cases, or between processes, have been highlighted in blue: defining boundary spanning roles, defining institutional accountabilities, defining institutional roles, designing process, facilitation, and managing process. In contrast to the others, the WWWA continued defining boundary spanning roles, designing processes, and using facilitation, even after it had formed, reflecting its social learning as it moved from project implementation to 
facilitation and support. "Defining institutional accountabilities" and "defining institutional roles" show a similar pattern of distribution to "defining boundary spanning roles" within the PC I process, but with only 3 observations each, it's difficult to make much of RWPC's contrast. Finally, the table shows that RWPC continued relying on process management strategies even after it formed, which reflects the sheer size and complexity of its negotiations.

Assessing the Theoretical Predictions

A second aim of this study is to test the validity of the underlying theory by evaluating 2 of its predictions. Let us restate the 2 original research questions and corresponding hypotheses:

Research Question I: How do partnerships form exactly?

Hypothesis I: A socio-technical or policy need creates a structural opportunity for boundary spanning practices to begin to influence the larger institutional ecology. Boundary spanning practices will begin to converge with the ecology of participating fields through an iterative process of social judgments embedded in communicative practice and capital exchange. If the boundary objects (innovations) are deemed both technically desirable and culturally feasible, then the practices and ideas that produced them diffuse along with the innovations, further reinforcing the convergence. Boundary spanners play an important role in managing the convergence (however imperfectly) through visioning, strategic judgments, and steering capital flows, even as they are thereby changed in the process. The entire process is summarized as "Social Learning (SL) I" and results in 
a partnership with a basic capacity (Partnership Capacity I) to address a fairly welldefined policy problem.

Research Question II: How do partnerships sustain themselves over time?

Hypothesis IIa: To survive in the face of changing policy conditions, a partnership must learn (SL II) to engage in alignment practices that periodically allow for the mutual adjustment of core operations and more strategic and even constitutional concerns. This ensures that partnership goals and strategies are informed by local practices and conditions and facilitates the partnership's role in shaping the community agenda on a policy issue. Therefore: partnerships demonstrating a pattern of alignment practices will tend to oscillate about a defined range of "partnership states," as measured by programs, initiatives, or other strategic emphases.

Hypothesis IIb: Partnerships that develop the capacity (SL III) to reconfigure or "design" alignment practices to address socio-technical and policy surprises acquire a general capacity to learn and adapt that is enhanced with each iteration of the social learning cycle. Partnerships demonstrating PC III are characterized by a learning culture that promotes innovation and critical reflection of alignment practices in experimental settings. Therefore: partnerships demonstrating a pattern of institutional design practices will tend to persist in varying forms and under a wide range of environmental conditions. 
Let us review the findings of these 2 basic questions. Table 9 shows the results of assessing Hypothesis I. 
Table 9: Results of Assessing Hypothesis I

\begin{tabular}{|l|l|l|l|l|l|l|l|l|l|}
\cline { 2 - 8 } \multicolumn{1}{|c|}{} & \multicolumn{3}{|c|}{ Predicted Factors of Partnership Formation } & & Intermediary & \multicolumn{2}{c|}{ Predicted outcomes } \\
\hline Cases & $\begin{array}{l}\text { Pre-existing } \\
\text { socio- } \\
\text { technical } \\
\text { and policy } \\
\text { need? }\end{array}$ & $\begin{array}{l}\text { Boundary } \\
\text { spanning } \\
\text { practices? }\end{array}$ & $\begin{array}{l}\text { Technical } \\
\text { desirability } \\
\text { (fit) }\end{array}$ & $\begin{array}{l}\text { Cultural } \\
\text { feasibility } \\
\text { (appropri } \\
\text { ate-ness) }\end{array}$ & $\begin{array}{l}\text { Degree of } \\
\text { institutional } \\
\text { interest and } \\
\text { support }\end{array}$ & $\begin{array}{l}\text { Exchange of } \\
\text { capital forms } \\
\text { to promote } \\
\text { innovations? }\end{array}$ & $\begin{array}{l}\text { Degree of } \\
\text { adoption of } \\
\text { innovations }\end{array}$ & $\begin{array}{l}\text { Structural } \\
\text { distance between } \\
\text { community of } \\
\text { practice and } \\
\text { boundary }\end{array}$ & $\begin{array}{l}\text { Pattern of } \\
\text { boundary } \\
\text { spanning } \\
\text { practices? }\end{array}$ \\
\hline $\begin{array}{l}\text { Counting on the } \\
\text { Environment } \\
\text { WG }\end{array}$ & Yes & Yes & Medium & Medium & Medium & Yes & Medium & Decreasing & No \\
\hline $\begin{array}{l}\text { Regional Water } \\
\text { Consortium }\end{array}$ & Yes & Yes & Medium & High & High & Not detected & High & Significant \\
reduction & Yes & \\
\hline $\begin{array}{l}\text { Upper } \\
\text { Deschutes River } \\
\text { Partnership }\end{array}$ & Yes & Yes & Medium & Medium & Medium & Yes & Medium & Some reduction & Yes \\
\hline $\begin{array}{l}\text { Walla Walla } \\
\text { Watershed } \\
\text { Alliance }\end{array}$ & Yes & Yes & High & High & High & Yes & High & Some reduction & Yes \\
\hline
\end{tabular}


The findings offer partial validation with respect to the theory's predictions about partnership formation. Generally, there was no disconfirmation of the hypothesis: for all 4 cases, none of the factors which the model predicts are important contributors to partnership formation measured negative ("no") or "low." Moreover, COTE WG and the WWWA are identical with respect to the model's variables and to-date, anyway, the formation processes have resulted in a discernable reduction in the structural distance between the boundary spanning practices and relevant policy community. RWPC and WWWA differed with respect to 2 of the variables: "technical desirability" of the boundary spanning innovation ("fit") and "exchange of capital forms to promote innovations." Interestingly, RWPC scored lower on both measures and yet scored a significantly higher reduction in structural distance during the convergence. This finding reflects the fact that "structural distance" is only a measure of magnitude and gives no sense how much either the new joint field or the larger community accommodated the other during formation. Significant reduction can occur when either the accommodation is very lop-sided or the convergence is balanced but the initial distance (prior to convergence) was large, or both. An examination of the "technical desirability" and "exchange of capital forms to promote innovations" variables suggests that the RWPC accommodated the water supply policy community more than the other way around, and secondary data from the case study confirms this interpretation. If this interpretation is correct, then it suggests that technical desirability and exchange of 
capital forms are important determinants of how balanced the convergence leading up to a partnership will be.

Still, several important data limitations need to be stated which restrict how much we can make of the findings. First, of course, we have only 4 cases. While 4 cases enables us to begin to use replication logic for purposes of confirmation or disconfirmation, it is a not a significant number of cases, particularly given the complexity of the problem space. ${ }^{36}$ Second, two of the variables - "pre-existing socio-technical and policy need?" and "boundary spanning practices?" - were used as criteria in selecting the cases. Since these variables cannot be regarded as being "independent" of the predicted outcomes, they should largely be ignored when evaluating the predictions. Third, measurement of the variables was ultimately subjective. True, model variables were identified before data collection and could therefore inform the development of the interview instrument and data collection more generally (see Appendix A). But those measures like "degree of institutional interest and support" that could be taken more directly often relied on either my qualitative judgment or the judgments of others. The general limitations of interviewing a non-random sample of subjects apply here. The interview instrument, while pilot-tested on 2 subjects, was not fully tested for measurement validity. And of course, ultimately, assignment of values was based on an overall assessment. Finally, as in the cataloguing of boundary spanning varieties, the levels

\footnotetext{
${ }^{36}$ If we consider just the model's 6 basic variables: 3 are binary and 3 are ternary, returning a parameter space $=\left(2^{3}\right)\left(3^{3}\right)=216$.
} 
of measurement - categorical and ordinal - were crude and likely miss subtler variances.

Because none of the cases could be classified as PC II or PC III, Hypotheses IIa and IIb could not be assessed. Table $\mathbf{1 0}$ shows the logic used to assess Hypothesis IIa. Note that the table does not include hybrid conditions.

Table 10: Logic to Assess Hypothesis IIa

\begin{tabular}{|l|l|l|}
\hline \multicolumn{2}{|c|}{ Predicted Factors for PC II } & $\begin{array}{l}\text { Outcome Measure of PC } \\
\text { II }\end{array}$ \\
\hline \multicolumn{2}{|c|}{ Pattern of alignment practices? } & $\begin{array}{l}\text { Oscillation through a } \\
\text { range of partnership } \\
\text { states? }\end{array}$ \\
\hline $\begin{array}{l}\text { Pattern of interaction between } \\
\text { operational and strategic concerns? }\end{array}$ & $\begin{array}{l}\text { Pattern of interaction between } \\
\text { boundary spanning functions } \\
\text { (e.g., initiatives or programs)? }\end{array}$ & \\
\hline Yes & Yes & Yes \\
\hline No & No & No \\
\hline
\end{tabular}

Only 1 case, the RWPC, demonstrated any traits which the theory predicts will be associated with PC II (see Table 11). Its decision flow structure enables issues to be vetted and addressed through multiple iterations of a cycle of committee deliberations that span operational, strategic, and even constitutional concerns. At the same time, however, RWPC did not demonstrate a pattern of interaction between its major program or other functions. The direct measure of PC II oscillation through a fixed range of "states" or functions - was not observed. Instead, RWPC could be characterized by a set of distinct programs and initiatives that remain largely separated and, it should be added, unevenly implemented. 
Table 11: Results of Assessing Hypothesis IIa

\begin{tabular}{|l|l|l|l|}
\hline Cases & \multicolumn{2}{|c|}{ Predicted Factors for PC II } & $\begin{array}{l}\text { Outcome Measure of } \\
\text { PCII }\end{array}$ \\
\hline & \multicolumn{2}{|c|}{ Pattern of alignment practices? } & $\begin{array}{l}\text { Oscillation through a } \\
\text { defined range of } \\
\text { partnership states? }\end{array}$ \\
\hline & $\begin{array}{l}\text { Pattern of } \\
\text { communication between } \\
\text { operational and strategic } \\
\text { concerns? }\end{array}$ & $\begin{array}{l}\text { Pattern of interaction } \\
\text { between boundary } \\
\text { spanning functions (e.g., } \\
\text { initiatives or programs)? }\end{array}$ & \\
\hline $\begin{array}{l}\text { Regional Water } \\
\text { Providers Consortium }\end{array}$ & Yes & No & No \\
\hline
\end{tabular}

It would appear, then, that RWPC is kind of hybrid or transitional entity between PC I and PC II. The theory did not predict such an entity, which may be an artifact of measurement error or may reflect a theoretical deficiency with the model. Regardless, the fact that none of the cases rose to the level of PC II might be interesting in and of itself. The absence may be another sign of a deficiency in the theory's account of partnership resilience. But it may indicate instead that PC II is rarer than the theory would suggest. In addition, the results do not disconfirm the hypothesis, that is: the absence of a pattern of alignment practices did not produce any partnerships that fit our definition of PC II.

Table $\mathbf{1 2}$ shows the logic used to assess Hypothesis IIb. None of the cases demonstrated PC III. While therefore Hypothesis IIb could not be directly assessed, the absence of any cases demonstrating PC III is at least consistent with the theory's expectation that partnerships with PC III are probably relatively rare. In addition, the results do not disconfirm the hypothesis, that is: the absence of a pattern of 
institutional design practices did not produce any partnerships that fit our definition of PC III.

Table 12: Logic to Assess Hypothesis IIb

\begin{tabular}{|l|l|l|l|l|}
\hline \multicolumn{2}{|c|}{ Predicted Factors for PC III } & $\begin{array}{l}\text { Outcome } \\
\text { Measure of } \\
\text { PC III }\end{array}$ \\
\hline \multicolumn{3}{|c|}{ Pattern of institutional design practices? } & $\begin{array}{l}\text { Any } \\
\text { outstanding } \\
\text { partnership } \\
\text { issues? }\end{array}$ \\
\hline $\begin{array}{l}\text { Pattern of } \\
\text { innovating }\end{array}$ & $\begin{array}{l}\text { Pattern of } \\
\text { critical } \\
\text { inquiry }\end{array}$ & $\begin{array}{l}\text { Knowledge-base of } \\
\text { institutional } \\
\text { designs/models }\end{array}$ & Culture of learning & \\
\hline Yes & Yes & Yes & Yes & No \\
\hline No & No & No & No & No \\
\hline
\end{tabular}

The hypotheses assessments also serve to partially validate the methodological framework. But here again, the validation is weak to the extent that it relies on subjective interpretation. With regard to partnership formation, of the 4 partnerships that experienced some degree of convergence, 3 of them demonstrated an established pattern of boundary spanning practices, which is the result the theory predicts, suggesting that presence of such a pattern is a good indicator that a partnership field has formed with minimal institutional capacity (PC I).

The study also highlights the awkwardness of using "oscillation through a fixed range of partnership states" as our direct measure of PC II. We need a more accessible measure of PC II against which we validate proposed correlates. In fact, the theory provides such a measure. Given that PC II is conceptualized in terms of the integration of core and boundary spanning practices, we should expect 
partnerships with PC II to enjoy broad and consistent implementation of multiple plans or broad and consistent participation in multiple campaigns, initiatives, or programs. Applying this proxy measure of PC II to the case studies does not change the findings. However, future assessments of the theoretical and methodological predictions of PC II would benefit from use of this more accessible proxy measure.

Directions for Future Research

A number of possible lines for future research have already been identified to build on the study's findings while addressing some of its limitations. I will now outline one more that ties together all 3 of the study's principal aims. Clearly, the study's findings would be enhanced by future research. It is too early to draw any conclusions about possible associations between specific boundary spanning practices and partnership processes or even partnership types. One way to build on the findings summarized in Table 8 while also further assessing the underlying theoretical and methodological framework would be to recode the observations in terms of alternative typologies - such as Rugkåsa et al.'s (2007) distinction between boundary spanning "up," "across," and "down" - and see whether any new associations with the partnership processes (i.e., SL I and PC I) emerge. If any do, the next step is to revisit other studies employing the same boundary spanning typology and recode the partnership processes in terms of the framework typology of partnership processes. This would enable us to "back-test" the framework's model onto other studies to determine whether any associations between types of boundary spanning practices (e.g., up, across, and down) and types of partnership 
processes (e.g., SL I and PC I) show a similar pattern across cases. Of course, variances in patterns across cases would not, by itself invalidate the theoretical or methodological framework. For example, one possible source of variance is low inter-coder reliability. On the other hand, any meta-pattern across cases would be a strong indicator of a meaningful relationship between the proposed types of boundary spanning practices and the framework's types of management processes. It would validate the theories underlying the typologies, including the framework's typology of social learning and partnership capacity and suggest concrete boundary spanning strategies which partnership practitioners could employ to grow and strengthen partnerships. These and other studies could also be recoded with respect to our general typology of boundary spanning practices ("boundary spanning," "core practices," "alignment practices," and "institutional design practices") in order to carry out similar back tests, although, without access to the studies' data, classification and the associated findings would be more suspect than would be classification of partnership capacity (and social learning), which, with the possible exception of PC I, can be assessed with more straightforward outcome measures. Regardless, these lines of research are outlined to illustrate the possibilities for theory-building that are opened up by a process-oriented methodology, even of the qualitative variety like the one proposed here.

\section{Specific Lessons from the Cases}

Partnership formation requires the right ingredients 
The cases partially confirm the convergence hypothesis (Hypothesis I). A review of those cases underscores how important processes and conditions came together in the right combination and at the right time to allow these partnerships to form. The cases share some common ingredients, among them: matching of idea with the times, alignment of BATNA's and interests, social network of strong and weak ties, adequate resources and resource mix, and visionary and charismatic leaders. On this last point, the case studies also suggest that while boundary spanners are as varied as the boundary spanning practices and processes in which they engage, they tend to share a set of core traits. Psychologically, boundary spanners appear to be relatively comfortable working in gray areas characterized by complexity and uncertainty. Whereas many would find such conditions disturbing or stressful, many boundary spanners, like the following member of the WWWA, find them engaging, even if trying:

It's been an experience for me. I've been part of a lot of different groups, but this is the one group where it's like being part of going to college again because you're part of a bunch of very intelligent, out-of-the-box thinkers, proactive, just some really nice people but they're just not...they're normal but they're not normal, you know what I'm saying? (laughs) It's pretty amazing what we've accomplished and to get those people together has been quite a run and quite a ride, you know?

All 4 partnerships reveal similar stories of sacrifices but also intellectual and spiritual adventure. It should be added, too, that in many cases the boundary spanners occupied prominent positions within their respective communities that gave them a certain degree of credibility and means to pull their communities along for the ride. But each pull brings tension and these tensions interact as the 
partnership forms. Those with considerable collaborative leadership experience were able to navigate the partnership through the sometimes reinforcing and often conflicting pulls.

It appears the precise management level of boundary spanners varied in importance from case to case. For the COTE WG, it was important to secure the participation of top management and board members to ensure adequate institutional support of the boundary spanning practices, especially among the larger and more conservative agencies. The WWWA likewise brought in top-level managers and board members, as did the RWPC, although it appears that middle managers such as system engineers and operators were also important in the formation of the RWPC. In the case of the UDRP, top-level staff members similarly were the ones to innovate, eventually enlisting many board members, although the precise role of boards in fostering the partnership would benefit from more research. The case study suggests that board interlocking and board-level network played a role in the formation of the UDRP, at the very least by preparing the institutional and policy "ground" for it in the context of the Pelton-Round Butte Dam relicensing negotiations.

Innovation is Risky

There was, in fact, a fair amount of both assessing and fostering policy and ultimately social "readiness" that went into the formation of these partnerships. The boundary spanning entailed, in a sense, spanning the past, present, and the future and working to make them meet somewhere in between. It's difficult enough to do 
this once, let alone on a continuous basis as the terrain of constraints and opportunities shifts, often unexpectedly, under one's feet. This is particularly the case as boundary spanners forge new relationships and identities that can change the cost-benefit calculus in surprising ways. To address this challenge, boundary spanners employed different strategies. The COTE WG Project Team designed a process that has relied heavily on a Technical Coordinating Team that could anticipate issues while also reading the opportunities for pushing the larger Working Group members - through strawman documents and other means - just beyond their comfort zones (the somewhat serendipitous overlap between the Technical Coordinating Team and the SB 513 WG has facilitated a similar convergence of theory and practice in the larger policy network). The RWPC's Technical Committee similarly employs an iterative decision-making cycle, although the Consortium's well-established routines and structure make it more conservative than the still-new and groundbreaking COTE WG.

Another important strategy for "managing many futures" - to paraphrase the title of a Ruckelshaus report (2007) on the capacity of the Walla Walla River Basin seems to be providing political cover to both the boundary spanners and their sponsors. Manning's challenge to the Walla Walla River Basin, groundbreaking as it was, had in fact been "tested" by a closer circle of basin leaders before he went public with it. Similarly, Senator Murray and Representative Nethercutt sought assurances from Alliance representatives that their "alliance" was not just a name. Alliance members displayed political and even performative savvy in staging tours 
and community circles to demonstrate their authenticity. Thus, the "moment of selection" that accelerated the formation of the WWWMP was not as top-down as the term might suggest. In the case of the UDRP, funders like OWEB are only too happy to disown the political liabilities associated with project-based funding and review. In both of the watershed management cases, in fact, we can discern a strong regional theme of local self-determination that carries significant political (and cultural) legitimacy. In neither case has the partnership been a creature of the state or of any other interest. And the political favors go both ways. The COTE WG Project Team showed keen political judgment in securing the support and ultimate "endorsement in concept" of organizational leaders, an endorsement they have skillfully converted into symbolic capital as they tout the legitimacy of their ECAS. And of course, the RWPC probably owes its longevity in large part to an institutional design that includes locally elected officials on its board. Finally, it should be added that "political covering" occurred on multiple levels, as boundary spanners also labored to reassure their "home field" constituents that the partnership in question was not a mere instrument of competing interests. Jutila's boundary spanning work to bring skeptical water providers on the eastside of the Willamette River into the still-forming Consortium and Rupar and Brown's comparable efforts to get irrigators and farmers to approach the CTUIR in the case of the WWWA are just 2 of many notable examples.

The formation of partnerships appears to entail a complex negotiation of concessions. Our theory of convergence predicts that concessions are inevitable, but 
the precise configuration of concessions is not a given. Social learning has a certain undemocratic quality to it, in so far as concepts must be proposed that, by defining what is relevant and what is not, necessarily foreclose debate to some extent. One aspect to the art of building partnerships appears to be knowing what the appropriate level of resolution and participation is for a given deliberation. As seasoned planners know all too well, if policy ideas or plans are paraded out too soon without first preparing a context to organize deliberations, they often become casualties of false issues or political posturing. If they are introduced to the "community of implementers" well after development, they risk irrelevance or outright resistance. In the former case, plans get lost in the weeds, while in the latter they get lost in the clouds. An architect of the RWPC captures the trickiness of, as he calls it, "that little gray area:"

I think in public policy the failure point so often tends to come in that little gray area between where you've got enough general support from a few key people for a concept to think, "I need to move ahead on this and put some flesh on the bones," and the point where you have enough flesh on the bones to get people to start signing up. Between there is where things go to hell in a hand basket[...] What happens I think is you get good ideas out of the incubator way too soon if you try to do a public process. You can't get it up in the air enough for people to be able to comment, make judgments, get good input, make improvements and things on a real thing. It all just becomes a bunch of emotional hot air around a concept so it never becomes a real thing. That is what happened here, I think. But that is the essence of public process is trying to get it up in the air. That's why not much happens. It's hard.

Making the right call in that little gray area requires considerable political judgment, but the case studies also suggest that convergence entails a series of judgments that, to use Koppenjan and Klijn's (2006) term, "steer" both the innovations and the readiness for those innovations so that they meet. Boundary spanners and their 
innovations more often than not need incubation. But for successful adoption to occur, the community of users also need to become owners of them.

Convergence, then, entails a complex alignment of concessions. It is in this alignment where tradeoffs are defined that much of the negotiations and struggles take place. In the development of the COTE WG crediting tools, its innovators made certain concessions to wider institutional concerns, including a bias toward precision, that left some stakeholders dissatisfied. The RWPC and WWWA were actually conceived as implementing entities of a previous agreement (the Negotiated Settlement Agreement) or plan (Regional Water Supply Plan). Thus, both partnerships started innovating with policy- and other sideboards built in from the start. In both cases, it seems that part of their struggles has centered on negotiating this tension between innovating and implementing. The RWPC has been more accommodative of the political and policy context of regional water supply at the price of being less innovative, while the WWWA eventually moved away from managing and implementing projects toward innovating basin-wide policies around watershed management. Consequently, the WWWA has arguably had a greater impact on its region's policy context, but it is also encountering a challenge of "scaling up" implementation of its vision. The study's theory of convergence suggests that diffusion of innovation should be facilitated by a narrowing of the gap between the innovative vision and the larger community of practice. This would suggest a common explanation for why neither RWPC nor WWWA have not enjoyed more consistent implementation of their programs and initiatives. The RWPC has 
been arguably too accommodative while the WWWA has arguably not compromised enough, with the same result that the larger community of practice tends to overlook them.

Scaling Up Requires Different Alignment Practices

Embedded in the problem of implementation is a chicken-and-egg dilemma similar to the one associated with partnership formation: one the one hand, innovations must be adopted by a sufficient number of "boundary spanners-inpractice," to use Levina and Vaast's (2005)term, for them to be taken seriously, but at the same time adoption requires legitimacy. A COTE WG member summarizes this dilemma in discussing the building of a multi-credit ecosystem marketplace:

The physical implementation is going to be a lot harder. That is one of the things we're really struggling with is there's a lot of the chicken and the egg. There's a lot of things that have to be built ahead of time. It's really hard to build them without having something piloted to test it against...I think there's a lot of people who have a bit of a wait-and-see attitude: "Great, we got through this philosophical conversation and we've got the tools in place, and the computer programs. Everything looks all hunky dory, but now what do we do?" When Bobby [Cochran] isn't hand-holding the landowner and a buyer through a process, how do you actually really make a market system work? That's a bit of a struggle. It boggles my mind every time I try to get to that next level. In theory I think people are going to jump right on it. In reality I think it's just going to take time to get there.

The delicate balance boundary spanners must strike between operational and strategic considerations has implications for their relationships to the community of users of their innovations and therefore for their effectiveness.

The UDRP seems to have intuited this balance fairly well. On the one hand, Heisler and his partners have emphasized the need to secure social agreement before undertaking any projects, eventually establishing it as a criterion for project 
selection. On the other hand, they have not tried to force funders, regulators,

advocacy groups, or other stakeholders to adopt their strategic matrices,

recognizing that the Basin lacks a unified watershed management framework which

would at least give partners a common language with which to evaluate them, as a

UDRP member explains:

I think that is one of the reasons the whole thing didn't crumble is because we didn't push that. We recognized that you can look at a creek from the perspective of a nonprofit, a federal agency, a state agency, a management agency, a regulator agency, a city and you can be interested in the same vision and see a bunch of different things. You have your own mandate. We didn't try to force that. One of the things I see people try to do with partnerships that just bogs them down is they try to make it so everybody agrees. I feel like the US Forest Service, under US Department of Agriculture, has its own set of mandates. There is no way you're going to get those perfectly aligned with the Upper Deschutes Watershed Counsel. You can get a lot of alignment in certain areas but you cannot get them perfectly aligned. To try to get that is a waste of time.

The case studies lend support to the notion that alignment practices play a role in securing community ownership in a partnership. And because typically partnerships contend with wicked problems that defy universal formulation, education and outreach alone are not enough. Deeper community differences will need to be spanned with visions and metaphors that communicate with, rather than around, those differences. The absence of such bridging visions may explain the mixed implementation success of the partnerships in this study. It suggests too that scaling up a partnership requires learning a different set of alignment practices than 
the ones that are mobilized to form a partnership, lending further support to the notion that there are qualitatively different kinds of social learning.

SSM Workshop

The SSM workshop, held in September 2010, had 3 primary objectives. First, it was an opportunity for me to present my preliminary findings, in the form of a PowerPoint, from the case studies to members of the 4 partnerships who had been interviewed and were participating in the study. Each of the workshop participants, then, functioned in a certain sense as expert witnesses/cultural informants who were in a position to provide partial validation as well as identify areas requiring fact-checking or more research. And although the change scenario exercises were driven to a large extent by the individual workshop participants - they selected the type of process, real or hypothetical, that they envisioned for their partnership there usually was enough overlap with their corresponding case studies that the exercises provided an additional instance of validation. In the case of the change scenarios, I was able to summarize my appreciation for each perspective in the form of a rich picture (see Appendix C). Prior to group discussion of each change scenario, I presented the pictures to the group and solicited feedback from the partnership representative to provide corrections or additions to the picture and underlying story. In the case of both my PowerPoint of the case studies' preliminary findings and the rich picture exercises, I received general confirmation that my findings were more or less accurate, although minor changes were recommended that mostly centered on factual discrepancies as opposed to issues with interpretation. 
However, we ran out of time and were not able to complete 2 of the 4 change scenario exercises. I estimate that the workshop in its current design requires approximately 6 hours to complete; ours ran for only 4 .

A second major objective of the workshop was to field-test SSM as a collaborative institutional design and management tool. In this respect, the workshop suggests that SSM can be very useful for problem-structuring and preliminary model-building. Participants reported that they found the rich picture technique especially useful for conveying complex information in a more concise and visual manner. Judging from the richness of the discussions and post-workshop evaluations, the rich pictures are effective in stimulating group learning around a particular problem or class of problems. The SSM process used in the workshop did not in fact strictly follow the conventional SSM structure (Mode 1), but instead used a modified process design adapted to the particular objectives and constraints of the workshop and larger study (Mode 2). Perhaps most significantly, each change scenario employed a single perspective of a participant designated to represent the partnership for purposes of the workshop, thus removing an important strength of SSM: that of comparing and integrating multiple perspectives bearing on a particular context. Nevertheless, it opened the way for boundary spanning practitioners from the other partnership cases to identify similarities and contrasts across different scenarios of institutional change. It furthermore facilitated discussion and learning across the academic and practitioner divide. The preliminary case study findings, which were presented immediately prior to the 
change scenario exercises, informed the discussions, but the particular learning that occurred within and across the exercises also informed my revisits of those findings long after the workshop's conclusion. The workshop, then, and its participants, became an integral part of the research effort.

Finally, the workshop sought to bring together boundary spanners from different partnership contexts in order to cultivate, following Armistead and Pettigrew (2004), a community of reflective practitioners. Such a network would ultimately facilitate social learning by providing resources and support to prospective or struggling boundary spanners and partnerships. Here, the findings are less clear. It turned out that most of the participants were already acquainted with one another and, in some cases, collaborating on various projects or efforts. No attempt has been made to measure what effect, if any, the workshop had on building and nurturing relationships, although it seems likely that the impact of a single workshop is limited. Additional workshops or efforts that engage the participants would need to occur to establish an enduring network of reflective practitioners that would begin to support social learning on a larger scale. 


\section{Chapter 9}

\section{Conclusion}

This study was motivated by two research questions which sought to address two distinct gaps in our knowledge with respect to partnership processes. The first question concerned the formation of partnerships, namely: what is the precise mechanism by which new joint fields of practice emerge? The second question concerned the resilience of partnerships once they form, namely: how do partnerships manage to stay together in the face of change, or contrawise, why do partnerships so often fail to achieve the outcomes they set out to achieve? Case studies of partnership formation tend to explain away the process through rational actor models, structural determinism, or an unconvincing combination of both. Most of these accounts suffer from an inconsistent application of the concept "agency" to explain how actors from different fields of practice manage to organize their disparate perspectives, aspirations, and resources in collective action. Similarly, theoretical attempts to generalize across cases rely on ad hoc reasoning that selectively use evidence to support a particular set of assumptions. The same can be said for accounts of partnerships once they form. While part of the problem is empirical - our tendency to concentrate on success stories distorts our understanding of the underlying processes - I argue that the gap in our understanding reflects a more fundamental problem. It is that, despite our best efforts to move past them, we still largely rely on dualistic systems of thought that posit false separations - between mind and matter, subject and object, the ideal and 
the material, agency and structure, and even theory and practice - and thereby produce false explanations of social organization and change.

A more complete and internally consistent explanation of partnership capacity and social learning therefore requires a different epistemology and methodology that can account for collective action that is neither wholly rational nor mindless. One of the contributions this study hopes to make is a new framework for examining partnership capacity and social learning, one premised on a concept of "social mind" that operates through - not on -patterns of social interaction. It adopts a socio-cybernetic view that posits that societies are held together by communication and that furthermore this communication is only made possible through the standardization of differences between "agents." This view holds that for there to be communication, there must be some interface that joins differences in a common language of interaction. In other words, as patterns of interaction, societies are fundamentally composed of boundaries and only secondarily of agents and their material conditions.

If our objective is to explain the social patterns we see, then it would seem that we all too often study, and argue about, the wrong thing. Regardless of whether that pattern concerns income disparities, a partnership initiative to address those disparities, or some other social phenomenon, the contention here is that our focus should be on boundary conditions. By extension, if our objective is to explain social change, then our focus should be on changes in boundary conditions. If we define social learning as a special kind of social change that leads to a new boundary, then 
it follows from this that the proper object of study is the standardization of difference. A more recursive understanding of "social mind" - one located in the interface of different worlds - leads us to a richer and probably more accurate understanding of social learning. Instead of focusing on individual and technical learning, as accounts of "social learning" so often do, we are driven to consider the emergence and inculcation of norms governing the interaction of classes of social facts, objects, practices, and identities.

Many insights along these lines have been made before, but these insights have to date largely been confined to high theory (cf. Bateson, 1972; Bourdieu, 1977; Luhmann, 1995). Perhaps because this work remains largely inaccessible, there has not been much sharing of insights across disciplines and schools of thought. The literature on boundary spanning, however, offers a starting point for the unification of insights that can shed light on particular problems. The term itself draws our attention to the boundary conditions of social processes. And if social communication always occurs through boundaries, then boundary spanning is quintessential communication. But "boundary spanning" also denotes boundary change, which suggests that there is a deep relationship between communication and change. Indeed, theoretical work in disparate fields ranging from cybernetics and information theory to action theory (and action research), practice theory, and social constructionism have reached the same general conclusion. There are many social areas where this twin problem is both expressed and addressed. Partnership work is one of them. 
This study has 3 principal aims. The first aim is to propose a new methodological framework grounded in a design view of systems to assess and hopefully facilitate social learning and partnership capacity. It is built on the premise that social processes and practices are communicative and that therefore the problem of collective action is also a problem of communication. Specifically, partnerships are, like all institutional fields of joint practice, shot through with (communication) boundaries of all kinds, which means that the formation and management of partnerships entails the generation and management of framing practices which this study calls "boundary spanning." Applying a socio-cybernetic lens allows us to appreciate that these boundary spanning processes introduce variety into fields which enable them to model their respective environments. They confer adaptability while being at the same time inherently destabilizing. A central argument being put forth here is that resilient partnerships are complex adaptive systems that are organized around addressing the problem of change and that this organization assumes the form of a recursive hierarchy of communication and control. Starting from this design view of systems, the framework proposes a way to explain partnership capacity and social learning based on a general typology of boundary spanning practices that is couched in a language of orders.

This methodological contribution to measuring partnership capacity and social learning, if it is substantiated, has real-life consequences for partnership practitioners. After all, any explanation of partnership capacity and social learning also suggests strategies for bringing them about. Thus, a second aim of the study is 
to assess the framework's theory of partnership formation and sustainability. This aim was motivated by the fact that, despite all the interest that has been directed toward partnership and partnership work in the past couple decades, we still do not understand precisely how partnerships congeal from boundary spanning practices into new joint fields of practice, nor do we understand why some partnerships thrive while others flounder or even fail. The study proposed 2 basic hypotheses the first explaining partnership formation and the second explaining resilience - to assess the theory and, ultimately, methodology. The theory of convergence predicts that partnerships form when boundary spanning practices match a socio-technical or policy need. It generally follows the Punctuated Equilibrium Theory to state that some kind of event in either boundary spanning or the larger field of institutions (or both) occurs that essentially reverses the direction of influence so that the boundary spanning practices become objects of considerable attention and interest. If boundary spanners are able to capitalize on this interest, a process of mutual influence unfolds that eventually results in a new joint field of core practices complete with its own set of boundary spanning practices. The second hypothesis concerns resilience. The paradox of resilience centers on the need to change in order to persist. The theory predicts that resilient partnerships address this paradox by enveloping or owning change so that it becomes, as John Paul Lederach (Fetzer Institute - Wilson Center Seminar, 2008) describes it, a part of their "character and spirit:"

By its very nature, resiliency as metaphor suggests a journey that is both internal and outward bound that rises from a quality of character and spirit. 
To place the term in a life journey, resiliency suggests that no matter the difficulty of the terrains faced by the traveler, $\mathrm{s} /$ he stays in touch with a core defining essence of being and purpose, and displays a tenacity to find a "way back" as a "way forward" that artistically stays true to his/her very being. We could say the defining quality of resiliency is the capacity to stay in touch (emphasis original).

To operationalize this metaphor into a measurable concept, the framework posits 2 forms of resilience: PC II, a more restricted form, is brought about by a pattern of alignment practices that integrates core and boundary spanning practices across multiple partnership functions; while PC III is brought about by a pattern or culture of institutional design and learning. Finally, a third aim of the study is to simply catalogue the various boundary spanning strategies occurring in different partnership types and processes.

To assess the hypotheses and the underlying framework's usefulness in measuring and explaining partnership processes, 4 case studies of water resource management partnerships were carried out: the Counting on the Environment Working Group, the Regional Water Providers Consortium, the Upper Deschutes River Partnership, and the Walla Walla Watershed Alliance. All 4 partnerships have been working on water issues within the Columbia River Basin, and all 4 could be considered regional in their scale and scope. Although contemporaries, they ranged in age from 1 to 13 years. Three of the 4 would qualify as "permanent and/or regular coordination" under Mandell and Steelman's (2003) typology of interorganizational innovations, while the fourth, COTE WG, functions as a "temporary taskforce." Data collection consisted primarily of interviews with individuals from all 4 cases whom were identified by others or me as "boundary spanners." 
Interviews centered on boundary spanning practices during the formation and management of the partnership. Interviews were transcribed, coded, and analyzed. The interviews were supplemented by field trips to the partnership communities, including observation of partner interactions. Secondary data, including archival materials, were also collected.

The findings offer tentative support for the convergence hypothesis (Hypothesis I). All 4 cases demonstrated the general characteristics predicted to be present in convergence, including: a felt socio-technical policy need and matching boundary spanning practices, cultural feasibility, technical desirability, exchange of capital forms to promote innovations, and interest and support. None of the cases fit the criteria for PC II; thus, the second hypothesis could not be assessed. However, the RWPC did demonstrate some, but not all, of the traits that are predicted to be associated with PC II, suggesting the need to refine the theory to accommodate hybrid or transitional entities. The absence of PC II or PC III does however support the notion that more resilient partnerships are more rare and is at least consistent with the theory's predictions, given the absence of the corresponding factors.

The methodology also demonstrated how boundary spanning practices could be mapped onto different orders of partnership processes (and social learning). The methodology calls for a considerable amount of qualitative judgment in the mapping. To address confirmation biases, coding criteria should be as transparent and descriptive as possible. Once criteria for coding were standardized, this would allow for meaningful comparison across cases to determine whether certain kinds of 
boundary spanning practices are associated with certain types of partnership processes or even types of partnerships (using, for example, Mandell and Steelman's typology). Especially, we would be in a position to more fully test the theory proposed here.

Finally, this study has been an experience in boundary spanning in at least 2 ways. First, the methodology is of course an instance of theoretical boundary spanning attempting to better integrate institutional theories, cybernetics, systems theories, and practice theories in a way that will hopefully recast familiar concepts and problems in a new light. Its emphasis on managing change moves us away from fallacies of misplaced abstraction that plague much of organizational and social theorizing. There is a tendency to develop concepts like "partnership," "collaborative capacity," and "social learning" that are divorced from the problem of change. When these reified concepts are applied to particular contexts, the applications are often inconsistent and only add to our confusion. Paradoxically perhaps, partnership practitioners commit a fallacy of misplaced concreteness by applying these concepts pro forma. This framework suggests that having an institutional design does not by itself ensure resilience. Similarly, having a rule to revisit a strategic plan every few years does not by itself ensure resilience. It compels us to consider how such revisits take place, not simply how often. The theory predicts that if no serious attempt is made to bring strategic and even constitutional thinking into alignment with daily practice, particularly with the local context of implementation, then strategic planning will not add a lot of value. In 
addition, it predicts that partnership-wide resilience comes when these alignments become routine practice. Adopting a change- or process-oriented methodology enables us to begin to test these claims across cases. From this social learning, the expectation is that partnership strategies will emerge.

\section{So What Have We Learned?}

Consistent with the view of learning posited here, we can summarize our learning in terms of the questions this study generates. For one, if partnerships are in fact composed of boundary spanning practices that communicate something about the relationships which those practices change, then how can we, as institutional designers and practitioners, be more strategic in our institutional change initiatives? And, perhaps more importantly, what are the natural limits to our interventions? The framework suggests that joint fact-finding should be accompanied by the joint development of a vision for institutional change - a Weltanschauung - against which those facts can be judged. This vision will be characterized by its capacity to articulate the nature of the coordination problem in a way that is doubly resonant with the universe of stakeholders: both in its own (technical) terms and in terms of the cultural feasibility of the response that is implied. Moreover, it suggests that the development of such a vision can usually only come about through a mechanism of social abduction whereby stakeholders are given the opportunity to share their understanding of a particular coordination problem so that the community can begin to search for and compare stories that don't gloss over differences in perspectives but rather join them in a common 
narrative. After all, as Argyris and Schön (1978) argue, if mental models drive social behavior, then these models should themselves be objects of reflection and modelbuilding.

Of course, there are limits to social learning. Not all social differences are readily reconcilable, especially deep value differences, as Forester (1999) and others point out. The framework presented here suggests that one reason for this may be rooted in the condition of social epistemology: to use an ocular metaphor, it is because communities cannot see their own seeing. Intractable disputes are often seen as "problematic," but it is altogether possible that the real problem is in the framing of the disputes as "problematic" in the first place. If, instead, we looked for the social purpose that such disputes served, the way is opened for identifying and removing the underlying barrier to change. But such a reframing is not trivial, particularly when the reframing involves an entire community. It entails the community reflecting on itself, but in doing so, it is thereby changed. Like an explorer walking backward on a landscape changed by her very tread, we are always one step behind ourselves. All that said: social learning is neither inherently "good" nor "bad" anymore than resilience is "good" or "bad." But the framework does suggest, anyway, that social learning on some level entails a surrendering to change while resilience buffers against it, in other words, transforms it! If so, then, for communities seeking to learn, the question becomes: what story are we already telling ourselves such that our "problems" appear natural and expectable? For 
communities trying to build resilience, the question becomes: what story can we tell ourselves that will transform our surprises into natural and expectable problems?

This study has hopefully drawn more attention to the socially communicative dimension of water resource management. Water resource management is about much more than the management of water resources. In the process of managing water, stakeholders communicate something about their relationships to one another, including, or perhaps most especially, to those who are not given a voice. Embedded in every water management study, plan, or action are assumptions about what passes for knowledge, who has access to that knowledge and its production, and the proper distribution of resources, roles, and responsibilities attached to them. The approach argued for here is not to evaluate the truth or even "goodness" of such assumptions, but rather to examine the ways in which errors, conceived here as ruptures in the social fabric of expectations, are "used" to mobilize social action in service of a still larger (collective) purpose. For example, water conflicts will often persist to the extent that they support the status quo. It should be clarified, however, that no conspiracy mechanism is implied here. While it is true that social actors may occasionally engage in conspiracies or even be influenced by conspiracy theories, broader community conflicts and controversies reflect a more distributed social mind operating through diverse contexts of action.

Contrary to Habermasian understandings, all communication is premised on some distortion. When, for example, someone advocates for environmental interests in a proposed watershed management planning process, others engaged in the same 
process will tend to "see" him as an environmentalist, while the rest of his story father, school bus driver, avid duck hunter, Republican, and so forth - will tend to be overlooked. And while no particular form of distortion is ever necessary or inevitable, the survival of social systems, even short-lived ones like planning processes, depends on presenting their version of reality as just so. The approach taken here, then, challenges us to reframe water resource management. Ideological appeals to scientific, technocratic, or rational management notwithstanding appeals which, like all ideological claims, only serve the social reproduction of their management regimes - water resource management is ultimately about a community wrestling with this paradox of communication, that is: of achieving conversational coherence through the management of uncertainty partly - and only partly - of its own making.

But while studies like this one hopefully contribute to our social learning about, as it were, social learning, practitioners need not wait for theory-building to occur. They can, and I would argue should, contribute to theory-building by engaging with researchers in a community of reflective practice by sharing stories and strategies and searching for connections. In this spirit, I convened a workshop in the fall of 2010 that brought boundary spanners from the 4 cases together to discuss the study's preliminary findings and, just as importantly, imagine institutional change scenarios, the issues arising from them, and ways to address them. The exercises afforded us all a chance to try out the Soft Systems Methodology, especially its rich picture technique, as a collaborative learning tool 
for planning for and managing institutional change. But they also provided a unique opportunity to span the theory/practice boundary by comparing experiences and perspectives and deepening our collective understanding of partnership capacity and social learning and ways to bring them about. 


\section{References}

Adelsman, H. (2008). Walla Walla Watershed Management Partnership: A Proposal for a Pilot Local Water Management Program in the Walla Walla Basin, Report to the Governor and the Washington State Legislature (pp. 67). Walla Walla, WA: Walla Walla Watershed Management

Agranoff, R. (2007). Managing within networks. Washington, D.C.: Georgetown University Press.

Agranoff, R. \& McGuire, M. (2003). Collaborative public management. Washington, D.C.: Georgetown University Press.

Alutto, J. A. (2002). Culture, levels of analysis, and cultural transition. In F. J. Yammarino \& F. Dansereau (Eds.), The many faces of multi-level issues (Research in Multi Level Issues) (Vol. 1, pp. 321-325). Bingley, United Kingdom: Emerald Group Publishing Limited.

Argyris, C., \& Schön, D. (1978). Organizational learning: A theory of action perspective. Reading, MA: Addison-Wesley.

Armistead, C., \& Pettigrew, P. (2004). Effective partnerships: building a sub-regional network of reflective practitioners. International Journal of Public Sector Management, 17(7), 571-585.

Ashby, W. R. (1956). An introduction to cybernetics. New York: J. Wiley.

Austin, M. J. (2002). Managing Out: The Community Practice Dimensions of Effective Agency Management. [Article]. Journal of Community Practice, 10(4), 33-48.

Axelrod, R. M. (1984). The evolution of cooperation. New York: Basic Books.

Banner, D. K., \& Gagné, T. E. (1995). Designing effective organizations : traditional \& transformational views. Thousand Oaks, Calif.: Sage Publications.

Bardach, E. (2001). Developmental Dynamics: Interagency Collaboration as an Emergent Phenomenon. Journal of Public Administration Research and Theory, 11(2), 149-164.

Barrett, F. J., \& L, C. D. (1990). Generative metaphor intervention: A new approach for working with systems divided by conflict and caught in defensive perception. The Journal of Applied Behavioral Science, 26(2).

Bateson, G. (1958). Naven, a survey of the problems suggested by a composite picture of the culture of a New Guinea tribe drawn from three points of view. Stanford, Calif.: Stanford University Press. 
Bateson, G. (1972). Steps to an ecology of mind. New York: Ballantine Books.

Bateson, G. (1979). Mind and nature: a necessary unity.

Baum, J. A. C., \& Rowley, T. J. (2005). Companion to organizations: An introduction. In J. A. C. Baum (Ed.), The Blackwell companion to organizations. Oxford: Blackwell Business.

Baumgartner, F. (2006). Punctuated Equilibrium Theory. In R. C. Repetto (Ed.), Punctuated equilibrium and the dynamics of U.S. environmental policy. New Haven: Yale University Press.

Baumgartner, F. R., \& Jones, B. D. (2002). Policy dynamics. Chicago: University of Chicago Press.

Berger, P. L., \& Luckmann, T. (1966). The social construction of reality; a treatise in the sociology of knowledge. Garden City, N.Y.: Doubleday.

Berkes, F. (2009). Evolution of co-management: Role of knowledge generation, bridging organizations and social learning. Journal of Environmental Management, 90(5), 1692-1702. doi: DOI: 10.1016/j.jenvman.2008.12.001

Bidwell, R. D., \& Ryan, C. M. (2006). Collaborative Partnership Design: The Implications of Organizational Affiliation for Watershed Partnerships. Society \& Natural Resources, 19(9), 827-843.

Bogason, P. (2009). Networks in policy analysis: towards a new pragmatism, from http://www.demnetgov.ruc.dk

Bourdieu, P. (1977). Outline of a theory of practice. Cambridge, U.K.; New York: Cambridge University Press.

Bradshaw, L. K. (1997). Boundary Spanning and Communication Patterns in Interagency Partnerships.

Brocklesby, J. (2007). The theoretical underpinnings of soft systems methodologycomparing the work of Geoffrey Vickers and Humberto Maturana. Systems research and behavioral science., 24(2), 157.

Burt, R. S. (2002). The Social Capital of Structural Holes. In M. F. Guillén (Ed.), The new economic sociology : developments in an emerging field. New York: Russell Sage Foundation.

Campbell, D. T. (1974). "Downward causation" in hierarchically organised biological systems. In F. J. Ayala \& T. Dobzhansky (Eds.), Studies in the philosophy of biology: reproduction and related problems. London. 
Campbell, S. (1996). Green Cities, Growing Cities, Just Cities? Urban Planning and the Contradictions of Sustainable Development. Journal of the American Planning Association., 62(3), 296.

Carpenter, S. L., \& Kennedy, W. J. D. (1988). Managing public disputes: a practical guide to handling conflict and reaching agreements. San Francisco: JosseyBass.

Cash, D., Adger, W., Berkes, F., Garden, P., Lebel, L., Olsson, P., . . Young, O. (2006). Scale and Cross-Scale Dynamics: Governance and Information in a Multilevel World. Ecology and Society, 11(2), 8.

Checkland, P. (2000). Soft Systems Methodology: A Thirty Year Retrospective. SYSTEMS RESEARCH AND BEHAVIORAL SCIENCE, 17, S11-S58.

Churchman, C. W. (1971). The design of inquiring systems: basic concepts of systems and organization. New York: Basic Books.

Cohen, J., Lesnick, A., \& Himeles, D. (2007). Temporary Anchors, Impermanent Shelter: Can the Field of Education Model a New Approach to Academic Work? [Article]. Journal of Research Practice, 3(2), 1-21.

Collins, J. C., \& Porras, J. I. (1996). BUILDING YOUR COMPANY'S VISION. Harvard business review., 74(5), 65.

Connick, S., \& Innes, J. E. (2003). Outcomes of Collaborative Water Policy Making: Applying Complexity Thinking to Evaluation. Journal of Environmental Planning and Management, 46(2), 177-197.

Conway, S. (1995). Informal Boundary-spanning Communication in the Innovation Process: An Empirical Study. Technology analysis \& strategic management., $7(3), 327$.

Crislip, D. D., Larson, C. E., \& King, C. S. (1997). Collaborative Leadership: How Citizens and Civic Leaders Can Make a Difference. Public productivity \& management review., 20(3), 336.

Curtis, D. R. (1997). Walla Walla River Watershed Study Reconnaissance Report.

d'Estree, P. T. (2003). Achievement of relationship change. . In R. O'Leary \& L. Bingham (Eds.), The promise and performance of environmental conflict resolution. Washington, DC: Resources for the Future. 
David, T. (2004). Interorganizational Partnerships as Inchoate Hierarchies: A Case Study of the Community Security Initiative. Administration \& Society, 36(1), 91-127.

Davidson-Hunt, I. (2006). Adaptive Learning Networks: Developing Resource Management Knowledge through Social Learning Forums. Human Ecology, 34(4), 593-614.

Dietz, T., Ostrom, E., \& Stern, P. C. (2003). REVIEW - The Struggle to Govern the Commons. Science., 302(5652), 1907.

DiMaggio, P. J., \& Powell, W. W. (1983). The Iron Cage Revisited: Institutional Isomorphism and Collective Rationality in Organizational Fields. American Sociological Review, 48, 147-160.

Dollinger, M. J. (1984). Environmental Boundary Spanning and Information Processing Effects on Organizational Performance. [Article]. Academy of Management Journal, 27(2), 351-368.

Emery, F. E., \& Trist, E. L. (1965). The causal texture of organizational environments. Human Relations, 18, 21-32.

Fernandez-Gimenez, M. E., Ballard, H. L., \& Sturtevant, V. E. (2008). Adaptive management and social learning in collaborative and community-based monitoring: A study of five community-based forestry organizations in the western USA. Ecol. Soc. Ecology and Society, 13(2).

Ferreyra, C., \& Beard, P. (2007). Participatory Evaluation of Collaborative and Integrated Water Management: Insights from the Field. Journal of Environmental Planning and Management, 50(2), 271-296. doi: http://www.tandf.co.uk/journals/titles/09640568.asp

Fetzer Institute - Wilson Center Seminar. (2008, December 2008). Community Resilience: A Cross-Cultural Study: Revitalizing Community Within and Across Boundaries. Paper presented at the Revitalizing Community Within and Across Boundaries, Washington, D.C.

Feyerherm, A. E. (1994). Leadership in collaboration: A longitudinal study of two interorganizational rule-making groups. The Leadership Quarterly, 5(3-4), 253-270. doi: Doi: 10.1016/1048-9843(94)90016-7

Fischer, F. (2000). Citizens, experts, and the environment: the politics of local knowledge. Durham, NC: Duke University Press. 
Fischer, F. (2003). Reframing public policy: discursive politics and deliberative practices. Oxford; New York: Oxford University Press.

Fischer, F., \& Forester, J. (1993). The Argumentative turn in policy analysis and planning. Durham, N.C.: Duke University Press.

Fisher, R., Ury, W., \& Patton, B. (1991). Getting to yes: negotiating agreement without giving in. New York, N.Y.: Penguin Books.

Flyvbjerg, B. (1998). Rationality and power: democracy in practice. Chicago: University of Chicago Press.

Forester, J. (1989). Planning in the face of power. Berkeley: University of California Press.

Forester, J. (1999). The deliberative practitioner : encouraging participatory planning processes. Cambridge, Mass.: MIT Press.

Giddens, A. (1984). The constitution of society : outline of the theory of structuration. Berkeley: University of California Press.

Goh, S., \& Richards, G. (1997). Benchmarking the Learning Capability of Organizations. European management journal., 15(5), 573.

Gold, J. (2001). Storying Systems: Managing Everyday Flux Using Mode 2 Soft Systems Methodology. Systemic Practice and Action Research, 14(5), 557-573.

González, S., \& Healey, P. (2005). A Sociological Institutionalist Approach to the Study of Innovation in Governance Capacity. [Article]. Urban Studies (Routledge), 42(11), 2055-2069. doi: 10.1080/0420980500279778

Gray, B. (1989). Collaborating: finding common ground for multiparty problems. San Francisco: Jossey-Bass.

Gronn, P. (2002). Distributed leadership as a unit of analysis. The Leadership Quarterly, 13(4), 423-451. doi: Doi: 10.1016/s1048-9843(02)00120-0

Hahn, T., Olsson, P., Folke, C., \& Johansson, K. (2006). Trust-building, Knowledge Generation and Organizational Innovations: The Role of a Bridging Organization for Adaptive Comanagement of a Wetland Landscape around Kristianstad, Sweden. Human Ecology, 34(4), 573-592.

Haines, S. G. (2000). The systems thinking approach to strategic planning and management. Boca Raton, Fla.: St. Lucie Press.

Hajer, M. A., \& Wagenaar, H. (2003). Deliberative Policy Analysis: Understanding Governance in the Network Society. Cambridge: Cambridge University Press. 
Hardin, G. (1968). The tragedy of the commons: The population problem has no technical solution; it requires a fundamental extension in morality. Science, 162(3859), 1243-1248.

Hardy, C., \& Phillips, N. (1998). Strategies of Engagement: Lessons from the Critical Examination of Collaboration and Conflict in an Interorganizational Domain. Organization Science, 9(2), 217-230.

Hardy, C., Phillips, N., \& Lawrence, T. B. (2003). Resources, Knowledge and Influence: The Organizational Effects of Interorganizational Collaboration. Journal of Management Studies, 40(2), 321-347.

Harter, L. M., \& Krone, K. J. (2001). The Boundary-Spanning Role of a Cooperative Support Organization: Managing the Paradox of Stability and Change in Nontraditional Organizations. [Article]. Journal of Applied Communication Research, 29(3), 248.

Heal, G. M. (2000). Nature and the marketplace : capturing the value of ecosystem services. Washington, D.C.: Island Press.

Healey, P. (1996). The communicative turn in planning theory and its implications for spatial strategy formation. Environment and planning. B, Planning \& design., 23(2), 217-234.

Healey, P. (1999). Deconstructing communicative planning theory: a reply to Tewdwr-Jones and Allmendinger. Environment \& planning A., 31(6), 11291135.

Healey, P. (2005). On the Project of \&lsquo;Institutional Transformation\&rsquo; in the Planning Field: Commentary on the Contributions. Planning Theory, 4(3), 301-310.

Hillier, J. (2003). 'Agon'izing Over Consensus: Why Habermasian Ideals cannot be 'Real'. Planning Theory, 2(1), 37-59.

Hoch, C. (2007). Pragmatic Communicative Action Theory. Journal of Planning Education and Research, 26(3), 272-283.

Huxham, C., \& Vangen, S. (2004). Realizing the Advantage or Succumbing to Inertia? Organizational dynamics., 33(2), 190. 
Imperial, M. T. (2005). Using Collaboration as a Governance Strategy: Lessons From Six Watershed Management Programs. Administration \& Society, 37(3), 281320.

Innes, J. E., \& Booher, D. E. (1999). Consensus Building and Complex Adaptive Systems: A Framework for Evaluating Collaborative Planning. Journal of the American Planning Association., 65(4), 412.

INR, I. f. N. R. (2008). Policy cornerstones and action stategies for an integrated ecosystem marketplace in Oregon Publications and Reports (INR).

Ison, R., Roling, N., \& Watson, D. (2007). Challenges to science and society in the sustainable management and use of water: investigating the role of social learning. ENVIRONMENTAL SCIENCE AND POLICY, 10(6), 499-511.

Ivery, J. (2007). Organizational Ecology: A Theoretical Framework for Examining Collaborative Partnerships. Administration in Social Work, 31(4), 7-19.

Jansen, K. J. (1996). Characteristic Level of Change: An Inherent Constraint to Organizational Action. INTERNATIONAL JOURNAL OF ORGANIZATIONAL ANALYSIS, 4(3), 285-298.

Jelinek, M. (2003). MAKING SENSE OF STRATEGIC CHANGE: A PROBLEM OF LEARNING AND LEVELS. In F. J. Yammarino \& F. Dansereau (Eds.), MultiLevel Issues in Organizational Behavior and Strategy (Research in Multi Level Issues) (Vol. 2, pp. 373-390). Bingley, United Kingdom: Emerald Group Publishing Limited.

Karkkainen, B. C. (2002). Collaborative Ecosystem Governance: Scale, Complexity, and Dynamism. Virginia environmental law journal., 21, 189-244.

Katz, D., \& Kahn, R. L. (1978). The social psychology of organizations (2nd ed.). New York: Wiley.

Katz, R., \& Tushman, M. (1979). Communication patterns, project performance, and task characteristics: An empirical evaluation and integration in an R\&D setting. Organizational Behavior and Human Performance, 23(2), 139-162. doi: Doi: 10.1016/0030-5073(79)90053-9

Keast, R., Mandell, M. P., Brown, K., \& Woolcock, G. (2004). Network Structures: Working Differently and Changing Expectations. Public Administration Review, 64(3), 363-371. 
Kerson, T. S. (2002). Boundary spanning: an ecological reinterpretation of social work practice in health and mental health systems. New York: Columbia University Press.

Kettl, D. F. (2002). Managing indirect government. In L. M. Salamon \& O. V. Elliott (Eds.), The tools of government : a guide to the new governance. Oxford; New York: Oxford University Press.

Khisty, C.J. (2000). Can Wicked Problems Be Tackled Through Abductive Inferencing? Journal of Urban Planning and Development, 126(3), 104-118.

Kingdon, J. W. (1995). Agendas, alternatives, and public policies. New York: Longman.

Klein, J. T. (1996). Crossing boundaries: knowledge, disciplinarities, and interdisciplinarities. Charlottesville, Va.: University Press of Virginia.

Knight, L., \& Pye, A. (2005). Network learning: An empirically derived model of learning by groups of organizations. Human Relations, 58(3), 369-392.

Kolb, D. M., \& Williams, J. (2003). Everyday negotiation: navigating the hidden agendas in bargaining. San Francisco, CA: Jossey-Bass.

Koppenjan, J., \& Klijn, E.-H. (2006). Managing uncertainties in networks : a network approach to problem solving and decision making. London: Routledge.

LaRocco, G., \& Vickerman, S. (2007). An Oregon Ecosystem Marketplace. Oregon Insider(416/417), 1-14.

Larsson, N. O. (2001). A Design View on Research in Social Sciences. Systemic Practice and Action Research, 14(4), 383-405.

Lasker, R. D., Weiss, E. S., \& Miller, R. (2001). Partnership Synergy: A Practical Framework for Studying and Strengthening the Collaborative Advantage. The Milbank Quarterly, 79(2), 179-205.

Lawrence, T. B., Hardy, C., \& Phillips, N. (2002). Institutional Effects of Interorganizational Collaboration: The Emergence of Proto-Institutions. Academy of Management Journal, 45(1), 281-290.

Lax, D. A., \& Sebenius, J. K. (1986). The negotiator's dilemma: Creating value or Where do joint gains really come from? . In D. A. Lax \& J. K. Sebenius (Eds.), The manager as negotiator : bargaining for cooperation and competitive gain. New York; London: Free Press ; Collier Macmillan. 
Lendaris, G. G. (1986). On systemness and the problem solver: tutorial comments. IEEE Trans. Syst. Man Cybern., 16(4), 603-610. doi:

10.1109/tsmc.1986.289266

Leopold, A. (1949). A Sand County Almanac and Sketches from Here and There. New York: Oxford University Press.

Levina, N., \& Vaast, E. (2005). THE EMERGENCE OF BOUNDARY SPANNING COMPETENCE IN PRACTICE: IMPLICATIONS FOR IMPLEMENTATION AND USE OF INFORMATION SYSTEMS. [Article]. MIS Quarterly, 29(2), 335-363.

Luhmann, N. (1995). Social systems. Stanford, Calif.: Stanford University Press.

Maarleveld, M., \& Dabgbegnon, C. (1999). Managing natural resources: A social learning perspective. Agriculture and Human Values, 16(3).

Mandell, M., \& Steelman, T. (2003). Understanding what can be accomplished through interorganizational innovations. Public Management Review, 5(2), 197-224.

Mandell, M. P. (Spring 1999). Policy Studies Review. The Impact of Collaborative Efforts: Changing the Face of Public Policy Through Networks and Network Structures, 16:1.

Mano-Negrin, R. (2003). Spanning the Boundaries: A Stakeholder Approach to Effectiveness Gaps and Empowerment in Public and Independent Human Service Organizations. [Article]. Administration in Social Work, 27(3), 25-45.

Manring, S. L., \& Pearsall, S. (2005). Creating an Adaptive Ecosystem Management Network Among Stakeholders of the Lower Roanoke River, North Carolina, USA. Ecology and Society, 10(2), 16.

Marcussen, M., \& Torfing, J. (2003). Grasping governance networks. Working paper series

Marsh, G. P. (1864 ). Man and Nature. New York: Charles Scribner.

Maturana, H. R., \& Varela, F. J. (1992). The tree of knowledge : the biological roots of human understanding. Boston; New York: Shambhala ; Distributed in the U.S. by Random House.

Maurel, P., Craps, M., Cernesson, F., Raymond, R., Valkering, P., \& Ferrand, N. (2007). Concepts and methods for analysing the role of Information and Communication tools (IC-tools) in Social Learning processes for River Basin 
Management. ENVIRONMENTAL MODELLING AND SOFTWARE, 22(5), 630639.

McDermott, R. (1999). Learning Across Teams. Knowledge Management Review, 8, 32-36.

McWilliam, E. (2007). Unlearning How to Teach. Paper presented at the Creativity or Conformity? Building Cultures of Creativity in Higher Education, University of Wales Institute, Cardiff

Meyer, J. W., \& Rowan, B. (1977). Institutionalized Organizations: Formal Structure as Myth and Ceremony. American Journal of Sociology, 83(2).

Meyer, J. W., \& Scott, W. R. (1983). Organizational environments: ritual and rationality. Beverly Hills: Sage.

Miller, P. M. (2008). Examining the work of boundary spanning leaders in community contexts. [Article]. International Journal of Leadership in Education, 11(4), 353-377. doi: 10.1080/13603120802317875

Miner, A. S., Amburgey, T. L., \& Stearns, T. M. (1990). Interorganizational Linkages and Population Dynamics: Buffering and Transformational Shields. Administrative Science Quarterly, 35(4), 689-713.

Moore, D., Willey, Z., Diamant, A., Calica, C. R., Sehgal, D. R., Environmental Defense, F., \& Confederated Tribes of the Warm Springs Reservation of, O. (1995a). Restoring Oregon's Deschutes River : developing partnerships and economic incentives to improve water quality and instream flows. New York; Warm Springs, OR: Environmental Defense Fund; Confederated Tribes of the Warm Springs Reservation of Oregon.

Moore, D., Willey, Z., Diamant, A., Calica, C. R., Sehgal, D. R., Environmental Defense, F., \& Confederated Tribes of the Warm Springs Reservation of, O. (1995b). Restoring Oregon's Deschutes River: developing partnerships and economic incentives to improve water quality and instream flows.

Ness, E. (2009). Oregon Experiments with Mixed Credits, from http://www.ecosystemmarketplace.com

Nokes, R. G. (1999, September 13, 1999). Citizens for safe water: Agency seeks autonomous water supply for westside, The Oregonian. 
NWPCC, N. P. a. C. C. (2004). Deschutes River Subbasin Plan, from http://www.nwcouncil.org/fw/subbasinplanning/deschutes/plan/

Orlikowski, W. J. (2002). Knowing in Practice: Enacting a Collective Capability in Distributed Organizing. [Article]. Organization Science, 13(3), 249-273.

Osborn, F. (1948). Our Plundered Planet. Boston: Little, Brown and Company.

Osborn, R. N., \& Hagedoorn, J. (1997). The Institutionalization and Evolutionary Dynamics of Interorganizational Alliances and Networks. Academy of Management Journal, 40(2), 261-278.

Ostrom, E. (1999). Institutional rational choice: An assessment of the institutional analysis and development framework. In P. A. Sabatier (Ed.), Theories of the policy process. Boulder, Colo.: Westview Press.

Ozawa, C. P. (1991). Recasting science: consensual procedures in public policy making. Boulder: Westview Press.

Pahl-Wostl, C., Craps, M., Dewulf, A., Mostert, E., Tabara, D., \& Taillieu, T. (2007). Social Learning and Water Resources Management. Ecology and Society, $12(2: 5)$.

Pearce, W. B., \& Cronen, V. E. (1980). Communication, action, and meaning: the creation of social realities. New York, N.Y.: Praeger.

Pentland, B. T., \& Feldman, M. S. (2007). Narrative Networks: Patterns of Technology and Organization. Organization science : a journal of the Institute of Management Sciences., 18(5), 781.

Perkins, D. D., Bess, K. D., Cooper, D. G., Jones, D. L., Armstead, T., \& Speer, P. W. (2007). Community organizational learning: Case studies illustrating a threedimensional model of levels and orders of change. [Article]. Journal of Community Psychology, 35(3), 303-328.

Poirier Elliott, M. L. (1999). The role of facilitators, mediators, and other consensus building practitioners. In L. Susskind, S. McKearnan \& J. Thomas-Larmer (Eds.), The consensus building handbook : a comprehensive guide to reaching agreement. Thousand Oaks, Calif.: Sage Publications.

Portland State Population Research Center. 2010 Census Profiles Oregon and its Counties and Metropolitan Areas, from 
http://www.pdx.edu/sites/www.pdx.edu.prc/files/media assets/2010 PL9 4 county MSA updated.pdf

Primozich, D. (2008). Developing the Willamette Ecosystem Marketplace: EPA Targeted Watershed Grant \#WS-96027101-0.

Repetto, R. C. (2006). Punctuated equilibrium and the dynamics of U.S. environmental policy. New Haven: Yale University Press.

Rodrìguez, C., Langley, A., Béland, F., \& Denis, J.-L. (2007). Governance, Power, and Mandated Collaboration in an Interorganizational Network. Administration \& Society, 39(2), 150-193.

Romme, A. G. L. (2003). Making a Difference: Organization as Design. Organization Science, 14(5).

Rosenblueth, A., Wiener, N., \& Bigelow, J. (1943). Behavior, Purpose and Teleology. Philosophy of Science, 10(1), 18-24.

Ruckelshaus Center. (2007). The Walla Walla Water Management Initiative: Insights on Design and Implementation from Innovative Water Management Efforts.

Rugkåsa, J., Shortt, N. K., \& Boydell, L. (2007). The right tool for the task: 'boundary spanners' in a partnership approach to tackle fuel poverty in rural Northern Ireland. [Article]. Health \& Social Care in the Community, 15(3), 221-230. doi: 10.1111/j.1365-2524.2006.00674.x

Rydin, Y. (2003). Conflict, consensus, and rationality in environmental planning : an institutional discourse approach. Oxford; New York: Oxford University Press.

Sabatier, P. A., \& Jenkins-Smith, H. C. (1999). The advocacy coalition framework: An assessment. In P. A. Sabatier (Ed.), Theories of the policy process (pp. 117168). Boulder, Colo.: Westview Press.

Salamon, L. M. (2002). The new governance and the tools of public action. In L. M. Salamon \& O. V. Elliott (Eds.), The tools of government : a guide to the new governance. Oxford; New York: Oxford University Press.

Scharpf, F. W. (1993). Coordination in hierarchies and networks. In F. W. Scharpf (Ed.), Games in hierarchies and networks : analytical and empirical approaches to the study of governance institutions. Frankfurt am Main; Boulder, Colo.: Campus Verlag; Westview Press.

Schön, D. A., \& Rein, M. (1994). Frame reflection: toward the resolution of intractable policy controversies. New York: BasicBooks. 
Scott, B. (2002). A Design for the Recursive Construction of Learning Communities. International Review of Sociology, 12(2), 257-268.

Scott, W. R. (1992). Organizations: rational, natural, and open systems. Englewood Cliffs, N.J.: Prentice Hall.

Sears, P. B. (1956). The processes of environmental change by man. In W. L. Thomas (Ed.), Man's Role in Changing the Face of the Earth (Vol. 2, pp. 1193). Chicago: University of Chicago Press.

Selsky, J. W., \& Parker, B. (2005). Cross-Sector Partnerships to Address Social Issues: Challenges to Theory and Practice. Journal of management., 31(6), 849.

Senge, P. M. (1990). The fifth discipline: the art and practice of the learning organization. New York: Doubleday/Currency.

Shandas, V., Graybill, J. K., \& Ryan, C. M. (2008). Incorporating ecosystem-based management into urban environmental policy: A case study from western Washington. J. Environ. Plann. Manage. Journal of Environmental Planning and Management, 51(5), 647-662.

Siemann, D., \& Martin, S. (2007). Managing Many Waters: An Assessment of Capacities for Implementing Water and Fish Improvements in the Walla Walla Basin: The William D. Ruckelshaus Center.

Silverman, D. (1971). The theory of organizations: a sociological framework. London: Heinmann.

Simon, H. A. (1996). The sciences of the artificial. Cambridge, Mass.; London: MIT Press.

Smircich, L., \& Stubbart, C. (1985). Strategic Management in an Enacted World. Academy of Management Review, 10(4), 724-736.

Star, S. L., Bowker, G. C., \& Neumann, L. J. (2003). Transparency beyond the Individual Level of Scale: Convergence between Information Artifacts and Communities of Practice. In A. P. Bishop, N. A. Van House \& B. P. Buttenfield (Eds.), Digital library use : social practice in design and evaluation. Cambridge, Mass.: MIT Press.

Sullivan, H., Barnes, M., \& Matka, E. (2002). Building Collaborative Capacity through 'Theories of Change': Early Lessons from the Evaluation of Health Action Zones in England. Evaluation, 8(2), 205-226.

Susskind, L., \& Cruikshank, J. L. (1987). Breaking the impasse: consensual approaches to resolving public disputes. New York: Basic Books. 
Tabara, D., \& Pahl-Wostl, C. (2007). Sustainability Learning in Natural Resource Use and Management Ecology and Society, 12(2:3).

Takahashi, L. M., \& Smutny, G. (2001). Collaboration Among Small Community-based Organizations: Strategies and Challenges in Turbulent Environments. Journal of Planning Education and Research, 21(2), 141-153.

Thompson, M. (2005). Structural and Epistemic Parameters in Communities of Practice. Organization science : a journal of the Institute of Management Sciences., 16(2), 151.

Toffler, A. (1970). Future shock. New York: Random House.

Torlak, G. N. (2001). Rationalization of Metaphorical Exploration: Improving the Creativity Phase of Total Systems Intervention (TSI) on the Basis of Theory and Practice. Systemic Practice and Action Research, 14(4), 451-482.

Tushman, M. L., \& Scanlan, T. J. (1981). Boundary Spanning Individuals: Their Role in Information Transfer and Their Antecedents. The Academy of Management Journal, 24(2), 289-305.

Uhl-Bien, M. (2006). Relational Leadership Theory: Exploring the social processes of leadership and organizing. The Leadership Quarterly, 17(6), 654-676. doi: DOI: $10.1016 /$ j.leaqua.2006.10.007

Vangen, S., \& Huxham, C. (2003). Nurturing Collaborative Relations: Building Trust in Interorganizational Collaboration. Journal of Applied Behavioral Science, 39(1), 5-31.

Vickerman, S. (2009). ECOSYSTEM MARKETS LEGISLATION. Oregon Insider(449), $17-20$.

Vickers, G. (1968). Value systems and social process. Harmondsworth [etc.]: Penguin Books.

Vickers, G. (1973). Making institutions work. New York: Wiley.

Vickers, G. C. (1965). The Art of Judgment. A study of policy making. pp. 242. Chapman \& Hall: London, 1965.

Vogt, W. (1948). Road to Survival. New York: William Sloan.

Von Krogh, G., \& Vicari, S. (1993). An autopoiesis approach to experimental strategic learning. In P. Lorange, B. Chakravarthy, J. Roos \& A. Van de Ven (Eds.), 
Implementing strategic processes : change, learning, and co-operation. Oxford; Cambridge, MA: Blackwell Business.

Walla Walla Watershed Management Partnership. (2010). 2010 Annual Report. Walla Walla, WA.

Warncke, B. (2006). Oregon Innovates, 2011, from http://www.ecosystemmarketplace.com/pages/dynamic/article.page.php?p age id=4298\&section=home

Water Providers of the Portland Metropolitan Area. (1996). Regional Water Supply Plan for the Portland Metropolitan Area: Final Report.

Weber, E., Lovrich, N., \& Gaffney, M. (2007). Assessing Collaborative Capacity in a Multidimensional World. Administration \& Society, 39(2), 194-220.

Weick, K. E. (1995). Sensemaking in organizations. Thousand Oaks: Sage Publications.

Weiss, E. S., Anderson, R. M., \& Lasker, R. D. (2002). Making the Most of Collaboration: Exploring the Relationship Between Partnership Synergy and Partnership Functioning. Health Education \& Behavior, 29(6), 683-698.

Wenger, E. (2000). Communities of Practice and Social Learning Systems. Organization, 7(2), 225-246.

Wenger, E. C., \& Snyder, W. M. (2000). Communities of Practice: The Organizational Frontier. Harvard Business Review, 78(1), 139-145.

West, D. (2005). Vickers' Concept of 'Relationship-Maintenance' as an Alternative to 'Goal-Seeking' Models of Organisation: A Difference in the Notion of Control. Systemic Practice and Action Research, 18(3), 261-274.

Whelan-Berry, K. S., Gordon, J. R., \& Hinings, C. R. (2003). Strengthening Organizational Change Processes: Recommendations and Implications from a Multilevel Analysis. Journal of Applied Behavioral Science, 39(2), 186-207.

Williams, P. (2002). The Competent Boundary Spanner. Public Administration, 80(1), 103-124.

Winch, G. M., \& Courtney, R. (2007). The Organization of Innovation Brokers: An International Review. [Article]. Technology Analysis \& Strategic Management, 19(6), 747-763. doi: 10.1080/09537320701711223 
Yin, R. K. (2003). Case Study Research: Design and Methods (Vol. 5). Thousand Oaks; London; New Delhi: Sage Publications.

Yukl, G. (1999). An Evaluative Essay on Current Conceptions of Effective Leadership. [Article]. European Journal of Work \& Organizational Psychology, 8(1), 33-48. doi: $10.1080 / 135943299398429$

Zollo, M., Jeffrey, J. R., \& Harbir, S. (2002). Interorganizational Routines and Performance in Strategic Alliances. Organization Science, 13(6), 701-713.

Zucker, L. G. (1991). Postscript: Microfoundations of institutional thought. In W. W. Powell \& P. DiMaggio (Eds.), The New institutionalism in organizational analysis. Chicago: University of Chicago Press. 
Appendix A

Interview Protocol

In this interview I will ask you to talk about your thoughts and feelings about "boundary spanning" and "partnership capacity" generally and as they relate to the [name of partnership] more specifically. By "boundary" I mean any interface between different ways of thinking or doing things. I am going to use the term "boundary spanning" to generally refer to any activity or process that brings together activities, processes, ideas, people, organizations, objects, and/or resources from different technical, policy and/or social domains. Similar concepts include "liaising," "bridge-building," and "brokering." One goal of this study is to build on this starting definition to gain a clearer understanding of how people and organizations actually carry out boundary spanning and how they understand their own work.

I will also ask you to talk about the partnership-building work that you and others have carried out in forming, implementing, and growing the [name of partnership]. The information and perspective you share in this interview will help to give me a better understanding of "boundary spanning," "partnership work," and "partnership capacity" in the [name of partnership] but also in water resource management more generally. Please remember that there are no right or wrong answers. If, as we go along, you think of anything you wish to add to a previous question please feel free to do so at anytime. You may also decline to answer any question or elect to take a break or end the interview at any time and for any reason. Do you have any questions? [Wait for response]. Good. Are you ready to begin? [Wait for response]

For this interview I will use the term "boundary spanning" according to the general definition I gave in my introduction. To help me assess whether my definition is clear, can you give me a brief example of boundary spanning that fits my definition? [Wait for example and clarify definition as needed]. Thank you for that. Please feel free to elaborate on or otherwise modify the working definition of "boundary spanning" as we talk, so long as you indicate to me that you are using the term in a different way.

Finally, I need to define a few more terms that will be used in the questions I will ask you. I will use the term "technical" to refer to processes and their corresponding knowledge domains that lend themselves to a precise and often quantitative 
language, such as: the physical environment and associated physical and biological sciences, the built environment and classical planning, technology and engineering, the economy and economics, and related disciplines. I will use the term "policy" to refer to decisions and decision-making processes concerned with legal, judicial, and administrative functions. These functions may be formal or less formal. Finally, I will use the term "social" to refer to the rest of societal processes and knowledge domains not covered by the other two terms, including: institutions, social ties, politics, ideology, and culture. Here is a list of the key terms with their definitions [Give respondent list]. Do you have any questions about these terms? [IF NEEDED, answer any questions]

The first few questions are about the formation and early history of [name of partnership].

1. How did [name of partnership] first come about? Especially, what was the water resource management problem that motivated its formation and were there any events or circumstances, ranging from the local to the global, that facilitated the formation of the partnership? [PROBE: Were there opportunities in the general policy and social environment that favored its formation in any way?]

2. Did boundary spanning and/or boundary spanners play any role in the formation and early development of [name of partnership]? If so, could you talk more about it and give some examples? [IF NEEDED: Were various technical, policy, and social elements from different domains brought together during its formation?]

3. Did the [name of partnership] face any early threats to its existence and, if so, how did it overcome them? [PROBE: Did boundary spanning play any role for the partnership in overcoming these threats?

4. Can you tell me a little more about the relationships that the [name of the partnership] had early on with the various communities of interest and how you think those relationships shaped its early history? By "communities of interest" I mean institutional stakeholders or communities having some kind of stake in the partnership, whether they have participated directly in it or not.

The next few questions are about the [name of the partnership] after the early stage and leading up to the present. [If the partnership has since dissolved, use the past tense]. 
5. What technical, policy, or social innovations would you say the [name of the partnership] has produced since its inception? By "innovation" I mean any new contribution either in the form of a tool, model, or similar object, a process, policy, or even an idea or vision. [IF NEEDED: What new ideas and/or ways of doing things, along with related products, has the partnership developed in the process of addressing its water resource management problem? PROBE for each dimension]

6. Have any of these innovations ever been adopted by the various communities of interest or beyond and if innovations have been adopted, were any changes made to them along the way? [PROBE: If changes were made along the way, have any of these changes impacted the original innovations within the partnership?]

7. What factors do you think contribute to the spread and adoption of the [name of the partnership]'s innovations among its communities of interest? [PROBE: Has boundary spanning played a role? If so, how?]

8. Have the relationships within the communities of interest changed since the early stages of the [name of the partnership]? In answering the question, I'd like you to comment on the both the changes in the relationships among stakeholder-communities as well as changes in the relationships between those communities and the [name of the partnership] itself. [IF NEEDED: By "relationship" I mean the ties that define roles, rights, responsibilities, and identities of the parties to the relationship. These relationships may be of a technical, policy, and/or social nature.] If so, can you talk more about these relationship changes? [PROBE for each dimension]

9. [IF 8 = "Yes," ASK: What do you think are some factors driving those relationship changes? [PROBE: Has the partnership led to changes in how stakeholders and communities work together or perceive one another and, if so, how?]

The final set of questions is about the relationship, if any, between boundary spanning and the continuing partnership work of managing change and uncertainty. [If the partnership has since dissolved, use the past tense].

10. Please tell me a little more about the relationship between the [name of the partnership]'s strategic planning and its day-to-day operations. Especially, what is the nature and extent of the communication and coordination between the partnership's planning and implementation functions? [PROBE: Among other things: how would you describe the working relationship between the staff and board or governing body? PROBE: To what extent does the [name of the partnership] engage in implementation planning?] 
11. How, and to what extent, does the [name of the partnership] address threats to the partnership and what role, if any, does boundary spanning play in facing and managing threats? [PROBE: How do you think the partnership's own efforts to manage threats across the technical, policy, and social domains reinforce or work against one another?]

12. Similarly, how, and to what extent, does the [name of the partnership] capitalize on opportunities to the partnership and what role, if any, does boundary spanning play in making, finding, and/or acting on opportunities? [PROBE: How do you think the partnership's own efforts to manage opportunities across the technical, policy, and social domains reinforce or work against one another?]

13. Does the [name of the partnership] position itself in any way to respond to surprises, be they of a technical, policy, or social nature? If so, what role, if any, does boundary spanning play in managing uncertainty? [IF NEEDED: By "surprises" I mean any events or changes that are unexpected. Does the partnership have a strategy for dealing with surprises?] [PROBE: How do you think the partnership's own efforts to manage uncertainties across the technical, policy, and social domains reinforce or work against one another?]

[Q14: IF the partnership has since dissolved, ASK INSTEAD: "What factors do you think finally contributed to the dissolution of the [name of partnership] and was boundary spanning involved in any way? If so, how?"]

14. Would you say the [name of the partnership] drives much of the water resource management agenda within the community, simply implements that agenda, or does a little bit of both? Could you elaborate and comment on what role, if any, boundary spanning plays?

15. That is all the questions I have. Before we end, is there anything else you would like to add? 


\section{Appendix B}

\section{Methodology of Institutional Change}

\begin{tabular}{|c|c|c|c|c|c|}
\hline \multicolumn{3}{|c|}{ Process/Transformation “ $\mathrm{T}$ ” } & \multirow{2}{*}{$\begin{array}{l}\text { Boundary spanning } \\
\text { activities carrying out } \\
\text { Process/T }\end{array}$} & \multirow{2}{*}{$\begin{array}{l}\text { Order of } \\
\text { Process/T }\end{array}$} & \multirow{2}{*}{$\begin{array}{l}\text { Outstanding issues that } \\
\text { threaten Process/T (Data) - } \\
\text { Driven by a particular } \\
\text { Worldview }^{37}\end{array}$} \\
\hline Input (Description) & Throughput (Mapping) & Output (Description) & & & \\
\hline $\begin{array}{l}\text { A surprise presents itself which } \\
\text { threatens the partnership ("We } \\
\text { don't know how to respond to } \\
\text { this") }\end{array}$ & $\begin{array}{l}\text { Reflexive practices guide the } \\
\text { search for institutional designs } \\
\text { in current knowledge base or } \\
\text { through model-building and } \\
\text { synthesis (Closed } \\
\text { Transformation) }\end{array}$ & $\begin{array}{l}\text { A coherent partnership response } \\
\text { which addresses the surprise ("We } \\
\text { have addressed the surprise") }\end{array}$ & $\begin{array}{l}\text { Innovation, critical self- } \\
\text { reflection, institutional } \\
\text { design through complex } \\
\text { alignment, monitoring and } \\
\text { control of learning }\end{array}$ & $\begin{array}{l}\text { Partnership } \\
\text { Capacity III }\end{array}$ & $\begin{array}{l}\text { Insufficient resources, waning } \\
\text { commitment to learning } \\
\text { (complacency), excessively long } \\
\text { adjustment times }\end{array}$ \\
\hline 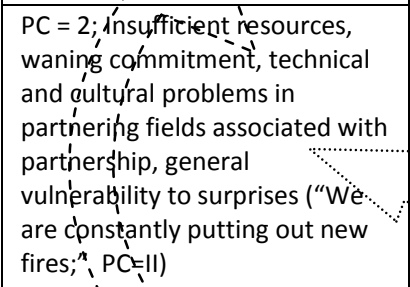 & $\begin{array}{l}\text { Learning how to learn how to } \\
\text { partner (Open Process) }\end{array}$ & $\begin{array}{l}\text { PC = III; Capacity of partnership to } \\
\text { appreciate the problem as one of } \\
\text { treating problems as opportunities } \\
\text { for learning ("We generate and put } \\
\text { out our own fires in order to identify } \\
\text { our vulnerabilities;" (PC = III) } \\
\end{array}$ & $\begin{array}{l}\text { Instilling a culture of } \\
\text { learning that combines } \\
\text { creativity and critical inquiry } \\
\text { and reflection, visioning, } \\
\text { setting up laboratories of } \\
\text { social learning }\end{array}$ & $\begin{array}{l}\text { Social Learning } \\
\text { III (Discrete } \\
\text { Change) }\end{array}$ & $\begin{array}{l}\text { How to specifically design } \\
\text { "learning partnerships" (with } \\
\text { PC III)? }\end{array}$ \\
\hline
\end{tabular}

${ }^{37}$ In the case of partnership processes, data on issues could be "found" at any of the three system levels: meta-("Worldview), system(I,T,0), and subsystem (Throughput), but, regardless of their level of resolution, their significance can be uniformly expressed ass "Chänge-in-(given) Process." Note that the issues associated with various kinds of social learning do not serve as sources of data for partnership systems; they are in a sense intractable. Learning is stochastic by nature. 


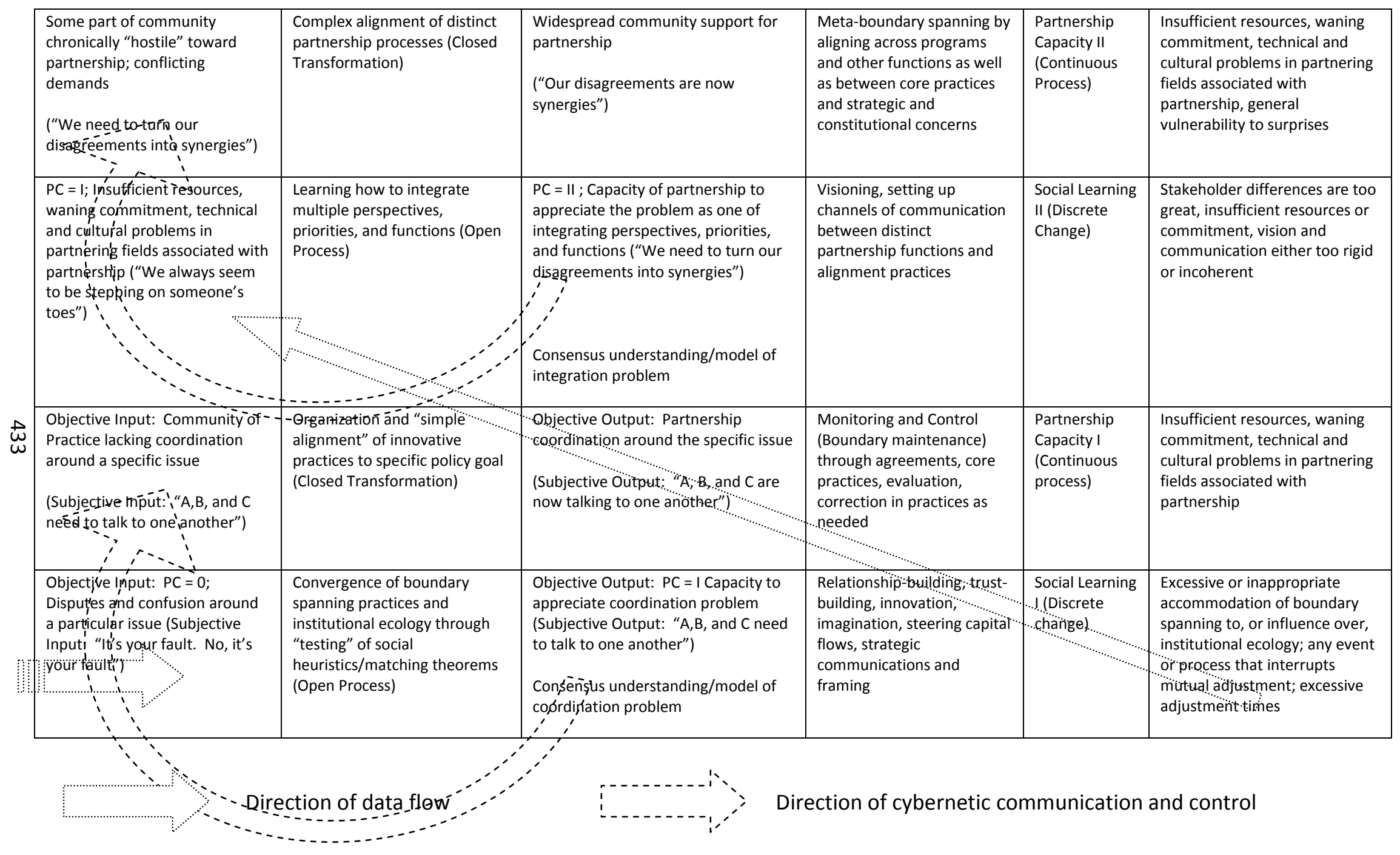




\section{Appendix C}

\section{Workshop Rich Pictures of Institutional Change Scenarios}

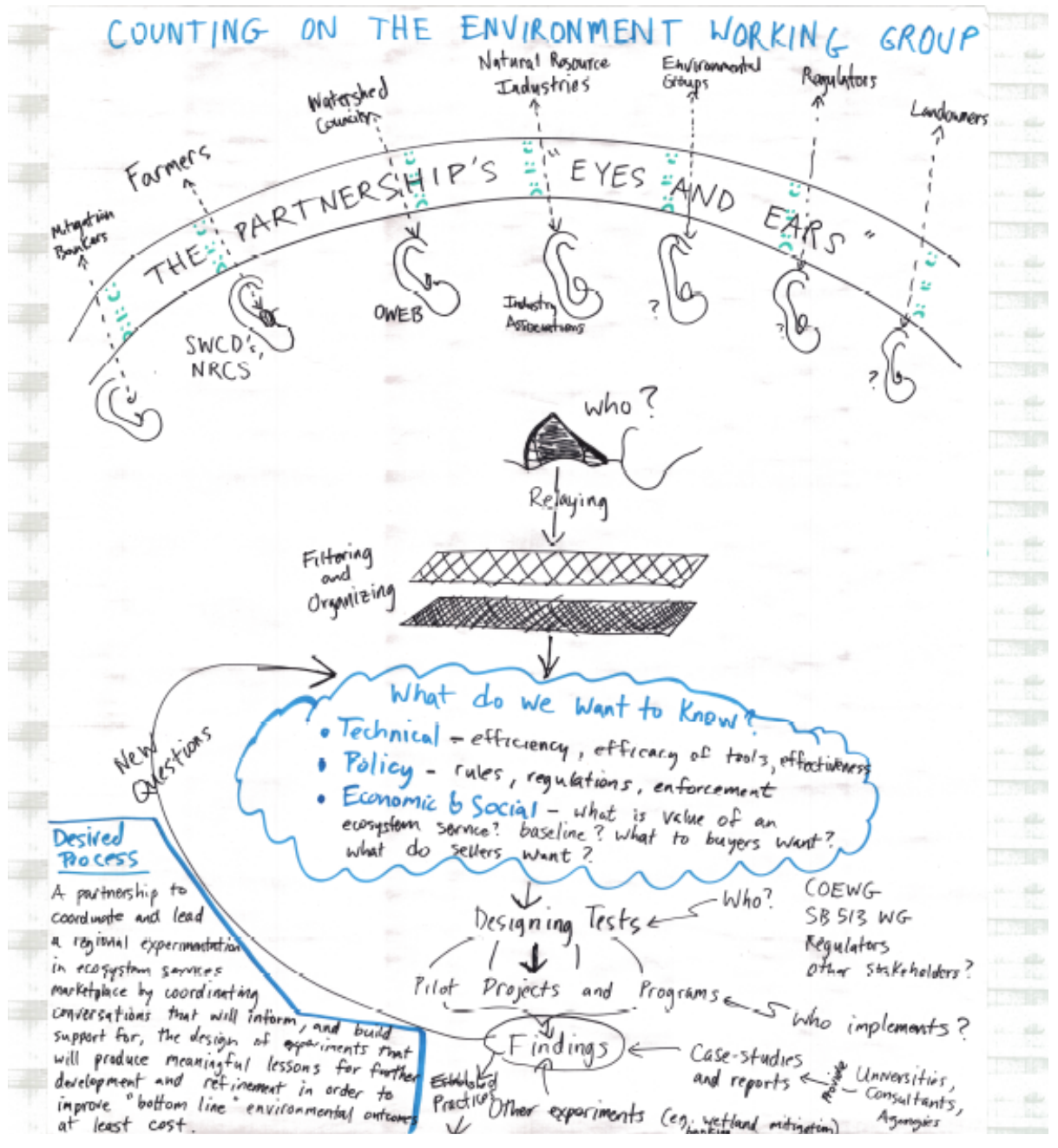




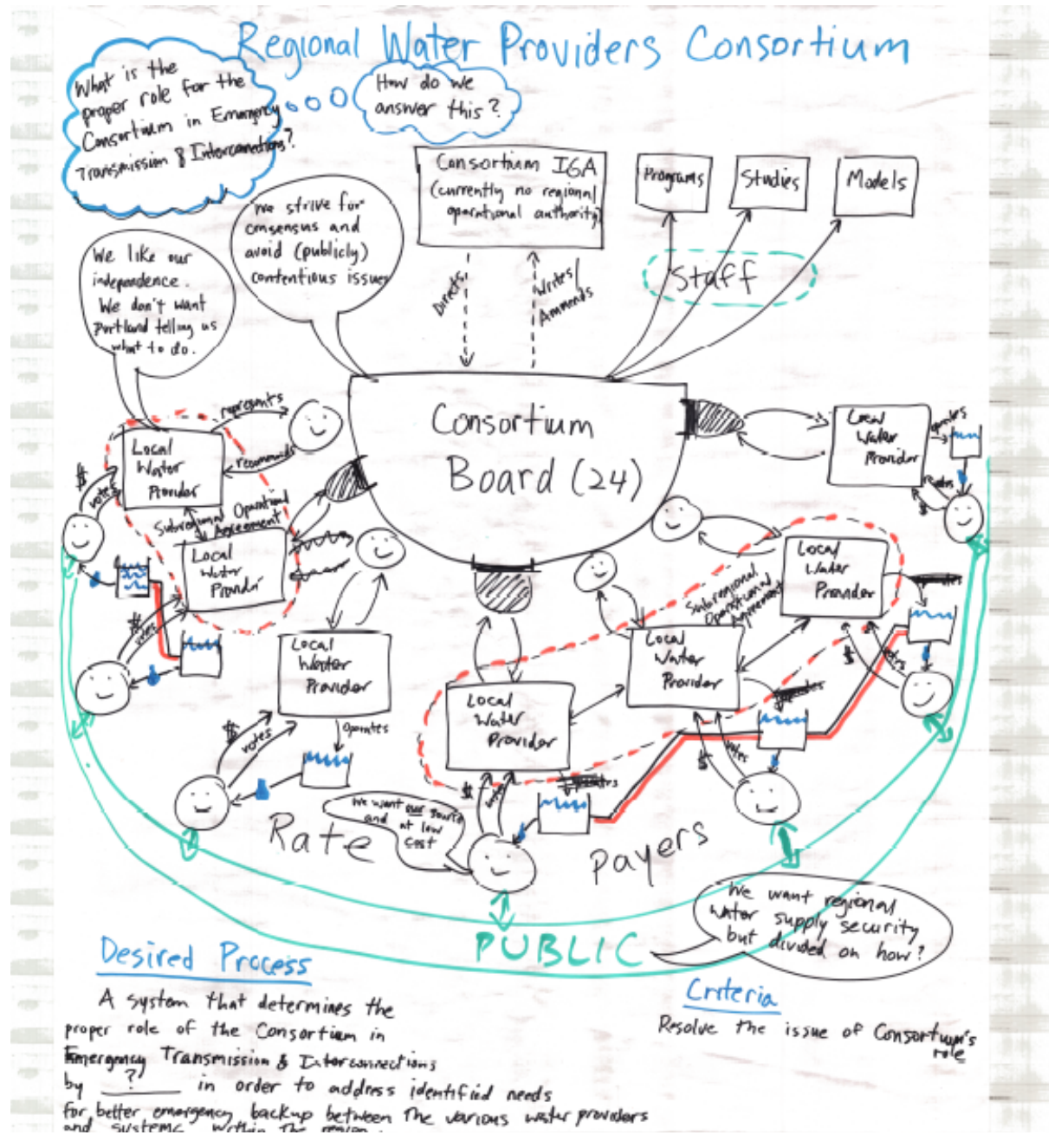




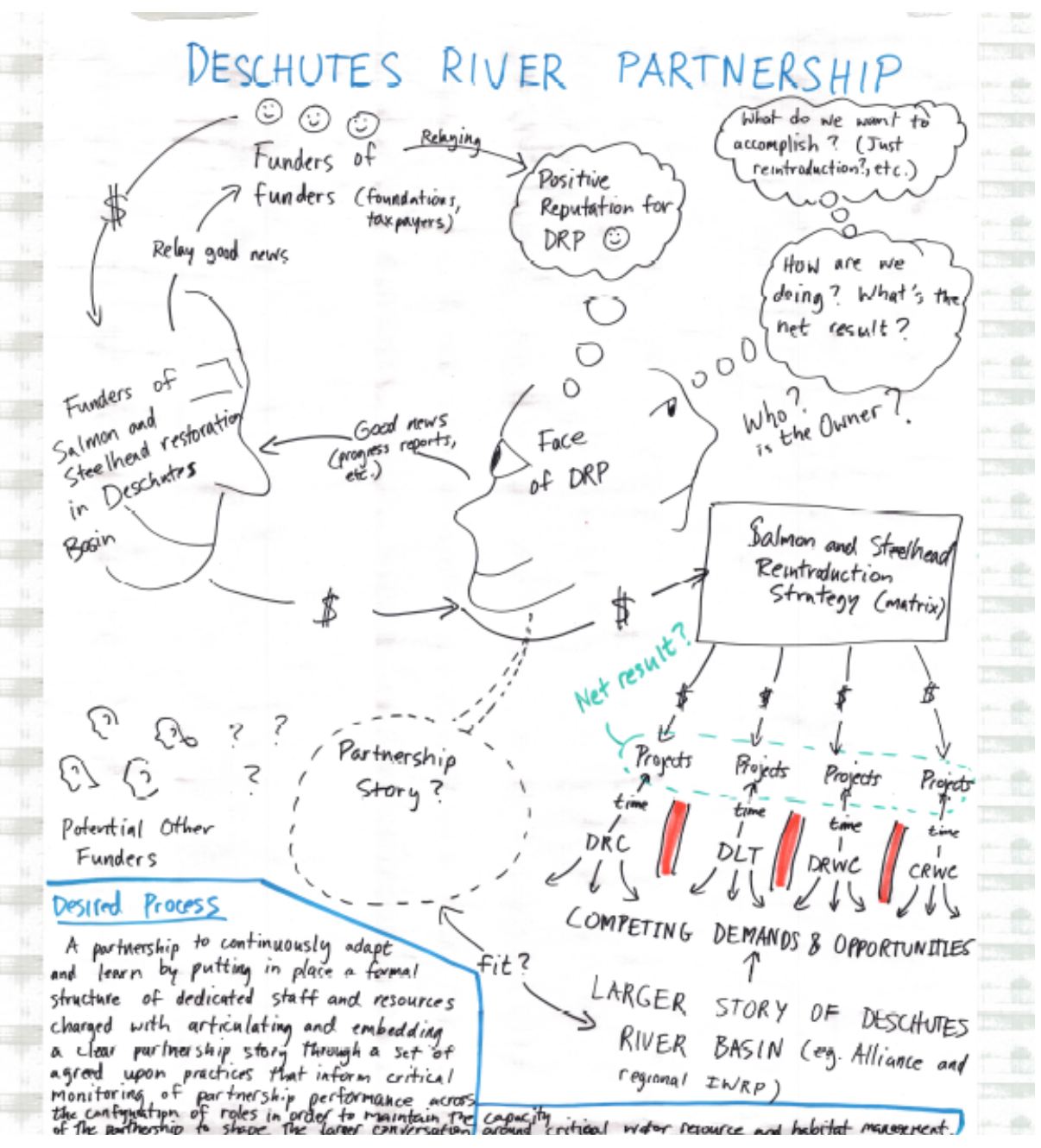




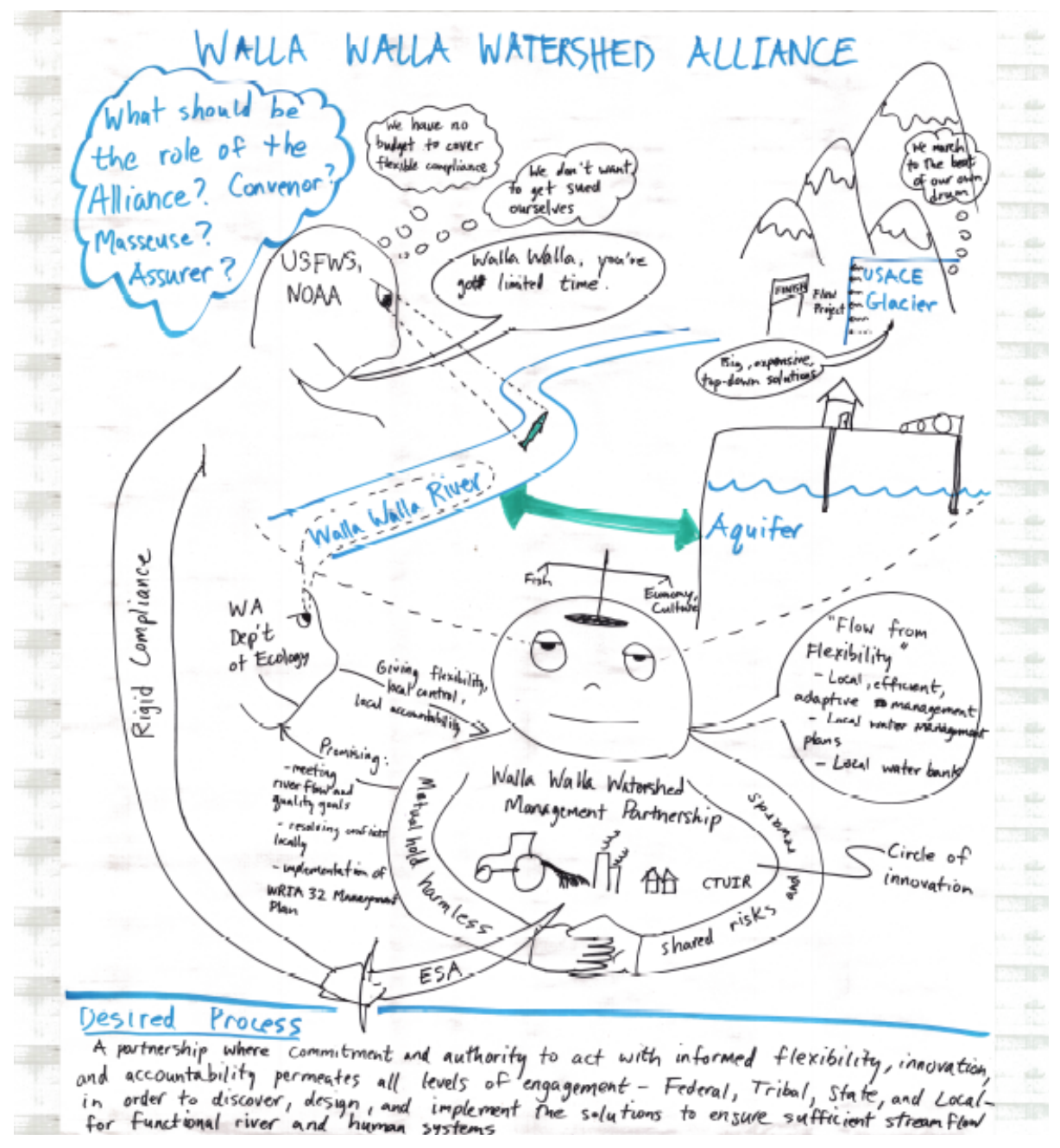


Appendix D: Learning Points of Change Scenarios

\section{Partnership: Counting on the Environment Working Group Type of Process: Continuous Adapting}

\section{Issues associated with process}

- Hard to sustain flow of conversation

- How to distinguish local and regional issues?

- How to maintain focus on both levels?

- Limited capacity (especially time and resources) for regional learning

- Currently there is little protected time set aside to learn and reflect

- State agencies aren't talking to one another enough

\section{Ways to address issues}

- A guidebook for funders and others interested in sustaining partnerships

- Stakeholders continually ask themselves: "How can I/we become a change agent?"

- Put in place a framework to encourage/stimulate/reward innovation at partnership level

- There should be such a framework at the state level

- Establish a process for dialogue about emergent issues (proactive)

- Spend time to scan the horizon for future issues

- Establish and sustain "readiness" to address issues $\rightarrow$ this means assessing and cultivating the readiness of both the partnership and its wider community 


\section{Partnership: Deschutes River Partnership Type of Process: Continuous Adapting}

\section{Issues associated with process}

- Hard to articulate what the partnership is about to larger audience because partners' individual interactions with larger world remains largely uncoordinated

- There are still tremendous benefits to maintaining the status quo (especially project-driven grants)

- Lack of clear "partnership criteria" to assess how the partnership is doing

- The partnership identity and brand remain underdeveloped

- Institutional egos

- Inadequate funding in current economic environment

- Partnership has a limited sphere of control to both frame and address water issues

- Not a clear sense of who the audience/market is

- Partnership attention span is limited beyond the specific projects tied to the SIP

- Partners still occasionally compete for funding

- Overlapping membership in multiple partnerships and initiatives makes for a complex "partnership environment"
Ways to address issues

- Set aside more time and funding to discuss overall direction and marketing

- Having a plan to sunset the organization will enhance accountability and clarity of criteria of success 